\title{
Abordagens para otimização integrada dos problemas de geração e seqüenciamento de padrões de corte
}

\author{
Gisele Castro Fontanella Pileggi
}

\author{
Orientador: \\ Prof. Dr. Reinaldo Morábito Neto \\ Co-orientador: \\ Marcos Nereu Arenales
}

Tese apresentada ao Instituto de Ciencias Matemáticas e de Computação ICMC-USP. como parte dos requisitos para obtenção do titulo de Doutor em Ciências - Ciências de Computą̧âo e Matemática C'omputacional.

\section{USP - São Carlos \\ Fevereiro/2003}

(Versão Revisada)

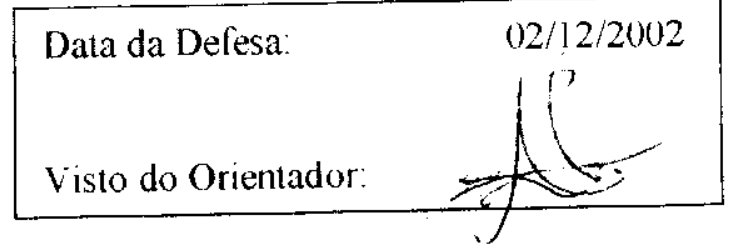


Ao meu marido Rafael e a minha filha Giovana 


\section{AGRADECIMENTOS}

A Deus pelo dom da vida.

Aos meus orientadores, Reinaldo Morabito e Marcos Nereu Arenales, pela orientação, incentivo, confiança e dedicação, e pela amizade construída ao longo dos anos de nossa convivencia.

À FAPESP pela bolsa de estudos concedida, sem a qual este trabalho não teria sido realizado.

A todos os funcionários do ICMC pelo apoio e paciência, em especial a Bete, Laura, Marília, Ana Paula, Tatiana e Gláucia.

Aos meus amigos, em especial, Renata Algisi Takeda e Lilian Kátia de Oliveira, pelo apoio e amizade, e Antônio $E$

rnandes M. Paiva por todas as vezes em que me auxiliou com problemas de configuração de hardware e software.

Aos meus pais, Maria Carmen (in memoriam) e Francisco, que me ensinaram a valorizar o conhecimento e que, com muito amor e carinho, contribuiram para que eu me tornasse a pessoa que sou hoje. Ao meu pai pela correção ortográfica feita neste trabalho.

A toda minha família, minhas irmãs, tias, cunhadas, cunhados e sobrinhos pela convivência fraterna e pela paciência em entender alguns momentos de ausência. Ao meu sogro e minha sogra pelo incentivo e a minha avó Nair (in memoriam), por sempre torcer muito por mim.

Com muito carinho agradeço a duas pessoas muito especiais em minha vida... minha filha Giovana que é só alegria e felicidade em minha vida e, meu marido Rafael, que é meu companheiro, amigo e maior incentivador.

Vocês dois e o bebê, que está para chegar, fazem a minha vida muito mais feliz. 


\section{SUMÁRIO}

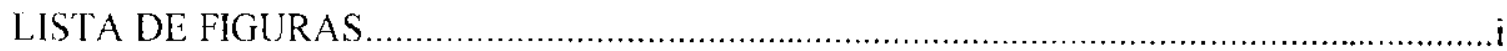

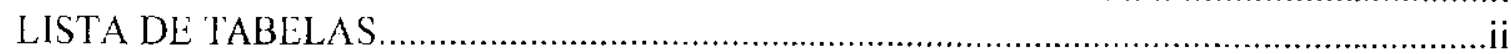

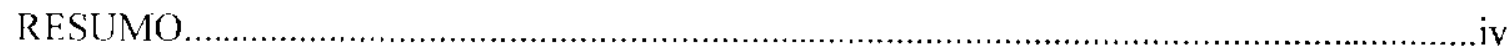

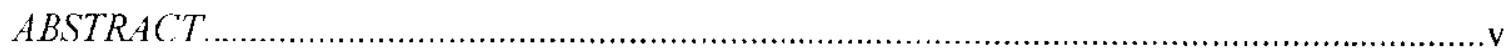

1 INTRODUÇÃO

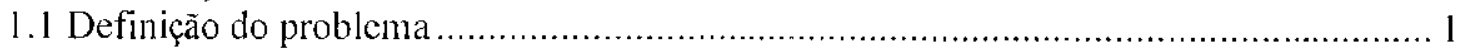

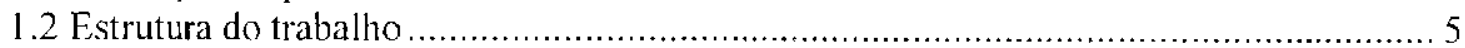

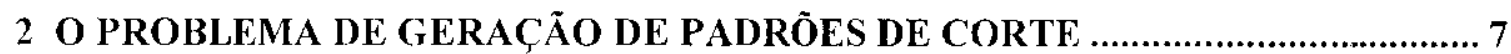

2.1 Classificação dos problemas de corte e empacotamento .......................................... 8

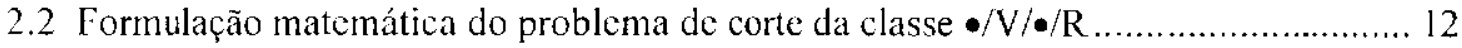

2.3 Método simplex e procedimento de geração de colunas......................................... 16

2.3.1 Geração de coluna para o caso unidimensional .......................................... 19

2.3.2 Geração de coluna para o caso bidimensional em 2-estágios ............................. 22

2.3.3 Geração de coluna para o caso bidimensional não-estagiado: abordagem $\mathrm{cm}$ grafo

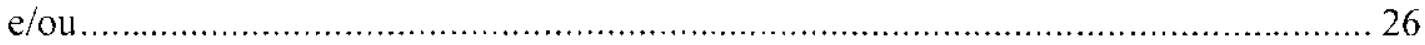

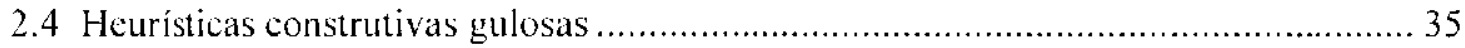

3 O PROBLEMA DE SEQÜENCIAMENTO DE PADRÕES DE COR'TE................... 38

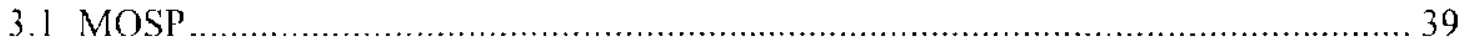

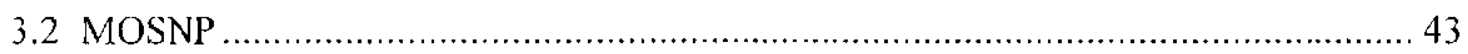

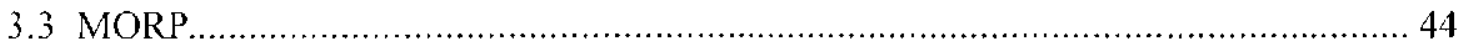

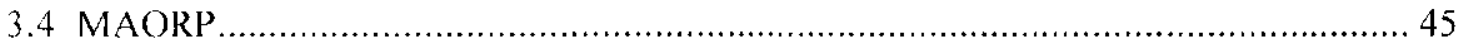

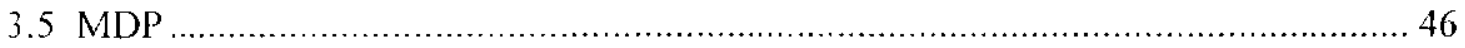

3.6 Revisão da literatura de seqüienciamento de padrões de corte ................................... 49

4 INTERAÇĀO DOS PROBLEMAS DE GERAÇÃO E DE SEQÜENCIAMENTO DE

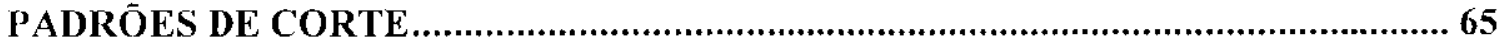

4.1 Modelo integrado dos problemas de geração e sequienciamento de padrões .............. 72

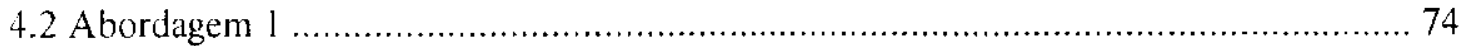

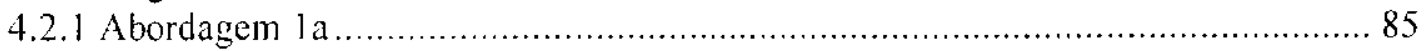

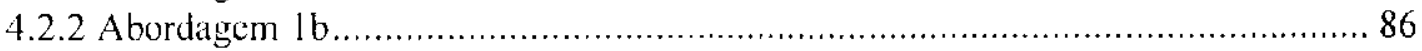

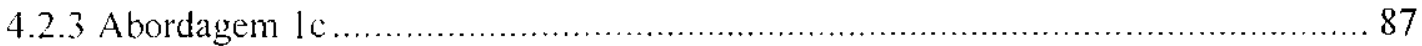

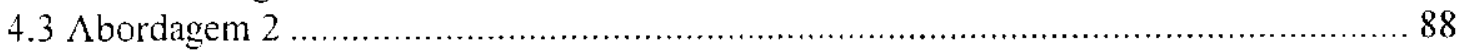

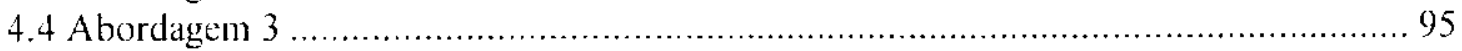

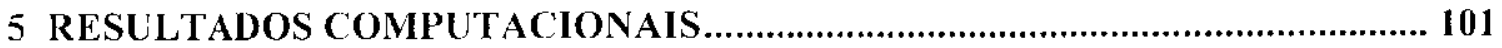

5.1 Implementações computacionais ..................................................................... 101

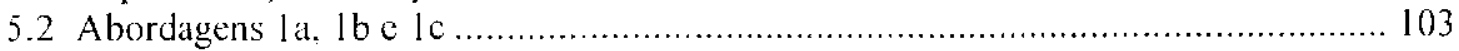

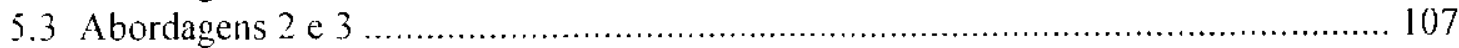

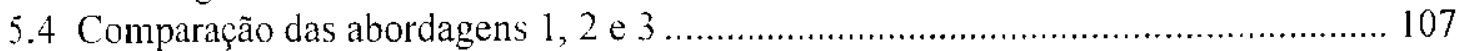

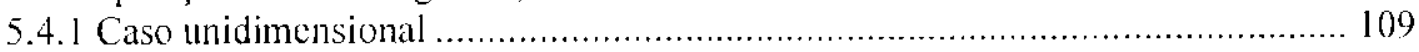

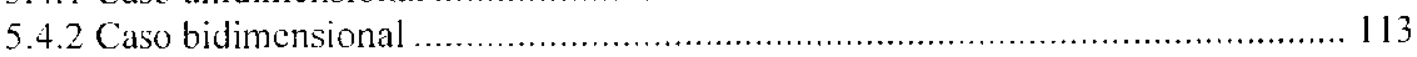

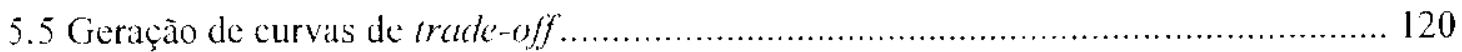

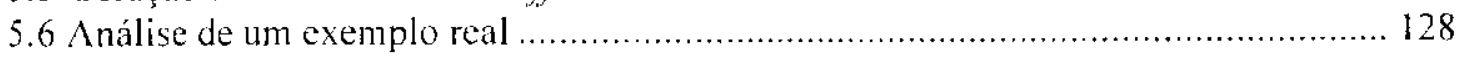




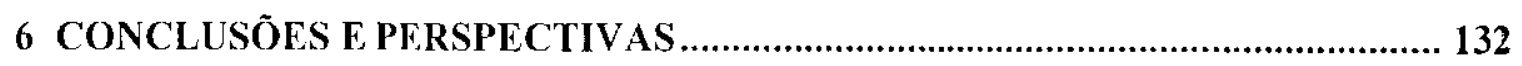

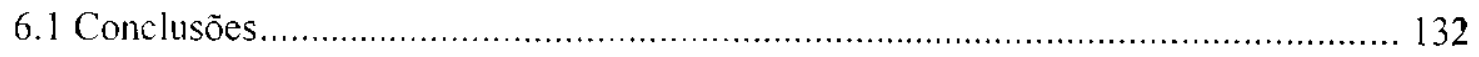

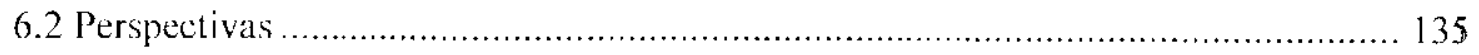

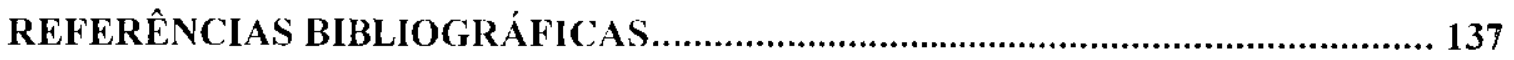

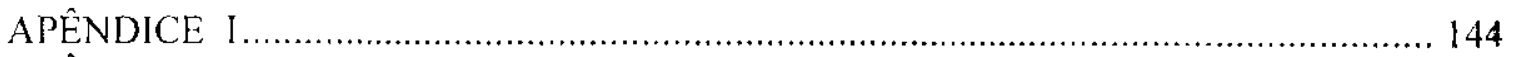

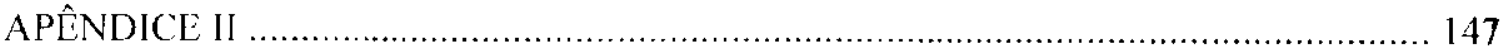




\section{LISTA DE FIGURAS}

FIGURA 2.1: Exemplos de padrões de corte unidimensionais e seus respectivos vetores e pcrdas associados.

FIGURA 2.2: Padrão de corte guilhotinado em 2-estágios: (a) caso exato, (b) caso não-exato e

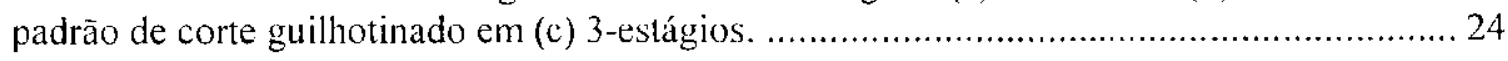

FIGURA 2.3: Representação da sequiência de cortes no grafo e/ou e no objeto..................... 27

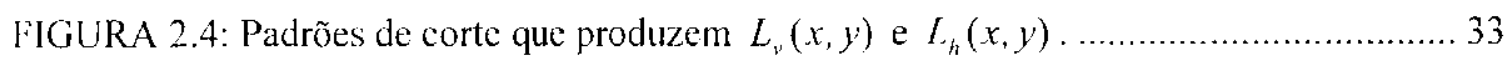

FIGUR $\Lambda$ 2.5: Esquema ilustrativo da heuristica construtiva gulosa.................................. 36

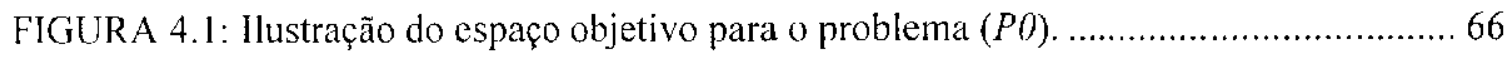

FIGURA 4.2: Ilustração da fronteira eficiente entre a perda (pe) e o númcro máximo de pilhas

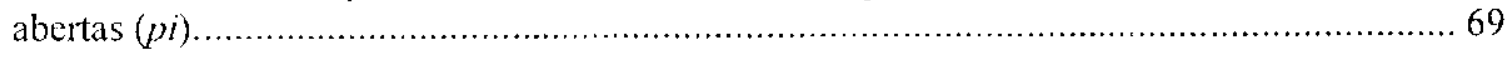

FIGURA 4.3: Esquema ilustrativo da Abordagem la .................................................. 75

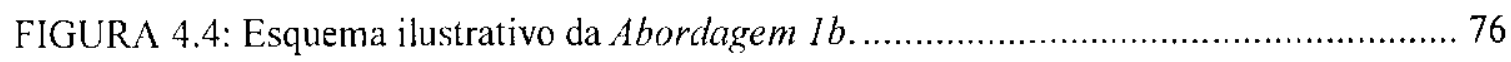

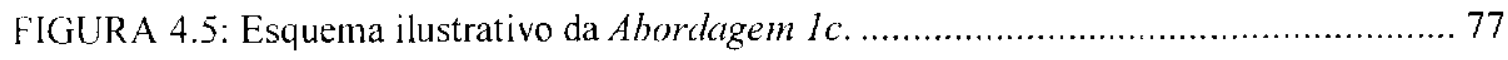

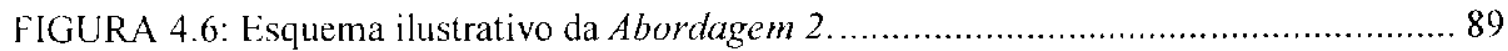

FIGURA 5.1: Curvas de trade-off entre a perda e o número máximo de pilhas abertas no caso

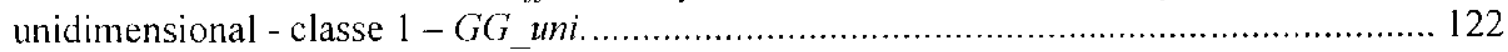

HIGURA 5.2: Curvas de trade-off entre a perda e o número máximo de pilhas abertas para o

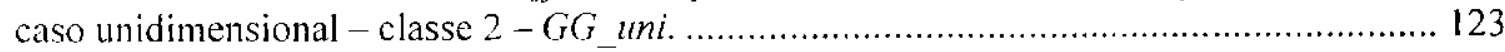

FIGURA 5.3: Curvas de trade-off entre a perda e o número máximo de pilhas abertas para o

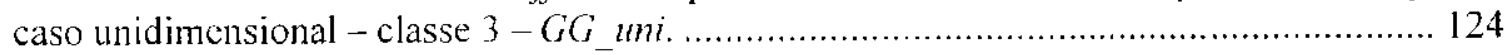

FIGURA 5.4: Curvas de trade-off entre a perda e o número máximo de pilhas abertas para o caso unidimensional - classe $4-G G$ uni.

FIGURA 5.5: Curvas de trade-off entre a perda e o número máximo de pilhas abertas para o caso bidimensional - classe $1-G G_{-} b i$.

FIGURA 5.6: Curvas de trade-off entre a perda e o número máximo de pilhas abertas para o caso bidimensional - classe 1 - Geou_bi.

FIGURA 5.7: Curvas de trade-off entre a perda e o número máximo de pilhas abertas para o caso bidimensional classe $2-G G$ bi.

FIGURA 5.8: Curvas de trade-off entre a perda c o número máximo de pilhas abertas para o casu bidimensional - classe 2 - Geou bi.

FIGURA 5.9: Curvas de trade-off entre a perda e o número máximo de pilhas abertas para o

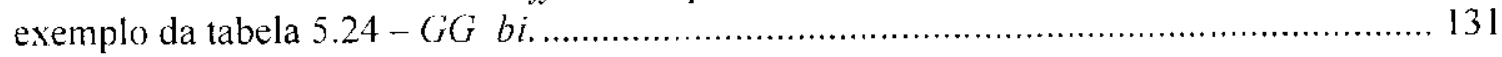

FIGURA A.l: Detalhamento do processo de acabamento para chapas duras.................... 144

FIGURA A.2: Detalhamento do processo de acabamento para chapa de madeira aglomerada.

FIGURA B.1: Ilustração dos fluxus de materiais na empresa Duratex............................ 150 


\section{LISTA DE TABELAS}

TABEL $\Lambda$ 2.1: Comprimentos e demandas. 13

TABELA 3.1: Exemplo de um conjunto de padrões de corte (YUEN, 1991). 39

TABEL^ 3.2: Número de pilhas abertas com a seqüencia $1-2-3-4-5 \ldots \ldots \ldots \ldots \ldots \ldots \ldots \ldots \ldots . . . . . . . . . . . . . . .11$

TABELA 3.3: Stack number obtido com a seqü̈encia 1-2-3-4-5 ..................................... 44

TABELA 3.4: Espalhamento de ordem resultante da seqüência 1-2-3-4-5 ...................... 45

TABELA 3.5: Espalhamento de ordem médio resultante da seqüência 1-2-3-4-5............... 46

TABELA 3.6: Descontinuidade resultante da seqüência 1-2-3-4-5................................. 47

TABELA 3.7: Exemplo de um conjunto de padrões de corte (BECCENERI, 1999) ............ 47

TABELA 3.8: Número de pilhas abertas com a seqüência 1-2-3-4-5 ............................... 48

TABELA 3.9: Espalhamento resultante das seqüências 1-2-3-4-5 e 1-4-2-5-3..................... 48

TABELA 3.10: Número de pilhas abertas com a seqüência 1-4-2-5-3............................. 48

TABELA 3.11: Exemplo de um conjunto de padrões de corte (BECCENERI, 1999), .......... 48

TABELA 3.12: Exemplo de um conjunto de padrões de corte (DYSON e GREGORY,

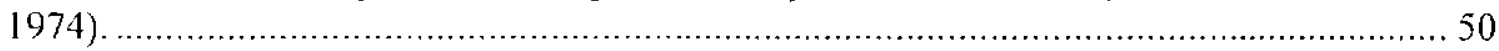

TABELA 3.13: Seqüencia obtida com a aplicação da heurística 1 sobre os dados da tabela 3.1. 55

TABELA 3.14: Seqüência obtida com a aplicação da heurística 2 sobre os dados da

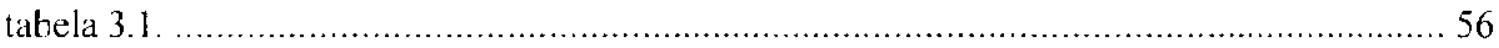

T'ABLLA 3.15: Seqüencia obtida com a aplicação da heurística 3 sobre os dados da

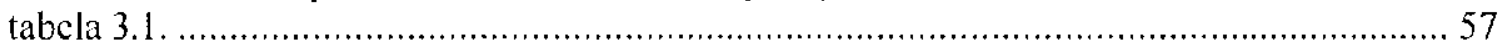

TABELA 3.16: Seqüència obtida com a aplicação da heurística 4 sobre os dados da

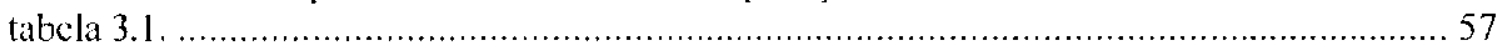

TABEI.A 3.17: Sequêencia obtida com a aplicação da heurística 5 sobre os dados da

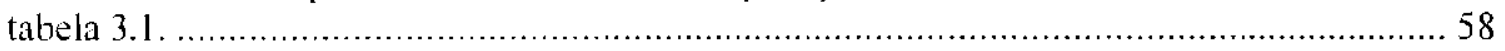

TABELA 3.18: Seqüenceia obtida com a aplicação da heurística 6 sobre os dados da tabela 3.1 . 58

TABELA 4.1: Diferentes soluções com os respectivos valores de perda (pe) e número máximo

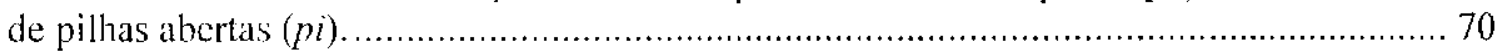

TABELA 4.2: Seqüências obtidas para os padrões de corte da tabela 3.1 ......................... 82

TABELA 4.3: Conjunto de padrões de corte obtido após a eliminação do padrão 2 .............. 84

TABELA 4.4: Dados utilizados na Abordagem 3........................................................ 98

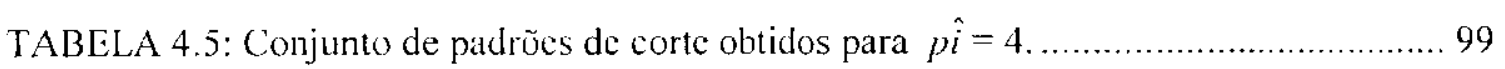

TABELA 4.6: Conjunto de padrões de corte obtidos para $p \hat{i}=5 \ldots \ldots \ldots \ldots \ldots \ldots \ldots \ldots \ldots \ldots . . . \ldots 9$ 
TABELA 5.1: Resultados do teste para escolha da versão da Abordagem 1caso unidimensional.

TABELA 5.2: Resultados do teste para escolha da versão da Abordagem 1 caso bidimensional. 105

TABELA 5.3: Resultado do teste para avaliação do número de exemplos. 108

TABELA 5.4: Resultados obtidos nos problemas unidimensionais - classe $1-G G \_$uni.... 110 TABELA 5.5: Resultados obtidos nos problemas unidimensionais - classe $2-G G_{-}$uni... 110 TABELA 5.6: Resultados obtidos nos problemas unidimensionais - classe $3-G G$ uni.... 111 TABELA 5.7: Resultados obtidos nos problemas unidimensionais - classe $4-G G_{-}$uni... 111 TABELA 5.8: Rank das abordagens nos problemas unidimensionais. ............................ 113 TABELA 5.9: Resultados médios obtidos nos problemas unidimensionais. ..................... 113 TABELA 5.10: Resultados obtidos nos problemas bidimensionais em 2-estágios - classe 1 $G G$ bi.

TABELA 5.11: Resultados obtidos nos problemas bidimensionais não-cstagiados - classe 1 Geou bi....

TABELA 5.12: Resultados obtidos nos problemas bidimensionais em 2-estágios --classe 2 $G G_{-} b i$.

TABELA 5.13: Resultados obtidos para os problemas bidimensionais não-estagiados - classe 2 Geou bi.

TABELA 5.14: Resultados obtidos nos problemas bidimensionais em 2-estágios - classe 3 $G G$ bi.

TABELA 5.15: Resultados obtidos nos problemas bidimensionais em 2-estágios - classe 4$G G$ bi.

TABELA 5.16: Rank das abordagens nos problemas bidimensionais. 119

TABELAA 5.17: Resultados médios oblidos nos problemas bidimensionais. 120

TABELA 5.18: Dados utilizados no caso unidimensional * classe 1. 121

TABELA 5.19: Dados utilizados no caso unidimensional - classe 2. 121

TABELA 5.20: Dados utilizados no caso unidimensional -- classe 3. 121

TABELA 5.21: Dados utilizados no caso unidimensional -- classe 4............................. 121

TABtiLA 5.22: Dados utilizados no caso bidimensional - classe 1 .............................. 121

TABELA 5.23: Dados utilizados no caso bidimensional · classe 2 ............................. 122

TABELA 5.24: Dados da fábrica de móveis Colombini................................................. 129

TABELA 5.25: Resultados obtidos para o exemplo da fábrica Colombini - $G G$ bi b......... 129

TABEL $\Lambda$ 5.26: Resultados obtidos para o exemplo da fábrica Colombini - Cieou_bi........ 130 
RESUMO

O problema de corte de estoque consiste em cortar unidades maiores (objetos) em unidades menores (itens) de maneira a satisfazer uma demanda e otimizar algum critério, por excmplo, minimizar a perda gerada pelos padrões de corte (um padrão descreve como arranjar itens dentro de um objeto). O problema de seqüenciamento de padrões de corte consiste $\mathrm{cm}$ determinar uma seqüência, na qual os padrões scrão processados a fim de otimizar algum critério, por exemplo, minimizar o número máximo de pilhas abertas (itens que ainda serão cortados de um ou mais padrões na seqüência) durante o corte dos padrões. Em alguns processos industriais os problemas de geração e seqüenciamento de padrões de corte não podem ser resolvidos de forma independente pois, em geral, uma boa solução para o problema de corte (isto é, com pequena perda de material) não corresponde a uma boa solução para o problema de seqüenciamento (isto é, com um pequeno número de pilhas abertas) e vice-versa. Existe, na verdade, um trade-off entre os objetivos desses dois problemas. Neste trabalho três abordagens heurísticas são apresentadas para resolver de forma integrada os problemas de geração e sequienciamento de padrões. Os resultados computacionais apresentados mostram que as abordagens geram boas soluções e são eficazes para analisar o trade-off entre esses dois problemas.

Palavras-chave: problema de corte, problema de seqüenciamento de padrões de corte, otimização multiobjetivo, procedimentos heurísticos. 


\section{ABSTRACT}

The cutting stock problem consists of cutting large units (objects) into smaller ones (items) in order to satisfy a demand and optimize a criterion, e.g., to minimize the trim loss. The sequencing problem consists of determining a sequence in which to cut pattems so as to optimize an objective, such as minimizing the maximum number of open stacks (items that will still be cut from one or more patterns in the sequence) during the pattern cut. In some industrial processes, the problems involved in generating and sequencing cutting patterns cannot be solved independently because a good solution for the cutting problem (i.e., with low trim loss) usually does not correspond to a good solution for the sequencing problem (i.e., with a small maximum number of open stacks) or vice-versa. There is, in fact, a tradcolf between the objectives of these two problems. In this work, three heuristic approaches are presented to solve the problems of generating and sequencing cutting patterns in an integrated manner. The computational results presented here demonstrate that these approaches offer good solution and are effective to analyze the tradeoff between these two problems.

Key Words: cutting problem, cutting pattern sequencing problem, multi-objective optimization, heuristic procedures. 


\section{INTRODUÇÃO}

\subsection{Definição do problema}

Problemas de corte consistem basicamente em determinar a "melhor" forma de cortar unidades maiores (objetos), de maneira a produzir um conjunto de unidades menores (itens). Ou seja, objetiva-se encontrar um conjunto de padrões de corte (um padrão de corte descreve como arranjar itens dentro de um objeto), que será repetido um certo número de vezes e que satisfaça algum critério a ser otimizado, por exemplo, minimizar a perda de material gerada pelo corte dos padrões. O problema de geração de padrões de corte (ou, simplesmente, problema de corte) pode aparecer em diversos processos industriais, em que os objetos, em geral disponíveis em estoque com dimensões padronizadas, correspondem a barras de aço, bobinas de papel c alumínio, placas metálicas e de madeira, placas de circuito impresso, chapas de vidro e fibra de vidro, peças de couro, etc.; os itens, com dimensões especificadas pelos clientes, são encomendados através de uma carteira de pedidos. Esses problemas em geral pertencem à classe de problemas NP-difíceis (DOWSLAND e DOWSLAND, 1992; DYCKHOFF e FINKE, 1992).

Em certos processos industriais um conjunto de padrões nem sempre pode ser cortado em qualquer ordem, por exemplo, quando há restrição de equipamentos de corte. Também há casos em que se deseja determinar a "melhor" seqüência, na qual os padrões serão cortados. O problema de seqüenciamento de padrões de corte (ou, simplesmente, problema de seqüenciamento) consiste em determinar uma seqüência para processar os padrões, de forma a 
otimizar algum critério, por exemplo, minimizar o número máximo de pilhas abertas (itens que ainda serão cortados de um ou mais padrões na seqüência). A seqüência de padrões interfere nos prazos de entrega, nos níveis de estoque intermediário, no manuseio de materiais, entre outros, uma vez que os padrões contêm diferentes conjuntos de itens. Desta maneira, o problema de seqüenciamento depende do problema de geração de padrões e, viceversa, o problema de geração depende do problema de seqüienciamento, pois os padrões de corte, a serem gerados, precisam ser seqüenciáveis do ponto de vista de algum critério. Em geral os problemas de seqüenciamento, assim como os problemas de geração de padrões, pertencem à classe de problemas NP-difíceis (YANASSE, 1997).

Centenas de artigos, que tratam dos problemas de geração de padrões de corte podem ser encontrados na literatura, conforme indicam os artigos de revisão e edições especiais em Hinxman (1980), Dyckhoff e Wäscher (1990), Dyckhoff e Finke (1992), Dowsland e Dowsland (1992), Sweeney e Paternoster (1992), Bischoff e Wäscher (1995), Dyckhoff et al. (1997), Arenales et al. (1999), Wang e Wäscher (2002) e SICUP (2002). O mesmo não se pode dizer sobre a literatura de seqüenciamento de padrões de corte. Alguns trabalhos tratando o problema de seqüenciamento podem ser encontrados em Dyson e Gregory (1974), Madsen (1979, 1988), Yuen (1991, 1995), Yanasse (1997), Faggioli e Bentivoglio (1998), Foerster e Wäscher (1998), Fink e Voß (1999), Becceneri (1999) e Ashikaga (2001).

Freqüentemente, uma boa solução para o problema de geração de padrões (isto é, um conjunto de padrões com baixa perda de material) não resulta numa boa solução para o problema de seqüenciamento (uma seqüência destes padrões com baixo número máximo de pilhas abertas), e vice-versa. Existe, portanto, um trade-off entre os objetivos dos dois problemas, o que sugere que os dois problemas devem ser resolvidos de forma integrada. Como os dois problemas pertencem à classe de problemas NP-difíceis, acredita-se que combiná-los num único problema bi-objetivo também resulta num problema pelo menos igualmente tão difícil. Em geral ambos são resolvidos, tanto na prática como na literatura, de forma independente e sucessiva. Em um primeiro estágio, resolve-se o problema de 'geração de padrões e, a partir da solução obtida (conjunto de padrões de mínima perda), resolve-se o problema de seqüenciamento, o que pode produzir uma solução com elevado número de pilhas abertas.

O presente trabalho tem como objetivo o desenvolvimento de abordagens integradas, que considerem a dependência entre esses dois problemas. Diferentes alternativas podem ser exploradas para isso: ( $i$ ) tratar os problemas de geração e seqüenciamento de padrões como 
um problema multi-critério, (ii) limitar no problema de geração o número máximo de tipos de itens nos padrões, (iii) separar os itens em subconjuntos disjuntos, de forma que os mesmos sejam otimizados separadamente, (iv) adaptar heuristicas construtivas gulosas, entre outras.

Encontrar a melhor alternativa não é simples. Por exemplo, resolver um modelo combinado com função objetivo multi-critério (i) não é uma tarefa fácil, visto que os problemas de geração e seqüenciamento de padrões, quando abordados de forma independente, já oferecem grandes dificuldades de solução. Limitar no problema de geração o número de tipos de itens nos padrões (ii) pode favorecer o objetivo do problema de seqüenciamento, mas, por outro lado, pode gerar perdas de materiais bastante grandes. Separar o conjunto de itens em subgrupos disjuntos (iii) envolve determinar a priori o número ótimo destes subgrupos e a composição de cada um deles. Na utilização de heurísticas construtivas gulosas (iv), a escolha de um padrão determina a escolha de itens nos próximos padrões, que serão gerados. A seqüência resultante depende do padrão inicial escolhido. Fazer a busca, iniciando a seqüência com diferentes padrões, faz com que o número de soluções a ser considerado aumente substancialmente, sem garantia de encontrar boas soluções.

Convém salientar que poucos são os trabalhos encontrados na literatura, que tratam dos problemas de geração e de seqüenciamento de padrões de forma integrada, por exemplo, Dyson e Gregory (1974), Madsen (1979, 1988) e Pinto (2001). Além disso, devido à complexidade dos problemas envolvidos, existe uma grande motivação para a busca de algoritmos mais eficientes. Uma abordagem, que resolva de forma integrada os problemas de geração e seqüenciamento de padrões, poderá scr aplicada, por exemplo, no processo de fabricação de móveis (em série), em indústrias de vidros planos, em fábricas de bebidas, em fábricas de circuito impresso, etc., aplicações industriais de importância técnica e econômica.

Existem dois problemas a serem resolvidos, e existem dois critérios a serem otimizados, que na maioria das vezes são conflitantes. Para resolver de forma integrada os problemas de geração e seqüenciamento de padrões de corte, duas estratégias podem ser utilizadas: ( $i$ ) otimizar a função objetivo do problema de seqüenciamento e considerar o objetivo do problema de geração de padrões como uma restrição (problema $(P I)$, seção 4), ou (ii) otimizar a função objetivo do problema de geração de padrões considerar o objetivo do problema de seqüenciamento como uma restrição (problema (P2), seção 4). Em ambos os casos, critérios de tolerância para os objetivos dos dois problemas podem ser definidos pelo decisor (por exemplo, um gerente de produção), a fim de que as soluções obtidas estejam dentro de limites estabelecidos pela empresa. Tais problemas podem ser úteis para gerar uma curva de trade-off (ou curva de eficiência) aproximada, relacionando os critérios a serem 
otimizados pelos problemas de geração e de seqüenciamento, por exemplo, perda e número máximo de pilhas abertas (seção 4).

No presente trabalho três abordagens heurísticas inspiradas no problema $(P 2)$ são propostas, para resolver de forma integrada os problemas de geração e de seqüenciamento de padrões, baseadas em procedimentos iterativos, heurísticas construtivas gulosas e algoritmo simplex com geração de colunas. O enfoque é $\mathrm{cm}$ abordagens simples c com bom desempenho, e que possam ser facilmente aplicadas na prática para apoiar decisões. Todas as abordagens têm como motivação a aplicação em situações reais, encontradas em processos de corte de materiais.

Uma das abordagens, denominada Abordagem 1, consiste em resolver os problemas de geração e de seqüenciamento de padrões de forma seqüencial e iterativa, isto é, o problema de geração de padrões é resolvido em um primeiro estágio e o de seqüenciamento, em um segundo estágio. Fm função da qualidade da solução obtida para o problema de seqüenciamento, o problema de geração de padrões é novamente resolvido, mas agora com informações adicionais, que permitam que um novo conjunto de padrões seja gerado no primeiro estágio. E assim por diante, até que uma solução seja encontrada, ou um certo número de iterações seja realizado. Outra abordagem proposta, Abordagem 2, baseia-se num procedimento também iterativo, que em cada iteração utiliza uma heurística construtiva gulosa, para gerar os padrões de corte, um após o outro, levando em conta o resultado da seqüência dos mesmos. Ou seja, uma solução para o problema de geração vai sendo construida, passo a passo, considerando o número máximo de pilhas abertas com o seqüenciamento dos padrões como uma restrição. Este procedimento é repetido por um certo número de vezes, variando-se os valores relativos dos itens. A terceira abordagem, Abordagem 3, consiste em resolver o problema de geração, utilizando o método simplex com um procedimento de geração de colunas, de modo que o número máximo de pilhas abertas seja considerado durante o processo de geração de colunas.

Estas abordagens poderão ser usadas interativamente, para dar suporte a algumas decisões de planejamento e controle da produção. Considere como exemplo a fábrica de móveis Colombini, analisada em Morabito e Arenales (2000). O custo do material cortado (chapas de madeira, chapas duras, aglomerados) pode representar mais de um terço do custo final do produto. O programa de produção do processo de corte tem como objetivo atender a carteira de pedidos encomendada pelos clientes, visando a minimização da perda de material gerada pelo corte dos padrões. Por outro lado, também objetiva minimizar o número máximo de pilhas de móveis abertas resultantes do corte dos padrões. Quanto maior o número de 
pilhas de móveis abertas, maior o nivel de estoque intermediário, maior a dificuldade para manuseio e administração dos itens e maior o tempo necessário para atender aos pedidos dos clientes (uma descrição do processo de produção e dos problemas de geração e de seqüenciamento de padrões desta empresa pode ser encontrada no Apêndice I).

Um outro exemplo é o da fábrica de chapas duras Duratex, analisada em Morabito e Garcia (1998) e Belluzzo (2002), que fabrica chapas de fibra de madeira reconstituída. O objetivo do programa de produção do processo de corte é atender à demanda de pedidos de clientes (mercado interno e externo) dentro dos prazos estabelecidos, visando a minimização da perda de material gerada pelo corte dos padrões. Ilá a restrição de que o conjunto de padrões gerado seja seqüenciável, pois a máquina de corte (serra Holzma) possui estações de descarregamento automáticas, o que limita o número máximo de tipos de itens nos padrões e também a sequïencia, na qual os mesmos serão cortados (uma descrição do processo de fabricação desta empresa, bem como dos problemas de geração e de seqüenciamento de padrões envolvidos, pode ser encontrada no Apêndice II). Para estes dois exemplos, as abordagens propostas podem ser utilizadas, pois o decisor pode examinar a curva de eficiência (seção 4), para escolher uma solução de maior interesse.

\subsection{Estrutura do trabalho}

Este trabalho está organizado da seguinte maneira: no capítulo 2 é apresentado o problema de geração de padrões com ênfase no problema de geração de colunas para o caso unidimensional e para os casos bidimensional guilhotinado em 2-estágios e bidimensional guilhotinado não-estagiado. Abordagens de solução, para resolver o problema de geração de padrões, são revistas, bem como abordagens para resolver o problema de geração de colunas.

No capítulo 3 o problema de seqüenciamento de padrões de corte é apresentado e em particular uma formulação matemática para o problema de minimização do número máximo de pilhas abertas é descrita. Uma revisão dos principais trabalhos da literatura de seqüenciamento de padrões de corte também é apresentada.

No capítulo 4 discute-se a dependência entre os problemas de geração e seqüenciamento de padrões de corte. As três abordagens de solução (Abordagem 1 , Abordagem 2 e Abordagem 3), que consistem em resolver o problema de geração de padrões e considerar o problema de seqüenciamento de padrões como uma restrição, são apresentadas. 
Também se discute como utilizar estas abordagens, para gerar curvas de trade-off entre os objetivos desses problemas.

No capítulo 5 são apresenta os resultados computacionais obtidos para os casos unidimensional e bidimensional guilhotinado em 2-estágios e guilhotinado não-estagiado. Tais resultados mostram que as abordagens são capazes de gerar boas soluções para os problemas, e permitem analisar os trade-offs envolvidos. Também são apresentados os resultados obtidos em um exemplo real da fábrica de móveis Colombini.

Finalmente no capítulo 6 são apresentadas as principais conclusões obtidas ao longo do trabalho e são descritas algumas perspectivas para pesquisa futura. 


\section{O PROBLEMA DE GERAÇÃO DE PADRÕES DE CORTE}

Conforme definido no capítulo 1, o problema de geração de padrões de corte consiste genericamente em cortar unidades maiores (objetos) em unidades menores (itens), de maneira a otimizar algum critério, por exemplo, minimizar a perda gerada pelo corte dos padrões. Este problema aparece em diferentes tipos de indústrias, tais como papel, vidro, aço, móveis, chapas de fíbra de madeira reconstituída, calçados, circuito impresso, plástico, têxtil, metalúrgica, fundição, etc.

Os problemas de geração de padrões de corte pertencem a uma classe mais geral denominada problemas de corte e empacotamento (DYCKHOFF, 1990). Estes problemas são objetos de pesquisa pelo menos desde a década de 60, devido à importância técnica e econômica das aplicações e devido à dificuldade de encontrar métodos de solução exatos em tempos computacionais razoáveis. Um aspecto, que tem motivado tantos autores a pesquisar os problemas de geração de padrões, é a ausência de abordagens de solução gerais e eficientes, devido principalmente à diversidade de casos, em que os problemas podem aparecer na prática, e à complexidade dos algoritmos exatos disponíveis. A importância econômica das aplicações, aliada à dificuldade de resolução desses problemas, tem motivado pesquisas na busca de métodos de solução eficientes, o que pode ser comprovado pelo número de publicações, principalmente na literatura de pesquisa operacional e gestão da produção, como por exemplo, Hinxman (1980), Dyckhoff e Wäscher (1990), Hacssler e Sweeney (1991), Dyckhoff e Finke (1992), Dowsland e Dowsland (1992), Sweeney e Paternoster (1992), Morabito e Arenales (1992), Bischoff e Wäscher (1995), Dyckhoff et al. (1997), Arenales et al. (1999), Wang e Wäscher (2002) e SICUP (2002). 


\subsection{Classificação dos problemas de corte e empacotamento}

Os problemas de corte e empacotamento aparecem na literatura sob vários nomes, como por exemplo, problema de corte de estoque, trim loss, problema de empacotamento de bins, problema de empacotamento de faixas, problema de carregamento de vcículos, de carregamento de paletes, etc. Dyckhoff (1990) propôs uma classificação, que integra os vários tipos de problemas numa noção única, denominada problemas de corte e empacotamento. Esta classificação é baseada na estrutura lógica dos problemas de corte e empacotamento e está descrita a seguir, referenciada, quando possível, por trabalhos anteriores desenvolvidos pelo grupo de pesquisa em corte e empacotamento da USP-São Carlos/UFSCar.

\section{Dimensão do problema}

A dimensão do problema é a característica mais importante e refere-se às dimensões relevantes no processo de corte.

- Unidimensional: uma única dimensão é relevante para a solução do problema. Por exemplo, no caso do corte de bobinas na indústria de papel (GILMORE e GOMORY, 1961, 1963), no corte de bobinas de aço (ARCARO, 1988; MARQUES, 2000; HOTO, 2001).

> Bidimensional: duas dimensões são relevantes para a solução do problema. Por exemplo, no caso do corte de chapas na indústria de chapas de fibra de madeira reconstituída (MORABITO e GARCIA, 1998; BELLUZZO, 2002), no caso de fábrica de móveis (MORABITO E ARENALES, 2000).

> Tridimensional: três dimensões são relevantes para a solução do problema. Por exemplo, no caso de carregamento de contêineres (MORABITO, 1989, 1992; MORABITO e ARENALES, 1994).

> I-5 dimensional: duas dimensões são relevantes para a solução do problema, porém uma delas é variável. Por exemplo, no caso do corte de rolos de tecido.

- 2-5 dimensional: três dimensões são relevantes para a solução do problema, uma das quais é variável. Por exemplo, no caso de carregamento de um contêiner suficientemente comprido. 
- Multidimensional: mais que três dimensões são relevantes para a solução do problema. Por exemplo, no problema de alocação de tarefas (MORABITO, 1992).

\section{Forma de alocação das unidades}

- Seleção de unidades grandes: todas as unidades grandes são suficientes, para alocar todas as unidades pequenas. Um conjunto de unidades grandes deve ser selecionado, para incluir todas as unidades pequenas. Um exemplo é o problema do corte de estoque (GILMORE e GOMORY, 1961, 1963, 1965).

- Seleção de unidades pequenas: todas as unidades grandes são insuficientes, para alocar todas as unidades pequenas. Um conjunto de unidades pequenas deve ser selecionado, para ocupar todas as unidades grandes. Nesta classe, um exemplo é o problema de carregamento de paletes do produtor (MORALES, 1995; MORABITO e MORALES, 1998; MORABITO e FARAGO, 2001).

\section{Ambiente de planejamento}

- Planejamento sucessivo: os problemas são tratados um após o outro (DYSON e GREGORY, 1974; MADSEN, 1979).

; Planejamento simultâneo: neste caso os problemas, ou os mais importantes deles, são tratados ao mesmo tempo, como um único problema (GRAMANI, 2001).

\section{Objetivos}

Os objetivos são definidos em função do ambiente de planejamento. Minimização da perda, minimização do custo, minimização do número de objetos são exemplos de objetivos definidos com ambiente de planejamento sucessivo. Já no ambiente com planejamento simultâneo os objetivos podem ser expressos por: minimização dos custos de estoque, minimização dos custos de setup.

\section{Restrições}

- Restrições das unidades grandes: as restrições com relação às unidades grandes podem ser divididas em formas, tamanhos diferentes e quantidades disponíveis. No problema de 
corte, os objetos podem aparecer em formas e tamanhos diferentes. As quantidades podem ser limitadas ou ilimitadas (no caso de haver quantidade suficiente em estoque, ou no caso em que as mesmas são facilmente produzidas ou adquiridas). As formas podem ser:

- regulares - retangulares, triangulares, formato L (ARENALES, 1993; VIANNA, 2000; SALOMÃO, 1993)

; irregulares (ORLANDI, 1992)

- Restrições das unidades pequenas: as restrições com relação às unidades pequenas podem ser divididas em formas (ORLANDI, 1992), tamanhos diferentes, quantidade demandada e orientação.

> Restrições dos processos: podem ser divididas em:

- propriedades dos materiais: a resistência física do vidro, por exemplo, limita os possiveis padrões de corte, visto que o mesmo não resiste a duas linhas de corte muito próximas uma da outra;

> condições organizacionais: por exemplo, no caso de cliente preferencial, quando se produzem somente os itens encomendados por esse cliente, os padrões de corte gerados ficam limitados;

- equipamentos de corte e empacotamento: os processos de corte estão restritos principalmente pela tecnologia dos equipamentos de corte, que em muitas situações restringe os possiveis padrões de corte a serem gerados (ARENALES, 1993; GARCIA, 1996; BELLUZZO, 2002; SILVA, 2001). Os principais tipos de corte podem ser:

- Cortes retos

- Cortes ortogonais

$>$ Cortes guilhotinados

; Cortes estagiados

- Cortes não estagiados

; Cortes não guilhotinados

; Cortes não ortogonais

- Cortes curvos

Para os cortes ortogonais pressupõe-se que os objetos sejam retangulares, para que este tipo de corte possa ser aplicado. Os cortes não ortogonais são cortes produzidos em qualquer direção. Cortes guilhotinados são cortes feitos a partir de uma borda até a borda oposta, de forma a dividir um retângulo em dois retângulos menores e adjacentes (MORABITO e ARENALES, 1995). No caso de cortes nĩo guilhotinados pode-se interromper o corte, antes de 
se chegar à borda oposta e, a partir deste ponto, prosseguir com o corte na direção perpendicular (SALOMÃO, 1993, ARENALES e MORABITO, 1995; VIANNA, 2000). Se o processo de corte limitar o número máximo de estágios no padrão, tem-se os cortes estagiados, ou cortes em n-estágios (MORABITO c ARENALES, 1996). Um estágio é definido através da produção de um conjunto de cortes cm uma mesma direção. Nos estágios sucessivos a direção dos cortes é alternada, ou seja, os cortes produzidos em um estágio subseqüente são ortogonais aos cortes produzidos no estágio anterior. Quando o processo de corte não limita o número máximo de estágios em um padrão de corte, têm-se os cortes não estagiados (MORABITO, 1989, 1992; MORABITO et al., 1992).

Podem aparecer outras restrições com relação aos equipamentos de corte, por exemplo, com relação ao número máximo de tipos de itens, que podem ocorrer em um padrão. Outro exemplo é a restrição quanto ao número máximo de vezcs, que um tipo de item pode ocorrer em cada padrão de corte. Problemas de corte com esta restrição são chamados de problemas restritos (GRAMANI, 1997; SILVEIRA e MORABITO, 2002) e os padrões de corte, de padrões restritos (denominação freqüentemente utilizada na literatura).

Dyckhoff (1990) sugeriu a utilização de quatro características principais, para indicar os problemas de corte e empacotamento, descritas abaixo:

\section{> Dimensão do problema}

(1) unidimensional

(2) bidimensional

(3) tridimensional

(N) N-dimensional, com $\mathrm{N}>3$

\section{Y Forma de alocação}

(V) seleção de unidades grandes (do alemão Verladeproblem)

(B) seleção de unidades pequenas (do alemão Berladeproblem)

\section{- Sortimento de unidades grandes}

(O) uma unidade (do inglês One)

(I) unidades de tamanhos iguais (do inglês Identical)

(D) unidades de tamanhos diferentes (do inglês Different) 


\section{Sortimento de unidades pequenas}

(F) poucas unidades de tamanhos diferentes (do inglês Few)

(M) muitas unidades de tamanhos diferentes (do inglês Many)

(R) muitas unidades de poucos tamanhos diferentes (do inglês Relatively)

(C) unidades de tamanhos iguais (do inglês Congruent)

A tipologia é denotada por: $\alpha / \beta / \gamma / \delta$, onde cada simbolo representa cada uma das quatro características descritas. Segundo esta tipologia o problema de corte de estoque é classificado como $\bullet / \mathrm{V} / \bullet / \mathrm{R}$, ou seja, todos as unidades pequenas devem ser alocadas em uma seleção de unidades grandes (V) e existem muitas unidades pequenas de poucos tamanhos diferentes (R). Nesta tipologia cada notação determina tipos mais gerais, que envolvem problemas distintos. Considere, por exemplo, o problema de corte bidimensional do tipo $2 / \mathrm{V} / \mathrm{I} / \mathrm{R}$, cujos objetos são de tamanhos iguais. Muitas diferenças ainda podem ser encontradas nos objetivos e restrições envolvidas (MORABITO, 1989), e em função disto, diferentes métodos de solução podem ser propostos.

Em particular, neste trabalho, além de problemas $\bullet / \mathrm{V} / \bullet / \mathrm{R}$ (problema de corte de estoque), são de interesse os problemas $\bullet / \mathrm{B} / \mathrm{O} / \bullet$ (por exemplo, o problema da mochila •/B/O/• - seção 2.3), que consistem em uma seleção de unidades pequenas (B), que devem ser alocadas em uma única unidade grande $(O)$. Como será visto nas seções seguintes, a resolução de problemas do tipo $\bullet / \mathrm{V} / \bullet / \mathrm{R}$ podem envolver a solução de vários problemas -/B/O/•. Na seção seguinte apresenta-se a formulação matemática para o problema de corte de estoque $(\bullet / \mathrm{V} / \bullet / \mathrm{R})$.

\subsection{Formulação matemática do problema de corte da classe $\bullet / V / \bullet / R$}

Considere a seguinte notação:

p número de padrões de corte

$m \quad$ número de tipos de itens 
$a_{i j} \quad$ quantidade de itens do tipo $i$ no padrão de corte $j$

$b_{i} \quad$ demanda do item $i$

$c_{j} \quad$ perda associada ao padrão de corte $j$

$x_{j} \quad$ número de vezes que o padrão de corte $j$ é utilizado

Por simplicidade, considere inicialmente apenas um tipo de objeto em estoque $(\bullet / \mathrm{V} / \mathrm{I} / \mathrm{R})$. Define-se por padrão de corte cada maneira diferente de cortar um objeto. A um padrão de corte $j$ pode-se associar um vetor $m$-dimensional, que contabiliza os itens produzidos da seguinte forma:

$$
a_{j}=\left(a_{1 j}, a_{2 j}, \ldots, a_{m j}\right) \quad j=1,2, \ldots, p,
$$

onde $a_{i j}$ foi definido anteriormente. Por exemplo, considere o caso unidimensional de objetos iguais de comprimentos $L=13$ e três tipos de itens $(m=3), i=1,2$ e 3 , com comprimentos $\left(l_{i}\right)$ e demanda $\left(b_{i}\right)$ descritos na tabela 2.1. Na figura 2.1 apresenta-se alguns possiveis padrões de corte unidimensionais com seus respectivos vetores $\left(a_{j}\right)$ e perda $\left(c_{j}\right)$ associados (o pedaço sombreado corresponde à perda).

TABELA 2.1: Comprimentos e demandas.

\begin{tabular}{c:cc}
\hline Item & $\boldsymbol{l}_{\boldsymbol{i}}$ & $\boldsymbol{b}_{\boldsymbol{i}}$ \\
\hline 1 & 3 & 420 \\
2 & 5 & 730 \\
3 & 7 & 290 \\
\hline
\end{tabular}

Padrão 1

\begin{tabular}{|l|l|l|l|l|}
\hline$l_{1}$ & $l_{1}$ & $l_{1}$ & $l_{1}$ & \\
\hline
\end{tabular}

$a_{1}=(4,0,0) c_{1}=1$

Padrão 2

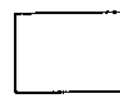

$l_{1}$

$l_{1}$

$1_{2}$

$a_{2}=(2,1,0) c_{2}=2$

Padrão 3

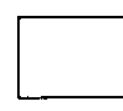
$l_{1}$

1

$i_{3}$

$a_{3}=(2,0,1) c_{3}=0$

Padrão 4

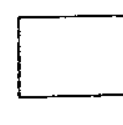

\begin{abstract}
$l_{1}$
\end{abstract}
$l_{2}$

$l_{2}$

$a_{4}=(1,2,0) c_{4}=0$

Padrão 5

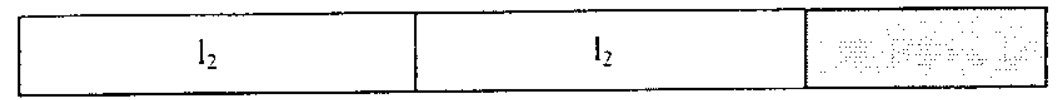

$a_{5}=(0,2,0) c_{5}=3$ 
Padrão 6

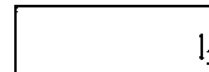

$l_{2}$ $l_{3}$

$a_{6}=(0,1,1) c_{6}=1$

Padrão 7

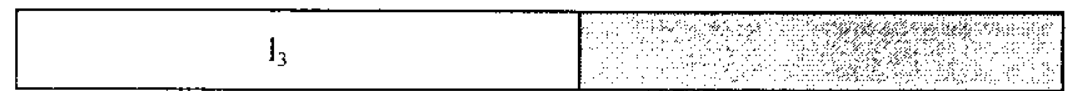

$a_{7}=(0,0,1) c_{7}=6$

FIGURA 2.1: Exemplos de padrões de corte unidimensionais e seus respectivos vetores e perdas associados.

Um padrão de corte, que produz apenas um tipo de item, é chamado de padrão de corle homogêneo, isto é, um padrão é homogêneo, quando apenas uma componente do vetor associado é não-nula: $\boldsymbol{a}_{j}=\left(0, \ldots, a_{i j}, \ldots, 0\right), a_{i j} \neq 0$. Os padrões 1,5 e 7 da figura 2.1 são exemplos de padrões homogêneos. Cabe observar que para todo problema sempre existirão pelo menos $m$ padrões homogêneos (onde $m$ é o número de tipos de itens), cujos vetores associados definem uma matriz diagonal (está implícita a suposição que $l_{t} \leq L$ para evitar infactibilidade trivial).

Considere que todos os $p$ padrões de corte sejam conhecidos a priori, e que as unidades grandes estão disponíveis em quantidades ilimitadas. O modelo de corte de estoque (problema $\bullet / \mathrm{V} / \mathrm{I} / \mathrm{R}$ ) pode ser formulado matematicamente da seguinte forma:

$$
\begin{array}{ll}
\min & f(\boldsymbol{x})=\sum_{j=1}^{p} c_{j} x_{j} \\
\text { s. a: } & \sum_{j=1}^{p} a_{i j} x_{j} \geq b_{i} \quad i=1, \ldots, m \\
& x_{j} \geq 0 \text { e inteiro } \quad j=1, \ldots, p
\end{array}
$$

A minimização da função $f(x)$ em (2.1) resulta no conjunto de padrões de corte de perda mínima. As restrições (2.2) garantem que toda a demanda seja atendida e as restrições (2.3) garantem que a repetição de cada padrão de corte $j$ seja um número inteiro e não-negativo.

Como na prática o número de padrões de corte $p$ pode ser extremamente grande, por exemplo, da ordem de centenas de milhares (GILMORE e GOMORY, 1961), apesar do número de tipos de itens $(m)$ ser da ordem de algumas dezenas, a determinação explícita de todos os padrões de corte, nesses casos, é inviável. O número extremamente grande de padrões de corte e a exigência de integralidade sobre as variáveis $x_{j}$ contribuem para tornar $o$ problema de corte difícil de ser resolvido otimamente. 
Em problemas práticos, com demandas razoavelmente grandes em relação aos elementos $a_{i j}\left(b_{i} \gg a_{i j}, i=1,2, \ldots, m\right)$, o número de vezes, que alguns padrões deverão ser utilizados, em geral, é grande. Gilmore e Gomory sugeriram, neste caso, relaxar a restrição de integralidade sobre as variáveis $x_{j}$, argumentando que o simples arredondamento da solução ótima do problema linear constitui uma boa solução para o problema intciro. Hcurísticas, para tratar o arredondamento de soluções, em casos onde o simples arredondamento da solução do problema linear não constitui uma boa solução para o problema inteiro, podem ser encontradas em Haessler (1980), Vance et al. (1994), Wäscher e Gau (1996), Riehme et al. (1996), Pinto (1999). O problema de corte (1)-(3) relaxado passa a ser definido simplesmente como:

$$
\begin{array}{ll}
\min & f(x)=\sum_{j=1}^{p} c_{j} x_{j} \\
\text { s. a: } & \sum_{j=\mathrm{i}}^{p} a_{j} x_{j}>b \\
& x_{j} \geq 0 \quad j-1, \ldots, p
\end{array}
$$

onde cada coluna $a_{j}$ corresponde a um padrão de corte.

A princípio, o método simplex pode ser diretamente aplicado, para resolver problemas de programação linear, como o problema (2.4)-(2.6) (BAZARRA et. al, 1990). Para tanto, é preciso que todas as colunas $\boldsymbol{a}_{j}$ estejam disponíveis, onde cada uma delas corresponde a uma coluna da matriz $A, A=\left(a_{i j}\right), i=1,2, \ldots, m$ e $j=1,2, \ldots, p$. Conforme mencionado, na prática o número de padrões de corte $p$ pode ser extremamente grande, o que torna a aplicação direta do método simplex computacionalmente inviável. Para contornar este problema, isto é, ao invés de gerar explicitamente todos os $p$ possíveis padrões e em seguida aplicar o método simplex, Gilmore e Gomory (1961) propuseram um método eficiente (conhecido como geração de coluna), para gerar explicitamente apenas uma coluna (padrão) durante cada iteração simplex, mantendo implicitamente as demais.

As Abordagens 1 e 3, propostas neste trabalho, utilizam o método simplex com um procedimento de geração de colunas para resolver o problema de corte. Nas seções seguintes uma breve revisão deste método e o procedimento de geração de colunas são descritos. 


\subsection{Método simplex e procedimento de geração de colunas}

Considere o problema de programação linear (2.4)-(2.6), com as restriçôes (2.5) na forma de igualdade, escrito em notação matricial:

$$
\begin{array}{ll}
\min & f(x)=c x \\
\text { s. a: } & A x=b \\
& x \geq 0
\end{array}
$$

onde $\boldsymbol{A} \in R^{m \times p}$ e posto $(\boldsymbol{A})=m$. Note que, para o problema de corte, sempre existirão $m$ colunas linearmente independentes na matriz $A$, formadas pelos padrões homogêneos (seção 2.2), o que garante posto $(A)=m$. Admita as seguintes partições: $A=[B, N], x=\left[x_{B}, x_{N}\right]$ e $c=\left[c_{B}, c_{N}\right]$. A matriz $\boldsymbol{B}$, onde $\boldsymbol{B} \in R^{m m}$, é chamada de matriz básica e é composta por $m$ colunas linearmente independentes da matriz $A$ e a matriz $N$ é chamada de matriz não-básica. $x_{B}$ é chamado vetor das variáveis básicas e $x_{N}$ vetor das variáveis não-básicas (ou variáveis livres). Reescrevendo o sistema (2.7)-(2.9) com as partições definidas obtém-se:

$$
\begin{array}{ll}
\min & f(x)=c_{B} x_{B}+c_{N} x_{N} \\
\text { s. a: } & B x_{B}+N x_{N}=b \\
& x_{B} \geq 0, x_{N} \geq 0
\end{array}
$$

A solução geral do sistema (2.7)-(2.9) pode ser descrita da seguinte forma: $B x_{B}+N x_{N}$ $=b \Leftrightarrow x_{B}=B^{-I} b-B^{-1} N x_{N}$. A atribuição de valores às variáveis não-básicas $x_{N}$ faz com que as variáveis básicas $x_{3}$ fiquem bem determinadas. A solução particular obtida por $x_{B}=\boldsymbol{B}^{-1} b$ e $x_{N}$ $=0$ é chamada solução básica. Se $x_{B}=B^{-1} b \geq 0$ então a solução básica é dita factivel e, neste caso, diz-se que a partição básica é factível. Demonstra-se que, se o problema (2.7)-(2.9) tem solução ótima, então existe uma partição básica ótima (BAZARRA et al., 1990). Escrevendo a função objetivo em termos das variáveis não-básicas, tem-se:

$$
\begin{aligned}
f(x) & =c_{B}\left(B^{-I} b-B^{-l} N x_{N}\right)+c_{N} x_{N} \\
& =c_{B} B^{-1} b+\left(c_{N}-c_{B} B^{-l} N\right) x_{N}
\end{aligned}
$$

Observe que $f_{B}=c_{B} B^{-1} b=c_{B} x_{B}$ é o valor da função objetivo para a solução básica. Seja $\pi=c_{B} B^{-1}$ o vetor das variáveis duais ou vetor multiplicador simplex. Com isso $f(x)$ pode ser escrita como: 


$$
f(x)=f_{B}+\sum_{j \in, 1}\left(c_{j}-\pi a_{j}\right) x_{j}
$$

onde $a_{j}$ corresponde à coluna $j$ de $A$ e $J$ é o conjunto dos índices das colunas da matriz $N$ (colunas não-básicas da matriz $A$ ). Isto mostra como a função objetivo se altera, quando alterações são feitas na solução básica. Os coeficientes $\left(c,-\pi a_{j}\right)$ são chamados "custos reduzidos".

A estratégia simplex é definida como uma alteração da solução básica, através da perturbação de apenas uma componente de $\boldsymbol{x}_{x}$. Como se quer minimizar $f(\boldsymbol{x})$ e $x_{j} \geq 0$ para todo $j \in J$, a componente $x_{k}$, a ser perturbada, deve ser tal que $c_{k}-\pi a_{k}<0$. Fazendo $x_{k} \geq 0$ e $x_{j}=0$, $\forall j \in J-\{k\}$, as variáveis básicas são alteradas resultando em $\boldsymbol{x}_{\boldsymbol{B}}=\boldsymbol{B}^{-1} \boldsymbol{b}-\left(\boldsymbol{B}^{-1} \boldsymbol{a}_{k}\right) x_{k} . \mathrm{O}$ crescimento da variável $x_{k}$ é limitado pela não-negatividade das variáveis básicas $\mathrm{e}$ o maior valor para $x_{k}$ anula uma variável básica, o que define uma nova partição básica, onde a coluna associada à variável $x_{k}$ (que se tornou positiva) substitui a coluna associada à variável básica, que se anulou. Soluções degeneradas (variável básica com valor nulo) podem determinar que o valor de $x_{k}$ seja nulo (há mudança de base sem alteração da solução). Quando mais que uma variável básica se anula (levando a uma solução degenerada), a escolha da variável a sair da base pode ser arbitrária. Soluções degeneradas podem produzir o fenômeno de ciclagem no método simplex (isto é, a mesma base pode ser repetida após algumas iterações). Entretanto, a ciclagem pode ser evitada na prática, com uma escolha aleatória das variáveis básicas, que se anulam.

Para determinar o menor custo reduzido, é preciso examinar todas as $p$ colunas da matriz $A$. É fácil mostrar que, caso todos os custos reduzidos sejam não-negativos: $c_{i}-\pi a_{j} \geq 0, \forall j \in J$, a solução básica é ótima (para mais detalhes do método simplex veja Bazarra et al. 1990).

Para ilustrar, um pequeno problema de corte unidimensional será resolvido, utilizando o método simplex. Considere o exemplo da tabela $2.1 \mathrm{c}$ objetos em estoque de comprimentos iguais a 13. Suponha que o objetivo seja a minimização da perda. Seja a matriz $\boldsymbol{A}$ formada pelos padrões de corte da figura 2.1. Observe que o conjunto de padrões da figura 2.1 (matriz $\boldsymbol{A}$ ) contém somente os padrões dominantes e os padrões homogêneos. Por exemplo, o padrão que contém 3 unidades do item tipo 1, 0 unidade do item tipo 2 e 0 unidade do item tipo 3, com vetor associado $(3,0,0)$, não está descrito, uma vez que o mesmo é dominado pelo padrão 1 com vetor associado $(4,0,0)$. A perda do padrão 1 é igual a 1 , menor que 4 , a perda do padrão $(3,0,0)$. Neste caso, o padrão 1 será sempre escolhido no lugar do padrão $(3,0,0)$. 
A matriz $A$ é dada por: $\left[\begin{array}{lllllll}4 & 2 & 2 & 1 & 0 & 0 & 0 \\ 0 & 1 & 0 & 2 & 2 & 1 & 0 \\ 0 & 0 & 1 & 0 & 0 & 1 & 1\end{array}\right]$, onde a coluna 1 corresponde ao padrão de corte 1 , a coluna 2 ao padrão de corte 2 , e assim sucessivamente. Seja a matriz $B$ formada pelas colunas $\left[a_{1}, a_{5}, a_{7}\right], B=\left[\begin{array}{ccc}4 & 0 & 0 \\ 0 & 2 & 0 \\ 0 & 0 & 1\end{array}\right]$.

A solução básica $x_{B}=\left[x_{1}, x_{5}, x_{7}\right]^{\mathrm{T}}$ é dada por:

$$
\boldsymbol{x}_{B}=\boldsymbol{B}^{-1} b=\left[\begin{array}{ccc}
1 / 4 & 0 & 0 \\
0 & 1 / 2 & 0 \\
0 & 0 & 1
\end{array}\right] \cdot\left[\begin{array}{l}
420 \\
730 \\
290
\end{array}\right]=\left[\begin{array}{c}
105 \\
365 \\
290
\end{array}\right]
$$

e o vetor multiplicador simlpex $\pi=c_{B} B^{-1}=\left[\begin{array}{lll}1 & 3 & 6\end{array}\right] \cdot\left[\begin{array}{ccc}1 / 4 & 0 & 0 \\ 0 & 1 / 2 & 0 \\ 0 & 0 & 1\end{array}\right]=\left[\begin{array}{lll}1 / 4 & 3 / 2 & 6\end{array}\right]^{\mathrm{T}}$

Os custos reduzidos das variáveis não-básicas devem ser calculados, para testar a otimalidade.

$$
\begin{aligned}
& \hat{c}_{2}=c_{2}-\pi^{T} a_{2}=2-\left[\begin{array}{lll}
1 / 4 & 3 / 2 & 6
\end{array}\right] \cdot\left[\begin{array}{l}
2 \\
1 \\
0
\end{array}\right]=0 \\
& \hat{c}_{3}=c_{3}-\pi^{T} a_{3}=0-\left[\begin{array}{lll}
1 / 4 & 3 / 2 & 6
\end{array}\right] \cdot\left[\begin{array}{l}
2 \\
0 \\
1
\end{array}\right]=-13 / 2 \\
& \hat{c}_{4}=c_{4}-\pi^{T} a_{4}=0-\left[\begin{array}{lll}
1 / 4 & 3 / 2 & 6
\end{array}\right] \cdot\left[\begin{array}{l}
1 \\
2 \\
0
\end{array}\right]=-13 / 4 \\
& \hat{c}_{6}=c_{6}-\pi^{T} a_{6}=1-\left[\begin{array}{lll}
1 / 4 & 3 / 2 & 6
\end{array}\right] \cdot\left[\begin{array}{l}
0 \\
1 \\
1
\end{array}\right]=-13 / 2
\end{aligned}
$$

Como as colunas $\boldsymbol{a}_{3}, \boldsymbol{a}_{4}$ e $\boldsymbol{a}_{6}$ apresentam custos relativos negativos, qualquer uma delas poderia ser escolhida para entrar na base, pois isso faria com que o valor da função objetivo diminuísse. Uma heurística consiste em escolher a variável com o menor custo relativo, conhecida como regra de Dantzig (BAZARRA et al. 1990), por exemplo a variável $x_{6}$. A coluna $a_{6}$ entrará na base no lugar da coluna $\boldsymbol{a}_{7}$. Continuando este procedimento, mais duas 
mudanças na base são feitas: a coluna $\boldsymbol{a}_{4}$ entra no lugar da coluna $\boldsymbol{a}_{5}$ e a coluna $\boldsymbol{a}_{3}$ entra no lugar da coluna $a_{1}$. A solução ótima obtida é $x_{3}^{*}=80, x_{4}^{*}=260$ e $x_{6}^{*}=210$ e com perda ótima $f\left(x^{*}\right)$ $=210$.

Para este exemplo, em cada iteração simplex foram calculados todos os custos reduzidos (necessitando-se explicitamente de todas as colunas da matriz $\boldsymbol{A}$ ), para se determinar o menor deles. Como em problemas reais este número pode ser extremamente grande, a avaliação computacional dos mesmos torna-se inviável. Gilmore e Gomory propuseram um método (conhecido por geração de coluna) que, em cada iteração simplex, procura implicitamente, (ou seja, sem a necessidade de analisar explicitamente todas as colunas da matriz $N$ ), uma coluna não-básica candidata a substituir uma coluna básica. O procedimento consiste em gerar a coluna $j$ (isto é, um padrão) cujo valor $c,-\pi a$, seja mínimo. Para ilustrar, apresenta-se a seguir este problema auxiliar inicialmente para o caso unidimensional, que será utilizado nas Abordugens $I$ e 3 .

\subsubsection{Geração de coluna para o caso unidimensional}

Considere a seguinte notação:

$L \quad$ comprimento do objeto

$l_{i} \quad$ comprimento do item $i, i=1,2, \ldots, m$

$v_{i} \quad$ valor do item $i, i=1,2, \ldots, m$

No problema unidimensional tem-se que a perda $c_{j}$ é dada por:

$$
c_{j}=L-\sum_{i=1}^{m} l_{i} a_{i j}
$$

e, neste caso, determinar o padrão cujo valor $c_{j}-\pi a_{j}$ seja mínimo consiste em:

$$
\min _{j}\left\{L-\sum_{i=1}^{n}\left(l_{i}+\pi_{1}\right) a_{t j}\right\}
$$

Considerando que una coluna qualquer de $A$, diga-se, $a=\left(a_{1}, \ldots, a_{m}\right)$ deve satisfazer:

$\sum_{i=1}^{m} l_{i} a_{i} \leq L, a_{i} \geq 0$ e inteiro, o problema acima pode ser escrito da seguinte forma: 


$$
\begin{array}{ll}
\max & f(a)=\sum_{i=1}^{m}\left(l_{i}+\pi_{i}\right) a_{i} \\
\text { s. a: } & \sum_{i=1}^{m} l_{i} a_{i} \leq L \\
& a_{i} \geq 0 \text { e inteiro, } \quad i=1, \ldots, m
\end{array}
$$

A maximização de $f(a) \mathrm{em}(2.10)$ resulta numa solução com a melhor combinação de unidades pequenas (itens). A restrição (2.11) garante que o comprimento da unidade grande $L$ não será violado. E, por fỉm, as restrições (2.12) garantem que o número de vezes, que cada unidade pequena (item) $i$ será alocada ao longo do comprimento da unidade grande (mochila) $L$, deve ser um número não-negativo e inteiro.

Este problema é denominado Problema da Mochila (Knapsack Problem) unidimensional (MARTELLO e TOTH, 1990). Como $\mathrm{cm}$ cada iteração simplex uma coluna deve ser gerada, tem-se que a solução do problema (2.4)-(2.6) depende da solução de diversos problemas da mochila, o que evidencia a importância de métodos de solução eficazes para este último problema.

A dificuldade em resolver o problema (2.10)-(2.12) está na restrição de integralidade sobre as variáveis. Diferentes técnicas podem ser utilizadas, para resolver o problema da mochila como, por exemplo, programação dinâmica, enumeração implícita (algoritmo branch-and-bound), métodos lagrangianos e heurísticos, busca em grafo e/ou (MARTELLO e TOTH, 1990; MORABITO, 1992). Um algoritmo de enumeração implícita foi apresentado por Gilmore e Gomory (1963), e será utilizado neste trabalho nas Abordagens 1, 2 e 3, para resolver o problema (2.10)-(2.12). Na seção seguinte este algoritmo será brevemente descrito. Cabe observar que outros métodos de solução poderiam ser utilizados, para resolver o problema (2.10)-(2.12) (MARTELLO e TOTH, 1990).

\section{Algoritmo de Busca em Profundidade Primeiro de Gilmore e Gomory}

No algoritmo de enumeração implícita de Gilmore e Gomory (1963) uma seqüência de vetores $\left(a_{1}, a_{2}, \ldots, a_{5}\right)$ com $a_{i} \geq 0$ e inteiro, e $1 \leq s \leq m$, para vários valores de $s$, que satisfaçam $\sum_{i=1}^{s} l_{i} a_{i} \leq L$, é gerada em ordem lexicograficamente decrescente. Um vetor $\left(a_{1}^{1}, a_{2}^{1}, \ldots, a_{s_{1}}^{1}\right)$ é lexicograficamente maior que um vetor $\left(a_{1}^{2}, a_{2}^{2}, \ldots, a_{s_{2}}^{2}\right)$ se, e somente se, para algum $i, 1 \leq i<\min \left\{s_{1}, s_{2}\right\}, a_{1}^{1}=a_{1}^{2}, \ldots, a_{i}^{1}=a_{i}^{2}$, e $a_{i+1}^{1}>a_{1+1}^{2}$. Muitos dos possiveis vetores, a serem 
investigados, são ignorados através de um simples teste realizado no passo 5 . O algoritmo de busca em profundidade primeiro proposto por Gilmore e Gomory (1963) está descrito a seguir.

Passo 1: ordene os itens tipo $i, i=1,2, \ldots, m$ tal que $v_{1} / l_{1} \geq v_{2} / l_{2} \geq \ldots \geq v_{m} / l_{m}$ e defina $v_{m+1}=0$ e $l_{m+1}=1$, onde $v_{i}=l_{i}+\pi_{i}$ corresponde ao valor do item i. Faça $f(a)=0$.

Passo 2: calcule $a_{1}=\left\lfloor L / l_{1}\right\rfloor$ e $a_{t}=\left\lfloor\frac{L-\sum_{k=1}^{i-1} l_{k} a_{k}}{l_{i}}\right\rfloor \quad i=2, \ldots, m$.

Neste passo, um padrão é definido, alocando-se a maior quantidade possivel do item mais valioso, seguido da alocação do segundo item mais valioso, no espaço que sobrou, e assim sucessivamente.

Passo 3: Dado $\left(a_{1}, a_{2}, \ldots, a_{m}\right)$ verifique se $\sum_{i=1}^{m} v_{i} a_{i}>f(a)$. Neste caso guarde este padrão e atualize $f(a)$.

Neste passo o padrão mais valioso até então encontrado é armazenado e seu valor atualizado.

Passo 4: Defina $s=\max \left\{i \mid a_{i}>0, i=1,2, \ldots, m\right\}$.

Lembrando que os itens estão ordenados em ordem decrescente de valor por unidade de comprimento, procure pelo item de menor valor unitário dentre os $m$ itens no padrão que está sendo avaliado.

Passo 5: Faça $a_{s} \leftarrow a_{s}-1$. Se $\left(L-\sum_{i=1}^{s} l_{i} a_{i}\right) v_{s+1}>v_{s} l_{s+1}$, então vá para o passo 7 . Caso contrário vá para o passo 6 .

Neste passo é avaliado se a substituição de itens do tipo $s^{+1}$ (que cabem no espaço, que sobrou, ao retirar uma unidade do tipo $s$ ) fornece um padrão mais valioso que o padrão disponível. Em caso afirmativo o passo 7 é executado, isto é, tenta-se alocar os itens $s+1, s+2$, $\ldots, m$ no espaço que sobrou, ao retirar uma unidade do tipo $s$; caso contrário, o passo 6 é executado.

Passo 6: Defina $s=\max \left\{i \mid a_{i}>0, i=1,2, \ldots, s-I\right\}$ e vá para o passo 5. Caso $s$ não exista, pare e retorne o padrão de valor $f(a)$.

Neste passo procura-se pelo item de menor valor unitário com índice $i \leq s-1$. 
Passo 7 : Calcule $a_{i}=\left\lfloor\frac{L-\sum_{k=1}^{t-1} l_{k} a_{k}}{l_{l}}\right\rfloor i=s+1, s+2, \ldots, m$ e volte para o passo 3.

A quantidade de itens do tipo $s+1, s+2, \ldots, m$ que é possível colocar no espaço que sobrou, ao retirar uma unidade do item tipo $s$, onde $s$ é definido no passo 4 ou no passo 6 , é calculada.

No final do algoritmo (no passo 6) o valor $f(a)$ ć o valor máximo para o problema (2.10)-(2.12). Ou seja, é determinado o padrão de corte ótimo $\left(a_{1}^{*}, a_{2}^{*}, \ldots, \dot{a}_{m}^{*}\right)$ mais valioso, uma vez que o algoritmo examina implicitamente todos os possíveis padrões de corte cescolhe o melhor deles, isto é, aquele que possui o maior valor para $f(a)$.

A seção seguinte descreve o problema de corte bidimensional em 2-estágios e o procedimento proposto por Gilmore e Gomory (1965), para resolver o problema de geração de padrão, que consiste na solução de vários problemas da mochila unidimensional. Este procedimento será utilizado nas Abordagens 1,2 e 3 deste trabalho.

\subsubsection{Geração de coluna para o caso bidimensional em 2-estágios}

Suponha um suprimento de peças retangulares em estoque (objetos) em quantidades ilimitadas e uma demanda por peças retangulares menores (itens). O problema de corte bidimensional é definido como o corte das peças em estoque em peças menores (itens demandados), com o objetivo de, por exemplo, minimizar a perda gerada pelo corte dos padrões. Considere a seguinte notação para a formulação matemática:

$L \times W$ tamanho do objeto

$l_{i} \times w_{i} \quad$ tamanho do item $i, i=1,2 \ldots ; m$

Apesar da restrição geométrica não representar nenhum problema para o caso unidimensional, o mesmo não se pode dizer em relação a problemas com mais de uma dimensão, pois, nestes casos, essa restrição é bem mais complexa de ser descrita matematicamente. Conforme mencionado anteriormente, existem muitos trabalhos na literatura, abordando o problema de corte bidimensional, como por exemplo Gilmore e Gomory (1965), Herz (1972), Dyson e Gregory (1974), Beasley (1985), Madsen (1988), Morabito (1989), Carnieri et al. (1994), Fayard e Zissimopoulos (1995), Hifi e Zissimopoulos (1996), Garcia 
(1996), Yanasse et al. (1991), Gramani (1997), Morabito e Garcia (1998), Morabito et al. (1992), Morabito e Arenales (1995, 1996, 2000), Vianna (2000), Belluzzo (2002).

Em muitas situações reais os equipamentos de corte restringem os possiveis padrões de corte, que podem ser gerados, por exemplo, aos cortes guilhotinados. Uma subclasse importante de padrões, envolvendo somente cortes guilhotinados, são os cortes em 2-estágios (a motivação para estudo deste tipo de padrões de corte é que eles são freqüentemente encontrados na prática, por exemplo, na fábrica de móveis Colombini).

No primeiro estágio cortes guilhotinados são feitos paralelos ao comprimento do objeto, produzindo um conjunto de faixas. No segundo estágio cortes guilhotinados são feitos paralelos à largura das faixas (figura 2.2). Quando todos os itens têm a mesma altura em cada faixa, o padrão é denominado padrão guilhotinado em 2-estágios exato (figura 2.2a); caso contrário é denominado padrão guilhotinado em 2-estágios não-exato (figura $2.2 \mathrm{~b}$ ). Se novamente cortes forem feitos paralelos ao comprimento da faixa, então o padrão é dito 3estágios (figura 2.2c). Na fábrica de móveis Colombini, a máquina de corte consegue produzir padrões de corte como os da figura 2.2a. Para produzir itens com larguras diferentes das faixas, como, por exemplo, o item 8 da figura $2.2 \mathrm{~b}$, o recorte dos mesmos é feito em outro equipamento. Note que todo padrão de corte guilhotinado 2-estágios não exato (figura $2.2 \mathrm{~b}$ ) pode ser visto como um padrão de corte guilhotinado três estágios (figura 2.2c), mas o inverso nem sempre é verdadeiro.

Por exemplo, considere um objeto de comprimento $L \times W=100 \mathrm{~cm} \times 70 \mathrm{~cm}$ e oito tipos de itens $(i=1,2, \ldots, 8)$ de tamanhos $l_{i} \times w_{i}=100 \times 20,30 \times 30,40 \times 20,20 \times 20,60 \times 20$, $40 \times 30,60 \times 10$ e $30 \times 25(\mathrm{em} \mathrm{cm})$. Na figura 2.2 apresenta-se um exemplo de um padrão de corte guilhotinado em 2-estágios exato (a), 2-estágios não-exato (b) e 3-estágios (c) com seus respectivos vetores $\left(a_{j}\right)$ e perda $\left(c_{j}\right)$ associados (o pedaço sombreado é considerado perda).

Padrão 1: $a_{1}=(1,3,2,1,0,0,0,0) \quad c_{1}=300$

Padrão 2: $a_{2}=(1,1,2,1,0,0,0,1) \quad c_{2}=600$

\begin{tabular}{|l|l|l|l|l|}
\hline$l_{3}$ & \multicolumn{2}{|c|}{$l_{3}$} & $l_{4}$ \\
\hline$l_{2}$ & $l_{2}$ & $l_{2}$ & \\
\hline \multicolumn{4}{|c}{} \\
\hline
\end{tabular}

(a) 2-estágios exato

\begin{tabular}{|l|l|l|l|}
\hline \multicolumn{1}{|c|}{$l_{3}$} & \multicolumn{2}{|c|}{$l_{3}$} & $l_{4}$ \\
\hline \multirow{2}{*}{$l_{2}$} & $l_{8}$ & $l_{8}$ & \\
\hline \multicolumn{3}{|c|}{$l_{1}$} \\
\hline
\end{tabular}

(b) 2-estágios não-exato 
Padrão 3: $a_{3}=(1,0,1,0,1,1,3,0) \quad c_{3}=0$

\begin{tabular}{|c|c|}
\hline \multirow{2}{*}{$l_{6}$} & \multicolumn{1}{|c|}{$l_{7}$} \\
\cline { 2 - 3 } & \multicolumn{2}{|c|}{$l_{7}$} \\
\hline$l_{5}$ & $l_{7}$ \\
\hline \multicolumn{3}{|c|}{$l_{3}$} \\
\hline
\end{tabular}

(c) 3-estágios

FIGURA 2.2: Padrão de corte guilhotinado em 2-estágios: (a) caso exato, (b) caso não-exato e padrão de corte guilhotinado em (c) 3-estágios.

Por simplicidade, os procedimentos para solução do problema da mochila bidimensional (padrões de corte bidimensionais) serão apresentados, considerando apenas um único tipo de objeto. Se existirem mais de um tipo de objeto, o procedimento deve ser repetido para cada tipo (Yanasse et al., 1991).

O método desenvolvido por Gilmore e Gomory (1965), para gerar padrões guilhotinados em 2-estágios envolve duas fases. Abordagens baseadas em duas fases são usuais na literatura. Veja por exemplo, Farley (1983), Morabito e Arenales (1994), Fayard e Zissimopoulos (1995), Hifi e Zissimopoulos (1996), Riehme et al. (1996), Hifi (1997), Morabito e Arenales (1995) e Morabito e Garcia (1998).

Na primeira fase, padrões de corte são determinados para cada faixa de tamanho $\left(L, w_{j}\right), j \in D_{w}$, onde $D_{w}=\left\{j \mid w_{j} \neq w_{i}, i>j, i, j=1, \ldots, m\right\}$ é o conjunto de indices de larguras diferentes. Na segunda fase o número de vezes, que cada faixa deverá ser utilizada, é calculado. É necessário apenas um padrão de corte para cada faixa, aquele que fornece o melhor valor para $\sum_{i=1}^{m} v_{i} a_{l j}$ onde $a_{i j}$ é o número de itens do tipo i em uma faixa do tipo $j$. $\mathrm{O}$ procedimento em duas fases para o caso não-exato (figura 2.2b) é apresentado a seguir (problema de corte $2 / \mathrm{B} / \mathrm{O} / \bullet$ ).

Primeira fase: Seja $W_{j}=\left\{i \mid w_{i} \leq w_{j}, i=1, \ldots, m\right\}$ e $V_{j}, j \in D_{w}$ definido por:

$$
\begin{array}{ll}
V_{j}=\max & \sum_{i \in V_{j}} v_{i} a_{i j} \\
\text { s. a: } \quad & \sum_{i \in V_{j}} l_{i} a_{i j} \leq L \\
& a_{i j} \geq 0 \text { e inteiro, } \quad i=1, \ldots, m
\end{array}
$$


Ou seja, para todas as larguras $w_{j}$, calcule $V_{j}$, o valor ótimo obtido, alocando retângulos $l_{i} \times w_{i}$, onde $w_{i} \leq w_{j}$, do início ao fim de uma faixa de largura $w_{j}$ e comprimento $L$. Para cada item $j \in D_{w}$ tem-se um problema da mochila. Convém observar que todos esses problemas podem ser resolvidos de uma única vez, se a técnica de programação dinâmica for utilizada (GILMORE e GOMORY, 1965; MORABITO, 1992).

Segunda fase: Seja $\mu_{j}$ o número de faixas do tipo $j$ na placa $L \times W, j \in D_{w}$. Então,

$$
\begin{array}{ll}
\max & \sum_{j \in D_{\mu}} V_{j} \mu_{j} \\
\text { s. a: } & \sum_{j \in D_{w}} w_{j} \mu_{j} \leq W \\
& \mu_{j} \geq 0 \text { e inteiro, } \quad j \in D_{w}
\end{array}
$$

O valor ótimo da função objetivo (2.16) é então obtido, resolvendo-se mais um problema da mochila, onde cada item corresponde a uma faixa e a solução de (2.16)-(2.18) corresponde à combinação mais valiosa de faixas. $O$ procedimento descrito pode ser adaptado, para tratar o caso exato (figura 2.2a) simplesmente redefinindo $W_{j}$ na primeira fase como $W_{j}=\left\{i \mid w_{i}=w_{j}, i=1, \ldots, m\right\}$. O padrão de corte obtido com a solução de (2.13)(2.15) e (2.16)-(2.18) é dado por:

$$
a=\left(\begin{array}{c}
a_{1}=\sum_{j \in D_{w}} a_{1 j} \mu_{j} \\
a_{2}=\sum_{j \in D_{w}} a_{2 j} \mu_{j} \\
\vdots \\
a_{m}=\sum_{j \in D_{w}} a_{m j} \mu_{j}
\end{array}\right)
$$

Seja $m_{W}$ o número de elementos de $D_{w}$. Cabe observar que $m_{W}+1$ problemas da mochila definidos por (2.13)-(2.15) e (2.16)-(2.18) produzem o padrão ótimo para o objeto de tamanho $L \times W$, considerando os cortes do primeiro estágio paralelos ao comprimento $L$ do objeto. O processo deve ser repetido considerando os cortes do primeiro estágio paralelos à largura $W$ do objeto. Esta repetição requer a solução de $m_{L}+1$ problemas da mochila, onde $m_{L}$ é o número de elementos em $D_{L}=\left\{j \mid l_{j} \neq l_{i}, i>j, i, j=1, \ldots, m\right\}$ e produz o padrão ótimo para o objeto agora considerando os cortes do primeiro estágio paralelos à largura $W$ do objeto. O padrão mais valioso dentre esses dois é então escolhido. O método descrito proposto por Gilmore e Gomory (1965) para resolver o problema de corte guilhotinado em dois 
estágios, consiste na resolução de uma série $\left(m_{W}+1\right.$ e $\left.m_{L}+1\right)$ de problemas unidimensionais. A formulação descrita acima pode ser estendida para os casos de padrões de corte guilhotinados em 2-estágios restritos, conforme Gramani (1997).

Neste trabalho, o procedimento proposto por Gilmore e Gomory (1965) foi utilizado para gerar os padrões de corte bidimensionais em 2-estágios.

\subsubsection{Geração de coluna para o caso bidimensional não-estagiado: abordagem em grafo e/ou}

O método de Gilmore e Gomory (1965) pode ser utilizado para resolver problemas de corte bidimensional guilhotinado em 2-estágios. Para resolver problemas de corte guilhotinado não-estagiado (conforme seção 2.1, um problema é dito não-estagiado quando não existe restrição para o número máximo de estágios nos quais os cortes poderão ser realizados), Morabito (1989) propôs uma abordagem de solução baseada numa busca em grafo e/ou. Esta abordagem pode ser estendida para tratar diferentes problemas de corte e empacotamento, como problemas de corte não-guilhotinados (ARENALES e MORABITO, 1995), problemas de corte estagiados e restritos (MORABITO e ARENALES, 1996), problemas de carregamento de contêineres (MORABITO e ARENALES, 1994), bem como processos de corte de formas variadas (ARENALES, 1993; VIANNA, 2000).

Neste trabalho, a abordagem em grafo e/ou é utilizada para gerar os padrões de corte guilhotinados não-estagiados das Abordagens 1, 2 e 3, aqui propostas. A seguir uma revisão desta abordagem é apresentada. Cabe notar que outras abordagens poderiam ser utilizadas para resolver esse problema (HERZ, 1972; GILMORE e GOMORY, 1965; WANG, 1983; BEASLEY, 1985; OLIVEIRA E FERREIRA, 1990; SICUP, 2002).

Um grafo $G=(V, E)$ consiste em um conjunto finito, não-vazio $V=\{1,2, \ldots, v\}$ de vértices e um conjunto $E=\left\{e_{1}, e_{2}, \ldots, e_{s}\right\}$ de $\operatorname{arcos}$ (ou arestas), cujos elementos são subconjuntos de $V$ de tamanho 2, isto é, $e_{u}=(i, j)$ onde $i, j \in V$. Os arcos podem estar direcionados e, neste caso, o grafo é dito direcionado. Se $e_{u}=(i, j)$ é um arco de $G$, então $i$ é o extremo inicial de $e_{u}$ e $j$ ć o extremo final de $e_{u}$. Um nó $j$ é dito sucessor de um nó $i$ se existe um arco para o qual $i$ é o extremo inicial e $j$ o extremo final.

Uma generalização de um grafo é feita permitindo arcos em $E$ de diferentes tamanhos, por exemplo, um arco $e_{u}=(i, j, k)$ onde $i, j, k \in V$. Neste caso o grafo $G=(V, E)$ é chamado de 
hipergrafo. Um tipo particular de hipergrafo é o grafo e/ou ou árvore e/ou, onde os arcos são definidos como pares $e_{u}=\left(i, V_{u}\right)$ onde $i \in V$ e $V_{u} \subset V$ com cardinalidade de $V_{u}$ maior que um; por exemplo um arco $e_{u}=(i,\{j, k\})$ onde $i \in V$ e $\{j, k\} \subset V$. Esta estrutura é útil para representar problemas que podem ser resolvidos através da decomposição em um conjunto de subproblemas menores (onde todos os subproblemas devem ser resolvidos para se encontrar a solução do problema original). Os arcos gerados por esta decomposição são chamados arcos-e. Os arcos-e podem apontar para qualquer número de nós sucessores. Como vários arcos podem emergir de um simples nó, assim como no grafo-ou (o que indica que diferentes caminhos deverão ser resolvidos para a solução do problema original), esta estrutura é chamada de grafo e/ou. Portanto, no grafo e/ou existem dois tipos de arcos: arcos-ou, que representam caminhos alternativos, a partir do nó do qual eles emanam, e arcos-e, os quais ligam um nó a um conjunto de nós que o compõem. Cabe notar que um arco de um grafo e/ou define um relacionamento entre um nó e um subconjunto de nós. Uma solução para um problema corresponde a um caminho completo num grafo e/ou, ou seja, um subgrafo e/ou desde o nó raiz até um conjunto de nós folhas. Para mais detalhes sobre grafos, hipergrafos e grafos e/ou veja Berge (1973) e Pearl (1984).

Uma árvore é um grafo conexo sem ciclos (GONDRAN e MINOUX, 1990), ou seja, todos os vértices estão ligados por uma cadeia (seqüência de arcos) e os extremos da cadeia não coincidem. Em uma árvore o nó inicial é chamado de raiz e os nós finais, isto é, nós sem sucessores, são chamados de folhas. Uma sequiência de arcos orientada $\left\{e_{1}, e_{2}, \ldots, e_{q}\right\}$ é chamada caminho e tem comprimento $q$. O valor do caminho é a soma dos valores de todos os arcos contidos neste caminho. Um caminho que liga um nó inicial a um nó final é dito completo. Na figura 2.3 ilustra-se a representação em grafo e/ou do padrão de corte da figura 2 a (seção 2.3.2).
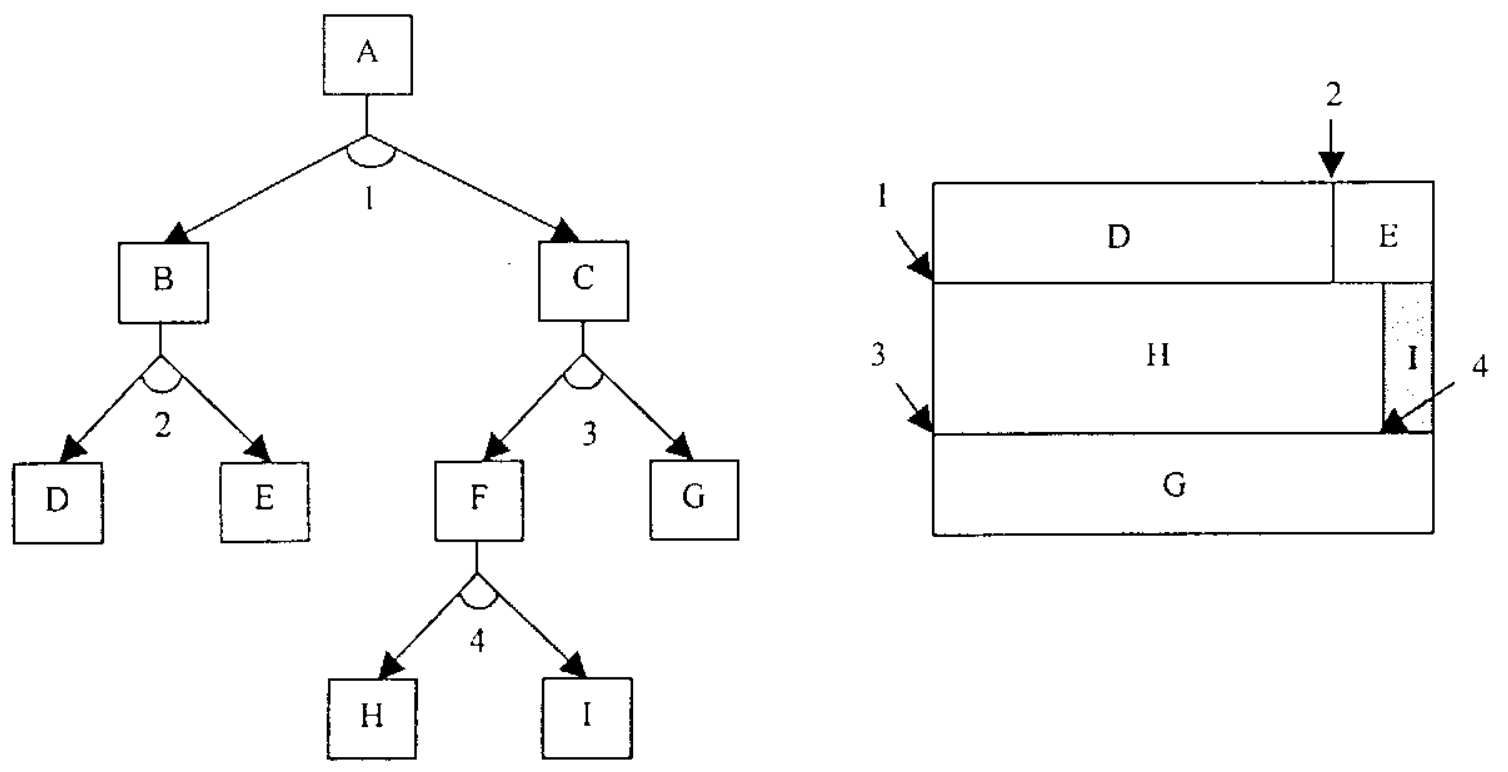

FIGURA 2.3: Representação da seqüência de cortes no grafo e/ou e no objeto. 
Considere o problema de geração de padrões de corte guilhotinados bidimensionais para um objeto de tamanho $L \times W$ e $m$ itens de tamanhos $l_{i} \times w_{i}$. Diferentes cortes guilhotinados podem ser realizados em cada objeto, o que implica em diferentes padrões de corte. Para gerar todos os padrões de corte guilhotinados, faz-se necessário investigar todos os possiveis cortes em cada retângulo. Cada retângulo sucessor apresenta um problema similar ao problema original. Os retângulos c os cortes podem ser representados respectivamente como nós e arcos em um grafo orientado e/ou, onde o nó inicial corresponde ao objeto ( $L \mathrm{x}$ $W)$ e os nós finais aos itens $\left(l_{i} \times w_{i}\right)$, cujos valores são $v_{i}$.

Cada corte guilhotinado, que é realizado em um nó não tinal, é representado por um arco-e e liga este nó aos seus dois sucessores. Para nós não finais $(l, w)$ nos quais $l<\min \left\{l_{i}\right.$, $i=1,2 \ldots, m_{\}}$ou $w<\min \left\{w_{i}, i=1,2 \ldots, m\right\}$ somente é possivel realizar um 0 -corte; 0 retângulo produzido por este corte corresponde à perda e tem valor igual a zero. Um caminho completo em um grafo e/ou é definido da seguinte forma: a partir do nó inicial pode-se escolher um arco-e (que corresponde a um corte guilhotinado) ou um 0-corte. Para cada nó sucessor novamente existem essas duas opções, e assim sucessivamente, até que todos os nós no grafo correspondam a nós finais. O valor de um caminho completo é definido como a soma de todos os valores dos nós finais, que fazem parte deste caminho. Para encontrar o padrão de corte mais valioso, basta determinar o caminho mais valioso no grafo e/ou.

A construção completa de um grafo nem sempre é necessária, visto que na prática ele pode conter um número extremamente grande de nós, e somente alguns deles precisam ser examinados, ou seja, define-se um grafo implicitamente e através de um procedimento de busca operações são aplicadas nos nós do grafo. Os nós gerados são classificados em abertos, aqueles que foram gerados e ainda não foram expandidos, e fechados, se todos os seus sucessores já foram investigados, isto é, nós que foram gerados e completamente expandidos.

Uma estratégia de busca define uma maneira de percorrer um grafo e conseqüentemente um método para resolver o problema. Em geral, a enumeração completa de todos os nós é computacionalmente inviável. $O$ uso de limitantes e de regras, para se evitar padrões equivalentes (diferentes padrões que possuem o mesmo número de itens do tipo $i$ ) podem ser utilizados para reduzir o problema. Mesmo assim, a busca pode ser computacionalmente infactível. É possivel definir heuristicas, utilizando-se limitantes, que permitem gerar soluções boas e computacionalmente factíveis. Algumas regras para evitar padrões equivalentes são: 
i) padrões normais: cortes guilhotinados podem ser reduzidos a combinações lineares inteiras não-negativas do tamanho das peças. Ou seja, os cortes verticais ao longo do comprimento $L$ podem ser reduzidos ao conjunto $X$ :

$$
X=\left\{x / x=\sum_{i=1}^{m} \alpha_{1} l_{l}, 1 \leq x \leq L-l_{0}, \alpha_{1} \geq 0 \text { e inteiro }\right\}
$$

onde $l_{0}=\min \left\{l_{i}, i=1,2, \ldots, m\right\}$. Da mesma forma um conjunto $Y$ pode ser definido para os cortes horizontais ao longo da largura $W$. Esses dois conjuntos são chamados de conjuntos de discretização. Fórmulas recursivas de como gerar esses conjuntos podem ser encontradas em Christofides e Whitlock (1977) ou em Morabito e Arenales (1996).

ii) simetria e exclusão: o conjunto $X$ pode ser significativamente reduzido, se for definido para cada nó $N$ o conjunto $X(N)$ e considerados os efeitos de simetria e exclusão. Suponha que o nó $N$ represente um retângulo de tamanho $(x, y)$. O conjunto $X(N)$ (e similarmente $Y(N)$ ) é definido por:

$$
X(N)=\left\{x_{1} / x_{1}=\sum_{i=1}^{m} \alpha_{1} l_{1},\left(\text { se } w_{1}>y \Rightarrow \alpha_{1}=0\right), 1 \leq x_{1} \leq\left\lfloor\frac{x}{2}\right\rfloor, \alpha_{1} \geq 0 \text { e inteiro }\right\}
$$

\section{Limitantes}

Considere um nó $N$ representando um retângulo $(x, y)$ e seja $M(N)=$ $\left\{i / l_{i} \leq x, w_{i} \leq y, i=1, \Lambda, m\right\}$. Um limitante inferior simples para o nó $N$ pode ser definido, utilizando somente itens de um tipo (padrões de corte homogêneos):

$$
\left.L(x, y)=\max _{i \in t /\left(x^{\prime}\right)}\left\{v_{i}\left\lfloor\frac{x}{l_{i}}\right\rfloor \frac{y}{w_{i}}\right]\right\},
$$

onde $v_{i}$ é o valor do item $i$. Este limitante inferior para qualquer retângulo $(x, y)$ é atualizado sempre que os retângulos sucessores fornecerem padrões homogêneos melhores. Por exemplo, se $L\left(x_{1}, y\right)+L\left(x-x_{1}, y\right)>L(x, y)$ então $L(x, y)$ é atualizado por $L\left(x_{1}, y\right)+L\left(x-x_{1}, y\right)$.

Um limitante superior para o retângulo $(x, y)$ também pode ser facilmente determinado, considerando o problema relaxado para $(x, y)$ : 


$$
\begin{aligned}
& U(x, y)=\max \sum_{i \in M(N)} v_{i} a_{i} \\
& \text { s.a: } \sum_{i \in M(N)}\left(l_{i} w_{i}\right) a_{i} \leq(x y) \\
& \\
& \quad a_{i} \geq 0, \quad i \in M(N)
\end{aligned}
$$

A restrição acima impõe que a área utilizada pelos itens seja menor ou igual à área do retângulo $(x, y)$ e desta forma todos os padrões factíveis em $(x, y)$ têm que satisfazê-la. $O$ problema acima é facilmente resolvido por:

$$
U(x, y)=(x y) \cdot \max \left\{v_{i} /\left(l_{i} w_{i}\right), i \in M(N)\right\}
$$

Esses limitantes podem ser utilizados para implicitamente enumerar nós do grafo. Seja $V(N)$ a molhor solução para o nó $N$. Esta solução é obtida pelo limitante inferior ou por um caminho completo emanando do nó $N . V(N)$ é atualizada se $V(N)<L\left(N_{1}\right)+L\left(N_{2}\right)$, onde $\left(N_{1}, N_{2}\right)$ é o par sucessor de $N$. Além disso se $V(N) \geq U\left(N_{1}\right)+U\left(N_{2}\right)$ então $N_{1}$ e $N 2$ não precisam ser considerados explicitamente.

Apesar de os cortes poderem ser restritos às combinações verticais e horizontais das dimensões dos itens, sem perder a solução ótima (HERZ, 1972), as mesmas podem ser bastante grandes, fazendo com que o problema se torne computacionalmente intratável. Heuristicas podem ser utilizadas, para limitar o tamanho dessas combinações (para o caso restrito as heurísticas $\mathrm{H1}, \mathrm{H} 2$ e $\mathrm{H} 3$, descritas mais adiante nesta seção, podem ser utilizadas).

Existem diferentes formas de percorrer um grafo. Herz (1972) propôs uma versão da busca depth-first, conhecida como back-tracking (BT), que consiste em cortar os retângulos mais recentemente abertos, até que todos os retângulos gerados estejam fechados. Outra estratégia de busca é a best-first que, em geral, é mais eficiente que a busca depth-first. Uma estratégia heurística simples baseada em otimização local é conhecida como hill-climbing (HC). Com essa estratégia a solução ótima pode não ser encontrada, visto que a mesma elege um melhor caminho local e abandona todos os outros, que embora localmente não sejam tão bons, podem fazer parte da solução ótima.

Uma estratégia de busca híbrida pode ser definida, combinando as estratégias backtracking (BT) e hill-climbing (HC) (MORABITO e ARENALES, 1996). Seja depth um número inteiro positivo, que representa um limitante para a profundidade de busca da 
estratégia BT. A implementação do algoritmo foi feita para uma busca em uma sub-árvore e/ou.

\section{Algoritmo BT-HC}

1: Defina depth para cada sub-árvore a ser gerada. Seja RAIZ uma lista, que no início contém somente o nó inicial.

2: Enquanto RAIZ ainda não for vazia, faça:

3: Seja $s$ o primeiro nó em RAIL. Gere uma sub-árvore e/ou a partir do nó raiz $s$, usando a estratégia BT. Retire $s$ da RAIZ.

4: Escolha o caminho mais valioso a partir de $s$ e descarte os outros caminhos estratégia $\mathrm{HC}$ ). Se existirem nós neste caminho cuja profundidade seja depth e que não são finais, coloque-os em RAIZ.

No passo 3, a geração de sucessores da raiz $s$ deve levar em conta as regras para se evitar padrões equivalentes e os limitantes e as heurísticas discutidas mais adiante. No passo 4, cada caminho escolhido a partir de $s$ corresponde a uma seção (com profundidade no máximo igual a depth) do caminho completo do nó inicial aos nós finais. Como a estratégia hill-climbing é utilizada, a solução ótima pode não ser alcançada. Por outro lado, se depth é infinito, então a estratégia de busca se resume à busca depth-first e a solução ótima pode ser encontrada. Para mais detalhes do algoritmo BT- HC v. Morabito e Arenales (1996).

A abordagem em grafo e/ou também pode ser adaptada para tratar problemas restritos, estagiados e com restrições adicionais. No caso de problemas restritos (seção 2.1), isto é, que possuem restrição quanto ao número de itens do tipo $i$ no padrão, além da limitação física sobre $a_{i}, a_{1} \leq\left\lfloor L / l_{1}\right\rfloor\left\lfloor W / w_{l}\right\rfloor, i=1,2, \Lambda, m$ imposta pelo tamanho do objeto, o número de itens do tipo $i, a_{i}$, no padrão tem que ser menor que um valor estabelecido, $a_{l} \leq l s_{\imath}$, onde $l s_{i}<\left\lfloor L / l_{l}\right\rfloor\left\lfloor W / w_{l}\right\rfloor, i=1,2, \Lambda, m$. Para problemas estagiados existe uma limitação para o número máximo de estágios, nos quais os cortes podem ser realizados (seção 2.1) e como restrição adicional pode existir uma limitação quanto ao número máximo de tipos de itens permitidos nos padrões (VIANNA, 2000). As regras para evitar padrões equivalentes, os limitantes inferiores e superiores e as heuristicas utilizadas para esses casos estão descritas a seguir. 
> padrōes normais:

$$
X_{1}=\left\{x / x=\sum_{i=1}^{n} \alpha_{i} l_{i}, 1 \leq x \leq L-l_{0}, 0 \leq \alpha_{i} \leq l s_{i} \text { e inteiro }\right\},
$$

onde $l_{0}=\min \left\{l_{i}, i=1,2 \ldots, m\right\}$.

isimetria e exclusão:

$$
X_{1}(N)=\left\{x_{1} / x_{1}=\sum_{i=1}^{m} \alpha_{i} l_{i},\left(\text { se } w_{i}>y \Rightarrow \alpha_{i}=0\right), 1 \leq x_{1} \leq\left\lfloor\frac{x}{2}\right\rfloor, 0 \leq \alpha_{i} \leq l s, \text { e inteiro }\right\}
$$

- limitante inferior - problema restrito: um limitante inferior simples para o nó $(x, y)$ pode ser definido através dos padrões homogêneos:

$$
\begin{aligned}
L^{0}(x, y) & \left.=\max _{l \in M(N)}\left\{v_{i} \min \left\{\left\lfloor\frac{x}{l_{l}}\right\rfloor \frac{y}{w_{i}}\right\rfloor, \overline{l s}_{i}(x, y)\right\}\right\} \\
& =v_{j} \min \left\{\left\lfloor\frac{x}{l_{j}}\right\rfloor\left\lfloor\frac{y}{w_{j}}\right\rfloor, \bar{l}_{i},(x, y)\right\}
\end{aligned}
$$

onde $\bar{l} s_{i}(x, y)$ é o número máximo de itens do tipo $i$ que podem ser produzidos a partir de um retângulo $(x, y)$.

- limitante inferior - problema estagiado: se o número de estágios para o nó $(x, y)$ é igual a $k$, pode-se definir dois limitantes inferiores para o nó $(x, y)$ :

$$
\begin{aligned}
& L_{v}(x, y)=\max _{i \in \mathbb{M}(x, y)}\left\{v_{i} \min \left\{\left[\frac{x}{l_{i}}\right]\right\}, l s_{i}(x, y)\right\} \\
& L_{h}(x, y)=\max _{i \in M(x, y)}\left\{v_{i} \min \left\{\left\{\frac{y}{w_{i}}\right\}, l s_{i}(x, y)\right\}\right\}
\end{aligned}
$$

$\mathrm{Na}$ figura 2.4a e $2.4 \mathrm{~b}$ ilustra-se os padrões de corte que geram $L_{\nu}(x, y)$ e $L_{h}(x, y)$. 

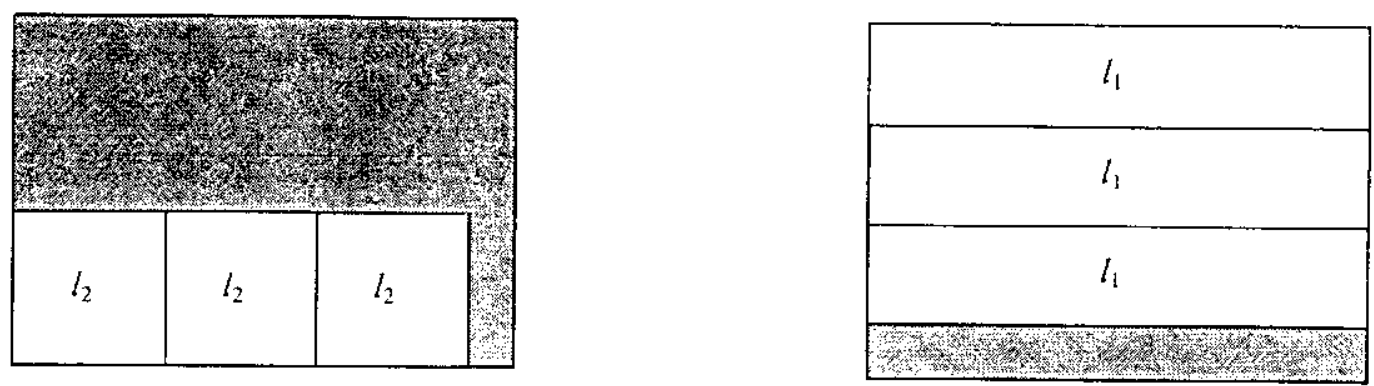

FIGURA 2.4: Padrões de corte que produzem $L_{v}(x, y)$ e $L_{h}(x, y)$.

- limitante inferior - limitação para o número máximo de tipos de itens no padrão: assim como nos outros casos descritos, um simples limitante inferior para o nó $(x, y)$ pode ser definido através dos padrões homogêneos:

$$
L^{\prime \prime}(x, y)=\max _{i \in M(N)}\left\{v _ { i } \left\lfloor\frac{x}{l_{l}}\left\lfloor\left\lfloor\frac{y}{w_{i}}\right\rfloor \text { tal que }\left(\delta\left(a_{i}\right)+\sum_{k \in M(N)-l} \delta\left(a_{k}\right)\right) \leq p \hat{i}\right\},\right.\right.
$$

onde $\delta\left(a_{k}\right)=1$ se $a_{k}>0$, e 0 caso contrário e pí é o número máximo de tipos de itens. Observe que $\delta\left(a_{i}\right)=1$, pois o item $i$ está sendo alocado no padrão.

> limitante superior - problema restrito: um limitante superior simples para o nó $(x, y)$ é obtido considerando uma relaxação do problema de corte no nó $(x, y)$ levando em conta as áreas envolvidas restritas.

$$
\begin{aligned}
U(x, y)= & \max \sum_{i \in M(N)} v_{i} a_{i} \\
\text { s.a }: & \sum_{i \in M(N)}\left(l_{i} w_{i}\right) a_{i} \leq(x y) \\
& \leq \leq a_{i} \leq \overline{l s},(x, y) \quad i \in M(N)
\end{aligned}
$$

A seguir algumas heurísticas são apresentadas para reduzir o espaço de busca.

- Heurística HI: Seja $X_{1}$ o conjunto de todos os possíveis cortes ao longo do comprimento $L$ (e analogamente o conjunto $Y_{1}$ formado pelas combinações de $w_{i}$ ). Seja $M$ o limite do número de elementos em $X_{1}$. Para reduzir $X_{1}$ o seguinte procedimento é utilizado (BEASLEY, 1985): 
Passo1: seja $\mathrm{P}=\{1,2, \ldots, m\}$. Calcule $X_{1}=\left\{x / x=\sum_{i=1}^{m} \alpha_{\imath} l_{\imath}, 1 \leq x \leq L-l_{0}, 0 \leq \alpha_{1} \leq l s_{l}\right.$ e inteiro $\}$

Passo 2: enquanto $\left|X_{1}\right|>M$, faça:

$$
\begin{aligned}
& \text { determine } l_{j}=\min \left\{l_{i} / i \in P\right\} \\
& \text { redefina } P=P-\{j\} \\
& \text { calcule } X_{1} \text { usando } P \\
& \text { saia com o } X_{1} \text { atual. }
\end{aligned}
$$

> Heurística H2: considere um nó $N$ e um par sucessor $\left(N_{1}, N_{2}\right)$ e seja $\alpha$ uma fração previamente definida. Se $(1+\alpha) V(N) \geq U\left(N_{1}\right)+U\left(N_{2}\right)$, então abandone a ramificação que leva à $N_{1}$ e $N_{2}$. Observe que se $\alpha=0$, então o procedimento acima não é mais heurístico.

> Heurística H3: seja $\beta$ outra fração previamente definida. Se: $\beta L(N) \geq L\left(N_{1}\right)+L\left(N_{2}\right)$, então abandone a ramificação que leva à $N_{1}$ e $N_{2}$. Observe que se $\beta=0$, então o procedimento acima não é mais heurístico.

- Heurística H4: considere o nó $N$ e seja $\overline{l s}_{i}(N)$ a quantidade máxima de itens do tipo $i$ que pode ser produzida, a partir de um retângulo $\mathrm{cm} N$. Seja $N_{1}$ e $N_{2}$ os nós sucessores de $N$ obtidos a partir de um corte guilhotinado. Inicialmente considera-se $\bar{l}_{2}(N)$ como o limite para o nó $N_{1}$ c após determinar o padrão de corte para o retângulo representado para o nó $N_{1}$, considera-se o nó $N_{2}$ com limite $\bar{l}_{i}(N)-\bar{a}_{t}, i=1,2, \ldots, m$, onde $\bar{a}_{i}$ é a quantidade de itens do tipo $i$ usada em $N_{1}$. Repete-se o mesmo procedimento para $N_{2}$. A melhor solução entre eles é escolhida.

Conforme dito, a abordagem em grafo e/ou pode ser utilizada para resolver problemas restritos, estagiados e com limitação para o número máximo de tipos de itens nos padrões através do algoritmo BT-HC, descrito anteriormente nesta seção. Na geração dos nós sucessores levam-se em conta as regras, para se evitarem padrões equivalentes e as heurísticas $(\mathrm{Hl}, \mathrm{H} 2, \mathrm{H} 3 \mathrm{e} \mathrm{H} 4)$ descritas. 


\subsection{Heurísticas construtivas gulosas}

Uma alternativa ao método simplex com geração de colunas (abordagem de Gilmore e Gomory), para resolver aproximadamente o problema de corte, $\bullet / \mathrm{V} / \bullet / \bullet$ (note que esta classe é mais genérica que a anterior, $\bullet / \mathrm{V} / \bullet / \mathrm{R}$ ) é através de heurísticas construtivas gulosas, (veja por exemplo HINXMAN, 1980; DYCKHOFF e FINKE, 1992; DOWSLAND e DOWSLAND, 1992; SWEENEY E PATERNOSTER, 1992; SILVEIRA c MORABITO; 2002; BELLUZZO. 2002). A estratégia, que consiste na redução do problema pela geração sucessiva de bons padrões de corte (repeated exhaustion reduction; veja p.e. Hinxman, 1980) é bastante utilizada na prática. Este procedimento, ilustrado na figura 2.5 e que será utilizado neste trabalho pela Abordagem 2, é um tipo de heurística gulosa e está descrito a seguir.

Passo 1: Defina um valor para cada item demandado;

Passo 2: Gere o padrão de corte mais valioso, dados os itens demandados e seus respectivos valores (note que se trata de resolver um problema de corte $\bullet / \mathrm{B} / \mathrm{O} / \bullet$ ) $\Rightarrow$ rotina de geração de padrões.

Passo 3: Determine o número de vezes que este padrão pode ser repetido, respeitando a demanda, isto é, de forma que a demanda de nenhum item seja excedida $\Rightarrow$ rotina de determinação de repetição dos padrões.

Passo 4: Atualize a demanda e exclua os itens com demanda satisfeita $\Rightarrow$ rotina de atualização da demanda.

Passo 5: Se a demanda de todos os itens estiver satisfeita, pare; caso contrário volte para o passo 2.

A Abordagem 2, a ser descrita em detalhes na seção 4.3, utiliza um procedimento guloso como o descrito na figura 2.5, para resolver o problema de geração de padrões (passo 2) na resolução do problema de geração de padrões de corte. Através do algoritmo descrito, o problema de corte $(\bullet / \mathrm{V} / \bullet / \bullet)$ é resolvido em até $m$ iterações (onde $m$ é o número de tipos de itens). Como será visto, utilizando este procedimento, não se tem garantia de encontrar uma solução ótima global, uma vez que o algoritmo determina uma seqüência de ótimos locais: em cada iteração determina-se o padrão mais valioso para esta iteração. 


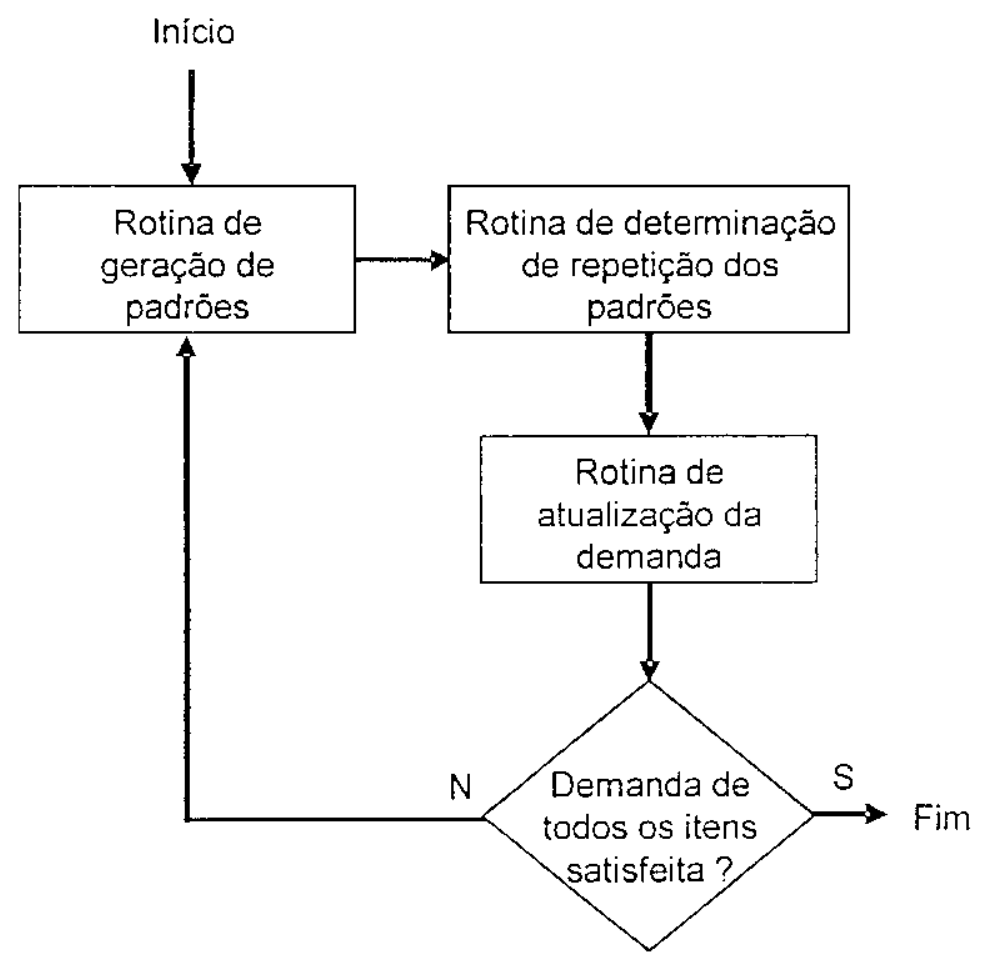

FIGURA 2.5: Esquema ilustrativo da heurística construtiva gulosa.

Uma vantagem atribuída a essa abordagem é que, na prática, novos pedidos podem ser incorporados à carteira de pedidos dentro do horizonte de planejamento. A incorporação de novos pedidos pode resultar em uma solução global mais satisfatória (isto é, com uma perda global menor), visto que novos itens ficam disponiveis, para serem combinados na geração dos padrões.

Uma das dificuldades, quando se utiliza heurísticas construtivas gulosas com objetivo de minimizar a perda, é a concentração de itens mais desfavoráveis (itens difíceis de serem combinados, isto é, itens cujas dimensões não formam uma boa combinação com os demais itens do problema, considerando as dimensões do objeto) nos padrões finais, o que pode resultar em padrões com perdas elevadas. No início do algoritmo, bons padrões, isto é, com pouca perda, são gerados e na medida em que o procedimento avança, começa a haver uma perda de qualidade dos padrões, ou seja, padrões com grandes perdas passam a ser gerados, o que compromete a solução geral do problema. Em geral isso ocorre, pois no início existe uma variedade maior de tipos de itens e também muitas vezes existem itens com dimensões pequenas, que são fáceis de serem alocados em pequenos espaços. Esta desvantagem pode se tornar uma vantagem, como dito anteriormente, se novos itens são incorporados, de modo que os padrões de baixa qualidade não precisam ser utilizados. 
Caso nenhuma interferência seja feita, esse procedimento resulta, em geral, em padrões finais com altas perdas (quando comparados com as perdas dos primeiros padrões). Para se evitar isso, é preciso interferir de alguma forma no processo de geração, a fim de que os itens mais desfavoráveis possam ser utilizados nos primeiros padrões (quando ainda existe uma variedade maior de tipos de itens para serem combinados). Una das questões que surge é como atribuir valores para os itens, de forma a se obter uma solução global mais satisfatória? Na Abordagem 2, através de um procedimento iterativo, procura-se calibrar os valores dos itens, com o objetivo de encontrar uma solução geral melhor. 


\section{O PROBLEMA DE SEQÜENCIAMENTO DE PADRÕES DE CORTE}

Para certos sistemas produtivos a ordem, na qual as tarefas serão executadas, pode ser muito importante, por exemplo, em ambientes industriais, que possuam limitação de espaço fisico, equipamentos de corte, que possuam estações de descarregamento de itens automáticas, etc. Nestes casos, antes que as tarefas sejam executadas, é preciso resolver um problema de seqüenciamento, isto é, determinar uma seqüência para a execução das mesmas, a fim de que algum critério seja satisfeito ou otimizado. Neste trabalho, em particular, o interesse se fixa no problema de seqüenciamento de padrões de corte.

Durante o seqüenciamento dos padrões de corte, diferentes objetivos podem ser de interesse. Por exemplo, a minimização do número de pilhas abertas (MOSP do inglês Minimization of Open Stack Problem); a minimização do número total de pilhas abertas (MOSNP do inglês Minimization of Open Stack Number Problem); a minimização do espalhamento de ordens (MORP do inglês Minimization of Order Spread Problem); a minimização do espalhamento de ordem médio (MAORP do inglês Minimization of the Average Order Spread Problem); a minimização do número de descontinuidades (MDP do inglês Minimization of Discontinuites Problem). Cada objetivo descreve um problema de seqüenciamento diferente; ao longo deste trabalho cada um deles será referenciado pela denominação aqui atribuída.

Cada um dos problemas de seqüenciamento, citados acima, será descrito e exemplificado, utilizando o conjunto de dados da tabela 3.1 (YUEN, 1991), onde cada linha corresponde a um padrão de corte e cada coluna, a um item. Cada célula indica a quantidade 
de itens presentes no padrão. $x_{j}$ corresponde ao número de repetições do padrão $j(j=1, \ldots, p)$, e $q_{i}$ ao número de padrões nos quais o item do tipo $i$ aparece $(i=1, \ldots, m)$.

TABELA 3.1: Exemplo de um conjunto de padrões de corte (YUEN, 1991).

\begin{tabular}{c|cccccccc|c}
\hline & \multicolumn{7}{|c|}{ Item } & \\
\cline { 2 - 10 } Padrão & $\mathbf{1}$ & $\mathbf{2}$ & $\mathbf{3}$ & $\mathbf{4}$ & $\mathbf{5}$ & $\mathbf{6}$ & $\mathbf{7}$ & $\mathbf{8}$ & $\boldsymbol{x}_{\boldsymbol{j}}$ \\
\hline $\mathbf{1}$ & & & 5 & & 7 & & & & 2 \\
$\mathbf{2}$ & 2 & 5 & & & 1 & 5 & & & 2 \\
$\mathbf{3}$ & 8 & & 5 & & & & & & 1 \\
$\mathbf{4}$ & & & & 3 & 2 & & & 4 & 5 \\
$\mathbf{5}$ & & & 8 & & & & 9 & & 1 \\
\hline$q_{i}$ & $\mathbf{2}$ & $\mathbf{1}$ & $\mathbf{3}$ & $\mathbf{1}$ & $\mathbf{3}$ & $\mathbf{1}$ & $\mathbf{1}$ & $\mathbf{1}$ & \\
\hline
\end{tabular}

\subsection{MOSP}

O MOSP consiste na determinação de uma sequêencia, que minimize o número máximo de pilhas abertas durante o processamento dos padrões. Este problema de seqüenciamento é o de maior interesse neste trabalho e será implementado na Abordagem 1 , conforme descrição na seção 4.2. Quando o corte de um padrão é iniciado, diferentes tipos de itens são produzidos. A cada novo tipo de item cortado associa-se uma pilha diferente. Uma pilha é considerada aberta, cada vez que a produção de um item foi iniciada, mas ainda não terminou. A mesma permanece aberta, até que o último padrão, que contenha este item, seja processado. Considere que uma pilha só pode ser removida após un padrão ser completamente cortado e, desta forma, o número máximo de pilhas abertas ocorre exatamente após o processamento de um padrão e antes que qualquer pilha completa seja removida. $\mathrm{Na}$ maioria dos trabalhos encontrados na literatura, considera-se que pilhas acabadas só poderão ser removidas, após o término do corte do padrão. Pinto (2001) admite a possibilidade da remoção de pilhas acabadas durante o corte do padrão.

Seja $s(x)=\left(a_{[1]}, a_{[2]}, \ldots, a_{[n]}\right)$ uma seqüência de $n$ padrões $([k]=j$ indica que o padrão $j$ ocupa a $k$-ésima posição da seqüência). Formalmente uma pilha associada ao item $i$ pode ser definida como aberta na $j$-ésima posição da seqüência de padrões, se:

$$
\left(\sum_{k=1}^{\prime} a_{i[k]}\right)\left(\sum_{k=j^{\prime}}^{n} a_{i[k]}\right)>0
$$


onde $a_{i[k]}$ corresponde ao número de vezes, que o item $i$ aparece no padrão, que ocupa $k$-ésima posição na seqüência $s(x)(F I N K$ e VOß, 1999).

O MOSP ocorre, por exemplo, em situações práticas, quando existe limitação de espaço físico, ou seja, quando o número de pilhas, que podem permanecer abertas ao redor da máquina de corte, é limitado. Como cada tipo de item abre uma nova pilha, que só será removida, quando a demanda do mesmo tiver sido totalmente atendida, dependendo da seqüência escolhida para o corte dos padrões, pode ser preciso que algumas pilhas scjam temporariamente removidas e posteriormente trazidas de volta para serem completadas, o que podeá acarretar um aumento de custos e comprometimento da produção final.

Considere o caso da fábrica de móveis Colombini, onde cada móvel é composto por diferentes tipos de itens. Para que a demanda possa ser atendida, um conjunto de padrões de corte deve ser processado em alguma ordem. Suponha que o objetivo scja determinar uma seqüência, para processar os padrões, a fim de minimizar o número máximo de móveis abertos. Quanto maior o número de móveis abertos, maiores são os custos de estoque em processo, maiores são os problemas de movimentação de materiais, maiores são as possibilidades de atraso na entrega dos pedidos dos clientes, etc. Em sistemas industriais similares ao descrito, o estudo do MOSP é de grande interesse.

Um móvel é composto por diferentes tipos de itens. Se o interesse for pela minimização do número máximo de itens abertos, o MOSP é aplicado diretamente, considerando-se pilhas de itens. Para o caso da minimização do número máximo de móveis abertos, como no caso da fábrica Colombini, o MOSP é aplicado, considerando-se pilhas de móveis e um mesmo item em dois móveis diferentes é considerado como dois itens diferentes. Também se pode ter um pedido composto por diferentes tipos de itens. O mesmo pode ser feito para o caso da minimização do número máximo de pedidos abertos, como por exemplo, no caso de indústrias de vidro. Neste caso, o MOSP é aplicado considerando-se pilhas de pedidos e itens comuns em pedidos diferentes são considerados como itens diferentes.

Seja $m$ o número de tipos de itens e $f$ o número de tipos de móveis, onde $m \geq f$. Considere o seguinte exemplo: $m=10(i=1,2, \ldots, 10)$ e $f=3(A, B$ e $C)$. Suponha que o móvel $\boldsymbol{A}$ seja composto pelos itens 1, 4, 6,8 e 10, o móvel $B$ pelos itens 1, 2, 3,8 e 9, e o móvel $C$ pelos itens 2, 5, 7 e 10. Para a minimização do número máximo de móveis abertos, os itens 1 e 8 comuns aos móveis $A$ e $B$ passam a ser chamados de $1 a$ e $8 a$, e de $1 b$ e $8 b$, respectivamente; O item 10 comum aos móveis $A$ e $C$ passa a ser chamado de $10 a$ e $10 c$, respectivamente; o item 2 comum aos móveis $B$ e $C$ passa a ser chamado de $2 b$ e $2 c$, respectivamente. Se o objetivo for 
minimizar o número de tipos de itens, então para o problema de geração de padrões e para o problema de seqüenciamento existem $m=10$ tipos de itens diferentes; se for minimizar o número de tipos de móveis, existem $m^{\prime} \geq m$, (onde $m^{\prime}=14: i=1 a, 1 b, 2 b, 2 c, 3 b, 4 a, 5 c, 6 a, 7 c$, $8 a, 8 b, 9 b, 10 a, 10 c)$ tipos de itens para o problema de geração, mas $f$ tipos de móveis para o problema de seqüenciamento (onde $f<m$ ).

Considere a seqüência 1-2-3-4-5 referente aos dados da tabela 3.1. A tabela 3.2 abaixo mostra o número de pilhas abertas e quais as pilhas abertas com o seqüenciamento dos padrões. Para este exemplo, o número máximo de pilhas de itens abertas é igual a 5.

TABELA 3.2: Número de pilhas abertas com a seqüência 1-2-3-4-5.

\begin{tabular}{c|c|c}
\hline $\begin{array}{c}\text { Padrões } \\
\text { seqüenciados }\end{array}$ & $\begin{array}{c}\mathrm{N}^{2} \text { de } \\
\text { pilhas abertas }\end{array}$ & $\begin{array}{c}\text { Pilhas } \\
\text { abertas }\end{array}$ \\
\hline 1 & 2 & 3 e 5 \\
$1-2$ & $\mathbf{5}$ & $1,2,3,5$ e 6 \\
$1-2-3$ & 3 & 1,3 e 5 \\
$1-2-3-4$ & 4 & $3,4,5$ e 8 \\
$1-2-3-4-5$ & 2 & 3 e 7 \\
\hline
\end{tabular}

\section{Formulação matemática para o MOSP}

A seguir apresenta-se uma formulação matemática para o MOSP, descrita em Pinto (2001), que é baseada na formulação apresentada por Tang e Denardo (1988) para o problema de minimizar o número de trocas de ferramentas (MTSP, do inglês Minimization of the number of Tool Switches Problem). Por esta razão o modelo de Tang e Denardo é descrito dentro do contexto de corte. Na formulação proposta considera-se que as pilhas acabadas só podem ser removidas com o término do processamento de cada padrão e que existe uma limitação para o número máximo de pilhas que pode ser aberto. Seja:

n número de padrões a serem processados;

$m$ número de itens;

$A_{j} \quad$ vetor $m \times 1$ de 1 's e 0 's que informa se o item do tipo $i$ está presente no padrão $j$ ou não, ou seja: $\left\{\begin{array}{l}1, \text { se } \alpha_{i j}>0 \text { no padrão } a_{j} \\ 0, \text { se } \alpha_{i j}=0 \text { no padrão } a_{j}\end{array}\right.$

c limitação para o número máximo de pilhas abertas;

e vetor auxiliar $1 \times m$ de 1 's; 
$y_{j k}\left\{\begin{array}{l}1, \text { se o padrão } j \text { é o } k \text { - ésimo padrão na seqüência } \\ 0, \text { caso contrário }\end{array}\right.$

$w_{k} \quad$ vetor $m \times 1$ de l's e 0's que fornece as pilhas que estão abertas imediatamente após o corte do $k$-ésimo padrão (inclusive as que fecham durante o processamento);

$p_{k} \quad$ vetor $m \times 1$ que contabiliza as trocas de pilhas ocorridas imediatamente após o corte do $k$ ésimo padrão e anterior ao corte do $(k+1)$-ésimo padrão;

É necessário também fazer uma consideração com relação à função objetivo do problema do MTSP. Conforme considerado em Yanasse (1997), $m-c$ é um limitante inferior para o problema MTSP, e deve ser sua solução ótima, caso seja imposta uma restrição ao número máximo de pilhas permitidas, c. Esta condição pode ser descrita da seguinte forma:

$$
\sum_{k=1}^{n-1} e p_{k} \geq m-c
$$

O problema de minimização do número máximo de pilhas abertas (MOSP) pode então ser definido como segue:

$$
\begin{aligned}
& \min \quad c \\
& \text { s. a: } \quad \sum_{k=1}^{n-1} e p_{k} \geq m-c \\
& p_{k} \geq w_{k+1}-w_{k} \quad k=1, \ldots, n-1 \\
& p_{k} \geq 0 \quad k=1, \ldots, n-1 \\
& e w_{k} \leq c \quad k=1, \ldots, n \\
& y_{j k} A_{j} \leq w_{k} \quad j=1, \ldots, n ; \quad k=1, \ldots, n \\
& \sum_{k=1}^{n} y_{j k}=1 \quad j=1, \ldots, n \\
& \sum_{j=1}^{n} y_{j k}=1 \quad k=1, \ldots, n \\
& y_{j k} \in\{0,1\} \quad j=1, \ldots, n ; \quad k=1, \ldots, n
\end{aligned}
$$

A função objetivo (3.1) procura minimizar o número máximo de pilhas abertas. A restrição (3.2) assegura que o número de troca de pilhas seja maior ou igual a $m-c$. A restrição (3.3), juntamente com a restrição (3.4), indica as pilhas novas abertas imediatamente 
após o corte do $k$-ésimo padrão. A restrição (3.5) limita a $c$ o número máximo de pilhas abertas após o processamento do $k$-ésimo padrão. A restrição (3.6) impõe a existência de uma pilha para cada item cortado com o processamento do $k$-ésimo padrão. As restrições (3.7). (3.8) e (3.9) impõem que todos os padrões sejam processados uma única vez em alguma posição na seqüiencia. A restrição (3.7) impõe que o padrão $j$ deve ser processado em alguma posição na seqüência, enquanto que a restrição (3.8) impõe que apenas um padrão seja processado na $k$-ésima posição na seqüência.

Pinto (2001) considera uma variação do modelo (3.1)-(3.9), em que as pilhas de itens acabadas podem ser removidas durante o processamento de um padrão. Para isso a restrição (3.5) deve ser retirada e substituída por novas restrições. Para mais detalhes v. Pinto (2001).

\section{$3.2 \operatorname{MOSNP}$}

Embora a minimização do número máximo de pilhas abertas seja de grande interesse prático, a quantidade de pilhas abertas durante o processamento dos padrões também pode ser relevante. Neste caso, diferentemente do MOSP, considera-se a pilha gerada pelo seqüenciamento de cada padrão ponderada pelo número de vezes, em que o mesmo é cortado.

O MOSNP consiste na determinação de uma seqüência, que minimize o número total de pilhas abertas. Uma medida, que pode ser utilizada para minimizar o número total de pilhas abertas, é o número de pilhas (stack number). Esta medida é definida pelo produto acumulado do comprimento da fila pelo número de repetições do correspondente padrão seqüienciado, somado para todos os tipos de padrões. De acordo com esta definição, o MOSNP pode ser formulado por (YUEN, 1991):

$$
\min \left(\sum_{k=1}^{n} r_{\mid[k]} q_{1 \mid k]}, \sum_{k=1}^{n} r_{2[k \mid} q_{2[k]}, \ldots, \sum_{k=1}^{n} r_{\mathrm{d}|k|} q_{d\lfloor k]}\right)
$$

onde $r_{s|k|}$ é o número de vezes que o padrão, que ocupa a $k$-ésima posição na seqüência $s$, $s=1,2, \ldots, d$ (onde $d=n$ !) é repetido, e $q_{s[k]}$ é a quantidade de pilhas obtida ao seqüenciar o padrão que ocupa a $k$-ésima posição na seqüência $s$. Considerando os dados da tabela 3.1 e a seqüência 1-2-3-4-5, o stack number é igual a 39. 
TABELA 3.3: Stack number obtido com a seqüência 1-2-3-4-5.

\begin{tabular}{c|c|c|c|c}
\hline Padrões & $\begin{array}{c}\text { Padrões } \\
\text { Seqüenciados }\end{array}$ & $\begin{array}{c}\mathbf{N}^{\underline{0}} \text { de } \\
\text { pilhas abertas }\end{array}$ & $\begin{array}{c}\mathbf{N}^{\underline{Q}} \text { de repetiçōes } \\
\text { do padrão }\left(x_{i}\right)\end{array}$ & $\begin{array}{c}\text { Componente do } \\
\text { stack number }\end{array}$ \\
\hline 1 & 1 & 2 & 2 & $2 \times 2=4$ \\
2 & $1-2$ & 5 & 2 & $5 \times 2=10$ \\
3 & $1-2-3$ & 3 & 1 & $3 \times 1=3$ \\
4 & $1-2-3-4$ & 4 & 5 & $4 \times 5=20$ \\
5 & $1-2-3-4-5$ & 2 & 1 & $2 \times 1=2$ \\
\hline
\end{tabular}

Dado o número de repetições dos padrões $\left(x_{j}\right)$ na tabela 3.3, considere a seqüência 1-3-5-2-4 (as pilhas abertas com o processamento desses padrões estão descritas na tabela 3.15 seção 3.6). Para esta seqüência o stack number é 37. Se o objetivo do problema for a minimização do número total de pilhas abertas, então a seqüência 1-3-5-2-4 é preferivel, quando comparada à seqüência 1-2-3-4-5.

\subsection{MORP}

Existem sistemas industriais, como por exemplo a indústria de vidros, nos quais itens, que fazem parte de um mesmo produto, devem ser cortados dentro de um certo intervalo de tempo. Isto ocorre, pois, o armazenamento de peças de vidro é bastante difícil; as peças precisam ser armazenadas individualmente; são bastante frágcis, quebrando com facilidade; muitas vezes é difícil distinguir entre itens praticamente idênticos; a reprodutibilidade das peças com relação à qualidade e à tonalidade do vidro também pode ser difícil (MADSEN, 1988). Ou seja, a identificação, armazenagem e administração dos itens, que fazem parte de um mesmo produto, ficam bem mais dificeis, caso os mesmos sejam cortados a uma distância grande uns dos outros.

Em sistemas como o descrito tem-se como objetivo minimizar a "distância" entre o corte do primeiro e do último padrão, nos quais os itens pertencentes a um mesmo produto aparecem. Este problema é conhecido como minimização do espalhamento de ordem (order spread), MORP. O problema de minimização do espalhamento de ordem consiste em manter uma pilha aberta durante o menor tempo possível, ou seja, consiste em minimizar o tempo de vida de uma pilha (YANASSE, 1997). 
Se um item estiver contido em um único padrão, seu espalhamento é zero. independentemente da seqüência na qual os padrões serão processados (por excmplo o item 2 da tabela 3.1, seção 3). Para itens, que aparecem em mais de um padrão, é necessário considerar a seqüência, na qual os mesmos serão processados. Na tabela 3.4 pode-se verificar o espalhamento de ordens para a seqüência 1-2-3-4-5 dos dados da tabela 3.1 .

O espalhamento de ordem máximo é obtido pelo item 3, que aparece no primeiro padrão (1) e no último padrão (5) a ser processado, resultando em $4=5-1$. Se o conjunto de padrões da tabela 3.1 for processado na seqüência 1-3-5-2-4, o espalhamento de ordem do item 3. por exemplo, passa a ser igual a 2, pois o último padrão, em que o item 3 aparece é o padrão 5 , que é o terceiro (3) na seqüência e o primeiro padrão é o 1, que é o primciro (1) na seqüência.

TABELA 3.4: Espalhamento de ordem resultante da sequiência 1-2-3-4-5.

\begin{tabular}{c|c}
\hline Item & Espalhamento \\
\hline $\mathbf{1}$ & 1 \\
2 & 0 \\
$\mathbf{3}$ & 4 \\
$\mathbf{4}$ & 0 \\
$\mathbf{5}$ & 3 \\
$\mathbf{6}$ & 0 \\
7 & 0 \\
$\mathbf{8}$ & 0 \\
\hline
\end{tabular}

\subsection{MAORP}

Assim como o MORP, o MAORP procura por uma seqüencia, que minimize o espalhamento de ordens. Mas, neste último, o interesse recai sobre a seqüência que minimize o espalhamento de ordens médio. Ou seja, procura-se pela seqüência, que minimize o tempo médio, que cada pilha fica aberta. Para tanto, o número de repetições de cada padrão $\left(x_{j}\right)$ precisa ser levado cm consideração. Dada uma seqüência $s$ (conforme definição em 3.1), pode-se definir o espalhamento de ordem médio por (FINK e VOß, 1999):

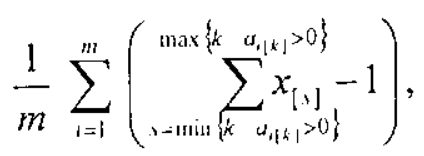

onde $m$ é o número de tipos de itens, $a_{i[k]}$ corresponde ao número de vezes que o item $i$ aparece no padrão que ocupa $k$-ésima posição e $x_{[s]}$ é o número de repetições do padrão que 
ocupa a $s$-ésima posição na seqüência. Para o exemplo da tabela 3.1 e considerando a seqüência 1-2-3-4-5, o espalhamento de ordem médio é 3.9 conforme pode ser verificado na tabela 3.5 (o número de repetições de cada padrão está indicado na tabela 3.1 )

TABELA 3.5: Espalhamento de ordem médio resultante da seqüência 1-2-3-4-5.

\begin{tabular}{c|l}
\hline Item & \multicolumn{1}{|c}{ Espalhamento } \\
\hline $\mathbf{1}$ & $2+1-1=2$ \\
$\mathbf{2}$ & $2-1=1$ \\
$\mathbf{3}$ & $2+2+1+5+1-1=10$ \\
$\mathbf{4}$ & $5-1=4$ \\
$\mathbf{5}$ & $2+2+1+5-1=9$ \\
$\mathbf{6}$ & $2-1=1$ \\
$\mathbf{7}$ & $1-1=0$ \\
$\mathbf{8}$ & $5-1=4$ \\
\hline Espalhamento Total & \multicolumn{1}{|c}{31} \\
\hline Espalhamento médio & $1 / 8 \times 31=\mathbf{3 . 9}$ \\
\hline
\end{tabular}

\section{$3.5 M D P$}

No problema de minimização do espalhamento de ordens objetiva-se continuar a produção de um item (order), quando a produção do mesmo tiver sido iniciada. Uma descontinuidade surge, quando a demanda de um item é somente parcialmente atendida com o processamento de um padrão e este mesmo item não aparece no padrão seguinte (MADSEN, 1988). O problema de minimização de descontinuidades ( $M D P$ ) pode surgir em sistemas industriais, nos quais o tempo de setup é um fator relevante na linha de produção, como por exemplo, em indústrias de bebidas, de tintas, etc.

O número de descontinuidades para a seqüência 1-2-3-4-5 (conforme dados da tabela 3.1) é igual a 3 , sendo que duas descontinuidades são provenientes do item 3 e uma, do item 5 , conforme pode ser verificado na tabela 3.6 .

Devido ao fato de minimizar o espalhamento de ordens (itens), ou minimizar a descontinuidade de itens poderem levar a uma solução com um menor número de pilhas abertas, poder-se-ia supor que os problemas, acima descritos, fossem equivalentes. Resolver o problema de minimização do espalhamento de ordens (MORP) não leva necessariamente a uma solução ótima do problema de minimização do número máximo de pilhas abertas $(M O S P)$, e vice-versa. Da mesma forma, uma solução, que seja ótima para o MORP, não é 
necessariamente ótima para o problema de minimização de descontinuidades $(M D P)$, e viceversa. O MDP também não é equivalente ao MOSP (YANASSE, 1997). Apesar dos problemas acima descritos serem similares, os mesmos não são equivalentes.

TABELA 3.6: Descontinuidade resultante da seqüência 1-2-3-4-5.

\begin{tabular}{c|c}
\hline Item & Descontinuidade \\
\hline $\mathbf{1}$ & 0 \\
2 & 0 \\
$\mathbf{3}$ & 2 \\
4 & 0 \\
5 & 1 \\
6 & 0 \\
7 & 0 \\
8 & 0 \\
\hline Total & $\mathbf{3}$ \\
\hline
\end{tabular}

Abaixo são apresentadas algumas comparações entre diferentes seqüências, para evidenciar que, para critérios diferentes a serem otimizados, seqüências diferentes fornecem a solução ótima. Considere o exemplo dado na tabela 3.7 (BECCENERI, 1999), onde o número 1 indica que o item faz parte do padrão.

TABELA 3.7: Exemplo de um conjunto de padrões de corte (BECCENERI, 1999).

\begin{tabular}{c|rrrrrr}
\hline & \multicolumn{7}{|c}{ Item } \\
\cline { 2 - 7 } Padrão & $\mathbf{1}$ & $\mathbf{2}$ & $\mathbf{3}$ & $\mathbf{4}$ & $\mathbf{5}$ & $\mathbf{6}$ \\
\hline $\mathbf{1}$ & 1 & 1 & & & & \\
$\mathbf{2}$ & & 1 & 1 & & & \\
$\mathbf{3}$ & & & 1 & & & \\
$\mathbf{4}$ & 1 & & & 1 & 1 & \\
$\mathbf{5}$ & & & & 1 & 1 & 1 \\
\hline
\end{tabular}

Para resolver o MOSP, utilizando os dados da tabela 3.7, uma solução ótima é dada pela seqüência 1-2-3-4-5, com número máximo de pilhas abertas igual a 3, como pode ser observado na tabela 3.8. O conjunto de dados da tabela 3.7 foi seqüenciado, utilizando um algoritmo, que gera todas as seqüências, a partir de um conjunto de padrões de corte. Este algoritmo armazena uma sequeência iniciada com cada um dos $n$ padrões $(n=5)$ com o menor número máximo de pilhas abertas obtido. Para os padrões $1,2,3$ e 5 foi encontrada pelo menos uma seqüência, para cada um deles, que abriu 3 pilhas, enquanto o menor número máximo de pilhas abertas para as seqüências iniciadas com o padrão 4 foi 4 . Cabe observar 
que a seqüência 1-2-3-4-5 é uma seqüência ótima, visto que qualquer outra abre um número máximo de pilhas maior ou igual a três.

TABELA 3.8: Número de pilhas abertas com a seqüência 1-2-3-4-5.

\begin{tabular}{c|c|c}
\hline $\begin{array}{c}\text { Padrões } \\
\text { seqüenciados }\end{array}$ & $\begin{array}{c}\mathbf{N}^{0} \text { de } \\
\text { pilhas abertas }\end{array}$ & $\begin{array}{c}\text { Pilhas } \\
\text { abertas }\end{array}$ \\
\hline 1 & 2 & 1 e 2 \\
$1-2$ & 3 & 1,2 , e 3 \\
$1-2-3$ & 2 & 1 e 3 \\
$1-2-3-4$ & 3 & 1,4 e 5 \\
$1-2-3-4-5$ & 3 & 4,5 e 6 \\
\hline
\end{tabular}

Para a mesma seqüência, 1-2-3-4-5, o espalhamento de ordem máximo é igual a 3 , conforme pode-se observar na tabela 3.9. Contudo, a solução ótima para o MORP é dada pela seqüência 1-4-2-5-3 com espalhamento máximo igual a 2 (tabela 3.9). Neste caso, o número máximo de pilhas abertas é igual a 4, conforme pode-se observar na tabela 3.10 .

TABELA 3.9: Espalhamento resultante das seqüências 1-2-3-4-5 e 1-4-2-5-3.

\begin{tabular}{c|cccccc}
\hline & \multicolumn{7}{|c}{ Item } \\
\cline { 2 - 7 } Seqüências & $\mathbf{1}$ & $\mathbf{2}$ & $\mathbf{3}$ & $\mathbf{4}$ & $\mathbf{5}$ & $\mathbf{6}$ \\
\hline $1-2-3-4-5$ & 3 & 1 & 1 & 1 & 1 & 0 \\
$1-4-2-5-3$ & 1 & 2 & 2 & 2 & 2 & 0 \\
\hline
\end{tabular}

TABELA 3.10: Número de pilhas abertas com a seqüência 1-4-2-5-3.

\begin{tabular}{l|c|c}
\hline $\begin{array}{c}\text { Padrōes } \\
\text { Seqüenciados }\end{array}$ & $\begin{array}{c}\mathbf{N}^{\mathbf{2}} \mathbf{d e} \\
\text { pilhas abertas }\end{array}$ & $\begin{array}{c}\text { Pilhas } \\
\text { Abertas }\end{array}$ \\
\hline 1 & 2 & 1 e 2 \\
$1-4$ & 4 & $1,2,4$ e 5 \\
$1-4-2$ & 4 & $2,3,4$ e 5 \\
$1-4-2-5$ & 4 & $3,4,5$ e 6 \\
$1-4-2-5-3$ & 1 & 3 \\
\hline
\end{tabular}

Para comparar o MOSP e o MDP considere os dados da tabela 3.11 (BECCENERI, 1999).

TABELA 3.11: Exemplo de um conjunto de padrões de corte (BECCENERI, 1999).

\begin{tabular}{c|cccc}
\hline \multirow{2}{*}{ Padrão } & \multicolumn{4}{|c}{ Item } \\
\cline { 2 - 5 } & $\mathbf{1}$ & $\mathbf{2}$ & $\mathbf{3}$ & $\mathbf{4}$ \\
\hline $\mathbf{1}$ & 1 & 1 & & \\
$\mathbf{2}$ & & 1 & 1 & \\
$\mathbf{3}$ & 1 & & 1 & \\
$\mathbf{4}$ & & 1 & & 1 \\
$\mathbf{5}$ & & & & 1 \\
\hline
\end{tabular}


Um seqüenciamento ótimo para o MOSP é dado pela seqüência 1-2-3-4-5, com um número máximo de pilhas abertas igual a 3. Com esse sequienciamento, o número de descontinuidades é igual a 6. Um melhor seqüenciamento para o $M D P$ é dado pela seqüência 1-3-5-4-2, pois, neste caso, o número de descontinuidades é igual a 5. Entretanto, com esta seqüência, o número máximo de pilhas abertas é 4 . Para ilustrar a não equivalência entre o MORP e o MDP, considere um conjunto de trinta padrões de corte e suponha que o item 2 esteja contido somente no primeiro e no trigésimo padrões da seqüência. Neste caso o espalhamento do item 2 ć máximo, e por outro lado sua descontinuidade é igual 1.

Apesar de a literatura que aborda os problemas de corte ser bastante vasta, o mesmo não se pode dizer sobre os problemas de seqüenciamento de padrões de corte.

\subsection{Revisão da literatura de seqüenciamento de padrões de corte}

A seguir uma revisão de alguns dos principais trabalhos na área de seqüenciamento de padrões são apresentados. Pode-se observar que alguns desses trabalhos fornecem contribuições tanto para o problema de seqüenciamento, como para o problema de geração de padrões. Os trabalhos estão apresentados em ordem cronológica.

\section{Abordagem de Dyson e Gregory}

No trabalho de Dyson e Gregory (1974) duas estratégias para resolver os problemas de geração e seqüenciamento de padrões em uma indústria de vidro são propostas. Numa delas, os dois problemas são resolvidos de forma seqüencial, na qual o método de Gilmore e Gomory é utilizado para resolver o problema de geração de padrões e o problema de seqüenciamento é modelado como um problema do caixeiro viajante, com o objetivo de minimizar o número de descontinuidades entre os padrões. Na segunda abordagem, uma heuristica é proposta, a qual inclui dois parâmetros; um para minimizar a perda total e o outro para minimizar o número de descontinuidades.

Para resolver os problemas geração e seqüienciamento de padrões, os autores propõem

uma abordagem seqüencial, em que primeiramente resolvem o problema de geração, encontrando o conjunto de padrões de perda mínima e, depois, em um segundo estágio, os 
padrões são seqüenciados de forma a minimizar o número de descontinuidades. O primeiro estágio é resolvido, utilizando um algoritmo baseado no método de Gilmore e Gomory.

O problema de seqüenciamento é modelado como um problema do caixciro viajante (TSP do inglês Travelling Salesman Problem) e resolvido utilizando o algoritmo de Little et al. (1963). No problema do caixeiro viajante um certo número de cidades devem ser visitadas numa determinada sequiência, que minimize a distância total percorrida. A matriz de custos contém as distâncias entre todos os pares de cidades, incluindo a origem. O problema de seqüenciamento torna-se equivalente ao problema do caixciro viajante, se os padrões de corte forem considerados como cidades. A matriz de custos é construída baseada na descontinuidade entre pares adjacentes de padrões, que constituem a seqüência. Quando o número de padrões a serem seqüenciados cresce, um esforço computacional grande passa a ser exigido, para resolver o problema do caixeiro viajante de forma ótima.

Considere o exemplo da tabela 3.12 (DYSON e GREGORY, 1974), onde 1 indica que o item faz parte do padrão.

TABELA 3.12: Exemplo de um conjunto de padrões de corte (DYSON e GREGORY, 1974).

\begin{tabular}{c|cccccc}
\hline & \multicolumn{6}{|c}{ Item } \\
\cline { 2 - 7 } Padrão & $\mathbf{1}$ & $\mathbf{2}$ & $\mathbf{3}$ & $\mathbf{4}$ & $\mathbf{5}$ & $\mathbf{6}$ \\
\hline $\mathbf{1}$ & 1 & 1 & & 1 & & \\
$\mathbf{2}$ & & 1 & & 1 & 1 & 1 \\
$\mathbf{3}$ & & & 1 & 1 & & \\
$\mathbf{4}$ & 1 & & 1 & & 1 & \\
$\mathbf{5}$ & 1 & & & & & 1 \\
$\mathbf{6}$ & & & & & 1 & 1 \\
\hline
\end{tabular}

A matriz de custos, $C$, para este exemplo é dada abaixo, onde cada elemento $c_{i j}$ é igual ao número de itens no padrão $i$, que não aparecem no padrão $j$. Os elementos da diagonal principal, $L$, que pela definição anterior seriam iguais a zero, devem ser números suficientemente grandes, para evitar que os mesmos sejam escolhidos pelo TSP.

$$
C=\left[\begin{array}{llllll}
L & 1 & 2 & 2 & 2 & 3 \\
2 & L & 3 & 3 & 3 & 2 \\
1 & 1 & L & 1 & 2 & 2 \\
2 & 2 & 2 & L & 2 & 2 \\
1 & 1 & 2 & 1 & L & 1 \\
2 & 0 & 2 & 1 & 1 & L
\end{array}\right]
$$

Como a matriz de custos corresponde às seqüencias circulares (roteiros), o custo de mudar do último padrão para o primeiro é incluído no custo total. Para evitar isto, um padrão 
fictício sem nenhum item é introduzido. Utilizando os dados da tabela 3.12, considere a seqüência 1-2-3-4-5-6. O custo de mudar do padrão 6 para o padrão 1 é incluído no custo total (este custo é igual a 2 , conforme pode ser verificado na célula $\mathrm{c}_{61}$ da matriz $C$ ). Para este exemplo, o padrão 7 (fictício) sem nenhum item é introduzido. A nova matriz $C$ 'apresenta os custos para este novo conjunto de padrões (padrões 1 a 7). Observe que a última linha desta matriz possui todos os elementos nulos, ou seja, não existe custo de mudar do padrão fictício para qualquer outro padrão.

$$
C^{\prime}=\left[\begin{array}{lllllll}
L & 1 & 2 & 2 & 2 & 3 & 3 \\
2 & L & 3 & 3 & 3 & 2 & 4 \\
1 & 1 & L & 1 & 2 & 2 & 2 \\
2 & 2 & 2 & L & 2 & 2 & 3 \\
1 & 1 & 2 & 1 & L & 1 & 2 \\
2 & 0 & 2 & 1 & 1 & L & 2 \\
0 & 0 & 0 & 0 & 0 & 0 & L
\end{array}\right]
$$

Quando uma solução é encontrada, o primeiro padrão a ser processado é aquele que vem imediatamente após o padrão fictício. Considerando a seqüência 2-5-3-1-6-4-(7), o custo total será igual a 13 .

Apesar de o interesse ser o da minimização do espalhamento de ordens (MORP), ou seja, o objetivo real é minimizar o tempo de vida das pilhas abertas, os autores resolvem o problema de minimização de descontinuidades $(M D P)$. Uma objeção contra esta abordagem é que, se o corte de un item for interrompido, não importa quando o mesmo será reiniciado, pois a minimização de descontinuidades não considera o tempo que a pilha de um item fica aberta, fato este que é relevante para o problema em questão.

Dada a seqüûência 2-5-3-1-6-4-(7), considere, que apenas o padrão 2 foi processado, ou scja, as demandas dos itens 2, 4, 5 e 6 ainda não foram totalmente atendidas. Em particular, considere o item 5. Uma descontinuidade é introduzida para este item, visto que sua demanda ainda não foi totalmente atendida. Suponha que a demanda restante do mesmo só seja atendida com o corte do quinto e sexto padrões da seqüência (padrões 6 e 4 , respectivamente). Se os padrões 4 e 6 (ou 6 e 4) fossem o terceiro e quarto padrões processados na seqüência, a descontinuidade introduzida seria a mesma. Para a grande maioria dos problemas reais, a segunda situação seria mais interessante, visto que, por exemplo, as pilhas de itens poderiam ser removidas mais rapidamente. 
Utilizando a abordagem de Gilmore e Gomory no primeiro estágio. pode acontecer de o conjunto de padrões produzidos não poder ser seqüenciado de forma a obter um número baixo de descontinuidades.

A segunda alternativa proposta por Dyson e Gregory para resolver os problemas de geração e de seqüenciamento de padrões é uma heurística, que consiste em produzir os padrões de corte na seqüência na qual os mesmos serão processados na máquina de corte. Utilizando este método um conjunto de padrões é gerado, onde cada novo padrão tem uma perda maior ou igual ao seu predecessor. Estes padrões não fornecem uma boa solução para os problemas por duas razões. Com esta abordagem os itens problemáticos (difíceis de serem combinados) só seriam incluidos nos padrões em um estágio mais avançado. Mas, para se obter uma perda geral satisfatória, esses itens precisam ser logo incluídos, quando ainda existem muitos tipos de itens diferentes, para serem combinados. A segunda razão é que o conjunto de padrões gerado não é produzido em uma seqüência, que tenha como objetivo minimizar o número de descontinuidades.

Para resolver este problema, algumas modificaçōes foram introduzidas. Os itens problemáticos identificados tiveram seus valores aumentados, o que fez com que os mesmos fossem incluídos nos primeiros padrões, reduzindo assim a perda geral. Esse aumento é controlado através de um parâmetro. Para reduzir o número de descontinuidades, um outro parâmetro é utilizado. Ele controla o valor de cada item, que apareceu em um padrão anterior e que ainda não foi eliminado do problema. Iestes foram realizados, para determinar os valores dos parâmetros, com o objetivo de atingir um balanço entre a perda gerada pelo corte dos padrões e o número de descontinuidade (os autores não apresentam maiores detalhes de como foi feita a calibração dos dois parâmetros). Essa abordagem heurística utilizou um tempo computacional menor do que a abordagem em dois estágios.

\section{Abordagens de Madsen}

Madsen (1979) aborda o problema de corte bidimensional em uma pequena indústria de vidro, utilizando um método de solução aproximado, que utiliza funções da mochila e sugere um procedimento para seqüenciamento dos padrões. Ao invés de utilizar funções da mochila bidimensional (o que requer muita memória e muito tempo computacional), o autor propõe o uso de procedimentos da mochila unidimensional (GILMORE e GOMORY, 1966). Primeiramente os itens são combinados, para formar sessões e depois as sessões são 
combinadas ao longo da placa de vidro. Esta alternativa pode levar a soluções sub-ótimas, mas podem ser resolvidas mais rapidamente.

Os itens devem ser cortados em pares, ou triplas, para facilitar a identificação, armazenagem e administração dos mesmos. Ou seja. objetiva-se diminuir a distância média entre pares (ou triplas) de itens. Para resolver esta restrição, duas abordagens foram adotadas. A mais simples delas consiste em reduzir o horizonte de planejamento.

A outra abordagem consiste em definir uma matriz simétrica $U=\left[u_{i j}\right]$, onde $u_{i j}=1$ significa que o padrão $i$ e $j$ tem no mínimo um iten em comum; e $u_{i j}=0$, caso contrário. Uma seqüência de corte é definida pelas linhas (ou colunas) de $U$. Ou seja, a linha 3 corresponde ao padrão, que é cortado em tercciro lugar na seqüiencia. Trocar linhas e/ou colunas de $U$ implica em obter uma nova seqüência, mas, com a mesma perda.

O objetivo é trocar linhas e colunas, de forma que a largura de banda de $U$ (bandwidth), $\beta(U)$ seja minimizada, onde $\beta(U)=\max _{i}\left(i-\min \left(j \mid u_{t,} \neq 0\right)\right) . \beta(U)$ será igual à máxima distância entre pares de itens. Minimizar a largura de banda implica em reduzir a distância entre o corte de padrões, que possuam itens em comum. Considere o exemplo da tabela 3.1 (seção 3). A matriz $U$ para os padrões desta tabela é dada abaixo:

$$
U=\left[\begin{array}{lllll}
1 & 1 & 1 & 1 & 1 \\
1 & 1 & 1 & 1 & 0 \\
1 & 1 & 1 & 0 & 1 \\
1 & 1 & 0 & 1 & 0 \\
1 & 0 & 1 & 0 & 1
\end{array}\right]
$$

A largura de banda $\beta(U)$ para esta matriz é igual a 4. Trocando as colunas 1 e 2 entre si e as linhas 1 e 2 entre si, ou seja, trocando a ordem dos padrões 1 e 2 , obtém-se a matriz resultante, $U$ abaixo:

$$
U^{\prime}=\left[\begin{array}{lllll}
1 & 1 & 1 & 1 & 0 \\
1 & 1 & 1 & 1 & 1 \\
1 & 1 & 1 & 0 & 1 \\
1 & 1 & 0 & 1 & 0 \\
0 & 1 & 1 & 0 & 1
\end{array}\right]
$$

A largura de banda da matriz $U$ é igual a 3 . A matriz $U$ implica em uma nova seqüência para os padrões de corte, com uma distância entre itens iguais menor que a seqüência dada pela matriz $U$. Mesmo realizando trocas entre as linhas e/ou colunas da matriz, pode ser que a solução encontrada para o problema de seqüenciamento não atenda à 
distância requerida entre pares de itens, pois a largura de banda depende do conjunto de padrões de corte, que foram gerados na primeira fase.

Assim como no trabalho de Dyson e Gregory (1974), a abordagem utilizada por Madsen, (1979) para resolver os problemas de geração e seqüenciamento de padrões, é seqüencial. Em um outro trabalho, Madsen (1988) propõe um procedimento em dois estágios, para resolver o problema de geração e seqüenciamento de padrões bidimensionais. No primeiro estágio, o problema de geração de padrões é resolvido e, no segundo, o problema de seqüenciamento é resolvido $(M O R P)$. Através desta abordagem seqüencial, é possível que o espalhamento de ordens seja reduzido, sem alterar a porcentagem de perda. Se o resultado do ponto de vista do seqüenciamento não for satisfatório, a perda poderá ter que ser aumentada, para reduzir o espalhamento de ordens. Madsen sugere que este problema poderia ser superado através de um modelo combinado, abordando os dois objetivos conflitantes, ou através de um procedimento iterativo, que alternasse entre os dois estágios. $\Lambda$ abordagem utilizada, como dito, é um procedimento em dois estágios sem iterações, em que a ênfase é dada no segundo estágio. O primeiro estágio é resolvido utilizando a abordagem proposta por Gilmore e Gomory (1966) e o segundo, através da modelagem do problema como um problema do caixeiro viajante (TSP).

Diferentemente de Dyson e Gregory (1974), que basearam a definição da matriz de custos, $C$, no número de ordens (itens), que não aparecem no próximo padrão, para Madsen, cada elemento da matriz $c_{i j}$ é definido como $k$ menos o númcro de ordens no padrão $i$, que também aparece no padrão $j$ (onde $k$ é uma constante suficientemente grande para garantir que todos os elementos $c_{i j}$ sejam não negativos). Isto garante que a matriz $C$ seja simétrica, o que implica em resolver o problema do caixeiro viajante simétrico. Se esta matriz for baseada no número de ordens que não aparecem no próximo padrão como no caso de Dyson e Gregory, a mesma só será simétrica se todos os padrões de corte contiverem o mesmo número de ordens. Os elementos da diagonal principal, $c_{i i}$ são iguais a $L(L>k)$, novamente para evitar que os mesmos sejam escolhidos pelo TSP.

Considerando o exemplo dado na tabela 3.12 (seção 3.6.1), e fazendo $k=10$, a matriz de custos, $C$, é dada a seguir (o padrão fictício já está sendo considerado). Conforme se pode observar, para um mesmo conjunto de padrões de corte (tabela 3.12), as matrizes construídas pela abordagem de Dyson e Gregory (1974) e de Madsen (1988) são diferentes. Note que Madsen também introduz um padrão fictício (sem nenhum item). Resolvido o problema do 
caixeiro viajante e utilizando a matriz de custos conforme descrito, uma solução é encontrada, em que o primeiro padrão a ser processado é o que vem justamente após o padrão fictício.

$$
C=\left[\begin{array}{ccccccc}
L & 8 & 9 & 9 & 9 & 10 & 10 \\
8 & L & 9 & 9 & 9 & 8 & 10 \\
9 & 9 & L & 9 & 10 & 10 & 10 \\
9 & 9 & 9 & L & 9 & 9 & 10 \\
9 & 9 & 10 & 9 & L & 9 & 10 \\
10 & 8 & 10 & 9 & 9 & L & 10 \\
10 & 10 & 10 & 10 & 10 & 10 & L
\end{array}\right]
$$

Cabe notar que, tanto no procedimento proposto por Dyson e Gregory (1974), como no proposto por Madsen (1988), o problema de seqüenciamento, que está sendo resolvido, é o de minimizar a descontinuidade entre os padrões $(M D P)$, e não o problema de minimizar o espalhamento de ordens $(M O R P)$, que objetiva minimizar a distância entre o corte do primeiro e do último padrão, nos quais os itens aparecem.

\section{Heurísticas de Yuen}

Yuen (1991, 1995) propôs seis heurísticas, para resolver o problema de seqüenciamento, com o objetivo de minimizar o número máximo de pilhas abertas (MOSP), que são formadas durante o processamento de um conjunto de padrões.

As heurísticas 1 e 2 possuem dois passos, sendo que o primeiro passo é igual para as duas. No passo 1, um item, que esteja contido em um ou mais padrões ainda não seqüenciados, é selecionado e, no passo 2 , seleciona-se um padrão dentre o conjunto de padrões não seqüenciados, que contenha o item selecionado no passo 1 .

Para exemplificar, considere o exemplo de padrões de corte dado na tabela 3.1 (seção 3) e o padrão 1 como padrão inicial. Nas tabelas 3.13 e 3.14, respectivamente, apresentam-se as seqüências encontradas, utilizando as heurísticas 1 e 2 .

TABELA 3.13: Seqüência obtida com a aplicação da heurística 1 sobre os dados da tabela 3.1 .

\begin{tabular}{c|c|c}
\hline $\begin{array}{c}\text { Padrões } \\
\text { Seqüenciados }\end{array}$ & $\begin{array}{c}\mathbf{N}^{0} \text { de } \\
\text { pilhas abertas }\end{array}$ & $\begin{array}{c}\text { Pilhas } \\
\text { abertas }\end{array}$ \\
\hline 1 & 2 & 3 e 5 \\
$1-2$ & $\mathbf{5}$ & $1,2,3,5$ e 6 \\
$1-2-3$ & 3 & 1,3 e 5 \\
$1-2-3-5$ & 3 & 3,5 e 7 \\
$1-2-3-5-4$ & 3 & 3,5 e 8 \\
\hline
\end{tabular}


TABELA 3.14: Seqüência obtida com a aplicação da heurística 2 sobre os dados da tabela 3.1.

\begin{tabular}{c|c|c}
\hline $\begin{array}{c}\text { Padrōes } \\
\text { seqüenciados }\end{array}$ & $\begin{array}{c}\mathbf{N}^{0} \text { de } \\
\text { pilhas abertas }\end{array}$ & $\begin{array}{c}\text { Pilhas } \\
\text { abertas }\end{array}$ \\
\hline 1 & 2 & 3 e 5 \\
$1-4$ & 4 & $3,4,5$ e 8 \\
$1-4-2$ & 5 & $1,2,3,5$ e 6 \\
$1-4-2-3$ & 3 & 1,3 e 5 \\
$1-4-2-3-5$ & 2 & 3 e 7 \\
\hline
\end{tabular}

As outras quatro heurísticas propostas são baseadas na medida de adequação (matching) de um padrão com as pilhas abertas. Quanto maior o número de itens em comum, melhor a adequação de um padrão com as pilhas atuais. Por outro lado, quanto maior o número de itens novos introduzidos, pior a adequação às pilhas atuais.

Para medir a adequação dos padrões às pilhas abertas, duas medidas são introduzidas. $C_{j}$ é o número de tipos de itens em comum entre o padrão $j$ e as pilhas abertas, e $N_{j}$ é o número de tipos de itens no padrão $j$ que não estão incluídos nas pilhas abertas. A adequação de um padrão $j, M_{j}$, é definida como o número de itens em comum ao padrão $j$ e às pilhas abertas, menos o número de tipos de itens novos contidos no padrão $j$, ou seja, $M_{j}=C_{j}-N_{j}$.

Nas tabelas 3.15 a 3.18 descrevem-se as seqüências encontradas para o conjunto de padrões da tabela 3.1 (seção 3) com a aplicação das heurísticas 3, 4, 5 e 6, respectivamente. Todas as heurísticas foram aplicadas, tendo como padrão inicial o padrão 1. As heurísticas 3 , 4 e 5 foram implementadas e encontram-se descritas a seguir. Em particular, a heurística 3 será utilizada nas Abordagens l e 3, propostas no presente trabalho, conforme próximo capítulo.

\section{Heurística 3}

Enquanto ainda existirem padrões não seqüenciados, faça:

Passo 1: selecione o padrão ainda não seqüenciado com a maior medida de adequação, $M_{j}$;

Passo 2: se ocorrer um empate, selecione o padrão com o menor número de tipos de itens novos introduzidos $\left(N_{j}\right)$;

Passo 3: em caso de novo empate, selecione o padrão que primeiro ocorre. 
TABELA 3.15: Seqüência obtida com a aplicação da heurística 3 sobre os dados da tabela 3.1 .

\begin{tabular}{c|c|c}
\hline $\begin{array}{c}\text { Padrões } \\
\text { seqüenciados }\end{array}$ & $\begin{array}{c}\mathbf{N}^{0} \text { de } \\
\text { pilhas abertas }\end{array}$ & $\begin{array}{c}\text { Pilhas } \\
\text { abertas }\end{array}$ \\
\hline 1 & 2 & 3 e 5 \\
$1-3$ & 3 & 1,3, e 5 \\
$1-3-5$ & 4 & $1,3,5$ e 7 \\
$1-3-5-2$ & 4 & $1,2,5$ e 6 \\
$1-3-5-2-4$ & 3 & 4,5 e 8 \\
\hline
\end{tabular}

\section{Heurística 4}

Enquanto ainda existirem padrões não seqüenciados, faça:

Passo 1: selecione o padrão ainda não seqüenciado com o menor número de tipos de itens novos introduzidos $\left(N_{j}\right)$;

Passo 2: em caso de empate, selecione o padrão que ocorre primeiro.

TABELA 3.16: Sequiência obtida com a aplicação da heurística 4 sobre os dados da tabela 3.1.

\begin{tabular}{c|c|c}
\hline $\begin{array}{c}\text { Padrões } \\
\text { seqüenciados }\end{array}$ & $\begin{array}{c}\mathbf{N}^{0} \text { de } \\
\text { Pilhas abertas }\end{array}$ & $\begin{array}{c}\text { Pilhas } \\
\text { abertas }\end{array}$ \\
\hline 1 & 2 & 3 e 5 \\
$1-3$ & 3 & 1,3 e 5 \\
$1-3-5$ & 4 & $1,3,5$, e 7 \\
$1-3-5-2$ & 4 & $1,2,5$ e 6 \\
$1-3-5-2-4$ & 3 & 4,5 e 8 \\
\hline
\end{tabular}

\section{Heurística 5}

Esta heurística é uma extensão da heurística 3.

Enquanto ainda existirem padrões não seqüenciados, faça:

Passo 1: selecione o padrão ainda não seqüenciado com a maior medida de adequação, $M_{j}$;

Passo 2: se ocorrer empate, selecione o padrão com a maior medida de adequação, $M_{j+l}$, dentre os padrões que empataram;

Passo 3: em caso de empate, selecione o padrão que primeiro ocorre. 
TABELA 3.17: Seqüência obtida com a aplicação da heurística 5 sobre os dados da tabela 3.1.

\begin{tabular}{l|c|c}
\hline $\begin{array}{c}\text { Padrões } \\
\text { seqüenciados }\end{array}$ & $\begin{array}{c}\mathbf{N}^{\mathbf{0}} \text { de } \\
\text { Pilhas abertas }\end{array}$ & $\begin{array}{c}\text { Pilhas } \\
\text { abertas }\end{array}$ \\
\hline 1 & 2 & 3 e 5 \\
$1-3$ & 3 & 1,3, c 5 \\
$1-3-2$ & 5 & $1,2,3,5$ e 6 \\
$1-3-2-5$ & 3 & 3,5 e 7 \\
$1-3-2-5-4$ & 3 & 4,5 e 8 \\
\hline
\end{tabular}

TABELA 3.18: Sequiência obtida com a aplicação da heurística 6 sobre os dados da tabela 3.1.

\begin{tabular}{c|c|c}
$\begin{array}{c}\text { Padrões } \\
\text { seqüenciados }\end{array}$ & $\begin{array}{c}\mathbf{N}^{\mathbf{0}} \text { de } \\
\text { pilhas abertas }\end{array}$ & $\begin{array}{c}\text { Pilhas } \\
\text { abertas }\end{array}$ \\
\hline 1 & 2 & 3 e 5 \\
$1-3$ & 3 & 1,3 e 5 \\
$1-3-5$ & 4 & $1,3,5$, e 7 \\
$1-3-5-2$ & 4 & $1,2,5$ e 6 \\
$1-3-5-2-4$ & 3 & 4,5 e 8 \\
\hline
\end{tabular}

As heurísticas 3 e 5 foram as que apresentaram melhor desempenho com relação ao objetivo de minimizar o número máximo de pilhas abertas (YUEN, 1995). Contudo, a heurística 3 requer menor tempo computacional, quando comparada com a heurística 5 . Em função dos resultados obtidos pela heurística 3 , com relação ao tempo computacional e ao menor número máximo de pilhas abertas, esta heurística será utilizada neste trabalho, para resolver o problema de seqüenciamento de padrões de corte, com o objetivo de minimizar o número máximo de pilhas abertas, MOSP.

\section{Abordagens de Yuen e Richardson}

Yuen e Richardson (1995) apresentam dois métodos para avaliar a qualidade das soluções obtidas pelos procedimentos heurísticos propostos em Yuen (1991, 1995). Um deles é o método do limitante inferior e o outro é um método de busca implícita. O limitante inferior $L B$ (Lower Bound) da fila máxima é o maior número de tipos de itens em qualquer padrão. Desta forma, se a fila máxima determinada por uma heurística for igual a $L B$, então a solução obtida por esta heurística é ótima.

No segundo método uma busca implícita é realizada na árvore, que contém todas as possíveis formas de seqüenciar os padrões. Primeiramente procura-se reduzir o tamanho da árvore, utilizando teoria de grafos, para detectar subgrupos disjuntos de padrões. O número de 
nós também é reduzido através do uso de limitantes, verificação de padrões, que não possuam itens em comum com as pilhas abertas, reutilização de buscas previamente feitas e reordenação de padrões (YUEN, 1995).

\section{Abordagens de Yanasse}

Yanasse (1996) considera o caso, onde existem no máximo dois tipos de itens por padrão e trata o MOSP como um problema de percorrimento em grafos. Yanasse (1997) propõc um método branch and bound, para resolver o problema de seqüenciar um conjunto de padrões, de forma a minimizar o número máximo de pilhas abertas (MOSP). No método proposto um critério guloso é utilizado para escolha do próximo nó, onde será feita a ramificação.

O autor discute a relação entre o $M O S P$ e a formulação matemática para o problema de minimizar o número de trocas de ferramentas (MTSP - do inglês Minimization of the Number of Tool Switches Problem) de Tang e Denardo (1988), já que os dois problemas são relacionados, mas não equivalentes. O MTSP consiste em encontrar uma seqüência, na qual os jobs deverão ser processados, de forma a minimizar o número total de troca de ferramentas, considerando que as mesmas são colocadas na máquina antes que cada job seja processado.

É apresentado um modelo para o MOSP baseado no MTSP. Como os resultados computacionais reportados por Tang e Denardo (1988) para o MTSP foram desapontadores, um comportamento similar seria de se esperar para a formulação proposta por Yanasse (1997), pois a maioria das restrições em ambos os problemas são as mesmas. Em vista disso, o autor propõe uma abordagem alternativa, utilizando um método branch and bound, para encontrar uma solução ótima para o MOSP.

A abordagem proposta explora a observação de que, para encontrar uma solução ótima para o MOSP, é suficiente buscar por uma seqüência ótima das pilhas, que estão sendo completadas. A estratégia de busca utilizada é busca em profundidade primeiro. A ramificação é feita no nó mais promissor através de um critério guloso: dentre os nós de nível mais alto, naquele que resultar no menor número possivel de tipos de itens incompletos. Limitantes inferiores e superiores são utilizados para a poda de nós da árvore através da comparação dos mesmos com a melhor solução disponivel. Os cálculos necessários para o método branch and bound proposto podem facilmente ser implementados, utilizando simples manipulações de matrizes. 


\section{Abordagem de Faggioli e Bentivoglio}

Um novo modelo matemático e uma abordagem em três fases são apresentados por Faggioli e Bentivoglio (1998) para o problema de seqüenciamento de padrões. O objetivo tratado é o de minimizar o número máximo de pilhas abertas (MOSP). Na primeira fase um algoritmo guloso produz uma solução inicial. Esta solução é melhorada na segunda fase, utilizando busca tabu ou um procedimento de busca local generalizada. Na terceira fase um procedimento de enumeração implícita, que utiliza a melhor solução encontrada na fase 2 , é utilizado para resolver otimamente o problema.

Na primeira fase um algoritmo guloso (com relação à pilha) é utilizado, para gerar uma solução inicial. Este procedimento constrói $n$ seqüências, cada uma começando com um padrão diferente (para que a busca seja independente do padrão inicial), e escolhe a melhor dentre elas. Dado que um padrão foi seqüenciado, na escolha do próximo padrão, a ser processado, um critério em estágios é utilizado.

$1^{0}$ estágio: seleciona os padrões, que abrem o menor número de pilhas novas;

$2^{0}$ estágio: seleciona o padrão, dentre os anteriormente selccionados, que remove o maior número de pilhas;

$3^{0}$ estágio: seleciona o padrão, que continua a produção do maior número de pilhas abertas.

Se ocorrer um empate, o primeiro padrão, que ocorre, é o escolhido. A heurística proposta apresentou melhores resultados, quando comparados aos gerados pelas heurísticas de Yuen (1995) nos problemas testes gerados aleatoriamente.

$\mathrm{Na}$ segunda fase um procedimento de busca tabu ou um procedimento de busca local generalizado é utilizado, para melhorar a solução encontrada pelo procedimento guloso. Como atributo de movimento considera-se o par de posições dos padrões $(j, k)$ e uma matriz $n \times n$ é utilizada para implementar a lista tabu. A busca termina, quando a solução não for melhorada por $9 n$ iterações (onde $n$ é o número de padrões).

$\mathrm{Na}$ abordagem de busca local generalizada proposta pelos autores, quando a mesma pára em um ótimo local, a busca é reiniciada a partir de uma nova solução gerada aleatoriamente. O procedimento guloso descrito na fase 1 é acoplado à busca local generalizada. No algoritmo resultante a primeira fase constrói uma seqüência e a segunda aplica o procedimento de busca local, com o objetivo de melhorar a solução anteriormente encontrada. 
O procedimento enumerativo implícito exato proposto é utilizado. para verificar a otimalidade das soluções encontradas. Como entrada para este algoritmo é utilizada a melhor solução encontrada (pela busca tabu ou pela busca local generalizada). Através da introdução de novos critérios de poda, problemas maiores podem ser resolvidos, quando se compara este procedimento com o de busca implícita de Yuen e Richardson (1995). Resultados computacionais sugerem que as heurísticas propostas apresentam um bom compromisso entre qualidade de solução e tempos de execução.

\section{Heurística de Foerster e Wäscher}

Os autores utilizam simulated annealing, para resolver o problema de minimizar o espalhamento de ordem $(M O R P)$ no seqüenciamento de padrões de corte. A versão desenvolvida é comparada com a abordagem de Madsen (1988) e com um procedimento 3-opt tradicional. Os procedimentos q-opt são heurísticas de busca local que, partindo de uma solução inicial, realizam uma série de movimentos consecutivos para soluções vizinhas, onde cada um deles melhora o valor da função objetivo. O procedimento termina quando nenhum movimento, que melhora o valor da função objetivo pode ser identificado. Um movimento consiste em particionar a solução em $q$ posições. As partes resultantes são remontadas de maneira a formar uma nova solução. Das diferentes maneiras de remontar as partes da solução, em geral escolhe-se aquela que fornece o maior ganho no valor da função objetivo.

$\mathrm{Na}$ versão de simulated annealing proposta a solução inicial é escolhida aleatoriamente. Como a determinação do valor da função objetivo consome bastante tempo, somente movimentos 2-opt são considerados. Uma seqüência é particionada em duas posições selecionadas aleatoriamente. A nova seqüência é obtida reconectando as três seqüências com a seqüência central, colocadas em ordem reversa.

Assim como Madsen (1988), os autores, ao invés de resolver o problema de minimizar o espalhamento de ordens (MORP), resolveram o problema de minimizar o número total de descontinuidades resultantes de uma sequiência, utilizando um procedimento 3-opt. Foerster e Wäscher (1998) introduziram uma pequena modificação na matriz custo, para que problemas maiores pudessem ser avaliados. Para avaliação das três abordagens (simulated annealing, 3opt tradicional e o procedimento de Madsen, 1988), uma seqüência inicial de padrões é gerada aleatoriamente, a partir dos padrões de corte resultantes da resolução do problema de corte. 
Os valores da função objetivo e dos tempos computacionais são utilizados para comparação dos procedimentos.

Segundo os autores, o procedimento 3-opt e simulated annealing são praticamente idênticos com relação à qualidade de solução. Todavia, o tempo computacional necessário para o procedimento 3-opt, é bem maior; para problemas com mais de 50 tipos de itens diferentes este procedimento torna-se inviável. Simulated annealing reduz o espalhamento de ordem médio mais que duas vezes, quando comparado ao procedimento de Madsen (1988). Apesar de o tempo computacional necessário pela abordagem simulated annealing ser maior, o mesmo é considerado aceitável, para resolver problemas práticos.

\section{Heurísticas de Fink e Vo $\beta$}

Fink e Voß (1999) avaliam a utilização das metas-heurísticas simulated annealing e busca tabu, para resolver problemas de seqüenciamento. Dois objetivos são considerados: a minimização do número de pilhas simultaneamente abertas e a minimização do espalhamento de ordem médio. Para aplicação das metas-heurísticas é preciso ter disponível uma solução inicial. Os autores utilizam a permutação identidade ou uma permutação determinada por duas heurísticas de construção diferentes: inserção mais barata e inserção mais barata do melhor padrão. A vizinhança é definida por um movimento 2-opt.

Os procedimentos de simulated annealing e busca tabu utilizam movimentos 2-opt. Três abordagens de busca tabu são utilizadas. A primeira tem o tempo tabu fixo, que necessariamente deve ser definido a priori (static tabu seach). A segunda proibe um movimento para un vizinho se, e somente se, cste vizinho já foi visitado durante a parte anterior da busca (strict tabu search). Na terceira, o tempo tabu é apropriadamente adaptado ao longo da busca (reactive tabu search).

Segundo os autores, em média, abordagens de simulated annealing fornecem melhores resultados que abordagens de busca tabu simples. A busca tabu reativa (reactive tabu search), com a inclusão de movimentos de escape, forneceu os melhores resultados gerais. De acordo com os autores, a diversificação foi um componente fundamental nas estratégias heurísticas consideradas. Os resultados computacionais obtidos, com relação à qualidade de solução e tempos de execução, são melhores que os apresentados na literatura. 


\section{Abordagem de Ashikaga}

Ashikaga (2001) propõe um método frugal (método, que além de utilizar poucos recursos computacionais - tempo e espaço --, possui idéias e implementações simples), para resolver o problema de minimizar o número máximo de pilhas abertas (MOSP). A modelagem do problema é feita utilizando teoria dos grafos e tem como base a modelagem utilizada por Yanasse et al.(1999). São propostas duas heurísticas: uma baseada na detecção de circuitos hamiltonianos (caminho indireto fechado, que passe uma única vez em cada vértice, com exceção do primeiro, que é igual ao último), onde o caminho inicial é composto pelos vértices do clique maximal, e a outra heurística é baseada na contração recursiva de cliques maximais.

No grafo MOSP cada vértice corresponde a um item e uma aresta é incidente a dois vértices se, e somente se, existe um padrão de corte, que contenha os itens por ele representado. Uma pilha associada a um item é dita aberta, se a demanda do mesmo foi apenas parcialmente atendida, e é dita fechada, quando a demanda foi totalmente atendida. A busca é feita no grafo MOSP por uma seqüência de pilhas de itens terminados e não por uma seqüência de padrões, pois a enumeração das permutações de pilhas fechadas é mais eficiente que a enumeração das possíveis seqüências de padrões (YANASSE, 1998, apud ASHIKAGA, 2001).

Na teoria dos grafos pode-se entender o grafo MOSP como uma união de cliques (conjunto de vértices mutuamente adjacentes). De acordo com a modelagem proposta por Yanasse et. $a l$ (1999), define-se $N=\left(n_{i j}\right)_{n \times m} \operatorname{com} n$ padrões e $m$ itens como uma matriz MOSP, onde:

$$
n_{j i}=\left\{\begin{array}{l}
1, \text { se } o i \text { ésimo item está presente no padrão } j \\
0, \text { caso contrário }
\end{array}\right\}, 1 \leq j \leq n, 1 \leq i \leq m
$$

O grafo MOSP pode então ser representado por uma matriz adjacência de colunas e o problema consiste em percorrer os arcos. O método proposto é baseado no conjunto independente maximal encontrado no grafo complementar. De acordo com este método devese começar o seqüenciamento a partir dos padrões associados aos itens relacionados ao clique maximal. Como um clique em um grafo corresponde a um conjunto independente no grafo complementar (grafo que contém o mesmo conjunto de vértices do grafo original e uma aresta incide sobre dois vértices se, e somente se, não existir uma aresta no grafo original), para detectar o clique maximal é utilizada uma busca gulosa por vértice de grau mínimo no grafo complementar. Para esta heurística de busca o tempo é linear no número de vértices e, 
conforme Ashikaga (2001), nos experimentos realizados, consegue-se quase sempre detectar o clique maximal MOSP.

Uma das heuristicas propostas, denominada her, utiliza os vértices do clique maximal como caminho inicial e o seqüenciamento dos vértices resultantes é feito, utilizando uma modificação do algoritmo extensão-rotação de Pósa (1976), apud Ashikaga (2001). A idéia é fazer extensões, a partir do caminho inicial. A outra heurística, denominada horc, baseia-se na existência de vários cliques no grafo MOSP, ao invés de um único grande clique. É feita uma contração recursiva dos cliques, idealmente maximais, no grafo MOSP associado. Inicialmente um clique idealmente maximal é contraido em um hiper-nó. A partir do hipergrafo induzido, um novo clique maximal que inclua o hipernó anteriormente encontrado é contraido em um hiper-nó.

Para avaliação do desempenho computacional das heurísticas propostas duas classes de testes foram consideradas com exemplos gerados aleatoriamente. No primeiro caso cada conjunto de testes tinha uma amostra de tamanho 20 e o número de padrões e itens foi limitado em 150. As duas heurísticas propostas (her e herc) foram comparadas com a heurística 3 de Yuen (1995), denominada yuen3 e a heuristica de Yanasse et. al (1999), denominada y bs 99 quanto às médias encontradas em relação ao tempo de processamento computacional e ao número máximo de pilhas abertas. A heuristica ybs 99 resultou no menor número máximo de pilhas abertas e a heurística her foi a que resultou no menor tempo de processamento. As duas heurísticas propostas apresentaram resultados melhores, quando comparados com a heurística yuen3, sendo que a heurística herc é pior para casos esparsos.

Para o segundo conjunto de testes realizados as amostras são de tamanho 2000 e possuem até 1000 padrões e itens. Neste caso é feita uma comparação entre as heurísticas her e yuen 3 . De acordo com os resultados obtidos a heurística her domina a heurística yuen 3 com relação ao tempo em todas as classes, realizando o processamento em uma pequena fração do tempo gasto pela heurística yuen3. Esta heurística abriu menos pilhas, na média, que a heuristica yuen3. 


\section{INTERAÇÃo dOS PROBLEMAS DE GERAÇÃo E DE SEQÜENCIAMENTO DE PADRÕES DE CORTE}

Conforme descrito na seção 1 os problemas de geração e seqüenciamento de padrões de corte são difíceis de serem resolvidos de forma ótima (NP-difíceis); acredita-se que combiná-los num único problema também resulta em um problema pelo menos tão difícil. Em geral eles são abordados, tanto na literatura como na prática, de forma independente e sucessiva. Porém, em diversos sistemas produtivos, o problema de geração de padrões não pode ser resolvido independentemente do problema de seqüenciamento, e vice-versa. Suponha, para efeito de ilustração, que o objetivo do problema de geração de padrões seja a minimização da perda (pe), e o objetivo do problema de seqüenciamento seja a minimização do número máximo de pilhas abertas (pi) (MOSP). Como na realidade existem dois problemas interdependentes com dois objetivos de importância equivalente (e na maioria das vezes conflitantes) a serem resolvidos, trata-se, portanto, de um problema bi-objetivo onde existe um trade-off entre os dois critérios a serem otimizados.

Tal problema bi-objetivo pode ser formulado matematicamente da seguinte maneira. Conforme o capítulo 2 , seja $A=\left[a_{1}, a_{2}, \ldots, a_{p}\right]$ o conjunto de todos os possíveis padrões de corte (colunas) para o problema (1)-(3), com $a_{j}=\left(a_{1 j}, a_{2 j}, \ldots, a_{m j}\right)$, onde $a_{i j}$ é o número de vezes que o item $i, i=1, \ldots, m$, é cortado no padrão $j$. Seja $x=\left(x_{1}, x_{2}, \ldots, x_{p}\right)$ uma solução factivel para o problema (1)-(3), isto é, $x \geq 0$ e satisfaz as restrições de demanda (2): $\sum_{j=1}^{p} a_{i j} x_{j}=b_{i}$. Logo, conforme (1), $f(x)=\sum_{j=1}^{p} c_{j} x_{j}$ corresponde à perda de $x$. Note que se $x_{j}>0$ então a solução $x$ utiliza o padrão $j$. Considere que a solução $x$ utilize $n$ padrões e, sem 
perda de generalidade, suponha que sejam os primeiros: $x_{1}>0, \ldots, x_{n}>0, x_{n+1}=0, \ldots, x_{p}=0$ e seja $s(x)=\left(a_{[1]}, a_{[2]}, \ldots, a_{[n]}\right)$ uma seqüência destes $n$ padrões $\left([k]=j\right.$ indica que o padrão $a_{j}$ ocupa a $k$-ésima posição da seqüência). Define-se $g(x)=\min _{s(x) \in S(x)}\{h(s(x))\}$, onde $S(x)$ é o conjunto de todas as possíveis seqüências $s(x)$ obtidas permutando-se os padrões $1,2, \ldots, n$ e $h(s(x))$ é o número máximo de pilhas abertas com a seqüência $s(x)$. Logo, chamando pe $=f(x)$ e $p i=g(x)$, temos o seguinte problema bi-objetivo:

$$
\begin{array}{ll} 
& \min z=(p e, p i)=(f(x), g(x)) \\
(P 0) \quad & x=\left(x_{1}, x_{2}, \ldots, x_{p}\right) \in X \\
& z=(p e, p i)=(f(x), g(x)) \in Z
\end{array}
$$

onde $x$ é o vetor decisão, $z$ é o vetor objetivo, $X$ é o conjunto de soluções factíveis e $Z$ é o espaço objetivo (imagem de $X$ ). Note que o valor de um ponto $x=\left(x_{1}, x_{2}, \ldots, x_{p}\right)$ em $X$ corresponde a um ponto $z=(p e, p i)$ em $Z$. Na figura 4.1 o espaço objetivo para o problema biobjetivo $(P 0)$ está ilustrado.

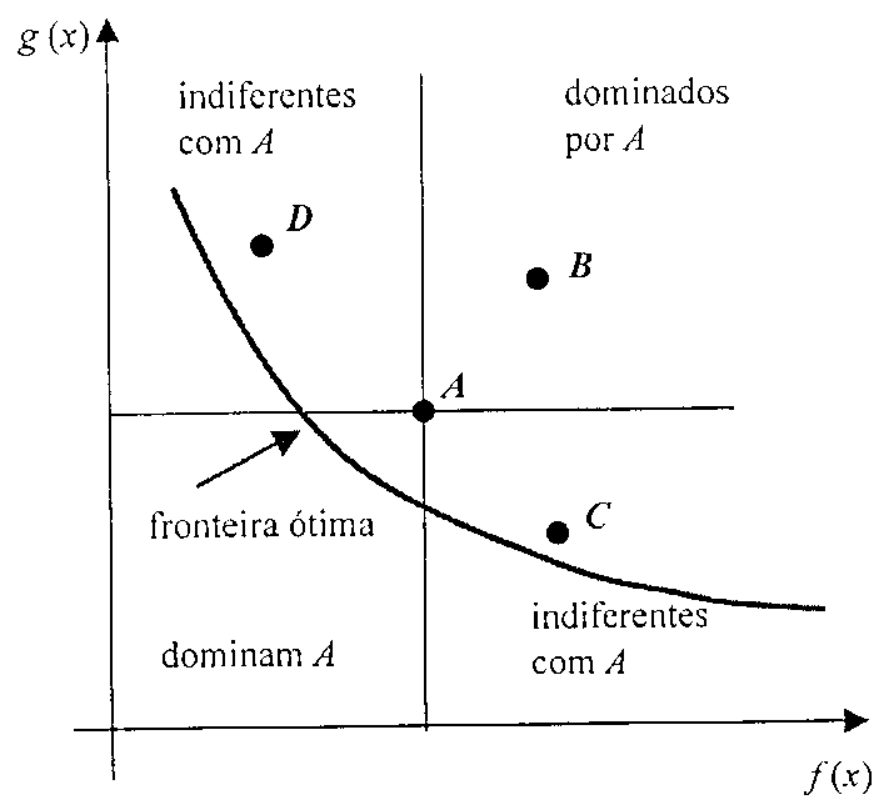

FIGURA 4.1: Ilustração do espaço objetivo para o problema $(P 0)$.

Em problemas mono-objetivos como o problema de corte (1)-(3) (seção 2.2), o espaço objetivo $Z$ é completamente ordenado, isto é, dados quaisquer dois pontos $x, y \in X$, é sempre verdade que: (i) $f(x) \leq f(y)$ ou $($ ii $) f(x) \geq f(y)$. Em problemas bi-objetivos com objetivos conflitantes (onde minimizar um objetivo pode causar o acréscimo de outro, e vice-versa), o espaço objetivo é parcialmente ordenado, isto é, dados quaisquer dois pontos $x \mathrm{e} y \in X$, existem três casos: (i) $f(x) \leq f(y)$ e $g(x) \leq g(y)$, (ii) $f(x) \geq f(y)$ e $g(x) \geq g(y)$, ou (iii) os dois casos 
anteriores não são verdadeiros. Por exemplo, se $f(x)=3$ e $g(x)=5$, e $f(y)=4$ e $g(y)=6$, então (i) é verdadeiro (veja pontos $A$ e $B$ na figura 4.1), mas se $f(x)=3$ e $g(x)=6$, e $f(y)=4$ e $g(y)=$ 5, então nem (i) nem (ii) são verdadeiros (veja pontos $A$ e $C$ na figura 4.1). Note que no caso (i) $x$ domina $y$, no caso (ii) $y$ domina $x$, e no caso (iii) nem $x$ domina $y$, nem $y$ domina $x$ (diz-se que $x$ e $y$ são indiferentes, ou seja, possuem o mesmo grau de dominância).

Obscrve na figura 4.1 que o ponto $A$ domina os pontos pertencentes ao retângulo superior direito, mas é dominado pelos pontos do retângulo inferior esquerdo. Pontos como $C$ e $D$ são indiferentes. Uma solução $x^{*} \in X$ é chamada solução eficiente, se não existe qualquer outra solução $x \in X$, que domine $x^{*}$. O conjunto de todas as soluções eficientes define uma fronteira ótima (curva de eficiência), conforme ilustrado na figura 4.1. Note que os pontos desta fronteira são indiferentes entre si. Em problemas com objetivos conflitantes, como é o caso do problema $(P O)$, é pouco provável que o conjunto das soluções eficientes seja unitário ou contenha poucos pontos.

Existem diversos métodos para resolver problemas multi-objetivos (COHON, 1978; STEUER, 1986, apud ARROYO, 2002). Conforme Arroyo (2002), dois aspectos importantes a serem considerados são: a busca de soluções e a tomada de decisões. O primeiro refere-se ao processo de otimização, na qual a região factível é direcionada para as soluções da fronteira eficiente. O segundo envolve a seleção de um critério adequado para a escolha de uma solução desta fronteira, levando-se em conta o trade-off entre os objetivos conflitantes (esta escolha em geral é feita pelo gerente ou decisor).

Alguns métodos são caracterizados pela participação do decisor antes do processo de busca de soluções (métodos a priori), isto é, antes de resolver o problema. Dois exemplos são: (i) Combinar os objetivos do problema em um único objetivo, o que requer a definição de pesos, para refletir a preferencia de cada objetivo. O problema obtido pode ser resolvido por métodos mono-objetivos. Por exemplo, para o problema $(P O)$ ter-se-ia o seguinte problema mono-objetivo: $\min z=w_{1} f(x)+w_{2} g(x)$ sujeito a $x \in X$. Uma dificuldade da aplicação deste método para o presente estudo é a estimativa dos pesos $w_{1}$ e $w_{2}$.

(ii) Classificar os objetivos do problema por ordem de prioridade. Inicialmente o problema original é resolvido por métodos mono-objetivos apenas para o primeiro objetivo (sem considerar os demais), depois para o segundo objetivo (sujeito à solução obtida para o primeiro objetivo e sem considerar os demais objetivos), e assim por diante, até o último objetivo. Por exemplo, para o problema $(P 0)$ resolver-se-ia 
primeiro: $f^{*}=\min f(x)$ sujeito a $x \in X$, e depois: $\min g(x)$ sujeito a $f(x)=f^{*}$ e $x \in X$. Uma dificuldade da aplicação deste método para o presente estudo é a validade desta prioridade de objetivos.

Outros métodos são chamados a posteriori, porque a participação do decisor ocorre depois do processo de busca de soluções. Primeiro a busca é feita sobre o conjunto de soluções eficientes, considerando que os objetivos têm igual importância, e depois o decisor escolhe a solução que achar mais adequada, levando em conta o trade-off entre os objetivos conflitantes. Existem também métodos interativos, em que o decisor intervém durante a busca de soluções (processo de otimização), procurando guiar a busca para regiões, onde existem soluções de interesse.

No presente trabalho aplicamos um método a posteriori baseado na minimização de um dos objetivos sujeito à limitação do outro objetivo. A idéia deste método é que, variandose esta limitação, é possivel gerar os pontos da fronteira eficiente. Por exemplo, podemos minimizar o número máximo de pilhas abertas $(p i)$ sujeito a uma limitação ( $p \hat{e}$ ) para a perda de material (pe), ou seja:

$$
\begin{array}{ll} 
& \min p i=g(x) \\
(P l) \quad & p e=f(x) \leq p \hat{e} \\
& x=\left(x_{1}, x_{2}, \ldots, x_{p}\right) \in X
\end{array}
$$

Note que o problema $(P l)$ consiste em determinar um conjunto de padrōes de corte $(x)$ que, quando seqüenciados, abram o menor número máximo de pilhas possível, sujeito à restrição de que a perda gerada pelo corte desses padrões (pe) seja menor ou igual à perda tolerada ( $p \hat{e}$ ). Variando-se convenientemente a limitação pé é possivel gerar os pontos da fronteira eficiente. Alternativamente ao problema $(P I)$, podemos minimizar a perda de material (pe) sujeito a uma limitação ( $p \hat{i})$ para o número máximo de pilhas abertas $(p i)$, ou seja:

$$
\begin{array}{ll} 
& \min p e=f(x) \\
(P 2) \quad & p i=g(x) \leq p \hat{i} \\
& x=\left(x_{1}, x_{2}, \ldots, x_{p}\right) \in X
\end{array}
$$

A solução do problema (P2) consiste na menor perda (pe) obtida por um conjunto de padrões de corte $(x)$, sujeito à restrição de que o número máximo de pilhas abertas $(p i)$ obtido com o seqüenciamento desses padrões seja menor ou igual ao número máximo de pilhas abertas tolerado $(p \hat{i})$. Similarmente ao problema $(P I)$, variando-se a limitação $\hat{i} \hat{i}$, é possível 
gerar os pontos da fronteira eficiente. Uma vantagem de $(P 2)$ sobre $(P 1)$ para aplicação deste método é que $p \hat{i}$ em $(P 2)$ é um número inteiro que varia discretamente $(1,2,3, \ldots)$, enquanto $p \hat{e}$ em $(P I)$ é um número real.

Para melhor ilustrar esta discussão, na figura 4.2 abaixo apresenta-se uma fronteira eficiente entre a perda e o número máximo de pilhas abertas, onde:

pe perda mínima (isto é, limitante inferior para a perda, corresponde à solução ótima do problema (4)-(6), seção 2.2)

pe perda máxima (isto é, limitante superior para a perda, correspondendo à solução obtida pelos padrões homogêneos)

$p \hat{e} \quad$ perda tolerada satisfazendo $\underline{p e} \leq p \hat{e} \leq \overline{p e}$ (isto é, tolerância definida pelo usuário para a perda)

$\overline{p i}$ número de pilhas máximo (isto é, limitante superior para o número de pilhas, correspondendo ao menor número de pilhas encontrado no seqüenciamento de padrões com perda igual à perda mínima)

$p \hat{i} \quad$ número de pilhas tolerado satisfazendo $l \leq p \hat{i} \leq \overrightarrow{p i}$ (isto é, tolerância definida pelo usuário para o número máximo de pilhas que pode ser aberto; 1 é o número máximo de pilhas abertas obtido pela solução homogênea)

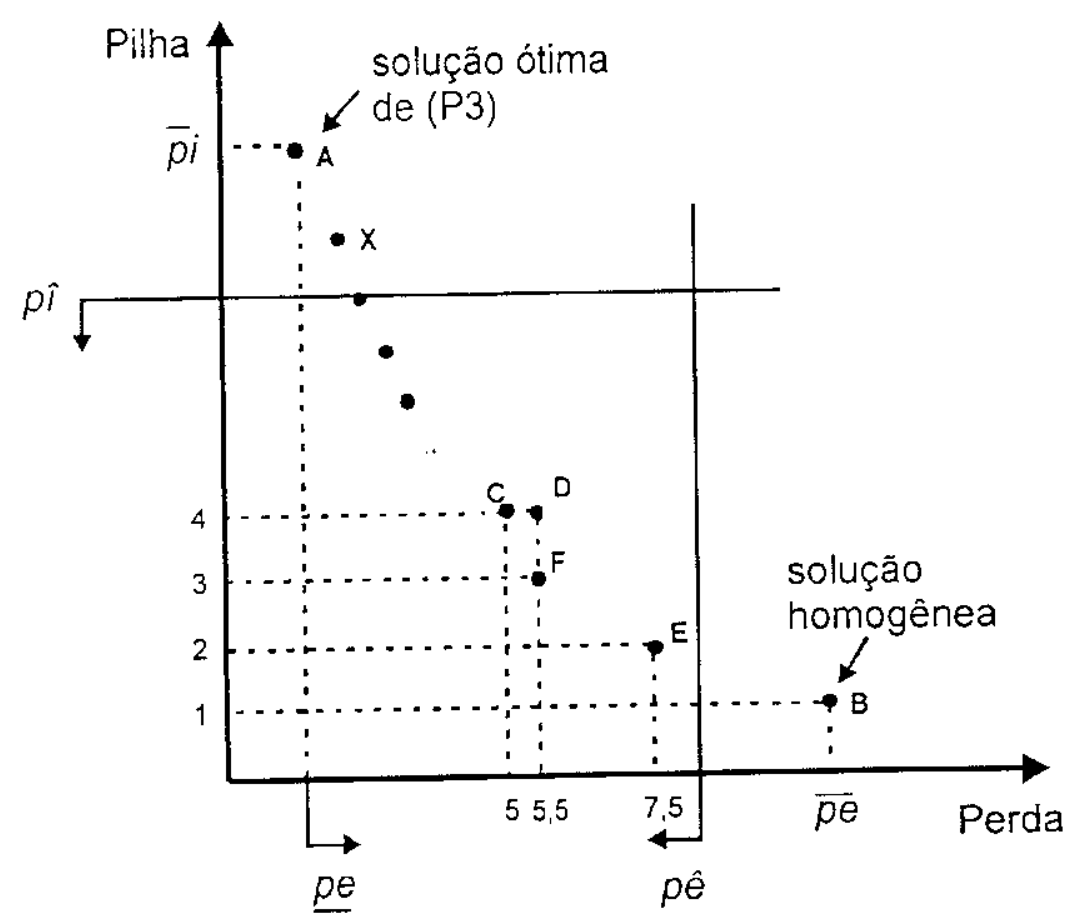

FIGURA 4.2: Ilustração da fronteira eficiente entre a perda $(p e)$ e o número máximo de pilhas abertas $(p i)$. 
Os pontos desta curva de eficiência correspondem às soluções de mínima perda para diferentes valores de número máximo de pilhas abertas ou, inversamente, às soluções de mínimo número máximo de pilhas abertas para diferentes valores de perda de material. Considere as quatro soluções C, D, E e F, representadas no gráfico da figura 4.2 , cujos valores para a perda (pe) e número máximo de pilhas ( $p i)$ estão descritos na tabela 4.1.

TABELA 4.1: Diferentes soluções com os respectivos valores de perda $(p e)$ e número máximo de pilhas abertas $(p i)$.

\begin{tabular}{c|c|c}
\hline Solução & $p e(\%)$ & $p i$ \\
\hline C & 5 & 4 \\
D & 5,5 & 4 \\
E & 7,5 & 2 \\
F & 5,5 & 3 \\
\hline
\end{tabular}

Como se pode observar pelo gráfico da figura 4.2, as soluções C e F dominam a solução $\mathbf{D}$, pois a perda e o número de pilhas das soluções $\mathbf{C}$ e $\mathbf{F}$ são menores ou iguais à perda e ao número de pilhas da solução $\mathbf{D}$. Por outro lado, as soluções $\mathbf{C}$ e $\mathbf{F}$ não dominam uma a outra, nem dominam a solução $\mathrm{E}$.

O número máximo de pilhas abertas é um número positivo e inteiro e, desta forma, o conjunto de pontos do eixo $y$ (número de pilhas) do gráfico da figura 4.2 é discreto e, mais que isso, é finito e definido pelo intervalo $[1, \overline{p i}]$, como é visto mais adiante. Neste caso, para cada valor do número de pilhas abertas, poderá existir uma solução eficiente, que define a fronteira eficiente entre a perda e o número máximo de pilhas abertas. Diz-se "uma" solução eficiente, visto que é possível encontrar diferentes conjuntos de padrões de corte (i.e., diferentes soluções eficientes $x^{*} \in X$ ) com a mesma perda (pe) e que resultam no mesmo número máximo de pilhas abertas $(p i)$.

Como as soluções precisam satisfazer aos critérios de tolerância dos problemas de geração e seqüenciamento de padrões, os valores pî (número máximo de pilhas abertas tolerado) e pê (perda máxima tolerada) delimitam a parte da curva, que contém as soluções factíveis (do ponto de vista das tolerâncias estabelecidas pelo usuário). Por exemplo, na fábrica de móveis Colombini procura-se evitar o corte de padrões com perdas acima de $10 \%$. Similarmente, na fábrica de chapas duras Duratex não é possível cortar padrões que, quando seqüenciados, abram mais que 5 pilhas. Ou seja, os pontos sobre a curva de eficiência contidos nos intervalos $[1, p \hat{i}] \mathrm{e}[\underline{p e}, p \hat{e}]$ são os soluções alvo entre minimizar a perda e minimizar o número de pilhas abertas (figura 4.2). 
Em particular, o ponto $A$ da fronteira eficiente (figura 4.2) pode ser obtido resolvendo o problema $(P 3)$,

$$
\begin{aligned}
& \min p i=g(x) \\
& \text { (P3) } \quad p e=f(x)=\underline{p e} \\
& x=\left(x_{1}, x_{2}, \ldots . x_{p}\right) \in X
\end{aligned}
$$

Para este problema a solução é definida por um conjunto de padrões de corte $(x)$ que, quando seqüenciados, abrem o menor número máximo de pilhas abertas ( $p i$ ) e que satisfazem à restrição de que a perda gerada pelo corte desses padrões (pe) seja igual à perda mínima ( $\underline{p e}$ ). Este problema é difícil de ser resolvido de forma ótima, devido à dificuldade de se examinarem todos os conjuntos de padrões de corte em $X$ com perda igual à perda mínima.

Por outro lado, o ponto $B$ da curva de eficiência pode ser facilmente obtido pela solução homogênea (padrões de corte com apenas um único tipo de item). Na prática, pode ser que não seja possível encontrar uma solução, que satisfaça aos critérios de tolerância de perda e de número de pilhas (ponto $X$ da figura 4.2). Note que o espaço de soluções definido pelas tolerâncias pode ser vazio, isto é, pode ser que um problema não tenha uma solução, que satisfaça às tolerâncias impostas.

Conforme discutido, os demais pontos da fronteira eficiente (figura 4.2) podem ser obtidos, variando-se o valor de $p \hat{e}$ no problema $(P l)$, ou variando-se o valor de $p \hat{i}$ no problema $(P 2)$. De fato, por meio deste procedimento, por exemplo, fazendo-se $p \hat{i}=1,2 \ldots$, $\overline{p i}$ no problema $(P 2)$, obter-se-ia todos os pontos da fronteira eficiente, embora isso seja em geral computacionalmente intratável do ponto de vista prático.

Em vista da dificuldade em definir a fronteira eficiente ótima para a perda e o número máximo de pilhas abertas, a procura é pelas soluções que estejam o mais próximo possível da fronteira eficiente (isto é, boas aproximações). Na verdade, pode-se estar com alguma solução bastante próxima da curva, sem saber quão perto se está; mais que isso, pode-se dispor de uma solução, que faça parte desta curva de eficiência, sem que se saiba disso, uma vez que não se dispõe de métodos exatos para a resolução de $(P I)$ ou $(P 2)$.

Duas abordagens de solução foram descritas, para abordar os problemas de geração e seqüenciamento de padrões de corte de forma integrada (problema $(P 0)$ ). Em uma delas o problema de seqüenciamento é resolvido, considerando o problema de geração de padrões como uma restrição (problema $(P l)$ ), e na outra, resolve-se o problema de geração de padrões, 
considerando como restrição o problema de seqüenciamento (problema $(P 2)$ ). Na seção seguinte apresenta-se uma possível formulação matemática mais detalhada para o problema $(P 2)$.

\subsection{Modelo integrado dos problemas de geração e seqüenciamento de padrões}

Pinto (2001) propõe um modelo matemático para a resolução integrada dos problemas de geração e seqüenciamento de padrões, baseado na formulação (3.1)-(3.9) da seção 3.1. Para tanto, apresenta uma formulação matemática, que combina os dois modelos em um problema de programação inteira, com o objetivo de minimizar a quantidade de peças em estoque a serem cortadas (observe que se todas as peças em estoque forem iguais, este objetivo é equivalente a minimizar a perda) e satisfazer as restrições de demanda e de limitação do número máximo de pilhas, que pode ser aberto. As variáveis $y_{j n}$ (igual a 1 se o padrão $j$ é o $n$-ésimo na seqüência e 0 , caso contrário) e $x_{j}$ (número de vezes que o padrão $j$ será repetido) ficam então relacionadas da seguinte forma:

$$
\begin{array}{ll}
v_{j} \leq x_{j} & j=1, \ldots, n \\
K v_{j} \geq x_{j} & j=1, \ldots, n \\
v_{j} \in\{0,1\} & j=1, \ldots, n
\end{array}
$$

onde $K$ é um número grande. Com isso a restrição (3.6) do modelo apresentado na seção 3.1 é substituída por:

$$
y_{j k} A_{j}+\left(v_{j}-1\right) A_{j} \leq w_{k} \quad j=1, \ldots, n ; \quad k=1, \ldots, n
$$

Feitas estas considerações, apresenta-se a seguir o modelo matemático proposto por Pinto (2001), que constitui uma possível formulação para o problema (P2) (a notação abaixo já foi definida na seção 3.1). Note que de acordo com a notação anterior píi é equivalente a $c$.

$$
\begin{aligned}
& \min f(\boldsymbol{x})=\sum_{j=1}^{p} c_{j} x_{j} \\
& \text { s. a: } \sum_{j=1}^{p} a_{i j} y_{j} \geq b_{t}
\end{aligned} \quad i=1, \ldots, m
$$




$$
\begin{array}{ll}
p_{k} \geq W_{k+1}-W_{k} & k=1, \ldots, n-1 \\
p_{k} \geq 0 & k=1, \ldots, n-1 \\
\sum_{k=1}^{n-1} e p_{k} \geq m-p \hat{i} & \\
y_{j k} A_{j}+\left(v_{j}-1\right) A_{j} \leq w_{k} & j=1, \ldots, n ; k=1, \ldots, n \\
v_{j} \leq x_{j} & j=1, \ldots, n \\
K v_{j} \geq x_{j} & j=1, \ldots, n \\
\sum_{k=1}^{n} y_{j k}=1 & j=1, \ldots, n \\
\sum_{j=1}^{n} y_{j k}=1 & k=1, \ldots, n \\
v_{j} \in\{0,1\} & j=1, \ldots, n \\
y_{j k} \in\{0,1\} & j=1, \ldots, n ; k=1, \ldots, n \\
x_{j} \geq 0 \text { e inteiro } & j=1, \ldots, n
\end{array}
$$

Este modelo integrado (4.5)-(4.17) é complexo e de dificil solução exata. Outra questão é que este modelo (pelo menos a princípio) pressupõe a existência de todos os possíveis padrões de corte, ou seja, para que o mesmo seja resolvido, todos os padrões devem ter sido gerados a priori. Como na prática este número é bastante grande, podendo chegar à casa de milhares ou milhões, encontrar a solução ótima do modelo (4.5)-(4.17), em casos reais, em geral é computacionalmente inviável.

Note que, ao resolver o modelo proposto por Pinto (2001) para diferentes valores de $\hat{p} \hat{i}=\overline{p i}, \overrightarrow{p i}-1, \ldots, 1$ (onde $p \hat{i}$ representa a limitação para o número máximo de pilhas que pode ser aberto), também é possível obter a curva de eficiência ótima entre a perda e o número máximo de pilhas abertas, conforme descrição na seção anterior. Dado que esta formulação para o problema $(P 2)$ já é computacionalmente pouco tratável considerando-se apenas um único valor para $p \hat{i}$, ao considerar-se diferentes valores de $p \hat{i}$, o modelo fica ainda mais dificil de ser resolvido otimamente.

Em vista da dificuldade em resolver otimamente um modelo combinado, diferentes abordagens heurísticas, que consideram a dependência entre os problemas de geração e seqüenciamento de padrões, são propostas no presente trabalho. Três abordagens, inspiradas 
no problema $(P 2)$ são apresentadas para resolver esses dois problemas. Para a descrição das abordagens propostas, considere um problema de geração de padrões de corte, cujo objetivo seja a minimização da perda de material, e um problema de seqüeciamento de padrões, cujo objetivo seja a minimização do número máximo de pilhas abertas (MOSP).

Nas seções 4.2, 4.3 e 4.4 descrevem-se respectivamente as abordagens propostas, aqui denominadas Abordagem 1, Abordagem 2 e Abordagem 3.

\subsection{Abordagem 1}

A Abordagem 1 consiste em otimizar o objetivo do problema de geração de padrões, considerando o critério a ser otimizado pelo problema de seqüenciamento como uma restrição. A idéia para esta abordagem surgiu da observação de como esses dois problemas em geral são resolvidos na prática: no primeiro estágio o problema de geração de padrões é resolvido e, a partir da solução obtida (conjunto de padrões de corte de perda mínima), resolve-se o problema de seqüienciamento em um segundo estágio. Se a solução obtida do ponto de vista do problema de seqüenciamento não satisfizer as tolerâncias impostas, um novo conjunto de padrões precisa ser gerado. Dyson e Gregory (1974) e Madsen (1988) resolvem o problema de geração e seqüenciamento de padrões de corte, utilizando procedimentos $\mathrm{em}$ dois estágios. Outros trabalhos abordam o problema de geração de padrões de forma integrada. Por exemplo, Hendry et al. (1996) propõem um procedimento em dois estágios, para resolver os problemas de scheduling e de corte de estoque. Gramani (2001) propõe um modelo de programação matemática para o problema combinado de corte de estoque capacitado e lot-sizing.

A presente abordagem resolve alternadamente os problemas de geração e seqüienciamento de padrões. Em um primeiro estágio o problema de geração é resolvido e, a partir do conjunto de padrões de corte obtido (padrões com pe $=\underline{p e}$ ), o problema de seqüenciamento é resolvido. Em função da qualidade da solução obtida (número máximo de pilhas abertas) interfere-se no problema de geração, a fim de que um novo conjunto de padrões seja gerado. Esta é a idéia central da Abordagem I: procurar conjuntos de padrões de corte alternativos com o objetivo de factibilizar a solução do ponto de vista do problema de seqüenciamento, ou seja, encontrar $p i \leq p \hat{i}$. Esta busca pode obter soluções factíveis para o problema $(P 2)$, mas, por outro lado, pode 
gerar perdas muito altas. Nestes casos pode-se estabelecer critérios de tolerância para a perda, o que implica em procurar soluções que satisfazem $p i \leq p \hat{i}$ e $p e \leq p \hat{e}$.

A primeira e mais simples versão (la) desta abordagem (ilustrada no diagrama de blocos da figura 4.3, discutida adiante na seção 4.2.1) consiste em resolver o problema de geração de padrões no primeiro estágio e no segundo, o problema de seqüenciamento. Se $p i \leq p \hat{i}$, o procedimento ternina; a solução encontrada é uma solução ótima de $(P 2)$, ou seja pe $=\underline{p e}$ e $p i$ $\leq p \hat{i}$. Caso contrário, o problema de geração de padrões é novamente executado, mas com uma nova restrição, que possibilita a geração de um novo conjunto de padrões de corte. O algoritmo termina assim que o número máximo de iterações estabelecido seja atingido, ou quando $p i \leq p \hat{i}$ para $p e=\underline{p e}$, ou seja, quando uma solução ótima de $(P 2)$ é encontrada. A estratégia utilizada na busca de uma solução, que satisfaça $p i \leq p \hat{i}$, consiste em proibir alguns padrões de serem gerados, por um certo número de iterações subseqüentes, com o objetivo de se obter diferentes conjuntos de padrões de corte. Com isso, no final do procedimento é possível que a solução cncontrada não seja uma solução factível para $(P 2)$, isto é, não satisfaça $p i \leq p \hat{i}$.

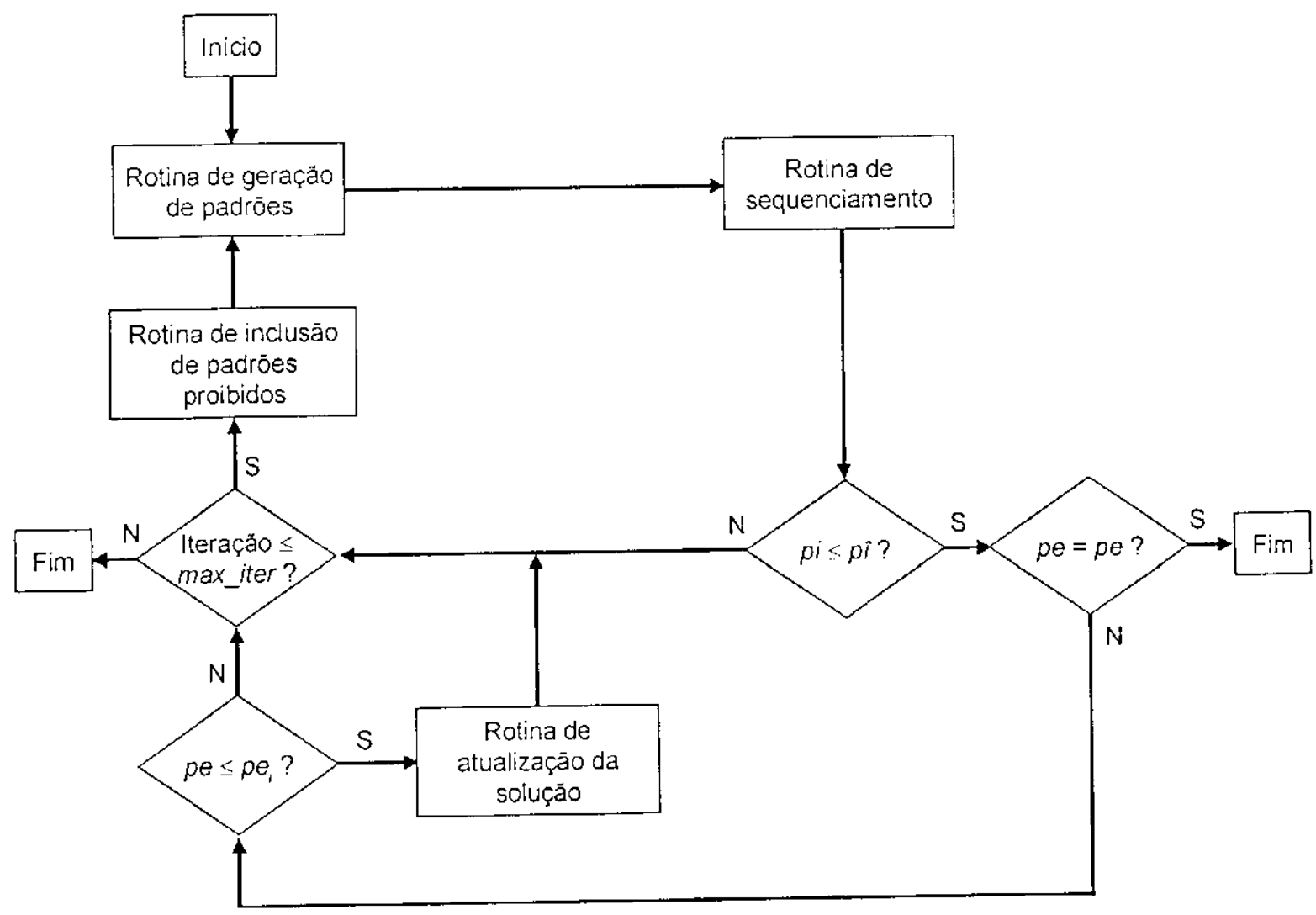

FIGURA 4.3: Esquema ilustrativo da Abordagem 1 a. 
Em vista disto, a segunda versão $(I b)$ da Abordagem 1 consiste em factibilizar todas as soluções encontradas em cada iteração (veja ilustração desta abordagem na figura 4.4 que será discutida na seção 4.2.2). Um conjunto de padrões de corte é gerado com a resolução do problema de geração; este conjunto é então seqüenciado. Caso $p i>p \hat{i}$, então a solução é factibilizada, ou seja, a partir do conjunto de padrões de corte obtido, um novo conjunto é gerado através da eliminação e inserção de novos padrões, até que pi $\leq p \hat{i}$. O término do procedimento é atingido da mesma forma que na versão $I a$.

A versão $l b$ sempre determina uma solução com $p i \leq p \hat{i}$, mas às vezes isso só é atingido com grande detrimento da perda de material. Ou seja, pode acontecer que, para factibilizar uma solução, a perda gerada pelo corte dos padrões aumente consideravelmente. Em vista disto, na terceira versão $(I c)$ da Abordagem $/$ (figura 4.5 discutida adiante na seção 4.2.3), uma pequena variação da versão $(I b)$ é explorada que consiste em tentar factibilizar uma solução alterando inicialmente apenas um padrão do conjunto de padrões gerado pelo problema de geração de padrões.

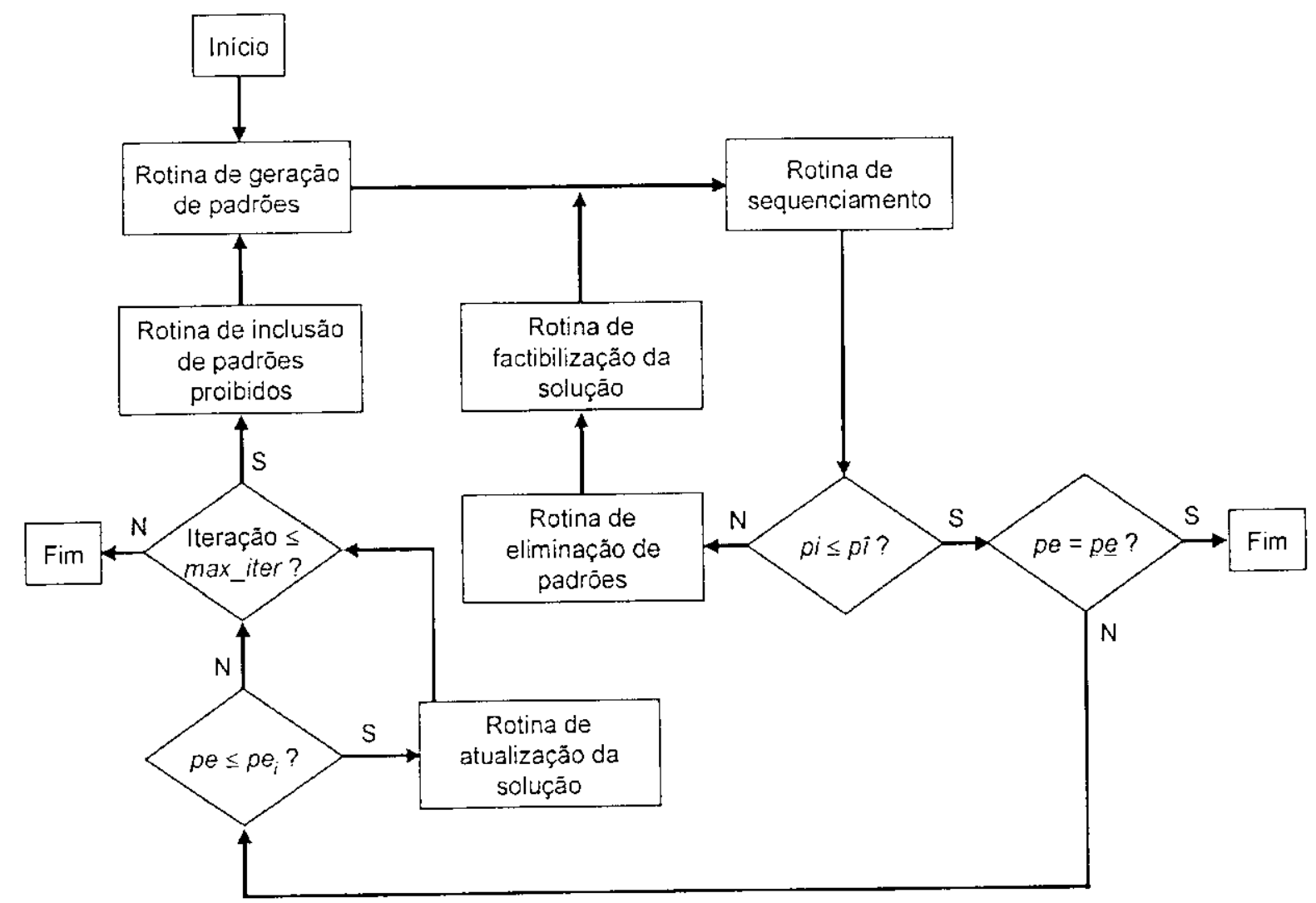

FIGURA 4.4: Esquema ilustrativo da Abordagem $1 b$. 


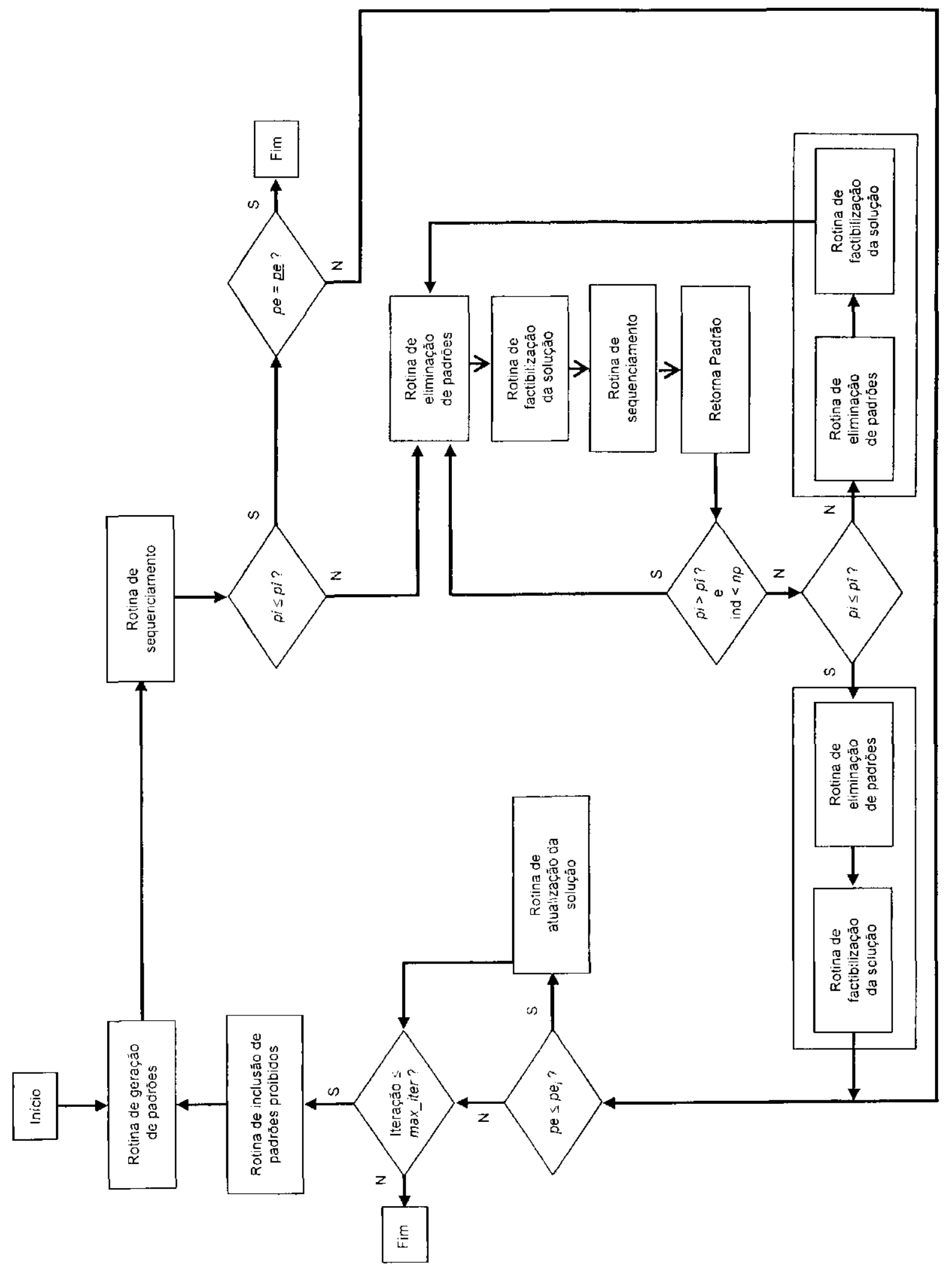

FIGURA 4.5: Esquema ilustrativo da $\mathrm{Abordagem} / \mathrm{c}$. 
Caso isso não seja suficiente para que $p i \leq p \hat{i}$, então um procedimento de eliminação e inserção de novos padrões, como na versão $l b$, é utilizado. que garante a factibilização do problema. A idéia da versão $l c$ é tentar encontrar em cada iteração um conjunto de padrões factíveis do ponto de vista do problema de seqüenciamento, que não deteriore muito a perda.

As diferentes versões da Abordagem 1 podem ser utilizadas para gerar aproximadamente diferentes pontos da curva de eficiência. o que é feito variando-se os valores de $p \hat{i}$. A seguir será descrito cada bloco dos diagramas das figuras $4.3,4.4$ e 4.5, para em seguida apresentar em detalhes as diferentes versões desta abordagem.

\section{Rotina de Geração de Padrões}

Esta rotina resolve o problema de geração de padrões (problema $\bullet / \mathrm{V} / \bullet / \mathrm{R}(2.4)-(2.6)$ ), utilizando o método simplex com geração de colunas (seção 2.3). No caso unidimensional (i) o método exato de Gilmore e Gomory (1963) foi utilizado para a geração dos padrões (seção 2.3.1). No caso bidimensional utilizou-se (ii) o método em duas fases de Gilmore e Gomory (1965) para gerar padrões de corte guilhotinados em 2-estág̣ios (seção 2.3.2) e (iii) a abordagem cm grafo e/ou para gerar padrões de corte guilhotinados não - estagiados (seção 2.3.3).

$\mathrm{Na}$ geração dos padrões de corte o número máximo de tipos de itens permitidos é limitado em $p \hat{i}$, visto que padrões com mais que $p \hat{i}$ itens são infactíveis, independentemente da seqüência em que os mesmos sejam cortados. Outra restrição, que precisa ser verificada na geração dos padrões, é em relação aos padrões proibidos (obtidos na rotina de inclusão de padróes proibidos). Com isso, para que ocorra a atualização de um padrão, o mesmo precisa ser mais valioso que o padrão incumbente, não conter mais que $p \hat{i}$ itens e não ser igual a nenhum padrão proibido.

Para satisfazer estas duas restrições, foram feitas adaptações nos algoritmos citados $(i$, ii e iii). No caso (i) modificações foram feitas nos passos 3 e 5 do algoritmo unidimensional de Gilmore e Gomory (seção 2.3.1). Por conveniência, o passo 3 deste algoritmo está reescrito abaixo:

Passo 3: Dado $\left(a_{1}, a_{2}, \ldots, a_{m}\right)$ verifique se $\sum_{i=1}^{m} v_{i} a_{i}>f(a)$. Neste caso guarde este padrão e atualize $f(a)$. 
Seja $\delta\left(a_{t}\right)=\left\{\begin{array}{l}1, \text { se } a_{t}>0 \\ 0, \text { caso contrário }\end{array}\right.$ e $P$ o conjunto corrente de padrões proibidos. O passo 3 modificado passa a ser definido da seguinte forma:

Passo 3': Dado $a=\left(a_{1}, a_{2}, \ldots, a_{m}\right)$ verifique se $\sum_{t=1}^{m} \delta\left(a_{i}\right) \leq p \hat{i}, a \notin P$ e $\sum_{i=1}^{m} v_{l} a_{i}>f(a)$. Neste caso guarde este padrão $a$ e atualize $f(\boldsymbol{a})$.

Ou seja, para atualização da solução incumbente, é verificado se o padrão contém um número de tipos de itens menor ou igual a $p \hat{i}$, se o mesmo não é igual a nenhum padrão proibido e se este padrão é mais valioso que a solução incumbente. Se essas três condições forem satisfeitas, então a solução é atualizada.

Para a adaptação do passo 5 do algoritmo de Gilmore e Gomory (1963) considere novamente sua descrição original:

Passo 5: Faça $a_{s} \leftarrow a_{s}-1$. Se $\left(L-\sum_{i=1}^{s} l_{i} a_{l}\right) v_{s+1}>v_{s} l_{s+1}$, então vá para o passo 7. Caso contrário vá para o passo 6.

O passo 5 modificado passa a ser definido por:

Passo 5': Faça $a_{s} \leftarrow a_{s}-1$. Se $\sum_{i=1}^{m} v_{i} a_{i}>f(a), \sum_{i=1}^{m} \delta\left(a_{i}\right) \leq p \hat{i}$ e $a \notin P$, então guarde o padrão $\left(a_{l}, a_{2}, \ldots, a_{s}-1, \ldots, a_{m}\right)$ e atualize $f(a)$. Se $\left(L-\sum_{t=1}^{*} l_{l} a_{l}\right) v_{s+1}>v_{s} l_{s+1}$, então vá para o passo 7. Caso contrário vá para o passo 6.

No passo 5 modificado a cada eliminação de um item no padrão atual é verificado se o mesmo é mais valioso que a solução incumbente, se a restrição quanto a $p \hat{i}$ é satisfeita e se o mesmo não é igual a um padrão proibido. A verificação de alocação de itens do tipo $s+1$ é feita como no passo 5 original.

Observe que para o caso irrestrito qualquer nó corresponde a uma solução factível e as soluções ótimas estão nos nós finais (folhas) da árvore de busca. Já para o caso, onde existe uma restrição quanto ao número máximo de tipos de itens no padrão, a solução ótima pode estar em nó intermediário. Como ilustração, considere o seguinte exemplo: $L=100, l_{1}=90$, $l_{2}=5, v_{1}=900$, e $v_{2}=5$ e seja $p \hat{i}=1$. Como $v_{1} / l_{1} \geq v_{2} / l_{2}$, a partir do nó $(0,0)$ o primeiro nó avaliado é o nó $(1,2)$ com valor 910. Como este nó corresponde a um padrão infactível (pois $p \hat{i}=1), f(a)$ não é atualizada. O segundo nó avaliado é o nó $(1,1)$ com valor 905 , que também 
é infactivel. O terceiro nó avaliado é o nó $(1,0)$ com valor 900 (que é um nó intermediário). Como este nó corresponde a um padrão factivel, $f(a)$ é atualizada. O último nó avaliado é o nó $(0,0)$ com valor 0 . A solução ótima tem valor 900 e corresponde ao nó $(1,0)$, que é um nó intermediário.

No caso (ii) bidimensional em 2-estágios no método de duas fases de Gilmore e Gomory (1965) esta verificação é feita inicialmente na geração das faixas da mesma forma que em (i) e em um segundo estágio na geração do padrão. Neste caso, é necessário considerar o número de tipos de itens de todas as faixas, que compõem o padrão, o que é feito de maneira similar à geração das faixas.

Nos problemas bidimensionais em 2-estágios com restrição para o número máximo de tipos de itens no padrão, diferentemente do que ocorre no caso unidimensional, a geração dos padrões é com perda de generalidade. Para ilustrar isso, considere o seguinte exemplo: $L=W^{\prime}=50, l_{1} \times w_{1}=15 \times 20, l_{2} \times w_{2}=35 \times 20, l_{3} \times w_{3}=50 \times 30, v_{1}=2, v_{2}=8 \mathrm{e} v_{3}=100 \mathrm{e}$ seja $p \hat{i}=2$. As seguintes faixas são geradas no primeiro estágio:

Faixa 1: tem largura $l_{1}=l_{2}$ e pode conter itens do tipo le 2. Desta forma $a_{1}=(1,1,0)$ e $v_{1}=10$ Faixa 2: tem largura $l_{3}$ e pode conter itens do tipo 1,2 e 3 . Desta forma $a_{2}=(0,0,1)$ e $v_{2}=100$

O padrão ótimo encontrado no segundo estágio com $p \hat{i}=2$ é formado apenas pela faixa 2 com valor igual a 100 , pois a combinação das duas faixas resulta em um padrão infactível, dado que o número de tipos de itens das duas faixas é igual a 3 . Na realidade a solução ótima para $p \hat{i}=2$ nunca seria encontrada, visto que a mesma é formada pela combinação da faixa 2 e de uma faixa com apenas itens do tipo 1 (que não é gerada no primeiro estágio pois os itens 1 e 2 têm a mesma largura e combinar um item do tipo 1 com um item do tipo 2 é mais valioso do que colocar apenas itens do tipo 1), o que resultaria em um padrão $a=(3,0,1)$ com valor $v=106$.

No caso (iii) bidimensional não-estagiado as restrições com relação a $p \hat{i}$ e aos padrões proibidos são verificadas na obtenção do limitante inferior. Um novo tipo de item só é inserido, caso o número de tipos de itens no padrão scja menor ou igual a $p \hat{i}$ e o padrão resultante não seja igual a nenhum padrão proibido. Se o número de tipos de itens no padrão, que está sendo gerado for estritamente menor que $p \hat{i}$, então qualquer tipo de item poderá ser inserido no padrão, pois como só um tipo de item é inserido, o número total de tipos de itens 
no padrão não será superior a $p \hat{i}$. Caso contrário, isto é, se o número de tipos de itens no padrão for igual a $p \hat{i}$, então só poderá ser inserido um tipo de item, que já esteja presente no padrão.

A segunda condição, que deve ser verificada, é quanto aos padrões proibidos. Após a inserção de um tipo de item (respeitando a restrição de $p \hat{i}$ ), é verificado se o padrão resultante desta inserção não é igual a nenhum padrão proibido. Se for, o item que foi inserido é retirado e tenta-se inserir um novo tipo de item. Caso contrário, a inserção desse item é aceita.

A verificação dessas duas condições é uma extensão do cálculo do limitante inferior (2.19) para o problema com limitação para o número de tipos de itens no padrão (seção 2.3.3). O limitante inferior passa a ser calculado da seguinte forma:

$$
L^{0}(x, y)=\max _{i \in A_{(N)}}\left\{v_{t}\left\lfloor\frac{x}{l_{i}}\right\rfloor\left\lfloor\frac{y}{w_{i}}\right\rfloor \operatorname{tal} \mathrm{que}\left(\delta\left(a_{i}\right)+\sum_{k \in A /(N)} \delta\left(a_{k}\right)\right) \leq p \hat{i} \mathrm{e}\left(a_{1}, \mathrm{a}_{2}, \ldots, a_{m}\right) \notin P\right\}
$$

onde $\delta\left(a_{k}\right)=1$, se $a_{k}>0$ e $\delta\left(a_{k}\right)=0$ caso contrário, $\left(a_{1}, a_{2}, \ldots, a_{m}\right)$ é o padrão que está sendo gerado, e $P$ é o conjunto corrente de padrōes proibidos de serem gerados.

Como a rotina do cálculo do limitante inferior é executada muitas vezes na geração de um padrão, este procedimento, com a restrição quanto ao número máximo de tipos de itens no padrão e com a verificação dos padrões proibidos, toma-se mais lento do que o cálculo do limitante inferior no caso irrestrito (seção 2.3.3), onde essas condições não precisam ser avaliadas.

\section{RoTINA DE SEQÜENCIAMENTO}

Na rotina de seqüenciamento o problema de minimizar o número máximo de pilhas abertas (MOSP) é resolvido. Esta rotina utiliza como método de seqüenciamento a heurística 3 de Yuen (1995) (seção 3.6). Esta heurística foi escolhida, por ser simples e de fácil implementação $e$ por apresentar relativamente bons resultados com baixos tempos computacionais. Dado um padrão inicial, a heurística determina uma seqüência com o menor número máximo de pilhas abertas. Para que a seqüência obtida não seja dependente do padrão inicial, são geradas $n$ seqüências (onde $n$ é o número de padrões de corte obtido pela rotina de geração de padrões) e uma seqüência com o menor número máximo de pilhas abertas é selecionada. Se ocorrer empate, isto é, se diferentes seqüências resultarem no mesmo número máximo de pilhas abertas, diferentes regras podem ser utilizadas para escolha da seqüência. 
Considere o conjunto de padrões da tabela 3.1 (seção 3). As seqüências geradas, iniciando com cada um dos 5 padrões (considerando que os padrões iniciais das seqüências são os mesmos da permutação identidade: $1,2, \ldots, n$ ) estão descritas na tabela 4.2.

TABELA 4.2: Seqüências obtidas para os padrões de corte da tabela 3.1.

\begin{tabular}{c|c|c}
\hline Seqüências & Padrões & $\begin{array}{c}\text { Número de } \\
\text { pilhas abertas }\end{array}$ \\
\hline 1 & $1,3,5,2,4$ & $2,3,4,4,3$ \\
2 & $2,1,3,5,4$ & $\mathbf{4}, 3,3,3,3$ \\
3 & $3,1,5,2,4$, & $2,3, \mathbf{4}, \mathbf{4}, 3$ \\
4 & $4,1,3,5,2$ & $3,2,3,4,4$ \\
5 & $5,1,3,2,4$ & $2,2,3,4,3$ \\
\hline
\end{tabular}

O número máximo de pilhas abertas é 4 (veja em negrito na tabela 4.2), que é obtido por todas as seqüências e desta forma o menor número máximo de pilhas abertas é 4 . Observe que o menor número máximo de pilhas abertas não poderia ser menor que 4 visto que o padrão 2 possui quatro itens (tabela 3.1 ).

A regra denominada primeira escolhe a primeira seqüencia com o menor número máximo de pilhas abertas. Para o exemplo da tabela 3.1 a seqüência escolhida é a seqüência que inicia com o padrão $1(1,3,5,2,4)$.

A regra denominada aleatória escolhe aleatoriamente uma seqüência, dentre as que empataram (isto é, dentre as que resultaram no menor número máximo de pilhas abertas). Neste caso qualquer uma das cinco seqüências pode ser escolhida, visto que o número máximo de pilhas abertas obtidos por todas as cinco seqüências é 4 .

E a regra denominada mais_demora escolhe a seqüencia que mais demora, para atingir o menor número máximo de pilhas abcrtas. Observe na tabela 4.2 que as seqüências 4 e 5 abrem 4 pilhas com o corte do quarto padrão (que são os padrões 5 e 2, respectivamente), ou seja, essas duas seqüências são as que mais demoram a abrir 4 pilhas. Como aconteceu um empate, escolhe-se arbitrariamente a primeira delas.

\section{Rotina de AtualizaÇÃo da SoluÇão}

Esta rotina armazena a melhor solução encontrada do ponto de vista de perda, dado que o número máximo de pilhas abertas é menor ou igual a $p \hat{i}$, isto é, a solução dominante 
do ponto de vista de perda é armazenada. Por exemplo, considere $p \hat{i}=5$ e duas soluções A e B, com perdas iguais a $2 \%$ e $4 \%$, respectivamente, e com números máximos de pilhas abertas iguais a 5 e 3 , respectivamente. A solução armazenada neste caso seria a solução $\mathbf{A}$. Também armazena a solução de menor número máximo de pilhas abertas para pe $=\underline{p e}$.

\section{Rotina de EliminaÇĀo de PAdRões}

Esta rotina determina um ou mais padrões para serem eliminados, com o propósito de diminuir o número máximo de pilhas abertas. Diferentes regras podem ser utilizadas na escolha do padrão (ou padrões) a ser eliminado. Considere novamente o conjunto de padrões da tabela 3.1 e suponha que a regra utilizada para escolha da seqüência seja a regra primeira. Desta forma, a seqüência 1 , com os padrões $1,3,5,2,4$ e número de pilhas abertas igual a 2, 3, 4, 4, 3 seria escolhida, conforme tabcla 4.2. Esta seqüência será então utilizada, para exemplificar as diferentes regras para escolha dos padrões a serem eliminados.

A regra primeiro escolhe o primeiro padrão dentre todos os padrões que, quando seqüenciados, abrem um número de pilhas igual ao número máximo de pilhas abertas obtido pela seqüência escolhida, neste caso 4. Utilizando esta regra, o padrão 5 seria o escolhido, dado que é o primeiro padrão que, quando seqüenciado, abre 4 pilhas.

A regra aleatório_mp escolhe aleatoriamente um padrão dentre aqueles que, quando seqüenciados, abrem um número de pilhas igual ao número máximo de pilhas abertas. Neste caso, um sorteio aleatório seria feito entre os padrões 2 e 5 , visto que ambos, quando seqüenciados, abrem 4 pilhas.

A regra aleatório escolhe aleatoriamente um padrão. Com isso qualquer um dos cinco padrões poderia ser aleatoriamente escolhido.

A regra menor perda escolhe, dentre todos os padrões que, quando seqüenciados. abrem um número de pilhas igual ao número máximo de pilhas abertas, aquele padrão que, quando substituído pelos respectivos padrões homogêneos (um padrão homogêneo é aquele com apenas um único tipo de item), fornece a menor perda. Utilizando esta regra, os padrões 2 e 5 seriam avaliados. O padrão 2 é substituído por quatro padrões homogêneos, um padrão com apenas itens do tipo 1 , um padrão com apenas itens do tipo 2, um com apenas itens do tipo 5 e outro com itens do tipo 6. O padrão 5 é substituído por dois padrões homogêneos, um com itens do tipo 3 e outro com itens do tipo 7. Suponha que a perda do padrão 2 seja de 90 
unidades (por exemplo de comprimento) e como o número de repetições deste padrão é igual a 2 (veja tabela 3.1), isto equivale a 180 unidades. Por outro lado, seja a perda do padrão 5 igual a 120 unidades, o que equivale a 120 unidades, pois o número de repetições deste padrão é igual a 1. Considere que a perda dos padrões homogêneos do padrão 2, ponderada pelos respectivos números de repetiçôes de cada padrão homogêneo, seja igual a 240 e que para o padrão 5 esta perda seja igual a 250 . Neste caso o padrão 2 seria escolhido para ser eliminado.

\section{ROTINA de FACTIBILIZAÇÃo DA SOLUÇÃO}

Após a eliminação de um padrão, a solução deixa de ser factível do ponto de vista do problema de geração de padrões, ou seja, as restrições de demanda deixam de ser atendidas. A rotina de factibilização determina uma solução factível do ponto de vista do problema de geração, incluindo um padrão homogêneo para cada tipo de item, que havia no padrão que foi eliminado. Estes padrões são inseridos, a partir da posição do padrão, que foi eliminado. Com a inclusão dos padrões homogêneos um novo conjunto de padrões de corte é obtido. Considere o conjunto de padrões de corte da tabela 3.1 e suponha que o padrão 2 tenha sido eliminado. O novo conjunto de padrões de corte obtido após a factibilização da solução está listado na tabela 4.3, onde o número 1 na célula indica que o item está presente no padrão.

TABELA 4.3: Conjunto de padrões de corte obtido após a eliminação do padrão 2.

\begin{tabular}{c|cccccccc}
\hline & \multicolumn{7}{|c}{ Item } \\
\cline { 2 - 8 } Padrão & $\mathbf{1}$ & $\mathbf{2}$ & $\mathbf{3}$ & $\mathbf{4}$ & $\mathbf{5}$ & $\mathbf{6}$ & $\mathbf{7}$ & $\mathbf{8}$ \\
\hline $\mathbf{1}$ & & & 1 & & 1 & & & \\
$\mathbf{2}$ & 1 & & & & & & & \\
$\mathbf{3}$ & & 1 & & & & & & \\
$\mathbf{4}$ & & & & & 1 & & & \\
$\mathbf{5}$ & & & & & & 1 & & \\
$\mathbf{6}$ & 1 & & 1 & & & & & \\
$\mathbf{7}$ & & & & 1 & 1 & & & 1 \\
$\mathbf{8}$ & & & 1 & & & & 1 & \\
\hline
\end{tabular}

\section{Rotina de InClusão de Padrões Proibidos}

Esta rotina escolhe um ou mais padrões de corte - que são nomeados proibidos - os quais não poderão ser gerados nas próximas iterações pela rotina de geração de padrões. $\mathrm{O}$ 
propósito desta proibição é obter um novo conjunto de padrões de corte com uma solução que satisfaça pí. Todo padrão proibido é obtido pela rotina de eliminação de padrões quando a rotina de seqüenciamento é executada após a rotina de geração de padrões. A proibição pode ser feita para um ou mais padrōes e os mesmos podem ficar proibidos por uma ou mais iterações.

Três opções são utilizadas: escolher um padrão para ficar proibido por uma iteração $(L C=1)$; escolher um padrão para ficar proibido por $x$ iterações $(L C=x)$; ou escolher um padrão para ficar proibido para sempre $(L C=\propto)$. A estrutura de dados utilizada para implementar a proibição dos padrões é uma lista circular.

Considere, por exemplo, o conjunto de padrões da tabela 3.1 (seção 3) e suponha que o padrão 3 foi escolhido como proibido na primeira iteração. Se $L C^{\prime}=1$, então ele não poderá ser gerado na segunda iteração, mas, a partir da terceira iteração, já estará liberado. No caso de $L C=x$, considere por exemplo $x=5$. O padrão 3 neste caso ficará proibido pclas iterações 2 a 6 e na iteração 7 estará liberado. No caso de $L C=\propto$ o padrão 3 ficará proibido para sempre, isto é, nunca mais poderá ser gerado.

\subsubsection{Abordagem 1a}

Considere novamente o diagrama de blocos da figura 4.3, descrevendo a Abordagem 1a. Inicialmente é preciso definir o valor de pi , o número máximo de iterações (max_iter), e quais regras serão utilizadas para escolha da seqüência (esc_seq), do padrão que será nomeado proibido (esc padrão) e por quantas iterações o padrão ficará proibido $(L C)$. O problema de geração é, então, resolvido pela rotina de geração de padrões sem nenhuma restrição adicional (a não ser as do problema de corte). A solução obtida, pe = pe (padrões de corte com perda mínima), é ótima do ponto de vista de perda. O conjunto de padrões obtido é então seqüenciado na rotina de seqüenciamento e uma seqüência é selecionada, usando a regra definida por esc_seq.

Se $p i \leq p \hat{i}$ e $p e=\underline{p e}$ o procedimento termina. Senão, se $p i \leq p \hat{i}$, pe $>\underline{p e}$ e o número da iteração atual for menor ou igual a max_iter, um padrão é nomeado proibido na rotina de inclusão de padrões proibidos, utilizando a regra definida por esc padrão, e o problema de geração é novamente resolvido na rotina de geração de padrões com esta 
nova restrição. Se $p i \leq p \hat{i}$ e $p e \leq p e_{i}(\operatorname{com} p e>\underline{p e})$ onde $p e_{i}$ é a solução factível de menor perda disponivel (solução incumbente), então a solução é atualizada na rotina de atualização da solução. O procedimento termina, quando max_iter for atingido, ou se uma solução factível $(p i \leq p \hat{i})$ com $p e=\underline{p e}$ for encontrada.

No final do algoritmo a melhor solução do ponto de vista de perda, com $p i \leq p \hat{i}$, é obtida, ou então uma solução infactivel de perda mínima com $p i>p \hat{i}$. Este algoritmo pode ser utilizado para gerar soluções aproximadas da curva de eficiência, variando-se os valores de $p \hat{i}$ em cada execução do mesmo.

\subsubsection{Abordagem 1b}

Na versão $l b$ alguns parâmetros também precisam ser definidos a priori, tais como: pî , max_iter, esc_seq, esc_padrão, $L C$, conforme versão $l a$ e qual será a politica utilizada para factibilizar a solução. Esta versão é uma extensão da versão $l a$, como sc pode observar no diagrama de blocos da figura 4.4. Ambas diferem entre si no tipo de soluções encontradas: a versão $l b$ sempre encontra uma solução factível enquanto a versão $l a$, não necessariamente.

A estratégia utilizada para factibilizar a solução consiste em alterar o conjunto de padrões gerado na rotina de geração de padrões, o que é realizado através de duas rotinas: rotina de eliminação de padrões e rotina de factibilização da solução (figura 4.4). A primeira delas elimina um padrão de acordo com a politica estabelecida (esc_padrão). Quando isso é feito, a solução não mais satisfaz as restrições do problema de geração, isto é, a demanda de alguns itens deixa de ser totalmente atendida. Na segunda rotina são inseridos tantos padrões homogêneos, quantos forem os tipos de itens que havia no padrão que foi eliminado. A motivação para se usar padrões homogêneos é que, além da simplicidade, suas inclusões não tendem a aumentar o número atual de pilhas abertas.

Como se pode observar na figura 4.4 , a rotina de seqüienciamento é realizada após a rotina de geração de padrões e também após a rotina de factibilização da solução. Um padrão é nomeado proibido, quando a rotina de seqüenciamento é realizada após a rotina de geração de padrões, ou seja, nomeia-se um padrão proibido, a partir do conjunto de padrões de corte obtido pela resolução do problema de geração, e não a partir do conjunto de padrões obtido pelas rotinas de eliminação e factibilização da solução. Suponha que o problema de 
geração tenha sido resolvido e o conjunto de padrões seqüenciado. Além disso, suponha que

$p i>p \hat{i}$. Neste caso, um padrão é eliminado (na rotina de eliminação de padrões). Antes de este padrão ser de fato eliminado, o mesmo é nomeado proibido. A solução é factibilizada, e se novamente $p i>p \hat{i}$, outro padrão é eliminado, mas não é nomeado proibido.

Nesta versão da Abordagem 1, dentre um conjunto com $n p$ padrões um deles é escolhido para ser eliminado. Se a factibilização da solução, que resulta em $n p^{\prime} \operatorname{com} n p^{\prime} \geq n p$, não resultar em $p i \leq p \hat{i}$, então outro padrão é escolhido para ser eliminado, a partir de n', e assim sucessivamente até que $p i \leq p \hat{i}$. Isto pode fazer com que a perda aumente consideravelmente, visto que pode ocorrer a inserção sucessiva de padrões homogêneos que, se por um lado não tendem a aumentar o número máximo de pilhas abertas, em geral aumentam a perda.

Com exceção do ciclo entre as rotinas de sequilenciamento, eliminação de padrões e factibilização da solução, as versões $l a$ e $l b$ são iguais. A versão $l b$ também pode ser utilizada, para gerar pontos da curva de eficiência da mesma maneira que a versão $1 a$.

\subsubsection{Abordagem 1c}

Na terceira variação da Abordagem $l$ (versão $l c$ ) os mesmos parâmetros utilizados na versão $I b$ também precisam ser definidos a priori. Esta versão consiste em tentar factibilizar a solução, ou seja, encontrar um conjunto de padrões tal que $p i \leq p \hat{i}$, sem deteriorar demais a perda gerada pelo corte dos padrões. Para isso, a cada conjunto de padrões de corte gerado (seja $n p$ o número de padrões de corte) na rotina de geração de padrões, procura-se, dentre todos eles, um padrão para ser eliminado pela rotina de eliminação de padrões, cuja substituição pelos respectivos homogêneos (rotina de factibilização da solução) satisfaça a tolerância do número máximo de pilhas (subciclo no diagrama de blocos da figura 4.5 entre as rotinas de eliminação de padrões, factibilização da solução e seqüenciamento). Cada padrão é avaliado, e se sua eliminação e a posterior factibilização da solução não satisfizerem o número máximo de pilhas tolerado, o padrão que foi avaliado é novamente inserido no conjunto de padrões. Os padrões são avaliados seqüencialmente até que $p i \leq p \hat{i}$ ou até que todos os $n p$ padrões tenham sido testados. Se a avaliação de todos não satisfizer o número máximo de pilhas tolerado; então, um padrão é eliminado, utilizando a regra definida por 
esc_padrão e após a factibilização da soluçâo o novo conjunto de padrões obtido, $n p^{\prime}$, com $n p^{\prime} \geq n p$, é então utilizado como entrada para o subciclo, que avalia cada padrão, para tentar factibilizar a solução com a remoção de apenas um deles. Este procedimento termina, quando uma solução com $p i \leq p \hat{i}$ for encontrada. O objetivo é conseguir factibilizar a solução com a remoção do menor número de padrões possível.

Novamente considere o conjunto de padrões da tabela 3.1 e seja $p \hat{i}=3$. Considere a seqüiencia $1,3,5,2,4$. Conforme visto na tabela 4.2, o número máximo de pilhas abertas por esta seqüência é 4. Cada um dos cinco padrões é investigado, para ver se a eliminação de algum deles factibiliza a solução. Primeiro o padrão 1 é avaliado: o mesmo é eliminado, a solução factibilizada e o novo conjunto de padrões seqüenciado; se $p i \leq 3$, então a solução é atualizada na rotina de atualização da solução. Caso contrário, isto é, se pi $>3$, então o padrão 1 é novamente inserido no conjunto de padrões e os próximos padrões na seqüência 3 , 5,2 e 4 são avaliados até que pi $\leq 3$ ou até que todos os cinco padrões tenham sido testados. Se a eliminação e factibilização de algum deles resultar $\mathrm{em} p i \leq 3$, então este subciclo termina; caso contrário, isto é, se todos os padrões tiverem sido avaliados e a eliminação (de algum deles) e posterior factibilização da solução não resultarem em $p i \leq 3$, então um padrão é escolhido, para ser eliminado de acordo com a regra definida por esc_padrão. A solução é factibilizada e novamente é testado se $p i \leq 3$. Para este novo conjunto de padrões, com algum dos padrões da seqüência 1, 3, 5, 2, 4 substituído pelos respectivos homogêneos, avalia-se novamente a eliminação de cada um deles, até que $p i \leq 3$, ou até que todos os padrões tenham sido testados. Este subciclo continua até que $p i \leq 3$. Observe que este o mesmo é finito, pois no limite obtém-se os padrões homogêneos.

Com exceção do subciclo mais elaborado entre as rotinas de seqüenciamento, eliminação de padrões e factibilização da solução, as versões $I b$ e $I c$ são iguais. A versão $I c$ também pode ser utilizada para gerar pontos da curva de eficiência da mesma maneira que a versão $1 b$.

\subsection{Abordagem 2}

A idéia para a Abordagem 2 é inspirada em alguns processos industriais de corte, encontrados na prática, em que os problemas de geração e seqüenciamento de padrões de 
corte são resolvidos de forma simultânea. Nestas situações tais problemas não são resolvidos independentemente (ou seja, resolve-se o problema de geração, e a partir da solução obtida. resolve-se o problema de seqüenciamento), pois desta forma pode ser que não se encontre nenhuma solıção factível $(p i \leq p \hat{i})$ para uma perda, que esteja dentro de limites especificados. Na resolução do problema de geração de padrões de alguma maneira critérios de restrições do problema de seqüenciamento também precisam ser considerados. Na figura 4.6 ilustra-se o diagrama de blocos desta abordagem. Observe que esta figura é uma extensão da figura 2.4 (seção 2.4), onde em cada iteração uma heurística construtiva gulosa é utilizada para gerar os padrões de corte.

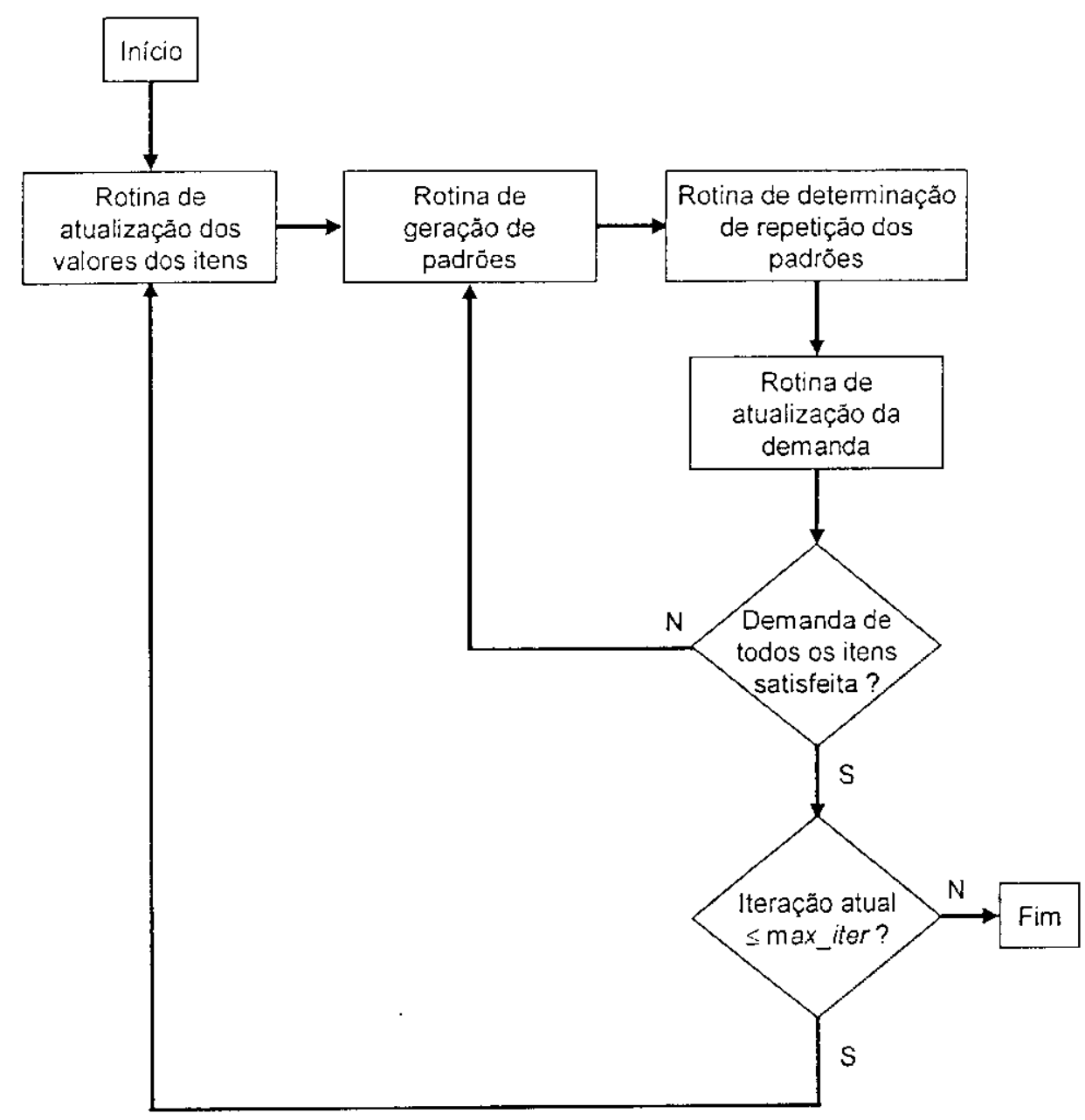

FIGURA 4.6: Esquema ilustrativo da Abordagem 2.

Através de um procedimento iterativo (figura 4.6), o objetivo do problema de corte é otimizado, considerando o número máximo de pilhas abertas como uma restrição. Em cada iteração uma heurística construtiva gulosa é utilizada para gerar os padrões de corte, considerando a restrição do número máximo de pilhas que podem ser abertas. Este procedimento é repetido por um determinado número de vezes variando-se os valores 
relativos dos itens. Assim como na Abordagem 1, primeiramente cada bloco do diagrama da figura 4.6 será descrito, para depois apresentar a descrição da abordagem.

\section{Rotina de ATUaLizaÇão dos VaLORES dos ITENS}

Conforme mencionado na seção 2.4, uma das dificuldades, quando se utiliza heurísticas construtivas gulosas com objetivo de minimizar a perda, está na concentração de itens menos favoráveis nos padrões finais, o que pode resultar em padrões com perdas elevadas. Logo, uma estratégia é alterar os valores dos itens (em rclação aos seus comprimentos ou áreas) com o objetivo de tentar produzir soluções gerais melhores, o que é explorado a seguir.

Seja $B=\left(a_{1}, a_{2}, \ldots, a_{m}\right)$ onde cada $a_{j}=\left(a_{1 j}, a_{2 j}, \ldots, a_{m j}\right)$ corresponde a um padrão de corte com custo $c_{j}$. A idéia aqui é encontrar valores de utilidade $\pi_{i}$ para os itens $i=1,2, \ldots, m$. que minimizem o desvio entre $c_{j}$ e $\sum_{i=1}^{m} \pi_{j} a_{i}$, numa tentativa heurística de imitar o método simplex, para o qual $B$ é uma base e o sistema $\pi^{\mathrm{T}} \boldsymbol{B}=\boldsymbol{c}$ tem solução única, produzindo os multiplicadores simplex. Aplicando-se o critério de mínimos quadrados, isto é, minimizando o desvio quadrático entre $c$ e $\pi^{\mathrm{T}} \boldsymbol{B}$, tem-se:

$$
\begin{aligned}
\mathrm{Q}(\pi) & =\left(c-\pi^{\mathrm{T}} \boldsymbol{B}\right) \cdot\left(\boldsymbol{c}-\pi^{\mathrm{T}} \boldsymbol{B}\right)^{\mathrm{T}} \\
& =\left(c-\pi^{\mathrm{T}} \boldsymbol{B}\right) \cdot\left(c^{\mathrm{T}}-\boldsymbol{B}^{\mathrm{T}} \pi\right) \\
& =c c^{\mathrm{T}}-\boldsymbol{c} \boldsymbol{B}^{\mathrm{T}} \pi-\pi^{\mathrm{T}} \boldsymbol{B} \boldsymbol{c}^{\mathrm{T}}+\pi^{\mathrm{T}} \boldsymbol{B} \boldsymbol{B}^{\mathrm{T}} \pi \\
& =c c^{\mathrm{T}}-2 \pi^{\mathrm{T}} \boldsymbol{B} c^{\mathrm{T}}+\pi^{\mathrm{T}} \boldsymbol{B} \boldsymbol{B}^{\mathrm{T}} \pi .
\end{aligned}
$$

Derivando-se em relação a $\pi$ e igualando-se a zero, obtém-se:

$$
\nabla \mathrm{Q}(\pi)=0-2 B c^{\mathrm{T}}+2 B B^{\mathrm{T}} \pi=0
$$

Portanto, $\pi$ é determinado pelo sistema linear:

$$
B B^{T} \pi=B c^{T}
$$

O sistema acima fornece a solução de $\nabla Q(\pi)=0$, o qual sempre tem solução, pois Q é uma função quadrática e convexa $\left(\nabla^{2} \mathrm{Q}=2 \boldsymbol{B} \boldsymbol{B}^{\mathrm{r}}\right.$ é definida semi-positiva, para toda matriz $\boldsymbol{B}$ ), apesar do sistema $\pi^{\mathrm{T}} \boldsymbol{B}=\boldsymbol{c}$ não ter solução, em geral, pois $\boldsymbol{B}$ não é uma base. Por simplicidade, considera-se que todo padrão tem custo unitário, isto é, $c=(1,1, \ldots, 1)$. 
Logo, em cada iteração do procedimento da figura 4.6, resolve-se o sistema linear $\left({ }^{*}\right)$, para atualizar os valores dos itens $i=1,2, \ldots, m$. Na primeira iteração todos os itens tem valor igual ao comprimento, $v_{i}=l_{i}$ (unidimensional), ou igual a área, $v_{i}=l_{i} \times w_{i}$ (bidimensional). Nas iterações seguintes esses valores são atualizados para $v_{i} \leftarrow\left(1+\pi_{\mathrm{i}}\right) v_{t}$, ou seja, o valor anterior acrescido (ou decrescido) do valor de utilidade $\pi_{l}$.

Cabe observar que o sistema $\left({ }^{*}\right)$ pode ser indeterminado (infinitas soluções), o que é identificado após aplicar o método de eliminação de Gauss e uma ou mais linhas serem nulas e, neste caso, as variáveis $\left(\pi_{\mathrm{i}}\right)$ livres, isto é, de pivôs nulos, são fixadas em zero.

\section{Rotina de GeraÇão de PadRÃo}

Esta rotina resolve um problema de corte $\bullet / \mathrm{B} / \mathrm{O} / \bullet$, por meio de algum algoritmo no caso unidimensional, neste trabalho utilizando (i), o algoritmo exato de busca em profundidade primeiro de Gilmore e Gomory (1963) (seção 2.3.1), no caso bidimensional guilhotinado em 2-estágios utilizando (ii) o método em duas fases de Gilmore e Gomory (1965), (seção 2.3.2) e no caso bidimensional não-estagiado utilizando (iii) a abordagem em grafo e/ou (seção 2.3.3). Cada vez que esta rotina é executada um padrão de corte é gerado. $\mathrm{O}$ primeiro padrão gerado será o primeiro a ser seqüenciado; o segundo padrão será o segundo a ser seqüenciado, e assim succssivamente. O melhor padrão de corte, do ponto de vista de perda, é obtido em cada iteração.

Uma restrição adicional é imposta, a qual limita o número máximo de tipos de itens permitidos no padrão, igual a $p \hat{i}$, dado que padrões com mais que $p \hat{i}$ itens são infactíveis. Além desta restrição, o número máximo de pilhas abertas com o seqüenciamento dos padrões também deve ser menor ou igual a $p \hat{i}$.

Para satisfazer estas duas restrições, assim como na Abordagem 1, foram feitas adaptações nos algoritmos citados ( $i$, ii e $i i i)$. No caso (i) uma modificação foi feita nos passos 3 e 5 do algoritmo unidimensional de Gilmore e Gomory (seção 2.3.1). Por conveniência, considere novamente a descrição do passo 3 deste algoritmo:

Passo 3: Dado $\left(a_{l}, a_{2}, \ldots, a_{m}\right)$ verifique se $\sum_{t=1}^{m} v_{l} a_{l}>f(a)$. Neste caso guarde este padrão e atualize $f(a)$. 
Considere um vetor $P i A b$ que indica quais pilhas de itens estão abertas quando um novo padrão vai ser gerado. $P i A b=\left(p i_{1}, p i_{2}, \Lambda, p i_{m}\right)$ onde $p i_{i}= \begin{cases}1, & \text { se a pilha associada ao item i está aberta } \\ 0, & \text { caso contrário }\end{cases}$

A modificação do passo 3 é feita da seguinte forma:

Passo 3': Dado $a=\left(a_{1}, a_{2}, \ldots, a_{m}\right)$ veritique se $\sum_{i=1}^{m} \delta\left(a_{i}\right)+\sum_{i=1}^{m} p i_{1} \leq p \hat{i}$ e $\sum_{i=1}^{m} v_{1} a_{i}>f(a)$. Neste caso guarde este padrão $a$ e atualize $f(a)$.

Neste caso, para atualização da solução incumbente, é verificado se o número de tipos de itens do padrão, que está sendo gerado, mais o número de tipos de itens associados às pilhas, que estão abertas, é menor ou igual a pî́. Se essa condição for verdadeira e se o padrão atual for mais valioso que a solução incumbente, então a solução é atualizada.

Para a adaptação do passo 5 do algoritmo de Gilmore e Gomory considere sua descrição abaixo:

Passo 5: Faça $a_{s} \leftarrow a_{s}-1$. Se $\left(L-\sum_{i=1}^{s} l a_{i}\right) v_{i+1}>v_{s} l_{s+1}$, então vá para o passo 7 . Caso contrário vá para o passo 6 .

O passo 5 modificado passa a ser definido por:

Passo 5': Faça $a_{s} \leftarrow a_{s}-1$. Se $\sum_{i=1}^{m} v_{i} a_{i}>f(a), \sum_{i=1}^{\prime \prime} \delta\left(a_{i}\right)+\sum_{i=1}^{m} p i_{t} \leq p \hat{i}$, então guarde o padrão $\left(a_{l}, a_{2}, \ldots, a_{s}-1, \ldots, a_{m}\right)$ e atualize $f(a)$. Se $\left(L-\sum_{i=1}^{*} l_{l} a_{1}\right) v_{s+1}>v_{s} l_{s+1}$, então vá para o passo 7. Caso contrário vá para o passo 6.

No passo 5 a cada eliminação de um item no padrão atual é verificado, se o mesmo é mais valioso que a solução incumbente e se o número de tipos de itens no padrão que está sendo gerado, mais o número de tipos de itens associados às pilhas, que estão abertas, é menor ou igual a $p \hat{i}$ para atualização da solução incumbente. A verificação de alocação de itens do tipo $s+1$ é feita como no passo 5 original.

No caso (ii) bidimensional guilhotinado em 2-estágios, a verificação quanto ao número máximo de tipos de itens abertos é feita inicialmente na geração das faixas, da mesma forma que em (i) e em um segundo estágio na geração do padrão, o que é feito de maneira 
similar à geração das faixas, mas, deve-se considerar o número de tipos de itens de todas as faixas, que compõem o padrão que está sendo gerado.

No caso (iii) bidimensional não-estagiado a restrição com relação ao número máximo de tipos de itens, que podem ser abertos com o seqüenciamento dos padrões, é verificada no cálculo do limitante inferior. Um novo tipo de item só é inserido, caso o número de tipos de itens no padrão que está sendo gerado mais os tipos de itens associados às pilhas de itens abertas, sejam menores ou igual a $p \hat{i}$. Caso contrário, ou seja, se o número total de tipos de itens for igual a $p \hat{i}$ então só poderá ser inserido um tipo de item que já esteja presente no padrão ou um tipo de item, cuja pilha associada esteja aberta. Com essa modifícação o cálculo do limitante inferior (2.19), definido na seção 2.3.3, passa a ser dado por:

$$
\left.L^{0}(x, y)=\max _{i \in M(N)}\left\{v_{i}\left\lfloor\frac{x}{l_{l}}\right\rfloor \frac{y}{w_{i}}\right\rfloor \text { tal que }\left(\delta\left(a_{i}\right)+\sum_{k \in M\left(N^{\prime}\right)} \delta\left(a_{k}\right)+\sum_{i=1}^{m} p i_{i}\right) \leq p \hat{i}\right\}
$$

onde $\delta\left(a_{k}\right)=1$, se $a_{k}>0$, e 0 caso contrário e $\left(p i_{1}, p i_{2}, \ldots, p i_{m}\right)$ para $i=1,2, \ldots, m$ é o vetor que contabiliza as pilhas abertas.

Por exemplo, considere 10 tipos de itens e $p \hat{i}$ igual a 3 . Inicialmente o vetor PiAb $=(0,0,0,0,0,0,0,0,0,0)$ visto que nenhuma pilha foi aberta, pois nenhum padrão foi gerado. Suponha que o primeiro padrão gerado contenha 3 tipos de itens diferentes, diga-se os itens 1, 7 e 9. Com o corte deste padrão suponha que a demanda do item 7 tenha sido satisfeita, ou seja, a pilha associada a este item foi fechada. O vetor PiAb neste caso passa a ser dado por $(1,0,0,0,0,0,0,0,1,0)$. O que indica que as pilhas associadas aos itens 1 e 9 estão abertas. Na geração do segundo padrão apenas um tipo de item, além dos itens 1 e 9 , poderá ser incluído, pois os itens 1 e 9 estão com suas pilhas abertas.

\section{Rotiva de Deterninação de Repetição do Padrāo}

Esta rotina determina quantas vezes cada padrão $j$ gerado na rotina de geração de padrões deve ser repetido $\left(x_{j}\right)$. Este número é o mínimo entre as demandas $b_{i}$ dos diferentes tipos de itens $i$, que fazem parte do padrão $j$, dividido pelo número de vezes $a_{i j}$ que os itens $i$ aparecem no padrão $j$, ou seja, $\min _{i \in a}\left\lceil\frac{b_{i}}{a_{i j}}\right\rceil$, onde $\lceil z\rceil$ é o menor inteiro maior ou igual a $z$. 
Considere um exemplo unidimensional com $L=100$ e $m=3$, com respectivos comprimentos e demandas dos itens: $l_{1}=15, l_{2}=20$ e $l_{3}=50$ e $b_{1}=1200, b_{2}=545$ e $b_{3}=300$. Suponha que o padrão $(0,2,1)$ tenha sido gerado. Este padrão scrá repetido 273 vezes, pois $\min \left[\frac{545}{2} ; \frac{300}{1}\right\rceil=\min \lceil 272.5 ; 300\rceil=273$.

\section{Rotina de AtualizaÇÃo da Demanda}

Esta rotina atualiza a demanda dos itens gerados com o corte do padrão previamente obtido, ou seja, $b_{i} \leftarrow b_{i}-a_{i j} x_{j}$, onde $x_{j}$ é o número de vezes que o padrão $j$ é repetido, definido na rotina de determinação de repetição do padrão.

\section{Rotina de Atual.izaçāo da SoluÇão}

Esta rotina armazena a melhor solução encontrada do ponto de vista de perda.

Considere novamente o diagrama da figura 4.6 para descrição da Abordagem 2. Inicialmente é preciso definir o número máximo de iterações, max_iter. Os valores dos itens são então atualizados com seus comprimentos ou áreas (respectivamente para o caso unidimensional e bidimensional). Na rotina de geração de padrão o melhor padrão do ponto de vista de perda é gerado, respeitando a limitação do número máximo de pilhas que pode ser aberto $p \hat{i}$. Para tanto é preciso considerar as pilhas de itens, que já estão abertas, para saber quantos e quais tipos de itens poderão fazer parte do padrão, que está sendo gerado. Após a geração do padrão, a rotina de determinação de repetição do padrão avalia a demanda atual e determina quantas vezes o mesmo poderá ser repetido. A rotina de atualização da demanda atualiza a demanda dos itens, que fazem parte do padrão previamente gerado. Neste passo, pelo menos um item terá sua demanda exaurida. Todos os itens, que tiverem sua demanda atendida são eliminados, a fim de que não sejam incluídos em nenhum outro padrão. Se a demanda de todos os itens ainda não tiver sido totalmente atendida, um novo padrão é gerado na rotina de geração de padrão. Esta sub-iteração continua até que a demanda de todos os itens tenha sido atendida. 
$\mathrm{Na}$ rotina de atualização dos valores dos itens os mesmos são atualizados e a subiteração interna, que consiste na geração dos padrões de corte através da heurística construtiva gulosa, é novamente executada. A cada novo conjunto de padrões gerado é avaliado se a perda obtida é menor que perda da solução incumbente para atualização da solução. $\mathrm{O}$ procedimento termina, quando o número máximo de iterações ( $m a x_{-}$iter) estabelecido tiver sido atingido. No final do algoritmo tem-se o conjunto de padrões de corte com a menor perda obtida e conseqüentemente uma seqüência para o corte dos mesmos, visto que a seqüiência de corte dos padrões é determinada na geração dos mesmos.

Conforme dito na seção 2.4, esta abordagem é mais flexível que a Abordagem 1 do ponto de vista do escopo de aplicação, pois também pode tratar problemas de corte, contendo itens com demandas pequenas. Utilizando esta abordagem para diferentes valores de $p \hat{i}$ também é possivel gerar soluções aproximadas para a curva de eficiência.

\subsection{Abordagem 3}

$\mathrm{Na}$ Abordagem 3 os problemas de geração e seqüenciamento de padrões são resolvidos, utilizando o método simplex com um procedimento de geração de colunas. A restrição do número máximo de pilhas abertas, $p \hat{i}$, é considerada durante a geração de cada coluna através da heurística 3 de Yuen (1995).

Diferentemente da Abordagem 1, todas as soluções obtidas pelo método simplex são factíveis, isto é, todo conjunto de padrões de corte gerado sempre satisfaz o número máximo de pilhas tolerado, $p \hat{i}$, quando seqüenciado. Além disto, no procedimento de geração de colunas, só são avaliadas as colunas, que possuem custo relativo negativo, ou seja, que, quando inseridas na base, melhorarão o valor da função objetivo. Para cada coluna com custo relativo negativo é avaliado se a entrada da mesma na base (e conseqüentemente a saída de uma outra coluna) resultará em $p i \leq p \hat{i}$, ou seja, toda coluna gerada pelo procedimento de geração de colunas resultará na melhora do valor da função objetivo e em $p i \leq p \hat{i}$.

Conforme a seção 2.3 do capítulo 2 , o método simplex com o procedimento de geração de colunas de Gilmore e Gomory pode ser resumidamente descrito como segue: 
PASSo 1: Dada uma base $B=\left[a^{(1)}, \ldots, a^{(m)}\right]$ (colunas de (2.4)-(2.6)), determine $\pi=c_{B} \cdot \boldsymbol{B}^{-1}, \mathrm{o}$ vetor multiplicador simplex.

PAsso 2: Resolva min $c$ - $\pi l$, sujeito a: $a=\left(a_{1}, \ldots, a_{m}\right)$ corresponda a um padrão factível ( $c$ é a perda da coluna $a$ )

PASSo 3: Se $c-\pi a \geq 0$ então a base $B$ é ótima, senão a coluna $a$ entra na base (uma coluna básica é escolhida para sair da base). Retorne ao passo 1 com a nova base $B$.

A Abordagem 3 consiste em alterar os passos 2 e 3 da seguinte forma:

PAsso 2': Sejam $a^{(1)}, a^{(2)}, \ldots$ a melhor solução, segunda melhor solução, etc, no subproblema min $c-\pi a$ do passo 2 (note que o algoritmo anterior considera apenas $a^{(1)}$ ). Denote por $c^{(1)}, c^{(2)}, \ldots$ as perda das colunas $\boldsymbol{a}^{(1)}, \boldsymbol{a}^{(2)}, \ldots$ respectivamente.

Passo 3': Se $c^{(1)}-\pi a^{(1)} \geq 0$, então pare com uma solução factível. Senão seja $a^{r(s)}$ a coluna a sair da base caso a coluna $a^{(s)}$ entre na base. Encontre o primeiro padrão $s$ tal que:

i) $\quad c^{(s)}-\pi a^{(s)}<0$ (custo relativo negativo, portanto a perda diminui)

ii) o conjunto $\left\{a^{(1)}, \ldots, a^{(s)}, \ldots, a^{(m)}\right\}$ (a coluna $a^{(s)}$ substitui a coluna $a^{()^{(s)}}$ ) abre um número máximo de pilhas menor ou igual a $p \hat{i}$ (estabelecido a priori).

Se não existe tal padrão, pare com uma solução factível; caso contrário, volte para o passo 1 .

Para resolver o problema de geração de padrões de corte no caso unidimensional, o (i) algoritmo de busca em profundidade primeiro de Gilmore e Gomory (1963) (seção 2.3.1) é utilizado. No caso bidimensional são utilizados o (ii) método exato de Gilmore e Gomory (1965) (seção 2.3.2) e a (iii) abordagem em grafo e/ou (seção 2.3.3), respectivamente para o caso 2-estágios e não-estagiado. Modificações foram feitas nesses algoritmos, a fim de garantir que a restrição do problema de seqüenciamento seja verificada.

No caso (i), assim como nas Abordagens 1 e 2, modificações foram feitas nos passos 3 e 5 do algoritmo unidimensional de Gilmore e Gomory (seção 2.3.1). Por conveniência, o passo 3 deste algoritmo está descrito abaixo: 
Passo 3: Dado $\left(a_{l}, a_{2}, \ldots, a_{m}\right)$ verifique se $\sum_{i=1}^{m} v_{i} a_{t}>f(\boldsymbol{a})$. Neste caso guarde este padrão e atualize $f(a)$.

O passo 3 modificado passa a ser definido da seguinte forma:

Passo 3': Dado $\boldsymbol{a}^{(s)}=\left(a_{l}, a_{2}, \ldots, a_{m}\right)$ verifique se $\sum_{i=1}^{m} v_{1} a_{i}>f(\boldsymbol{a}), \quad \sum_{i-1}^{m} \delta\left(a_{i}\right) \leq p \hat{i}$, $c_{s}-\pi a_{s}<0$ e $p i \leq p \hat{i}$ para os padrões $\left\{a^{(1)}, \ldots, a^{(s)}, \ldots, a^{(m)}\right\}$. Neste caso guarde este padrão e atualize $f(a)$.

Com esta modificação no passo 3 , é verificado se o padrão gerado, coluna $a^{(s)}$, é mais valioso que a solução incumbente, se a restrição quanto ao número máximo de tipos de itens no padrão está sendo respeitada, se o custo relativo dessa coluna é negativo (ou seja, a entrada da coluna $a^{(s)}$ na base fará com que a perda diminua) e se o novo conjunto de padrões, obtido com a entrada da coluna $\boldsymbol{a}^{(s)}$ na base, é seqüenciável, ou seja, se o número máximo de tipos de itens obtido com o seqüenciamento desses padrões é menor ou igual a $p \hat{i}$. Caso todas essas condições sejam satisfeitas, então a solução é atualizada.

Com relação ao passo 5 do algoritmo de Gilmore e Gomory (1963) considere novamente sua descrição abaixo:

Passo 5: Faça $a_{s} \leftarrow a_{s}-1$. Se $\left(L-\sum_{i=1}^{s} l_{i} a_{i}\right) v_{s+1}>v_{s} l_{s+1}$, então vá para o passo 7. Caso contrário vá para o passo 6.

O passo 5 modificado passa a ser definido por:

Passo 5': Faça $a_{s} \leftarrow a_{s}-1$. Se $\sum_{i=1}^{m} v_{i} a_{i}>f(a), \sum_{i=1}^{m} \delta\left(a_{i}\right) \leq p \hat{i}, \quad c_{j}-\pi a,<0$ e pi $\leq p \hat{i}$ para os padrões $\left\{\boldsymbol{a}^{(1)}, \ldots, \boldsymbol{a}^{(s)}-1, \ldots, \boldsymbol{a}^{(m)}\right\}$, então guarde o padrão $\left(a_{1}, a_{2}, \ldots, a_{s}-1, \ldots, a_{m}\right)$ e atualize $f(a)$. Se $\left(L-\sum_{t=1}^{s} l_{i} a_{i}\right) v_{s+1}>v_{x} l_{s+1}$, então vá para o passo 7. Caso contrário vá para o passo 6.

No passo 5 modificado (passo 5') a cada eliminação de um item no padrão atual é verificado, se o mesmo é mais valioso que a solução incumbente, se a restrição quanto a $p \hat{i}$ é satisfeita, se o custo relativo do padrão é negativo e se o novo conjunto de padrões, obtido com a entrada da coluna $a^{(s)}$ na base (padrão avaliado com o elemento $a_{s}$ igual a $a_{s}-1$ ), é 
seqüenciável, ou seja, se o número máximo de tipos de itens obtido com o seqüenciamento desses padrões é menor ou igual a $p \hat{i}$. Caso todas essas condições sejam satisfeitas, então a solução é atualizada. Estas verificações são feitas, antes de verificar se compensa retirar um item tipo $s$ para colocar itens tipo $s+1, s+2, \ldots, m$.

No método em duas fases de Gilmore e Gomory (1965) para os problemas bidimensionais em 2-cstágios (ii) isto é feito no primeiro estágio para geração das faixas e também no segundo estágio para geração do padrão, da mesma forma que para a geração das faixas. No segundo estágio as faixas geradas no primeiro estágio não sofrem alterações.

$\mathrm{Na}$ (iii) abordagem em grafo e/ou, utilizada no caso bidimensional não-estagiado, isto é feito no cálculo do limitante inferior: a cada inserção de um novo tipo de item é avaliado se a restrição de seqüienciamento é satisfeita para atualização da solução incumbente. O limitante inferior (2.19), definido na seção 2.3.3, passa a ser definido por:

$$
\left.L^{0}(x, y)=\max _{i \in M(M)}\left\{v_{1}\left\lfloor\frac{x}{l_{i}}\right\rfloor \frac{y}{w_{1}}\right\rfloor \text { tal que }\left(\left(\delta\left(\mathrm{a}_{t}\right)+\sum_{k \in M / N)} \delta\left(\mathrm{a}_{k}\right)\right) \leq p \hat{i} \text { e } p i \leq p \hat{i}\right)\right\}
$$

onde $\delta\left(a_{k}\right)$ foi definido anteriormente e pié o menor número máximo de pilhas abertas com o conjunto de padrões $\left\{a^{(1)}, \ldots, a^{(s)}, \ldots, a^{(m)}\right\}$.

Observe que, utilizando a abordagem em grafo e/ou, a heurística de seqüenciamento é executada um número bem maior de vezes, visto que a cada inserção de um novo tipo de item a mesma é executada. Isto é diferente do que ocorre, quando a abordagem de Gilmore e Gomory (1965) é utilizada, onde a heurística de seqüenciamento é executada para cada padrão avaliado. Ou seja, o custo computacional desta abordagem é mais alto, quando comparado com a abordagem de Gilmore e Gomory.

Esta abordagem também pode ser utilizada, para gerar pontos aproximados da curva de eficiência, variando-se $p \hat{i}$.

Convém salientar que a Abordagem 3, mesmo com método exato de seqüenciamento, assim como as Abordagens $I$ e 2 , não é exata. Considere um exemplo unidimensional com $L$ $=100$ e os comprimentos, $l_{i}$, e demandas, $b_{i}$, dos itens descritos na tabela 4.4 .

TABELA 4.4: Dados utilizados na Abordagem 3.

\begin{tabular}{l|c|c|c|c|c|c|c|c|c|c}
\hline Item & $\mathbf{1}$ & $\mathbf{2}$ & $\mathbf{3}$ & $\mathbf{4}$ & $\mathbf{5}$ & $\mathbf{6}$ & $\mathbf{7}$ & $\mathbf{8}$ & $\mathbf{9}$ & $\mathbf{1 0}$ \\
\hline $\boldsymbol{l}_{\boldsymbol{i}}$ & 39 & 30 & 38 & 24 & 28 & 37 & 17 & 15 & 11 & 35 \\
$\boldsymbol{d}_{\boldsymbol{i}}$ & 9799 & 3903 & 7460 & 5525 & 2116 & 1691 & 5675 & 1730 & 7165 & 6878 \\
\hline
\end{tabular}


Utilizando a Abordagem 3 para resolver este exemplo com $p \hat{i}=4$ a perda mínima obtida é de $0,19 \%$ e o menor número máximo de pilhas abertas, pi, é 4. Por outro lado, quando $p \hat{i}=5$ a perda mínima obtida é de $0,06 \%$ para pi também igual a 4 . Ou seja, a solução anterior não é ótima, uma vez que a segunda solução tem perda menor satisfazendo $p \hat{i}=4$. Isto mostra que a Abordagem 3 não é exata.

Os conjunto de padrões de corte obtidos para $p \hat{i}=4$ e $p \hat{i}=5$ estão descritos nas tabelas 4.5 e 4.6 , respectivamente ( $x_{j}$ é o número de vezes que o padrão $j$ é repetido).

TABELA 4.5: Conjunto de padrões de corte obtidos para $p \hat{i}=4$.

\begin{tabular}{c|cccccccccc|c}
\hline \multicolumn{10}{c}{ Item } \\
\hline Padrão & $\mathbf{1}$ & $\mathbf{2}$ & $\mathbf{3}$ & $\mathbf{4}$ & $\mathbf{5}$ & $\mathbf{6}$ & $\mathbf{7}$ & $\mathbf{8}$ & $\mathbf{9}$ & $\mathbf{1 0}$ & $x_{j}$ \\
\hline $\mathbf{1}$ & 2 & 0 & 0 & 0 & 0 & 0 & 1 & 0 & 0 & 0 & 143 \\
$\mathbf{2}$ & 1 & 2 & 0 & 0 & 0 & 0 & 0 & 0 & 0 & 0 & 232 \\
$\mathbf{3}$ & 0 & 0 & 2 & 1 & 0 & 0 & 0 & 0 & 0 & 0 & 3730 \\
$\mathbf{4}$ & 0 & 0 & 0 & 3 & 1 & 0 & 0 & 0 & 0 & 0 & 271 \\
$\mathbf{5}$ & 0 & 0 & 0 & 0 & 1 & 1 & 2 & 0 & 0 & 0 & 710 \\
$\mathbf{6}$ & 1 & 0 & 0 & 1 & 0 & 1 & 0 & 0 & 0 & 0 & 981 \\
$\mathbf{7}$ & 0 & 0 & 0 & 0 & 0 & 0 & 5 & 1 & 0 & 0 & 595 \\
$\mathbf{8}$ & 1 & 0 & 0 & 0 & 1 & 0 & 1 & 1 & 0 & 0 & 1135 \\
$\mathbf{9}$ & 2 & 0 & 0 & 0 & 0 & 0 & 0 & 0 & 2 & 0 & 3583 \\
$\mathbf{1 0}$ & 0 & 1 & 0 & 0 & 0 & 0 & 0 & 0 & 0 & 2 & 3439 \\
\hline
\end{tabular}

TABELA 4.6: Conjunto de padrões de corte obtidos para $p \hat{i}=5$.

\begin{tabular}{c|cccccccccc|c}
\hline \multicolumn{10}{c|}{} & \multicolumn{10}{c}{ Item } \\
\hline Padrão & $\mathbf{1}$ & $\mathbf{2}$ & $\mathbf{3}$ & $\mathbf{4}$ & $\mathbf{5}$ & $\mathbf{6}$ & $\mathbf{7}$ & $\mathbf{8}$ & $\mathbf{9}$ & $\mathbf{1 0}$ & $x_{j}$ \\
\hline $\mathbf{1}$ & 0 & 0 & 1 & 0 & 1 & 0 & 2 & 0 & 0 & 0 & 1323 \\
$\mathbf{2}$ & 1 & 2 & 0 & 0 & 0 & 0 & 0 & 0 & 0 & 0 & 232 \\
$\mathbf{3}$ & 0 & 0 & 2 & 1 & 0 & 0 & 0 & 0 & 0 & 0 & 3068 \\
$\mathbf{4}$ & 0 & 0 & 0 & 3 & 1 & 0 & 0 & 0 & 0 & 0 & 255 \\
$\mathbf{5}$ & 1 & 0 & 0 & 0 & 0 & 0 & 0 & 4 & 0 & 0 & 174 \\
$\mathbf{6}$ & 1 & 0 & 0 & 1 & 0 & 1 & 0 & 0 & 0 & 0 & 1691 \\
$\mathbf{7}$ & 0 & 0 & 0 & 0 & 0 & 0 & 5 & 1 & 0 & 0 & 498 \\
$\mathbf{8}$ & 1 & 0 & 0 & 0 & 1 & 0 & 1 & 1 & 0 & 0 & 537 \\
$\mathbf{9}$ & 2 & 0 & 0 & 0 & 0 & 0 & 0 & 0 & 2 & 0 & 3583 \\
$\mathbf{1 0}$ & 0 & 1 & 0 & 0 & 0 & 0 & 0 & 0 & 0 & 2 & 3439 \\
\hline
\end{tabular}

Em particular, a solução com $0,06 \%$ de perda, obtida com $p \hat{i}=5$, é ótima em termos de perda, pois é uma solução de perda mínima. Isto foi verificado utilizando o método simplex sem restrição para o número máximo de tipos de itens nos padrões. Além disso, o 
número máximo de pilhas abertas obtido, $p i=4$, é igual ao maior número de tipos de itens nos padrões (limitante inferior de Yuen e Richardson, 1995), o que garante que uma solução ótima para o MOSP deverá ter pelo menos quatro pilhas abertas, para o conjunto de padrões gerado. 


\section{RESULTADOS COMPUTACIONAIS}

Para a avaliação das três $A b o r d a g e n s$ propostas os objetivos dos problemas de geração e seqüenciamento de padrões considerados foram a minimização da perda e a minimização do número máximo de pilhas abertas (MOSP), respectivamente.

Certa dificuldade foi encontrada para analisar o desempenho das Abordagens devido à falta de métodos exatos e/ou exemplos resolvidos otimamente na literatura para comparação. Também não foram encontrados na literatura limitantes inferiores eficazes para a perda mínima e o número máximo de pilhas abertas do problema integrado de geração e seqüenciamento de padrões de corte. Dispõe-se apenas do limitante inferior para a perda mínima, obtido resolvendo-se o problema de geração de padrões de corte de forma independente, que não necessariamente é um bom limitante para a perda mínima do problema integrado. Em função desses fatos, a estratégia utilizada neste trabalho foi comparar as Abordagens entre si e com esse limitante inferior para a perda mínima.

\subsection{Implementações computacionais}

Neste trabalho, para resolver o problema de corte (2.4)-(2.6), uma versão do método simplex com um procedimento de geração de colunas em Morabito (1992) foi utilizada. Nesta versão, os padrões homogêneos são utilizados como solução inicial para a fase I, e os sistemas lineares são resolvidos pelo método de eliminação de Gauss com pivotamento parcial. De 
acordo com Gilmore e Gomory $(1961,1963$, 1965), um critério de parada é interromper o algoritmo simplex, se após algumas iterações a melhoria na função objetivo for pouco significativa. Neste trabalho, o método é interrompido, se após 10 iterações a redução do valor da função objetivo não for superior a $0,1 \%$.

O problema de geração de padrões de corte unidimensionais (problema (2.10)-(2.12)) foi resolvido, utilizando o algoritmo de busca em profundidade primeiro de Gilmore e Gomory (1963) (seção 2.3.1). Outros métodos poderiam ter sido utilizados, como, por exemplo, alguns dos discutidos em Martello e Toth (1990). Modificações foram realizadas, a fim de garantir que os padrões gerados não tenham mais que pî itens (conforme passo 3' descrito na seção 4.2 , sem a verificação dos padrões proibidos), e que a solução ótima para o problema restrito não seja perdida (veja exemplo na seção 4.2).

Para a geração dos padrões de corte bidimensionais guilhotinados em 2-estágios utilizou-se o método exato de Gilmore e Gomory (1965) e, no caso não-estagiado, a abordagem em grafo e/ou em Morabito e Arenales (1996). Outros métodos poderiam ter sido utilizados, como, por exemplo, a heurística de Wang (1983) e a heurística de Silveira e Morabito (2002) baseada no método exato de Hadjconstantinou e Christofides (1995). Para o método de Gilmore e Gomory, adaptações foram realizadas, que consistem em restringir o número máximo de tipos de itens na geração das faixas e posteriormente na geração do padrão, conforme discutido na seção 4.2. Assim como para o caso unidimensional, a cada remoção de um item (no primeiro estágio) ou de uma faixa (no segundo estágio) é verificado se a solução disponivel respeita a restrição de $p \hat{i}$ itens no padrão. No caso da abordagem em grafo e/ou isto é feito da mesma forma que para o caso unidimensional (ou seja, no cálculo do limitante inferior).

As Abordagens 1 e 3 utilizam os métodos descritos acima para resolver os problemas de geração de padrões de corte (seções 4.2 e 4.4). Um outro método utilizado neste trabalho, para resolver o problema de corte (2.4)-(2.6), foi utilizando heuristicas construtivas gulosas (seção 2.4). Neste caso em cada iteração um padrão de corte é gerado, utilizando os métodos descritos acima para a geração de colunas. Em cada iteração o padrão mais valioso é gerado, considerando os valores e a demanda dos itens. A Abordagem 2 utiliza esse procedimento, para resolver o problema de geração de padrões de corte, respeitando a restrição de $p \hat{i}$ itens nos padrões e no seqüenciamento dos mesmos (seção 4.3).

Para resolver o problema de seqüenciamento foi implementada a heurística 3 de Yuen (1995) devido à sua simplicidade e superioridade com relação às demais heurísticas propostas 
por esse autor com relação à qualidade das soluções obtidas e ao tempo computacional, e também devido à facilidade de sua implementação computacional. Outras heurísticas de seqüenciamento poderiam ter sido utilizadas, como, por exemplo, a heurística com busca tabu de Faggioli e Bentivoglio (1998) e o método frugal de Ashikaga (2001), que envolve teoria dos grafos.

Dado um padrão inicial, a heurística 3 de Yuen (1995) determina uma seqüência, que abre o menor número máximo de pilhas. a partir de um conjunto de padrões de corte. $\mathrm{Na}$ implementação da mesma foram geradas seqüências, iniciando com cada um dos $n$ padrões de corte (onde $n$ é o número de padrōes de corte obtido pela resolução do problema de corte). As Abordagens 1 e 3 utilizam essa heurística para resolver o problema de seqüenciamento, conforme descrito nas seções 4.2 e 4.4 .

As implementações das Abordagens 1, 2 e 3 (com os métodos acima descritos) foram escritas na linguagem Pascal e foram compiladas, utilizando o compilador do Delphi, versão 5.0. O computador utilizado foi um Pentium IV com 1600Mhz e 512Mb de memória.

\subsection{Abordagens $1 \mathrm{a}, 1 \mathrm{~b}$ e $1 \mathrm{c}$}

Inicialmente testes computacionais foram realizados para escolha de uma das três versões $(l a, I b$ e $I c)$ da Abordagem $l$ e também para aferir os parâmetros utilizados por esta abordagem: número máximo de iterações ( $\max _{-}$iter), regra utilizada para escolha da seqüência (esc_seq), regra utilizada para escolha do padrão a ser eliminado (alt padr), e número de iterações que os padrões ficam proibidos $(L C=x)$, conforme discutido na seção 4.2.

Exemplos de problemas de corte unidimensionais e bidimensionais em 2-estágios foram gerados aleatoriamente para a realização dos testes. Foram gerados exemplos, até se obter 50 exemplos infactíveis (este número parece razoável, uma vez que, desta maneira, cada exemplo gerado contribui com apenas $2 \%$ para a média final), ou seja, com número máximo de pilhas abertas (obtido com o seqüenciamento do conjunto de padrões de corte gerado pelo método simplex) maior que o número máximo de pilhas abertas tolerado, $p \hat{i}$, arbitrariamente fixado em 3. O número de tipos de itens considerado foi $m=10$ (o uso de $p \hat{i}=3$ parece uma limitação razoável utilizando $m \geq 10$ ). 
Para os problemas unidimensionais o tamanho do objeto considerado foi $L=100$, o comprimento $l_{i}$ dos itens, $i=1, \ldots, m$ foi sorteado de uma distribuição uniforme no intervalo $[0,10 L ; 0,75 L]$. Optou-se por utilizar un intervalo bem amplo por generalidade. Este intervalo permite gerar itens de comprimentos bem diversos, tanto pequenos quanto grandes. A demanda $b_{i}$ dos itens, $i=1, \ldots, m$ foi sorteada de uma distribuição uniforme no intervalo [1000;10000], ou seja, valores bem elevados, a fim de se evitar problemas de arredondamento de solução do método simplex. No caso bidimensional em 2-estágios o tamanho do objeto considerado foi $L \times W=100 \times 100$, o comprimento $l_{i}$, a largura $w_{i}$, e a demanda $b_{i}$ dos itens, $i=1, \ldots, m$ foram sorteados de uma distribuição uniforme nos intervalos $[0,10 L ; 0,75 L]$, $[0,10 L ; 0,75 L]$ e $[1000 ; 10000]$, respectivamente. Utilizou-se o algoritmo de busca em profundidade primeiro de Gilmore e Gomory (1963), aqui chamado de GG_uni, para resolver os exemplos unidimensionais, e o método exato em duas fases de Gilmore e Gomory (1965), aqui chamado de $G G_{-} b i$, para os exemplos bidimensionais.

Para se comparar o desempenho computacional das diferentes versões $(l a, l b$ e $l c)$ da Abordagem 1, os seguintes parâmetros foram arbitrariamente utilizados: $m a x$ iter $=500$, esc_seq $=$ aleatória, alt $p a d r=$ aleatório, $p \hat{i}=3$ e $L C=3$, em função de resultados obtidos em experimentos anteriores. Nas tabelas 5.1 e 5.2 a coluna "Método de Solução" corresponde ao método simplex com limitação de $p \hat{i}$ itens nos padrões (que é utilizado como um limitante inferior para a perda mínima) com a heurística 3 de Yuen (1995), que corresponde à apenas cortar e seqüenciar, ou seja, à primeira iteração da Abordagem $1 a$, e as diferentes versões da Abordagem 1 utilizadas para resolver os problemas de corte e de seqüenciamento para o caso unidimensional.

As colunas "Perda", "Pilha", "Tempo" e "Proporção" correspondem, respectivamente, à perda média (em porcentagem) obtida por cada versão, (onde perda é igual à porcentagem da dimensão - comprimento ou área, respectivamente para os casos unidimensional e bidimensional - não ocupada), ao número médio de pilhas abertas obtido por cada versão, ao tempo médio (em segundos) gasto para o término do algoritmo de cada versão e à proporção de exemplos (com solução factível ou infactível) com perda mínima (isto é, igual ao limitante inferior) dentre o número total de exemplos. 
TABELA 5.1: Resultados do teste para escolha da versão da Abordagem $l$ - caso unidimensional.

\begin{tabular}{|c|c|c|c|c|}
\hline \multicolumn{5}{|c|}{$m=10, l_{1}=[0,10 L ; 0,75 L], G_{\text {G uni }}$} \\
\hline Método de Solução & Perda(\%) & Pilha & Tempo & Proporção \\
\hline Simplex com Heuristica 3 & 5,47 & 4,10 & $<0,01$ & - \\
\hline Abordagem $1 a$ & 5,52 & 3,00 & 0,17 & $98 \%$ \\
\hline Abordagem $1 b$ & 5,94 & 2,98 & 0,62 & $58 \%$ \\
\hline Abordagem 1c & 5,54 & 2,98 & 1,71 & $90 \%$ \\
\hline
\end{tabular}

TABELA 5.2: Resultados do teste para escolha da versão da Abordagem 1 - caso bidimensional.

\begin{tabular}{|c|c|c|c|c|}
\hline \multicolumn{5}{|c|}{$m=10, I_{i}=[0,10 L ; 0,75 L], w_{i}=[0,10 W ; 0,75 W], G G \_b i$} \\
\hline Método de Solução & Perda(\%) & Pilha & Tempo & Proporção \\
\hline Simplex com Heuristica 3 & 23,35 & 4,48 & $<0,01$ & - \\
\hline Abordagem 1a & 23,73 & 3,60 & 0,64 & $74 \%$ \\
\hline Abordagem $1 b$ & 24,43 & 3,00 & 1,54 & $52 \%$ \\
\hline Abordagem 1c & 23,81 & 3,00 & 5,92 & $74 \%$ \\
\hline
\end{tabular}

Como pode-se observar (tabela 5.1), no caso unidimensional as três versões da Abordagem 1 encontraram soluções bastante próximas do limitante inferior para a perda mínima $(5,47 \%)$. As versões $l a$ e $l c$ encontraram as menores perdas médias $(5,52 \%$ e $5,54 \%)$, enquanto a maior diferença entre o limitante inferior e as diferentes versões foi obtido pela versão $1 \mathrm{~h}(0,47 \%)$. Todas as versões encontraram soluções factíveis (para todos os 50 exemplos o número de pilhas abertas foi menor ou igual a 3 ). A versão $l a$ foi a que encontrou a menor perda média $(5,52 \%)$ e o maior número de exemplos com menor perda dentre o número total de exemplos (98\%), apesar da versão $l c$ estar logo atrás com $90 \%$.

Já no caso bidimensional em 2-estágios (tabela 5.2) as diferenças entre as abordagens ficam mais evidentes. A versão $l a$, apesar de encontrar perdas médias bastante próximas do limitante inferior (diferença de $0,38 \%$ ), e o maior número de exemplos com menor perda dentre o número total de exemplos (74\%) juntamente com a Abordagem 1c, nem sempre encontra soluções factíveis, o que pode ser observado pelo número máximo de pilhas abertas igual a 3.6 (isto é, maior que $p \hat{i}=3$ ). Dos 50 exemplos, 14 deles, ou seja, $28 \%$ encontram $p \hat{i}>3$. Para a versão la a porcentagem de exemplos com menor perda na tabela 5.2 corresponde às soluções factíveis e infactíveis.

As versões $l b$ e $l c$ também encontram perdas médias próximas do limitante inferior (diferenças de $1,08 \%$ e $0,46 \%$, respectivamente), apesar da versão $I c$ encontrar um maior número de exemplos com menor perda dentre o número total de exemplos $(74 \%)$, enquanto a versão $l b$ encontrou $52 \%$. 
Como pode-se observar pelas tabelas 5.1 e 5.2, os tempos computacionais aumentam da versão $l a$ para a versão $l c$ tanto no caso unidimensional como no caso bidimensional em 2estágios. Como a versão $I a$ pode não resolver o problema de minimizar a perda sujeito a uma limitação para o número máximo de pilhas tolerada (problema (P2)), a mesma foi eliminada da análise nos próximos experimentos. Note que tanto no caso unidimensional como no caso bidimensional em 2-estágios, a perda média obtida por esta versão é menor que a perda média obtida pelas versões $l b$ e $l c$, mas conforme dito, nem sempre é factível (no caso unidimensional todas as soluçõcs encontradas foram factíveis e no caso bidimensional 2-estágios, $28 \%$ dos exemplos apresentaram soluções infactíveis). Em vista dos resultados com relação à perda média e ao número de exemplos com menor perda obtidos pela versão $I c$, quando comparados com a versão $1 b$, a versão $l c$ foi escolhida para representar a Abordagem 1 . Note que os tempos computacionais da versão $I b$ são menores que os da versão $l c$.

Para aferir os parâmetros da Abordagem 1 , a versão $l c$ foi então utilizada com os mesmos valores de $p \hat{i}=3$ e $m=10$, nos casos unidimensional e bidimensional em 2-estágios. Extensivos testes computacionais foram realizados, variando-se $\max$ iter $=1,10,50,100$, 150, 200, 300, 500 e 1000; alt_padr = (i) primeiro, (ii) aleatório_mp, (iii) aleatório e (iv) menor_perda; esc_seq $=($ i) primeira, (ii) aleatória e (iii) mais_demora, e $L C=x=1,2,3,5$, $10,25,50,100,200$ e 500 .

Antes de apresentar os resultados obtidos para escolha dos parâmetros, algumas considerações serão feitas. A partir de 100 iterações observou-se que o ganho obtido em termos de perda média não compensa o tempo computacional despendido, tanto no caso unidimensional como no caso bidimensional. Em vista disso, para a Abordagem 1 utilizou-se $\max$ iter $=100$ tanto no caso unidimensional como no bidimensional.

Deixar os padrões de corte proibidos por muitas iterações $(L C>100)$ faz com que a perda média comece a deteriorar, em vista de muitos padrões de corte ficarem proibidos de serem gerados. As piores perdas foram obtidas para valores de $L C=1,100,200$ e 500 , tanto no caso unidimensional como no caso bidimensional. Cabe observar que para $L C=1$ as perdas obtidas também são ruins, em vista da dificuldade de se gerar conjuntos de padrões de corte diferentes. As perdas obtidas para $L C=25$ e $L C=50$ foram piores, quando comparadas com as perdas obtidas com $L C=3,5$ e 10 . Dentre essas três opções as menores perdas foram obtidas para $L C=5$.

Uma análise dos testes realizados revelou os melhores desempenhos (em termos de perda média e tempo computacional) com: $m a x_{-}$iter $=100$ iterações, alt padr $=$ menor_perda 
para a escolha dos padrões proibidos, esc_seq = aleatória para a escolha da seqüência e $L C=x=5$, ou seja, $m / 2$ para o número de iterações que os padrões ficam proibidos.

\subsection{Abordagens 2 e 3}

Para a Abordagem 2 um único parâmetro precisa ser aferido: o número máximo de iterações, max_iter (veja seção 4.3). Foram realizados testes computacionais com 50 exemplos gerados aleatoriamente no caso unidimensional com $m=10$ e max_iter fixado em $1,5,10(m), 15(m+m / 2), 20(2 m)$ e 100 , e com $m=20$ e max_iter fixado em $1,5,10,15$, $20(m), 35(m+m / 2), 40(2 m)$ e 100 . Também foram realizados testes com 50 exemplos gerados aleatoriamente no caso bidimensional novamente com $m=10$ e $m=20$, e com a mesma variação de $\max$ iter.

Após a realização dos testes computacionais pôde-se observar que a redução na perda média obtida para $m a x$ iter $>m$ não compensa o tempo computacional despendido. Em função disso, o número máximo de iterações para a Abordagem 2 foi fixado em $m$.

Para a Abordagem 3 o único parâmetro utilizado é a regra para escolha da seqüência (esc_seq) (veja seção 4.4). Para cada coluna com custo relativo negativo é avaliado se o conjunto de padrões, resultante da substituição desta coluna por alguma coluna básica, quando seqüenciado, não abrirá mais que $p \hat{i}$ itens (seção 4.4). Isto é feito utilizando a heurística 3 de Yuen (1995). Conforme já discutido na seção 4.2, são geradas $n$ seqüências e é preciso escolher uma delas. A escolha da seqüência é feita utilizando a regra definida por esc_seq. Conforme os resultados dos testes com a Abordagem 1, a regra alealória obteve o melhor desempenho e foi utilizada na Abordagem 3.

\subsection{Comparação das abordagens 1, 2 e 3}

Antes de iniciar os testes para avaliação de desempenho das três abordagens, um experimento foi realizado para avaliar a robustez de se usar apenas 50 exemplos aleatórios para a realização dos mesmos. Dois conjuntos de exemplos aleatórios foram utilizados, um 
com 50 e outro com 100 exemplos, tanto para o caso unidimensional como no caso bidimensional em 2-estágios. Foram utilizadas quatro classes de testes, classes 1 a 4 , no caso unidimensional e quatro classes, classes 1 a 4 no caso bidimensional em 2-estágios (definidas abaixo).

Para cada classe do conjunto com 50 exemplos, tanto no caso unidimensional como no caso bidimensional, foi calculada a perda média obtida pelo método simplex (limitante inferior para a perda) e a perda média obtida pelas Abordagens 1,2 e 3. Calculou-se a diferença entre a perda média obtida pelo método simplex e cada uma das abordagens. $\mathrm{O}$ mesmo foi feito para o conjunto com 100 exemplos. Na tabela 5.3 a coluna "Soma das diferenças" apresenta a soma dessas diferenças e a coluna "Média" a média obtida para o conjunto com 50 e com 100 exemplos.

TABELA 5.3: Resultado do teste para avaliação do número de exemplos.

\begin{tabular}{c|c|c}
\hline $\begin{array}{c}\text { Conjuntos de } \\
\text { exemplos }\end{array}$ & $\begin{array}{c}\text { Soma das } \\
\text { diferenças }\end{array}$ & Média \\
\hline 50 & 27,60 & 1,6235294 \\
100 & 27,65 & 1,6264705 \\
\hline
\end{tabular}

Como a média para os dois conjuntos de exemplos pode ser considerada praticamente a mesma e o tempo computacional aumenta com o número de exemplos, definiu-se 50 como o número de exemplos a serem utilizados nos testes comparativos das três abordagens.

Os testes para avaliação de desempenho das abordagens 1,2 e 3 foram realizados nos casos unidimensional e bidimensional. Para o primeiro caso, considerou-se $L=100 \mathrm{com}$ a demanda dos itens gerada aleatoriamente no intervalo $[1000,10000]$. O comprimento dos itens $\left(l_{i}\right)$ foi gerado aleatoriamente nos intervalos $[0.10 L, 0.75 L]$ (tamanhos diversos) e $[0,05 L ; 0,50 L]$ (tamanhos pequenos). No caso bidimensional considerou-se um objeto $L \times W=100 \times 100$ com dois intervalos para a geração aleatória dos tamanhos dos itens: comprimento e largura gerados aleatoriamente nos intervalos $[0,10 \mathrm{~L} ; 0,75 \mathrm{~L}]$ e $[0,10 \mathrm{~W} ; 0,75 \mathrm{~W}]$ (tamanhos diversos), e $[0.05 \mathrm{~L} ; 0.50 \mathrm{~L}]$ e $[0,05 \mathrm{~W} ; 0,50 \mathrm{~W}]$ (tamanhos pequenos). A demanda dos itens foi gerada aleatoriamente no intervalo [1000, 10000]. Desta forma os testes foram divididos nas seguintes classes:

\section{Caso unidimensional}

Classe 1: $m=10$ e $l_{i} \in[0,10 L ; 0,75 L]$

-Classe 2: $m=20$ e $l_{i} \in[0,10 L ; 0,75 L]$ 
Classe 3: $m=10$ e $l_{i} \in[0,05 L ; 0,50 L]$

$>$ Classe 4: $m=20$ e $l_{i} \in[0,05 L ; 0,50 L]$

\section{Caso bidimensional}

;Classe 1: $m=10, l_{i} \in[0,10 L ; 0,75 L]$ e $w_{i} \in[0,10 \mathrm{~W} ; 0,75 \mathrm{~W}]$

Classe 2: $m=20, l_{i} \in[0,10 L ; 0,75 L]$ e $w_{\imath} \in[0,10 \mathrm{~W} ; 0,75 \mathrm{~W}]$

-Classe 3: $m=10, l_{i} \in[0,05 L ; 0,50 L]$ e $w_{i} \in[0,05 \mathrm{~W} ; 0,50 \mathrm{~W}]$

>Classe 4: $m=20, l_{i} \in[0,05 L ; 0,50 L]$ e $w_{i} \in[0,05 W ; 0,50 W]$

O número máximo de pilhas abertas tolerado, $p \hat{i}$, foi fixado arbitrariamente em 3 . Note que esta restrição é bem mais apertada para os problemas das classes 2 e 4 ( $\operatorname{com} m=20$ ) do que para os das classes 1 e 3 ( $\mathrm{com} m=10$ ), respectivamente, conforme é visto nas tabelas a seguir. Em cada classe, tanto no caso unidimensional como no caso bidimensional, foram gerados exemplos, até se obterem 50 exemplos infactíveis, ou seja, com número máximo de pilhas abertas (obtido com o seqüenciamento do conjunto de padrões de corte gerado pelo método simplex) maior que o número máximo de pilhas abertas tolerado, pî. Para a Abordagem 1 os parâmetros utilizados foram: alt padr = menor_perda, esc_seq $=$ aleatória, $L C=m / 2$ e max_iter $=100$. Para a Abordagem 2 max iter foi fixado $\mathrm{em} m$. E para a Abordagem 3, a regra utilizada para esc_seq foi aleatória.

\subsubsection{Caso unidimensional}

Para cada classe 1-4 do caso unidimensional os padrões de corte foram gerados, utilizando o algoritmo de busca em profundidade primeiro de Gilmore e Gomory (1963), $G G_{-}$uni.

Nas tabelas abaixo a coluna "Método de Solução" corresponde ao método utilizado para resolver os problemas de corte e de seqüenciamento. A linha "Simplex com Heurística 3" corresponde à utilização do método simplex com o procedimento de geração de colunas padrão (isto é, sem restrição para o número máximo de tipos de itens nos padrões) para solução do problema de corte e posterior seqüenciamento do conjunto de padrões, utilizando a heurística 3 de Yuen (1995). A linha "Simplex ( $p \hat{i})$ com Heurística 3" corresponde à 
utilização do método simplex com o procedimento de geração de colunas (com no máximo $p \hat{i}$ tipos de itens nos padrões) para solução do problema de corte e posterior seqüenciamento do conjunto de padrões, utilizando a heuristica 3 de Yuen (1995). Note que estes métodos não garantem uma solução com número de pilhas $\leq 3$ (veja discussão anterior sobre geração dos exemplos alcatórios), mas produzem limitantes inferiores para a perda mínima. As colunas "Perda (\%)", "Pilha" e "Tempo" correspondem respectivamente à perda média (em porcentagem) obtida por cada método de solução, ao número médio de pilhas abertas obtido por cada método de solução e ao tempo médio (em segundos) gasto para o término do algoritmo. Nas tabelas 5.4 a 5.7 descrevem-se os resultados no caso unidimensional para as classes 1-4 utilizando o método $G G_{-}$Uni para a geração dos padrões de corte.

TABELA 5.4: Resultados obtidos nos problemas unidimensionais - classe 1-GG_uni.

\begin{tabular}{l|ccc}
\hline \multicolumn{4}{c}{$m=\mathbf{1 0}, l_{i} \in[0, \mathbf{1 0} L ; \mathbf{0 , 7 5 L}, \mathrm{GG}$ uni } \\
\hline \multicolumn{1}{c}{ Método de Solução } & Perda $(\%)$ & Pilha & Tempo \\
\hline Simplex com Heuristica 3 & 4,88 & 4,14 & $<0,01$ \\
Simplex $(p \hat{i})$ com Heurística 3 & 4,88 & 4,10 & $<0,01$ \\
Abordagem 1 & 4,96 & 3,00 & 0,18 \\
Abordagem 2 & 5,65 & 3,00 & $<0,01$ \\
Abordagem 3 & 5,06 & 3,00 & 0,01 \\
\hline
\end{tabular}

Observe na tabela 5.4 que a Abordagem 1 apresenta os melhores resultados, seguida da Abordagem 3. Note que a diferença entre as perdas médias encontradas por essas abordagens são bastante próximas do limitante inferior $(4,88 \%)$, ou seja, $0,08 \%$ e $0,18 \%$ para as Abordagens $I$ e 3 , respectivamente, enquanto o número máximo de pilhas abertas é reduzido em média de 4,1 para 3. Para a Abordagem 1, dos 50 exemplos resolvidos, em 46 deles a solução é obtida a partir da rotina de corte e apenas em 4 deles a partir da rotina de factibilização da solução. Note na tabela 5.4 que o gap entre o limitante inferior e as perdas das Abordagens é pequeno, logo o gap de otimalidade é pequeno (menos de $1 \%$ de perda, conforme tabela 5.4) e, portanto, as Abordagens são capazes de gerar boas soluções para essa classe com tempos computacionais bem pequenos.

TABELA 5.5: Resultados obtidos nos problemas unidimensionais - classe 2-GG_uni.

\begin{tabular}{l|ccc}
\hline \multicolumn{4}{c}{$m=20, l, \in[0,10 L ; 0,75 L], G G \_$uni } \\
\hline \multicolumn{1}{c}{ Método de Solução } & Perda $(\%)$ & Pilha & Tempo \\
\hline Simplex com Heuristica 3 & 3,77 & 5,36 & 0,01 \\
Simplex $(p i)$ com Heuristica 3 & 3,77 & 5,34 & 0,01 \\
Abordagem 1 & 4,40 & 3,00 & 29,11 \\
Abordagem 2 & 4,56 & 3,00 & 0,02 \\
Abordagem 3 & 4.57 & 3.00 & 0.87 \\
\hline
\end{tabular}


Novamente a Abordagem 1 obteve os melhores resultados com uma diferença de $0,63 \%$ para o limitante inferior $(3,77 \%$ ), mas com um tempo computacional bem maior (quase 30 segundos em média). Dos 50 exemplos resolvidos, 13 obtiveram a solução a partir da rotina de corte e 37, a partir da rotina de factibilização da solução. As Abordagens 2 e 3 obtiveram praticamente as mesmas perdas $(4,56 \%$ e $4,57 \%$, respectivamente), mas a Abordagem 2 com um tempo computacional bem menor, quando comparado com a Abordagem 3 (menos de 0,1 segundos contra 0,87 segundos, respectivamente). Como era esperado, conforme o número de tipos de itens aumenta, o tempo computacional também aumenta (compare os tempos das tabelas 5.4 e 5.5). O número máximo de pilhas abertas é reduzido em média de 5.3 para 3. Note na tabela 5.5, que assim como para a classe 1 , o gap entre o limitante inferior e as perdas das Abordagens é pequeno (menos de $1 \%$ de perda, conforme tabela 5.5), o que indica que as Abordagens também são capazes de gerar boas soluções para essa classe.

TABELA 5.6: Resultados obtidos nos problemas unidimensionais - classe 3-GG_uni.

\begin{tabular}{l|ccc}
\hline \multicolumn{4}{c}{$m=10, l_{i} \in[0,05 L ; 0,50 L], G G$ uni } \\
\hline \multicolumn{1}{c}{ Método de Solução } & Perda $(\%)$ & Pilha & Tempo \\
\hline Simplex com Heurística 3 & 0,36 & 5,04 & $<0,01$ \\
Simplex (pî) com Heurística 3 & 0,42 & 4,56 & $<0,01$ \\
Abordagem 1 & 0,61 & 3,00 & 0,85 \\
Abordagem 2 & 1,44 & 3,00 & $<0,01$ \\
Abordagem 3 & 0,75 & 3,00 & 0,03 \\
\hline
\end{tabular}

Note que novamente a Abordagem $I$ apresenta os melhores resultados seguida da Abordagem 3 e que os tempos computacionais da Abordagem $l$ são bem maiores quando comparados com as Abordagens 2 e 3 . Observe que o gap entre o limitante inferior e as perdas das Abordagens é razoavelmente pequeno para esta classe (menos de $1 \%$ de perda para as Abordagens 1 e 3, conforme tabela 5.6), logo, as Abordagens também são capazes de gerar boas soluções para esta classe.

TABELA 5.7: Resultados obtidos nos problemas unidimensionais - classe 4-GG_uni.

\begin{tabular}{l|ccc}
\hline \multicolumn{4}{c}{$m=20, l, \in[0,05 L ; 0,50 L], G G \_$uni } \\
\hline \multicolumn{1}{c}{ Método de Solução } & Perda $(\%)$ & Pilha & Tempo \\
\hline Simplex com Heurística 3 & 0,00 & 6,92 & 0,01 \\
Simplex (pI) com Heurística 3 & 0,00 & 6,58 & 0,01 \\
Abordagem 1 & 1,28 & 3,00 & 65,49 \\
Abordagem 2 & 0,95 & 3,00 & 0,03 \\
Abordagem 3 & 0,47 & 3,00 & 9,20 \\
\hline
\end{tabular}


Observe que, diferentemente do que ocorreu para as classes 1, 2 e 3, a Abordagem 1 apresentou os piores resultados (perda média de 1,28\%), o que pode em parte ser explicado pelo fato de todos os 50 exemplos terem obtido sua solução a partir da rotina de factibilização da solução, e pelo fato de a diferença $(3,92)$ entre a perda média obtida pelo seqüenciamento dos padrões de corte gerados pelo método simplex (sem restrição para o número máximo de tipos de itens nos padrões) e pi ser relativamente maior que as diferenças das outras classes. Para a classe 1 a redução que deve ser feita no número de pilhas é de apenas 1,14, para a classe 2 é de 2,34 e para a classe 3 é de 2,04.

Como esta classe apresenta itens de tamanhos pequenos, os padrões de corte gerados apresentam, em média, mais tipos de itens que os padrões das outras classes (o que pode ser verificado pelo número médio de pilhas abertas, 6,92). Note que a Abordagem 3 apresenta bons resultados em um tempo computacional razoável e que para esta classe a Abordagem 2 foi melhor que a Abordagem 1. Observe que o gap entre o limitante inferior e as perdas das Abordagens ainda é razoavelmente pequeno para esta classe (menos de $1 \%$ de perda para as Abordagens 2 e 3, conforme tabela 5.7), sendo que a maior distância é obtida pela Abordagem 1, diferentemente das classes 1, 2 e 3, cuja maior distância é obtida pela Abordagem 2.

A Abordagem 1 encontrou as menores perdas médias para as classes 1,2 e 3 , quando comparada com as Abordagens 2 e 3 (por outro lado, o tempo computacional foi maior, observe nas tabelas 5.4 a 5.6). Porém, para a classe 4, foi a abordagem que encontrou a pior solução (veja tabela 5.7). Observe que a diferença entre a perda média obtida pela $\mathrm{Abordagem}$ 2, e pelo limitante inferior para as classes 1 e 2 (itens de tamanhos diversos) é praticamente constante, menor que $0,80 \%$. O mesmo ocorre para as classes 3 e 4 (itens de tamanhos pequenos), onde esta diferença fica em torno de $1 \%$.

Para problemas unidimensionais nos quais a diferença entre o número máximo de pilhas abertas, obtido pelo seqüenciamento dos padrões de corte gerados pelo método simplex e pîi não for muito grande, a Abordagem 1 apresenta melhor desempenho que as Abordagens 2 e 3 . Porém, quando esta diferença começa a aumentar, a Abordagem 3 apresenta melhores resultados, seguida da Abordagem 2. À medida que o número de tipos de itens aumenta, o tempo computacional das abordagens também aumenta, mas o tempo da Abordagem 1 é bem maior que os das demais.

Uma análise foi feita para comparar as três abordagens de uma forma mais agregada, considerando o desempenho médio das mesmas em todas as classes. Na tabela 5.8 o desempenho das abordagens está avaliado pelo número de colocações das mesmas. As colunas "Primeira", "Segunda" e "Terccira" indicam respectivamente o número de classes nas quais as Abordagens 1 , 
2 e 3 obtiveram a primeira colocação (isto é, a menor perda), a segunda e a terceira colocação, respectivamente. Convém observar que não houve casos de empate entre as abordagens.

TABELA 5.8: Rank das abordagens nos problemas unidimensionais.

\begin{tabular}{l|ccc}
\hline Método de Solução & Primeira & Segunda & Terceira \\
\hline Abordagem 1 & 3 & 0 & 1 \\
Abordagem 2 & 0 & 2 & 2 \\
Abordagem 3 & 1 & 2 & 1 \\
\hline
\end{tabular}

Pela tabela 5.8 pode-se observar que a Abordagem $I$ obteve a menor perda média em 3 dos 4 dos casos. A Abordagem 2 em nenhuma classe e a Abordagem 3 em apenas uma classe. Observe que a Abordagem 2 obteve o pior desempenho em 2 dos 4 casos e a Abordagem 3 foi a que mais variou seu desempenho médio no caso unidimensional.

Na tabela 5.9 o desempenho médio das abordagens com relação à perda obtida e ao tempo computacional utilizado está ilustrado. Nesta tabela a coluna "Perda" indica a perda média (em porcentagem) obtida por cada abordagem e "Tempo" indica o tempo médio (em segundos) gasto por cada abordagem, considerando todas as classes do caso unidimensional.

TABELA 5.9: Resultados médios obtidos nos problemas unidimensionais.

\begin{tabular}{l|rc}
\hline \multicolumn{1}{c|}{ Método de Solução } & Perda & Tempo \\
\hline Simplex com Heuristica 3 & 2,25 & 0,01 \\
Abordagem 1 & 2,81 & 23,91 \\
Abordagem 2 & 3,15 & 0,02 \\
Abordagem 3 & 2,71 & 2,53 \\
\hline
\end{tabular}

Do ponto de vista da perda média, para as classes consideradas, a Abordagem 3 apresenta os menores valores (tabela 5.9), uma diferença de $0,46 \%$ da média obtida para 0 limitante inferior $(2,25 \%)$. Note que a diferença entre o limitante inferior e a Abordagem 2 $(0,90 \%)$ é praticamente o dobro da diferença obtida para a $A b o r d a g e m ~ 3(0,46 \%)$ e mais que 1.5 vezes para a Abordagem $I(0,56 \%)$. Observe que o tempo computacional da Abordagem 1 é maior que das Abordagens 2 e 3.

\subsubsection{Caso bidimensional}

No problema de corte bidimensional em 2-estágios os padrões foram gerados, utilizando o método exato em duas fases de Gilmore e Gomory (1965), GG_bi, e para o caso não-estagiado, a abordagem em grafo e/ou, aqui chamada de Geou_bi. 
De acordo com Morabito e Arenales (1996), os melhores valores dos parâmetros depth, $\alpha$ e $\beta$ para o caso bidimensional não-estagiado e restrito, são 6, 1.01 e 0.90 , respectivamente. Com esses valores de parâmetros o tempo mćdio para geração de uma coluna é da ordem de 30 segundos (MORABITO e ARENAI,ES, 1996). Em função disso, testes foram realizados, para calibrá-los, a fim de se obter um conjunto de valores de parâmetros considerados bons em tempos computacionais razoáveis, visto que um número grande de colunas é gerado especialmente pelas Abordagens 1 e 3 . Nos testes realizados utilizou-se os 50 exemplos gerados aleatoriamente no caso bidimensional com $m=10$, $l_{i} \in[0,10 L ; 0,75 L]$ e $w_{i} \in[0,10 \mathrm{~W} ; 0,75 \mathrm{~W}]$. Para avaliar a qualidade das soluções obtidas, comparou-se a perda média obtida pelo método simplex, utilizando o método GG_bi para a geração dos padrões, com a perda média obtida pelo método simplex, utilizando o método Geou_bi para diferentes valores dos parâmetros depth, $\alpha$ e $\beta$. Para os dois casos utilizou-se o método simplex sem restrição para o número máximo de tipos de itens nos padrões.

A perda média obtida pelo método simplex com $G G_{-}$bi foi igual a $21,82 \%$. Como GG_bi gera padrões de corte com no máximo 2-estágios, é de se esperar que a perda média obtida por Geou bi seja menor (no pior caso igual), dado que este método não tem limitação para o número máximo de estágios. Para escolha dos parâmetros para a abordagem grafo e/ou avaliou-se o trade-off entre a perda média e o tempo computacional. Para os parâmetros sugeridos por Morabito e Arenales (1996), depth, $\alpha$ e $\beta$ iguais a 6, 1,01 e 0,90, respectivamente, a perda encontrada utilizando Geou_bi foi igual a $20.96 \%$, num tempo computacional de 1,14 segundos, o que corresponde a uma melhoria de $0.86 \%$ (quando comparada com o limitante inferior - perda mínima obtida pelo método $G G_{-}$uni $)$. Avaliou-se reduzir depth para 3, mantendo os demais parâmetros constantes, e a perda obtida foi de $21,00 \%$ em 0.10 segundos, o que corresponde a uma piora de apenas $0,04 \%$ (quando comparada com o resultado obtido com depth $=6$ ), porém, à custa de um tempo computacional quase 12 vezes menor. Para depth, $\alpha$ e $\beta$ iguais a 3, 1,0 e 0,0 , respectivamente a perda média obtida foi de $20,98 \%$ em 0,16 segundos, o que representa uma melhoria de $0,84 \%$, quando se compara com a perda média obtida pelo método GG_uni. Em função das perdas médias e dos tempos computacionais obtidos optou-se, para o caso bidimensional, utilizar depth, $\alpha$ e $\beta$ iguais a 3, 1,01 e 0,9 , respectivamente.

Para $m=10$ a perda média encontrada pelo método simplex sem a utilização da regra de simetria (seção 2.3.3) é de 20,98\%, consumindo um tempo de 7,28 segundos. O uso da regra de simetria no caso irrestrito é sem perda de generalidade e no caso restrito é com perda 
de generalidade. Quando a regra de simetria é utilizada, a perda média obtida é de $21,00 \% \mathrm{em}$ apenas 0,10 segundos, o que representa uma piora muito pequena para um ganho significativo no tempo computacional. Para $m=20 \mathrm{sem}$ a regra de simetria a perda média obtida é de $18,02 \%$ em 120,63 segundos e com a regra de simetria a perda é de $18,04 \%$ em 2,58 segundos. Observe que, tanto para $m=10$ como para $m=20$, a piora na perda média é muito pouco significativa $(0,02 \%)$, quando a regra de simetria é utilizada mas, em compensação, a redução no tempo computacional é bastante significativa.

Avaliou-se também a utilização, ou não, da regra de simetria na Abordagem 2, em vista de o tempo computacional utilizado por esta abordagem ser menor, quando comparado com os tempos das Abordagens $/$ e 3. Para $m=10$, a perda média obtida sem a utilização da regra de simetria foi de $24,04 \%$ e com a regra de simetria foi de $23,90 \%$, o que corresponde a uma melhoria de $0,14 \%$, e para $m=20$ obteve-se uma melhora de $0,03 \%$, quando o regra de simetria foi utilizada. Como as abordagens já são heurísticas, a utilização da regra de simetria não implica necessariamente em encontrar soluções com piores perdas (conforme resultado obtido pela Abordagem 2), porém o tempo computacional é reduzido significativamente. Em vista disso e do fato de o tempo computacional aumentar à medida que $m$ cresce, optou-se por utilizar a regra de simetria, para resolver os problemas bidimensionais.

Nas tabelas 5.10 e 5.11 são apresentados os resultados obtidos no caso bidimensional em 2-estágios, $G G_{-} b i$, e no caso bidimensional não-estagiado, Geou_bi para a classe 1 $\left(m=10, l_{i} \in[0,10 L ; 0,75 L]\right.$ e $\left.w_{i} \in[0,10 \mathrm{~W} ; 0,75 \mathrm{~W}]\right)$. Os valores do método "Simplex com Heurística 3" são limitantes inferiores para a perda minima apenas dos problemas bidimensionais em 2-estágios, uma vez que apenas o método $G G$ bi é exato. Diferentemente do que ocorre no caso unidimensional, esse valor não é mais um limitante inferior para a perda mínima, no caso de se utilizar a abordagem em grafo elou, Geou_bi (caso bidimensional não-estagiado).

TABELA 5.10: Resultados obtidos nos problemas bidimensionais em 2-estágios - classe 1 GG bi.

\begin{tabular}{l|ccc}
\hline \multicolumn{4}{c}{$m=10, I_{i} \in[0,10 L ; 0,75 L], G G \_b i$} \\
\hline \multicolumn{1}{c}{ Método de Solução } & Perda $(\%)$ & Pilha & Tempo \\
\hline Simplex com Heurística 3 & 21,82 & 5,32 & $<0,01$ \\
Abordagem 1 & 23,97 & 3,00 & 1,16 \\
Abordagem 2 & 26,98 & 3,00 & 0,01 \\
Abordagem 3 & 24,40 & 3,00 & 0,07 \\
\hline
\end{tabular}


TABELA 5.11: Resultados obtidos nos problemas bidimensionais não-cstagiados - classe 1 Geou_bi.

\begin{tabular}{|c|c|c|c|}
\hline \multicolumn{4}{|c|}{$m=10, l_{i} \in[0,10 L ; 0,75 L], G e o u \_b i$} \\
\hline Método de Solução & Perda (\%) & Pilha & Tempo \\
\hline Simplex com Heuristica 3 & 21,00 & 5,26 & 0,10 \\
\hline Abordagem 1 & 23,56 & 3,00 & 19,92 \\
\hline Abordagem 2 & 23,90 & 3,00 & 0,41 \\
\hline Abordagem 3 & 23,09 & 3,00 & 36,01 \\
\hline
\end{tabular}

Pela tabela 5.10 pode-se observar que os desempenhos da Abordagem 1 (23,97\%) e da Abordagem $3(24,40 \%)$, quando o método $G G \_$uni é utilizado, são bastante parecidos e relativamente próximos do limitante inferior $(21,82 \%)$. Note que o número máximo de pilhas abertas é reduzido em média de 5.3 para 3.

Como era esperado, quando o método Geou_bi é utilizado (tabela 5.11), as soluções obtidas são melhores que as soluções obtidas pelo método $G G_{-} b i$ para todas as abordagens. Convém lembrar que, ao contrário da tabela 5.10, o valor do "Simplex com Heurística 3" da tabela 5.11 não é um limitante inferior para a perda mínima, dado que o método Geou_bi não é exato. Note que a Abordagem l apresenta a menor perda média, quando o método GG_bi é utilizado, porém, quando Geou_bi é utilizado, a Abordagem 3 é a que apresenta a menor perda. De fato, a Abordagem 3, utilizando Geou_bi, foi a que obteve o melhor desempenho dentre todas $(23,09 \%)$. Note nas tabelas 5.10 e 5.11 que, ao utilizar-se o método Geou_bi ao invés de $G G_{-} b i$, a Abordagem 1 foi a que obteve a menor reduçâo de perda $(0.40 \%)$, enquanto a Abordagem 2 e a Abordagem 3 obtiveram reduções de $3.08 \%$ e $1.31 \%$, respectivamente.

Nas tabelas 5.12 e 5.13 abaixo os resultados obtidos para a classe $2(m=10$, $l_{i}=[0.10 L, 0.75 L]$ e $\left.w_{i}=[0.10 \mathrm{~W}, 0.75 \mathrm{~W}]\right)$ utilizando o método $G G_{-}$bi para a geração dos padrões de corte bidimensionais em 2-estágios e o método Geou_bi para os padrões bidimensionais não-estagiado são apresentados.

TABELA 5.12: Resultados obtidos nos problemas bidimensionais em 2-estágios - classe 2 $G G_{-} b i$.

\begin{tabular}{l|ccc}
\hline \multicolumn{4}{c}{$m=20, I, \in[0,10 L ; 0,75 L], G G \_b i$} \\
\hline \multicolumn{1}{c}{ Método de Solução } & Perda (\%) & Pilha & Tempo \\
\hline Simplex com Heuristica 3 & 18,57 & 8,44 & 0,03 \\
Abordagem 1 & 26,90 & 3,00 & 89,15 \\
Abordagem 2 & 26,31 & 3,00 & 0,25 \\
Abordagem 3 & 28,00 & 3,00 & 10,21 \\
\hline
\end{tabular}


TABELA 5.13: Resultados obtidos para os problemas bidimensionais não-estagiados - classe 2 Geoubi.

\begin{tabular}{l|ccr}
\hline \multicolumn{4}{c}{$m=20, l_{i} \in[0,10 L ; 0,75 L]$, Geou_bi } \\
\hline \multicolumn{1}{c}{ Método de Solução } & Perda $(\%)$ & Pilha & Tempo \\
\hline Simplex com Heuristica 3 & 18,04 & 9,14 & 2,58 \\
Abordagem 1 & 26,94 & 3,00 & 555,59 \\
Abordagem 2 & 22,24 & 3,00 & 7,82 \\
Abordagem 3 & 24,25 & 3,00 & 4569,09 \\
\hline
\end{tabular}

Observe nas tabelas 5.12 e 5.13 que, utilizando o método Geou_bi os resultados obtidos com relação à perda média são melhores, como era de se esperar, do que quando o método $G G$ bi ć utilizado. A exceção foi a Abordagem l, com uma perda ligeiramente pior de $26,94 \%$, o que corresponde a uma piora de apenas $0,04 \%$ quando comparada com o método GG bi (26,90\%). Por outro lado, as Abordagens 2 e 3 apresentaram reduções significativas, quando o método Geou_bi foi utilizado $(4,07 \%$ e 3,75\%, respectivamente). Observe nas tabelas 5.10 e 5.11 que as perdas médias obtidas pelas Abordagens não são mais tão próximas do limitante inferior, no entanto, há de se considerar que o número máximo de pilhas abertas é reduzido em média de 8,4 para 3 na tabela 5.12 , e de 9,1 para 3 na tabcla 5.13 .

Note nas tabelas 5.12 e 5.13 que, diferentemente do que ocorreu com a classe 1 (caso bidimensional), a Abordagem 2 é a que apresentou os melhores resultados $(26,31 \%$ e 22,24\%). Observe também que o tempo computacional médio da Abordagem 3 aumentou significativamente de $m=10$ para $m=20$ (36,01 segundos e 4569,09 segundos, respectivamente).

Nas tabelas 5.14 e 5.15 apresentam-se os resultados para os itens de tamanhos pequenos da classe $3\left(m=10, l_{i} \in[0,05 L ; 0,50 L]\right.$ e $\left.w_{i} \in=[0,05 W ; 0,50 W]\right)$ e da classe 4 $\left(m=20, l_{i} \in[0,05 L ; 0,50 L]\right.$ e $w_{i} \in[0,05 W ; 0,50 \mathrm{~W})$ utilizando o método $G G_{-}$bi. Por conveniência, para estas duas classes optou-se por não utilizar o método Geou_bi, em vista do maior consumo de tempo computacional (veja os tempos computacionais da tabela 5.13).

TABELA 5.14: Resultados obtidos nos problemas bidimensionais em 2-estágios - classe 3 GG_bi.

\begin{tabular}{l|rcc}
\hline \multicolumn{4}{c}{$m=10, I_{i} \in[0,05 L ; 0,50 L]$, GG bi } \\
\hline Método de Solução & Perda & Pilha & Tempo \\
\hline Simplex com Heurística 3 & 6,03 & 6,24 & $<0,01$ \\
Abordagem 1 & 8,06 & 3,00 & 1,53 \\
Abordagem 2 & 11,29 & 3,00 & 0,01 \\
Abordagem 3 & 8,20 & 3,00 & 0,17 \\
\hline
\end{tabular}

Observe que novamente a Abordagem $I$ apresenta o melhor resultado, seguida da Abordagem 3, assim como no caso unidimensional (classe 3). Note que o gap entre o 
limitante inferior $(6,03 \%)$ e a Abordagem 2 é relativamente grande, diferentemente do que ocorre para as Abordagens $l$ e 3, que apresentam gaps menores $(2,03 \%$ e 2,17\%, respectivamente). O número máximo de pilhas abertas é reduzido em média pela metade, isto é, de 6,2 para 3.

TABELA 5.15: Resultados obtidos nos problemas bidimensionais em 2-estágios - classe 4 $G G_{-}$bi.

\begin{tabular}{l|ccr}
\hline \multicolumn{4}{c}{$m=20, I_{i} \in[0,05 L, 0,50 L]}$, \\
\hline \multicolumn{1}{c}{ Gétodo de Solução } & Perda & Pilha & Tempo \\
\hline Simplex com Heuristica 3 & 3,39 & 11,70 & 0,05 \\
Abordagem 1 & 9,57 & 3,00 & 111,39 \\
Abordagem 2 & 10,18 & 3,00 & 1,68 \\
Abordagem 3 & 8,63 & 3,00 & 53,13 \\
\hline
\end{tabular}

Assim como no caso unidimensional para $m=20$ e itens de tamanhos pequenos, a Abordagem 3 comporta-se melhor (compare as tabelas 5.7 e 5.15). A Abordagem 1 não apresentou um descmpenho tão bom, assim como no caso unidimensional, o que em parte pode ser explicado pela grande redução do número máximo de pilhas (de 11,7 para 3), que deve ser feita satisfazer a restrição de $p \hat{i}$.

Observe na tabela 5.15 que o gap entre o limitante inferior e as Abordagens é grande, o que indica que, ou o limitante inferior é pobre para este caso (há de se considerar que o número de pilhas tem de ser reduzido em quase quatro vezes, isto é, de 11,7 para 3), ou que as Abordagens não conseguem encontrar boas soluções. Os tempos computacionais (em média menos de 2 minutos) são aceitáveis para os tipos de decisões envolvidas nas situações reais.

Similarmente ao caso unidimensional, a diferença entre a perda média obtida pela Abordagem 2 com $G G_{-} b i$ e pelo limitante inferior para todas as classes é praticamente constante. A Abordagem $I$ encontrou as menores perdas médias para as classes 1 a 3 , quando o método $G G_{-} b i$ foi utilizado, e a $A b o r d a g e m ~ 3$ encontrou os melhores resultados para a classe 4 , assim como no caso unidimensional.

Quando a diferença entre o número máximo de pilhas abertas, obtido pelo seqüenciamento dos padrões de corte gerados pelo método simplex e pîi não for muito grande, a Abordagem 1 apresentou melhor desempenho que as Abordagens 2 e 3 (veja tabelas $5.10,5.12$ e 5.14), assim como no caso unidimensional. Porém, quando esta diferença começa a aumentar (veja tabela 5.15), a Abordagem 3 apresenta melhores resultados, seguida da Abordagem 2. 
O método Geou_bi foi utilizado com as classes 1 e 2 e para elas, as perdas médias obtidas foram menores quando comparadas às perdas médias obtidas pelo método $G G_{-} b i$ (com exceção da Abordagem 1 na classe 2). Para a classe 1 a Abordagem 3 obteve os melhores resultados e para a classe 2 a Abordagem 2 apresentou melhor desempenho. Note que quando o método $G G_{-}$bi é utilizado, a Abordagem 1 é a que apresenta os maiores tempos computacionais, porém, quando o método Geou_bi é utilizado, os maiores tempos computacionais são obtidos pela Abordagem3 (veja tabelas 5.11 a 5.13). Isto ocorre devido ao conjunto de testes (para verificação da factibilidade do seqüenciamento) aplicado na abordagem em grafo e/ou da Abordagem 3, que é muito mais demorado do que o conjunto de testes aplicado na Abordagem 1.

Os tempos computacionais aumentam consideravelmente, quando o método Geou_bi é utilizado (compare as tabelas 5.10 e 5.11 e as tabelas 5.12 e 5.13). De forma geral, pode-se dizcr que o método Geou bi encontra soluções melhores que o método $G G_{-}$bi, mas à custa de um tempo computacional maior, que em muitos casos pode inviabilizar sua utilização. Cabe observar que os valores dos parâmetros depth, $\alpha$ e $\beta$, sugeridos na literatura (MORABITO e ARENALES, 1996) para o caso bidimensional restrito, são 6, 1,01 e 0,9, respectivamente e que os mesmos não foram utilizados devido aos resultados obtidos para o método simplex irrestrito com depth $=3$ (com $\alpha$ e $\beta$ iguais a 1,01 e 0,9 , respectivamente) e devido ao alto tempo computacional necessário para resolver os problemas à medida que depth e $m$ aumentam.

Assim como para o caso unidimensional, uma avaliação geral foi feita, para comparar o desempenho das três abordagens. Nesta avaliação considerou-se as quatro classes do caso bidimensional, utilizando apenas o método $G G_{-}$bi para a geração dos padrões de corte. Na tabela 5.16 o desempenho das abordagens está avaliado pelo número de colocações das mesmas. As colunas "Primeira", "Segunda" e "Terceira" indicam respectivamente o número de classes nas quais as Abordagens 1,2 e 3 obtiveram a primeira colocação (isto é, a menor perda), a segunda e a terceira colocação, respectivamente. Convém observar que não houve empates entre as abordagens.

TABELA 5.16: Rank das abordagens nos problemas bidimensionais.

\begin{tabular}{l|ccc}
\hline Método de Solução & Primeira & Segunda & Terceira \\
\hline Abordagem 1 & 2 & 2 & 0 \\
Abordagem 2 & 1 & 0 & 3 \\
Abordagem 3 & 1 & 2 & 1 \\
\hline
\end{tabular}


Observe que a Abordagem I foi a primeira em 2 das 4 classes e as Abordagens 2 e 3 empataram com um. Note que a Abordagem 2 obteve as piores colocações. Observe que a Abordagem 3 obteve um comportamento parecido com o do caso unidimensional (tabela 5.8).

Assim como no caso unidimensional, na tabela 5.17 ilustra-se o desempenho médio das abordagens com relação à perda obtida e ao tempo computacional utilizado. Nesta tabela a coluna "Perda" indica a perda média (em porcentagem) obtida por cada abordagem e "Tempo" indica o tempo médio (em segundos) gasto por cada abordagem, considerando as classes do caso bidimensional, que utilizaram o método $G G \_b i$.

TABELA 5.17: Resultados médios obtidos nos problemas bidimensionais.

\begin{tabular}{l|cc}
\hline \multicolumn{1}{c|}{ Método de Solução } & Perda & Tempo \\
\hline Simplex com Heurística 3 & 12,45 & 0,46 \\
Abordagem 1 & 17,13 & 50,81 \\
Abordagem 2 & 18,15 & 0,49 \\
Abordagem 3 & 17,31 & 15,90 \\
\hline
\end{tabular}

Observe na tabela 5.17 que a Abordagem $I$ apresentou as menores perdas médias, uma diferença de $4,68 \%$ da média obtida para o limitante inferior $(12,45 \%)$, seguida bem de perto pela Abordagem 3. Note que as diferenças entre o limitante inferior e as perdas das Abordagens I e 3 são parecidas, 4,68\% e 4,86\%, respectivamente. Observe que o tempo computacional da AbordagemI é maior que os das demais abordagens.

Cabe observar que, quando o método $G G_{-}$bi é utilizado, a $A b o r d a g e m ~ I$ apresenta os maiores tempos computacionais, porém, quando o método Geou bi é utilizado os maiores tempos computacionais são obtidos pela Abordagem 3 (compare as tabelas 5.10 e 5.11 , e 5.12 e 5.13) e a Abordagem 2 apresenta os menores tempos independentemente de qual gerador de padrões seja utilizado.

\subsection{Geração de curvas de trade-off}

Todos os experimentos anteriores foram realizados para $p \hat{i}=3$. Um novo experimento foi realizado, para avaliar o desempenho das três abordagens para diferentes valores de $p \hat{i}$, ou seja, para avaliar o desempenho das mesmas, para gerar curvas de trade-off (variando-se os valores de $p \hat{i}$ ). Como não se dispõe de bons limitantes inferiores para a perda 
e o número de pilhas, mas apenás para a perda, a análise da qualidade das $A b o r d a g e n s$ fica um pouco limitada à comparação das mesmas entre si.

As três abordagens foram utilizadas, para resolver um exemplo (escolhido arbitrariamente) de cada classe 1-4 do caso unidimensional e de cada classe 1-2 do caso bidimensional. Os dados utilizados para a geração das curvas de eficiência para o caso unidimensional encontram-se listados nas tabelas 5.18 a 5.21 .

TABELA 5.18: Dados utilizados no caso unidimensional - classe 1.

\begin{tabular}{c|c|c|c|c|c|c|c|c|c|c}
\hline Item & $\mathbf{1}$ & $\mathbf{2}$ & $\mathbf{3}$ & $\mathbf{4}$ & $\mathbf{5}$ & $\mathbf{6}$ & $\mathbf{7}$ & $\mathbf{8}$ & $\mathbf{9}$ & $\mathbf{1 0}$ \\
\hline $\boldsymbol{l}_{i}$ & 11 & 36 & 22 & 53 & 31 & 44 & 16 & 40 & 13 & 41 \\
$\boldsymbol{d}_{i}$ & 3042 & 1683 & 9637 & 7911 & 2971 & 7746 & 4701 & 4580 & 5174 & 5825 \\
\hline
\end{tabular}

TABELA 5.19: Dados utilizados no caso unidimensional - classe 2.

\begin{tabular}{c|c|c|c|c|c|c|c|c|c|c}
\hline Item & $\mathbf{1}$ & $\mathbf{2}$ & $\mathbf{3}$ & $\mathbf{4}$ & $\mathbf{5}$ & $\mathbf{6}$ & $\mathbf{7}$ & $\mathbf{8}$ & $\mathbf{9}$ & $\mathbf{1 0}$ \\
\hline$l_{i}$ & 22 & 42 & 33 & 64 & 24 & 38 & 41 & $\mathbf{1 0}$ & 30 & 45 \\
$d_{i}$ & 4913 & 8383 & 4454 & 5563 & 5674 & 5228 & 5009 & 4736 & 9063 & 6160 \\
\hline Item & $\mathbf{1 1}$ & $\mathbf{1 2}$ & $\mathbf{1 3}$ & $\mathbf{1 4}$ & $\mathbf{1 5}$ & $\mathbf{1 6}$ & $\mathbf{1 7}$ & $\mathbf{1 8}$ & $\mathbf{1 9}$ & $\mathbf{2 0}$ \\
\hline $\boldsymbol{l}_{i}$ & 70 & 11 & 26 & 57 & 39 & 71 & 37 & 72 & 20 & 62 \\
$\boldsymbol{d}_{i}$ & 7412 & 6245 & 8954 & 9553 & 9339 & 6440 & 4941 & 1976 & 7372 & 4200 \\
\hline
\end{tabular}

TABELA 5.20: Dados utilizados no caso unidimensional - classe 3.

\begin{tabular}{c|c|c|c|c|c|c|c|c|c|c}
\hline Item & $\mathbf{1}$ & $\mathbf{2}$ & $\mathbf{3}$ & $\mathbf{4}$ & $\mathbf{5}$ & $\mathbf{6}$ & $\mathbf{7}$ & $\mathbf{8}$ & $\mathbf{9}$ & $\mathbf{1 0}$ \\
\hline $\boldsymbol{l}_{\boldsymbol{i}}$ & 40 & 23 & 5 & 41 & 24 & 48 & 31 & 34 & 11 & 20 \\
$\boldsymbol{d}_{i}$ & 1193 & 3772 & 1946 & 8282 & 5274 & 7554 & 1070 & 7998 & 8618 & 5735 \\
\hline
\end{tabular}

TABELA 5.21: Dados utilizados no caso unidimensional - classe 4.

\begin{tabular}{c|c|c|c|c|c|c|c|c|c|c}
\hline Item & $\mathbf{1}$ & $\mathbf{2}$ & $\mathbf{3}$ & $\mathbf{4}$ & $\mathbf{5}$ & $\mathbf{6}$ & $\mathbf{7}$ & $\mathbf{8}$ & $\mathbf{9}$ & $\mathbf{1 0}$ \\
\hline $\boldsymbol{l}_{i}$ & 8 & 33 & 12 & 22 & 11 & 9 & 46 & 48 & 26 & 15 \\
$\boldsymbol{d}_{i}$ & 2214 & 8548 & 1482 & 4633 & 6794 & 9797 & 1736 & 7129 & 4285 & 6473 \\
\hline Item & $\mathbf{1 1}$ & $\mathbf{1 2}$ & $\mathbf{1 3}$ & $\mathbf{1 4}$ & $\mathbf{1 5}$ & $\mathbf{1 6}$ & $\mathbf{1 7}$ & $\mathbf{1 8}$ & $\mathbf{1 9}$ & $\mathbf{2 0}$ \\
\hline $\boldsymbol{l}_{i}$ & 44 & 35 & 7 & 18 & 38 & 41 & 40 & 30 & 13 & 8 \\
$\boldsymbol{d}_{i}$ & 5918 & 5077 & 1575 & 2025 & 4314 & 4652 & 8123 & 2949 & 7027 & 8219 \\
\hline
\end{tabular}

No caso bidimensional os dados dos exemplos das classes 1 e 2 estão listados nas tabelas 5.22 e 5.23 , respectivamente.

TABELA 5.22: Dados utilizados no caso bidimensional - classe 1.

\begin{tabular}{c|c|c|c|c|c|c|c|c|c|c}
\hline Item & $\mathbf{1}$ & $\mathbf{2}$ & $\mathbf{3}$ & $\mathbf{4}$ & $\mathbf{5}$ & $\mathbf{6}$ & $\mathbf{7}$ & $\mathbf{8}$ & $\mathbf{9}$ & $\mathbf{1 0}$ \\
\hline $\boldsymbol{l}_{i}$ & 40 & 32 & 57 & 25 & 33 & 72 & 23 & 13 & 55 & 27 \\
$\boldsymbol{w}_{i}$ & 40 & 60 & 31 & 26 & 54 & 35 & 25 & 65 & 21 & 67 \\
$\boldsymbol{l}_{i}$ & 7340 & 7269 & 2413 & 3805 & 1004 & 9869 & 9165 & 9331 & 2720 & 4222 \\
\hline
\end{tabular}


TABELA 5.23: Dados utilizados no caso bidimensional - classe 2.

\begin{tabular}{c|c|c|c|c|c|c|c|c|c|c}
\hline Item & $\mathbf{1}$ & $\mathbf{2}$ & $\mathbf{3}$ & $\mathbf{4}$ & $\mathbf{5}$ & $\mathbf{6}$ & $\mathbf{7}$ & $\mathbf{8}$ & $\mathbf{9}$ & $\mathbf{1 0}$ \\
\hline $\boldsymbol{l}_{i}$ & 30 & 66 & 68 & 56 & 50 & 16 & 35 & 53 & 70 & 51 \\
$\boldsymbol{w}_{i}$ & 63 & 21 & 34 & 29 & 69 & 69 & 43 & 23 & 23 & 51 \\
$\boldsymbol{d}_{i}$ & 9719 & 5243 & 6670 & 2667 & 2127 & 7389 & 1599 & 9171 & 7326 & 5869 \\
\hline Item & $\mathbf{1 1}$ & $\mathbf{1 2}$ & $\mathbf{1 3}$ & $\mathbf{1 4}$ & $\mathbf{1 5}$ & $\mathbf{1 6}$ & $\mathbf{1 7}$ & $\mathbf{1 8}$ & $\mathbf{1 9}$ & $\mathbf{2 0}$ \\
\hline $\boldsymbol{l}_{i}$ & 16 & 58 & 69 & 58 & 22 & 55 & 50 & 47 & 67 & 47 \\
$\boldsymbol{w}_{i}$ & 47 & 47 & 29 & 36 & 56 & 71 & 60 & 18 & 30 & 18 \\
$\boldsymbol{d}_{\boldsymbol{i}}$ & 7646 & 3675 & 5117 & 8508 & 3295 & 5358 & 7999 & 6382 & 1080 & 7429 \\
\hline
\end{tabular}

Nas figuras 5.1 a 5.8 o eixo $x$ corresponde à perda (em porcentagem) e o eixo y ao menor número máximo de pilhas abertas, obtido com o seqüenciamento dos padrões gerados pelo método simplex. Para o exemplo unidimensional da classe 1 ( $m=10$ e $l_{i} \in[0,10 L$; $0,75 L]$ ), variou- se $p \hat{i}=1,2, \ldots, 5$ (note que 5 é o limitante superior para este exemplo, pois é o número máximo de pilhas abertas obtidas pelo método simplex, sem a restrição para o número máximo de tipos de itens nos padrões, e a heurística 3). Nas figuras 5.1 e 5.2 ilustramse as curvas de eficiência para o exemplo unidimensional da classe 1 e da classe 2 (os dados desses exemplos estão listados nas tabelas 5.18 e 5.19 , respectivamente).

$\diamond$ Simplex com Heurística $3 \square$ Abordagem $1 \quad \Delta$ Abordagem $2 \quad 0$ Abordagem 3

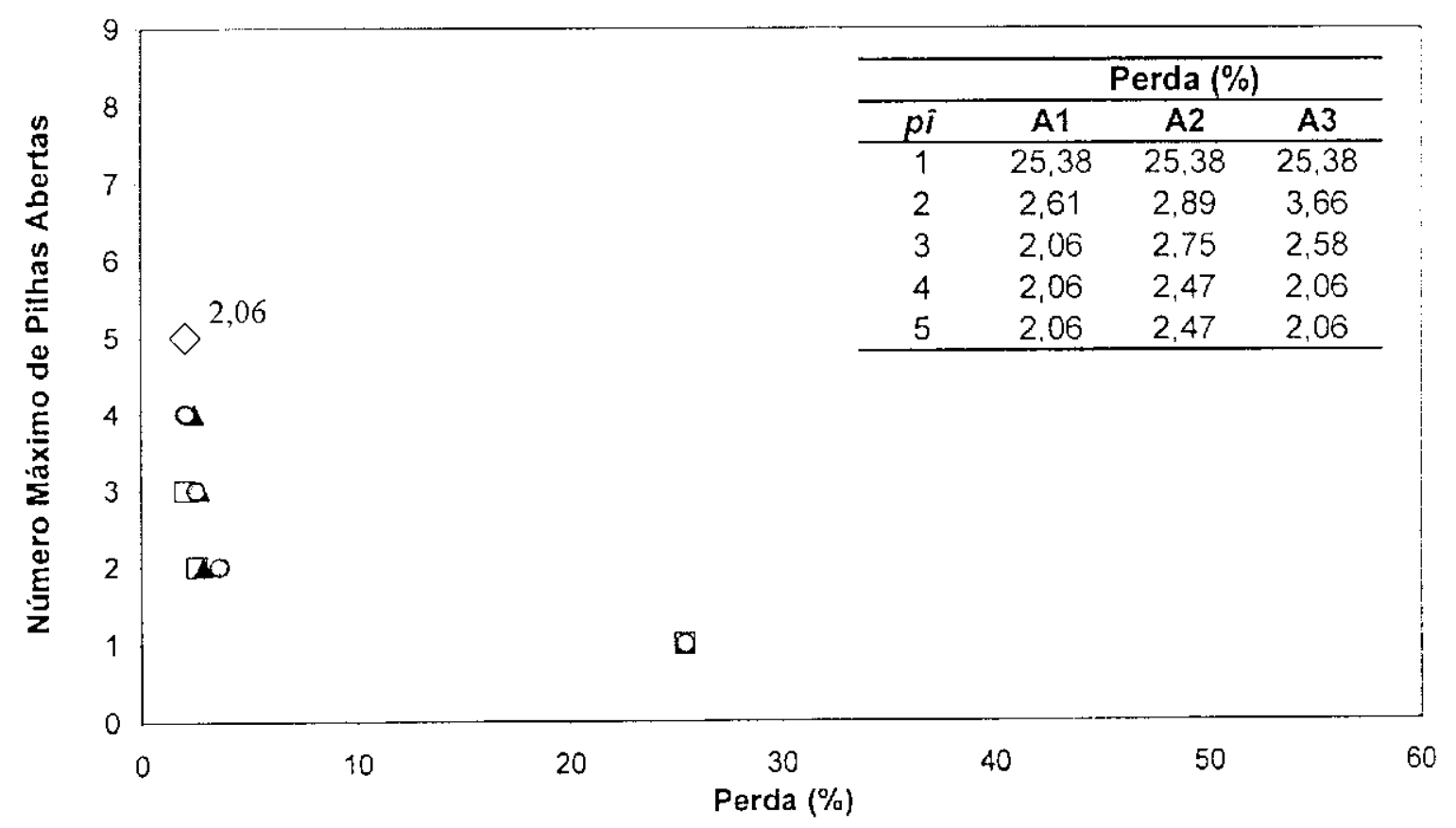

FIGURA 5.1: Curvas de trade-off entre a perda e o número máximo de pilhas abertas no caso unidimensional - classe $1-G G_{-}$uni.

Observe na figura 5.1 que as curvas geradas pelas três abordagens são bastante próximas, porém, a Abordagem I apresenta soluções um pouco melhores que as demais. Para este exemplo unidimensional da classe 1 a Abordagem 1 dominou as Abordagens 2 e 3. 
Para o exemplo unidimensional da classe $2\left(m=20\right.$ e $\left.l_{i} \in[0,10 L ; 0,75 L]\right)$, variou-se $p \hat{i}=1,2, \ldots, 7$ (note que 7 é o limitante superior para este exemplo, pois foi o número máximo de pilhas abertas obtidas pelo método simplex, sem a restrição para o número máximo de tipos de itens nos padrões, e a heurística 3).

$\diamond$ Simplexcom Heuristica $3 \square$ Abordagem 1 A Abordagem 2 A Abordagem 3

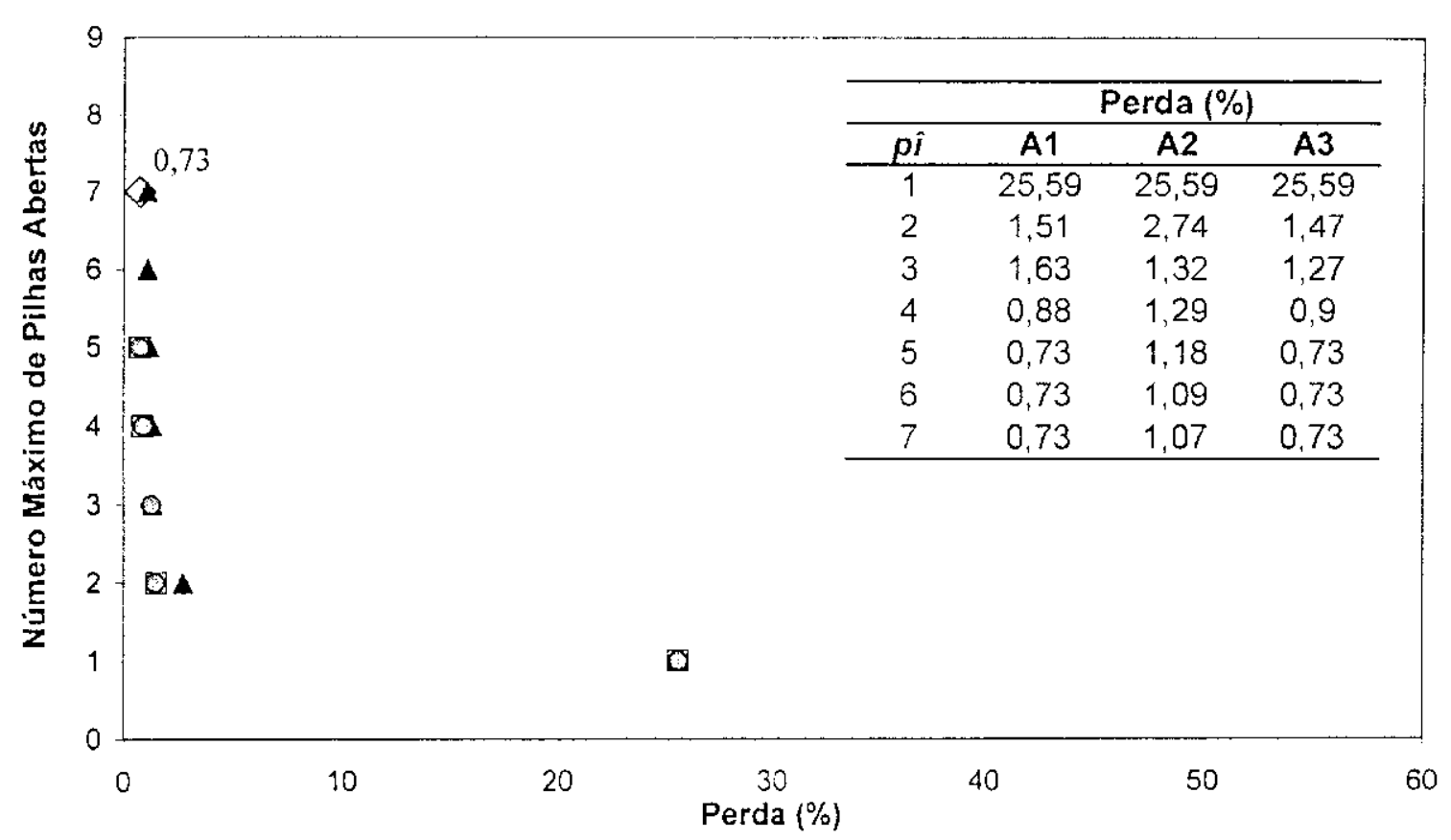

FIGURA 5.2: Curvas de trade-off entre a perda e o número máximo de pilhas abertas para o caso unidimensional - classe $2-G G_{-}$uni.

Note na figura 5.2 que as Abordagens 1 e 3 apresentam um desempenho um pouco melhor que a Abordagem 2 e além disso uma não domina a outra. Observe que Abordagem 1 não domina a Abordagem 2 e vice versa, a Abordagem 2 não domina a Abordagem 1 (veja as colunas A1 e A2 da tabela do gráfico da figura 5.2, as linhas com $p \hat{i}=3$ e 4). A Abordagem 1 também não domina a Abordagem 3 e vice versa, a Abordagem 3 não domina a Abordagem 1 (veja as colunas A1 e A3 da tabela do gráfico da figura 5.2, as linhas com $p \hat{i}=3$ e 4).

Nas figuras 5.3 e 5.4 as curvas de eficiência para as classes $3\left(m=10, l_{i} \in[0,05 \mathrm{~L} ;\right.$ $0,50 L])$ e $4\left(m=20, l_{i} \in[0,05 L ; 0,50 L]\right)$ são apresentadas (os dados destes exemplos estão descritos nas tabelas 5.20 e 5.21). Para a classe 3 variou-se $p \hat{i}=1,2, \ldots, 6$ e para a classe 4 $p \hat{i}=1,2, \ldots, 8$, visto que 6 e 8 são os limitantes inferiores para cada classe respectivamente.

Observe na figura 5.3 que as três abordagens apresentam soluções bastante próximas e que novamente a Abordagem 1 não domina a Abordagem 2 e vice versa, e também a 
Abordagem 1 não domina a Abordagem 3 e vice e versa (veja as colunas Al e A2, e A1 e A3 da tabela do gráfico da figura 5.3, as linhas com $p \hat{i}=2$ e 3 ).

$\diamond$ Simplex com Heuristica $3 \square$ Abordagem 1

A Abordagem 2

- Abordagem 3

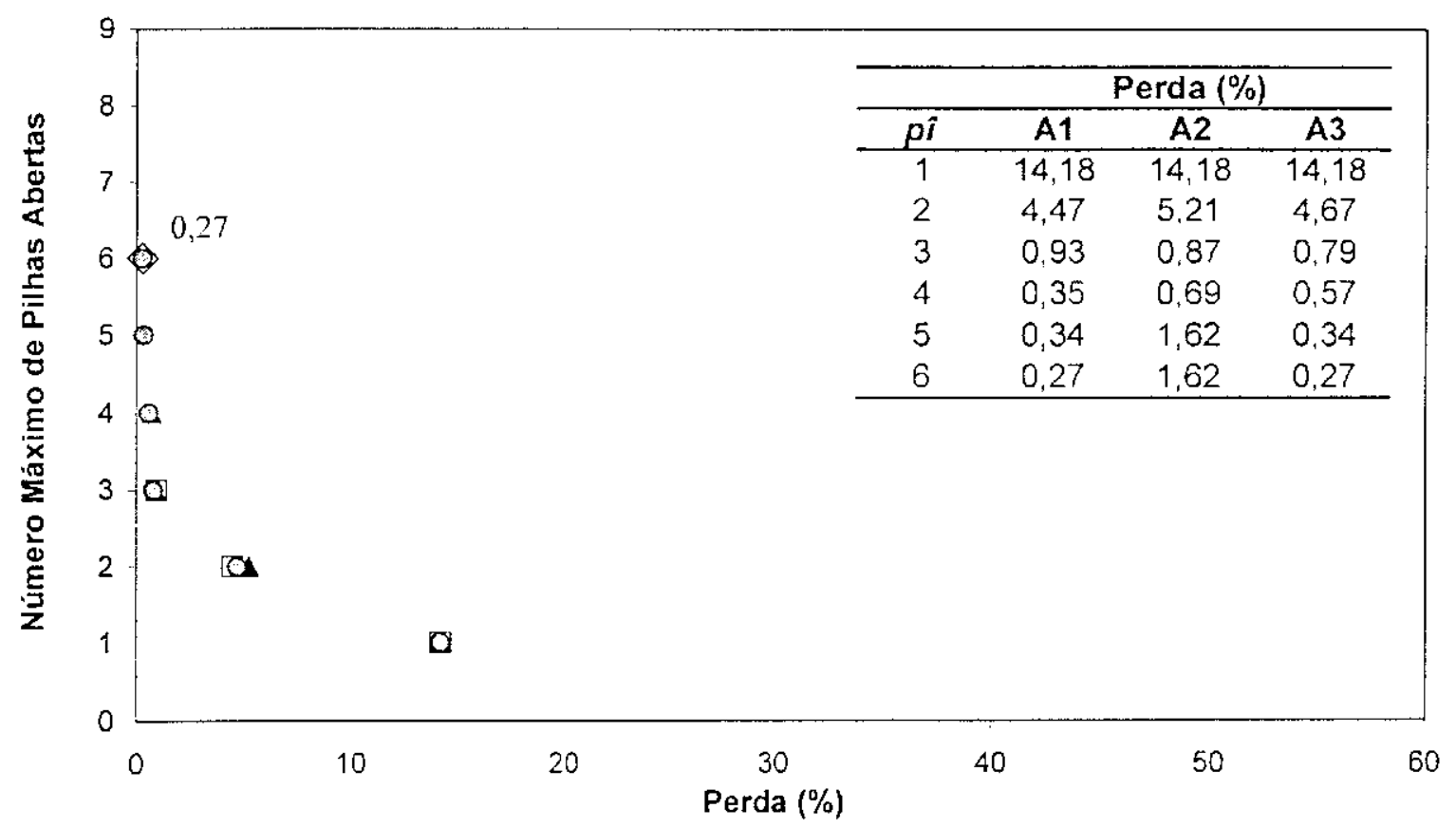

FIGURA 5.3: Curvas de trade-off entre a perda e o número máximo de pilhas abertas para o caso unidimensional - classe $3-G G_{-}$uni.

$\diamond$ Simplex com Heuristica 3

$\square$ Abordagem 1

A Abordagem 2

- Abordagem 3

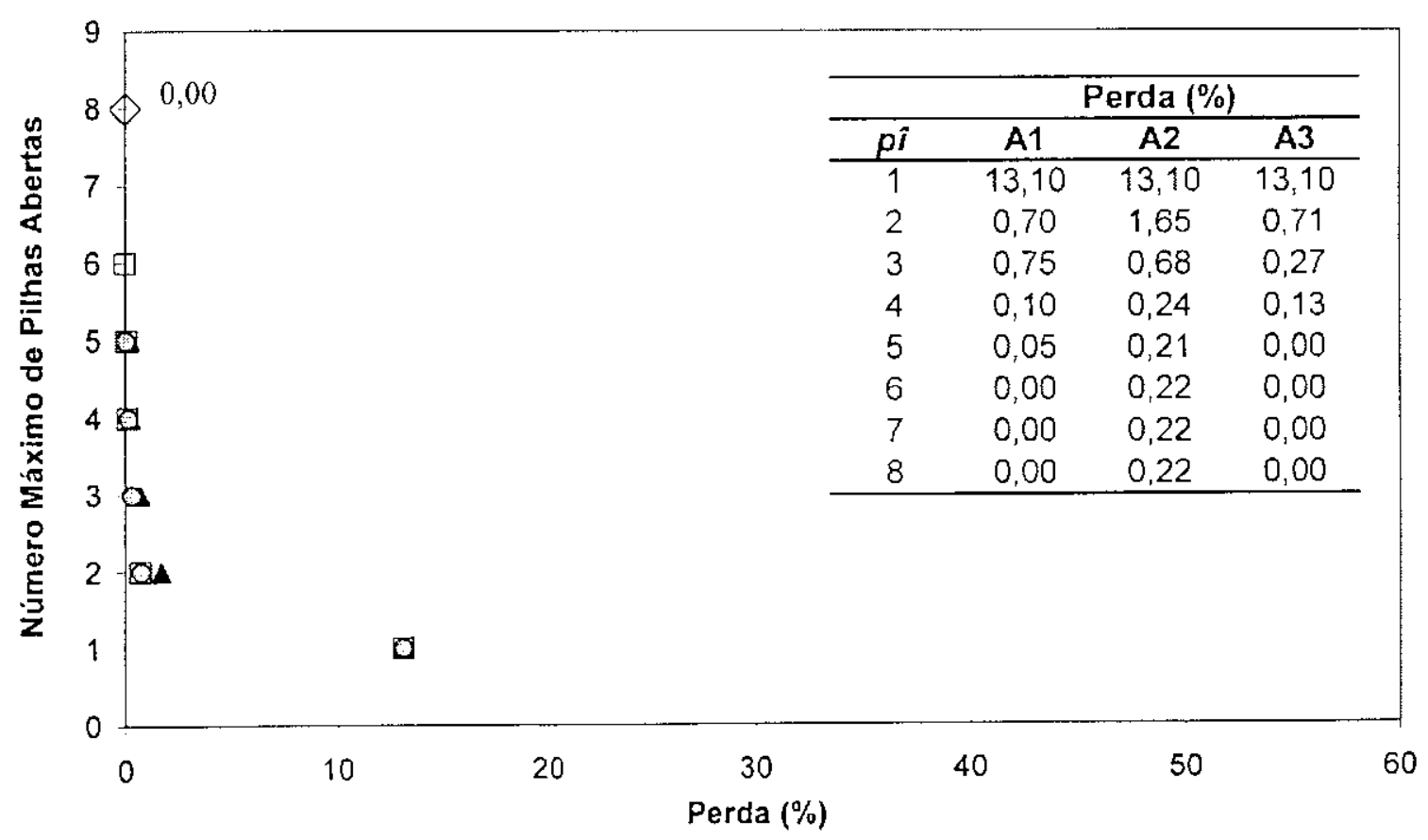

FIGURA 5.4: Curvas de trade-off entre a perda e o número máximo de pilhas abertas para o caso unidimensional - classe 4-GG_uni. 
Pela figura 5.4 pode-se observar que os valores obtidos pelas três abordagens são próximos, com uma pequena piora da Abordagem 2 para $p \hat{i}=2$ e 3 . Novamente, como aconteceu para as classes 2 e 3, a Abordagem 1 não domina a Abordagem 2 e vice versa, e a Abordagem 1 também não domina a Abordagem 3 e vice versa (veja as colunas Al e A2, e A1 e A3 da tabela do gráfico da figura 5.4, as linhas com $p \hat{i}=3$ e 4

As figuras 5.5 c 5.6 ilustram as curvas de eficiência para o exemplo bidimensional da classe 1, utilizando o método $G G_{-}$bi e Geou bi, respectivamente (os dados deste exemplo estão listados nas tabelas 5.22). Para este exemplo $\left(m=10, l_{i} \in[0,10 L ; 0,75 L]\right.$ e $w_{i} \in[0,10 W$; $0,75 \mathrm{~W}$ ), variou-se $p \hat{i}=1,2, \ldots, 6$ (note que 6 é o limitante superior para este exemplo).

$\diamond$ Simplex com Heurística $3 \quad \square$ Abordagem 1

A Abordagem 2

- Abordagem 3

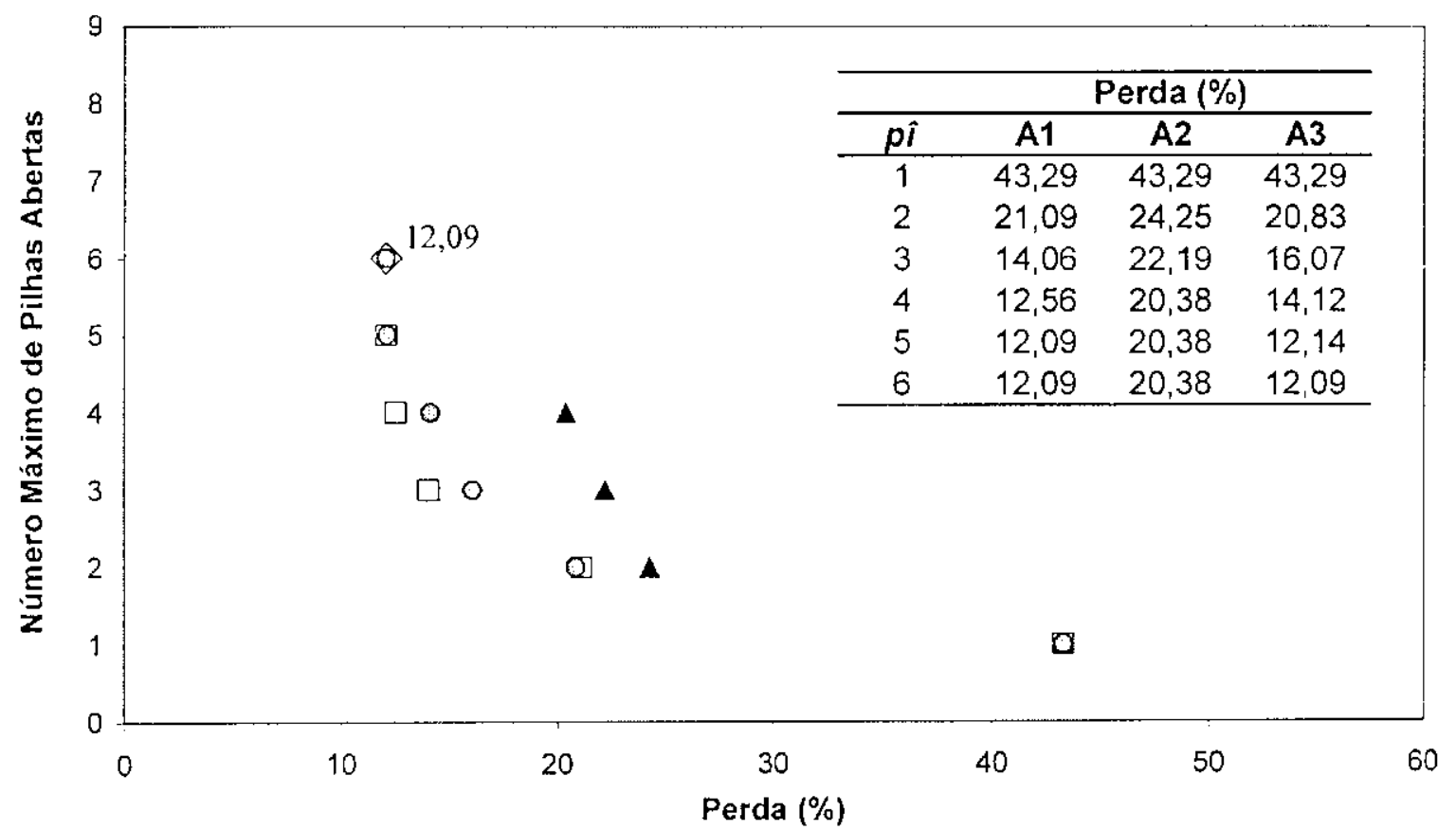

FIGURA 5.5: Curvas de trade-off entre a perda e o número máximo de pilhas abertas para o caso bidimensional - classe $1-G G_{-} b i$.

Observe nas figuras 5.5 e 5.6 que as Abordagens 1 e 3 apresentam um desempenho melhor que a Abordagem 2. Note que a Abordagem 1 apresenta um comportamento em geral melhor que a Abordagem 3. 
$\diamond$ Simplex com Heuristica 3

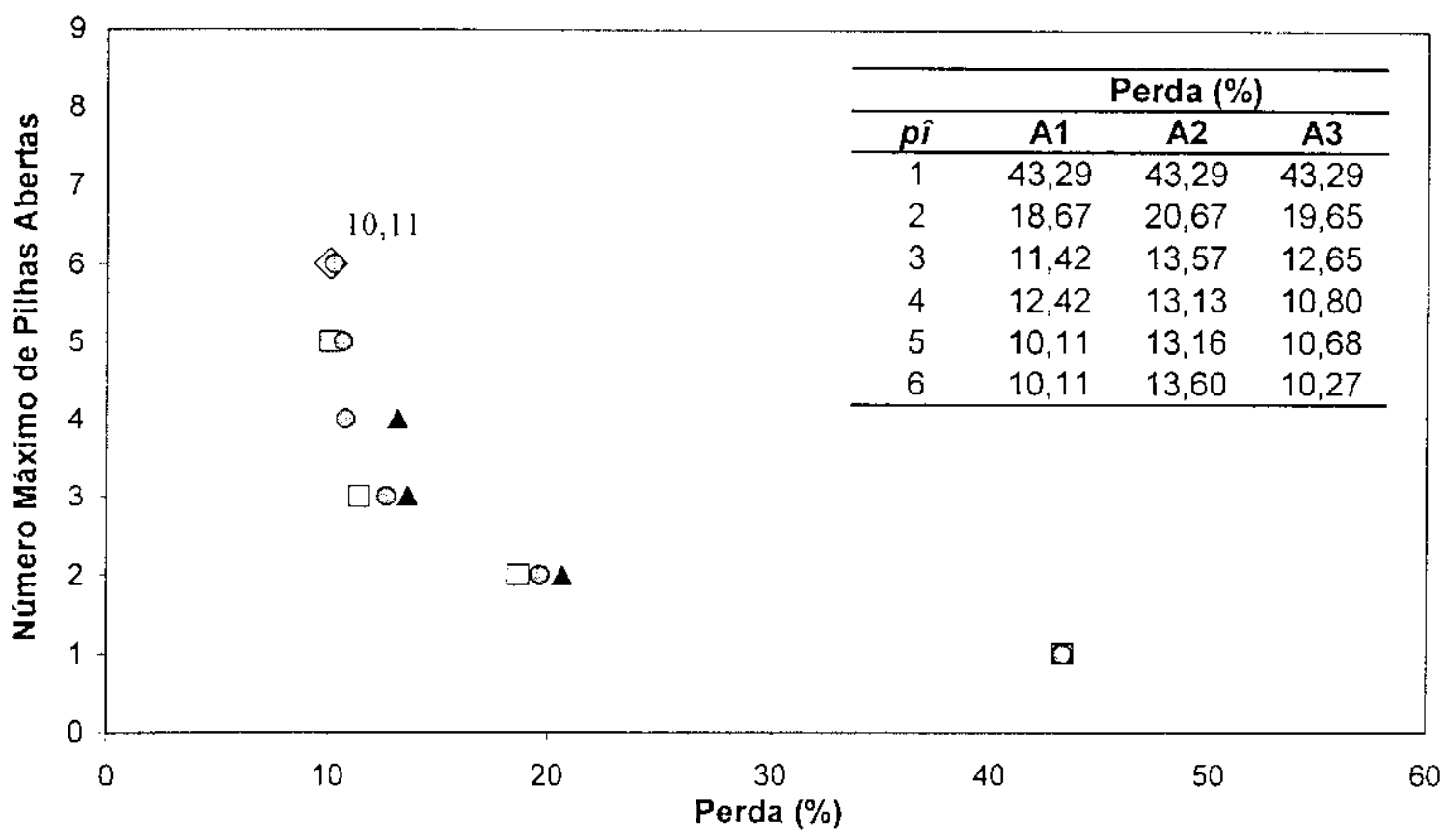

FIGURA 5.6: Curvas de trade-off entre a perda e o número máximo de pilhas abertas para o caso bidimensional - classe 1-Geou_bi.

Nas figuras 5.7 e 5.8 as curvas de eficiência para o exemplo bidimensional da classe 2, utilizando o método $G G_{-} b i$ e Geou_bi, respectivamente são ilustradas (os dados deste exemplo está listado na tabela 5.23).

Para este exemplo $\left(m=20, l_{i} \in[0,10 L ; 0,75 L]\right.$ e $\left.w_{i} \in[0,10 \mathrm{~W} ; 0,75 \mathrm{~W}]\right)$, variou-se $p \hat{i}=$ $1,2, \ldots, 8$ (note que 8 é o limitante superior para este exemplo, pois foi o número máximo de pilhas abertas obtidas pelo método simplex, sem a restrição para o número máximo de tipos de itens nos padrões, e a heurística 3). 
$\diamond$ Simplex com Heuristica $3 \square$ Abordagem 1 ॥ Abordagem 2 Abordagem 3

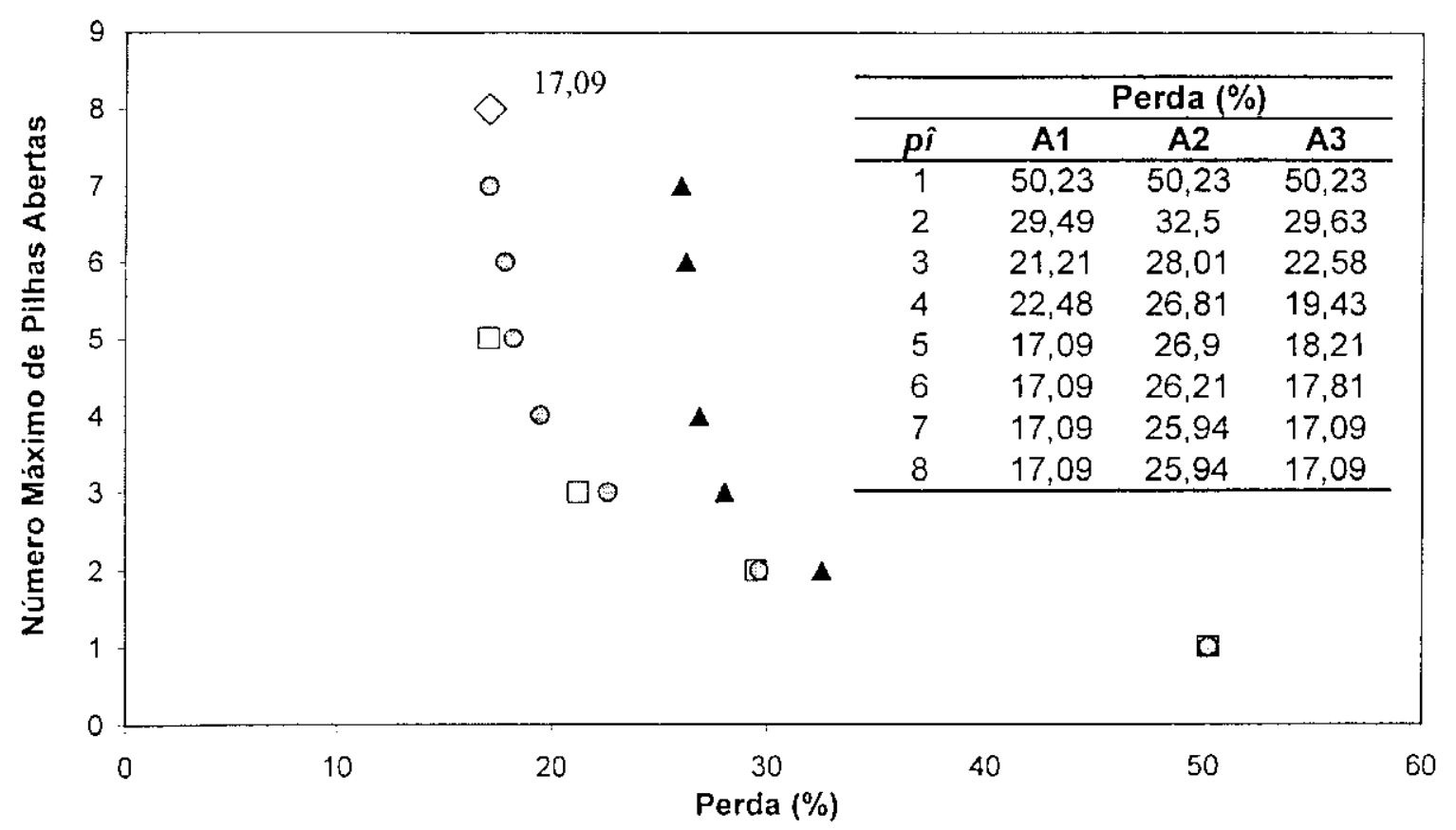

FIGURA 5.7: Curvas de trade-off entre a perda e o número máximo de pilhas abertas para o caso bidimensional - classe $2-G G_{-} b i$.

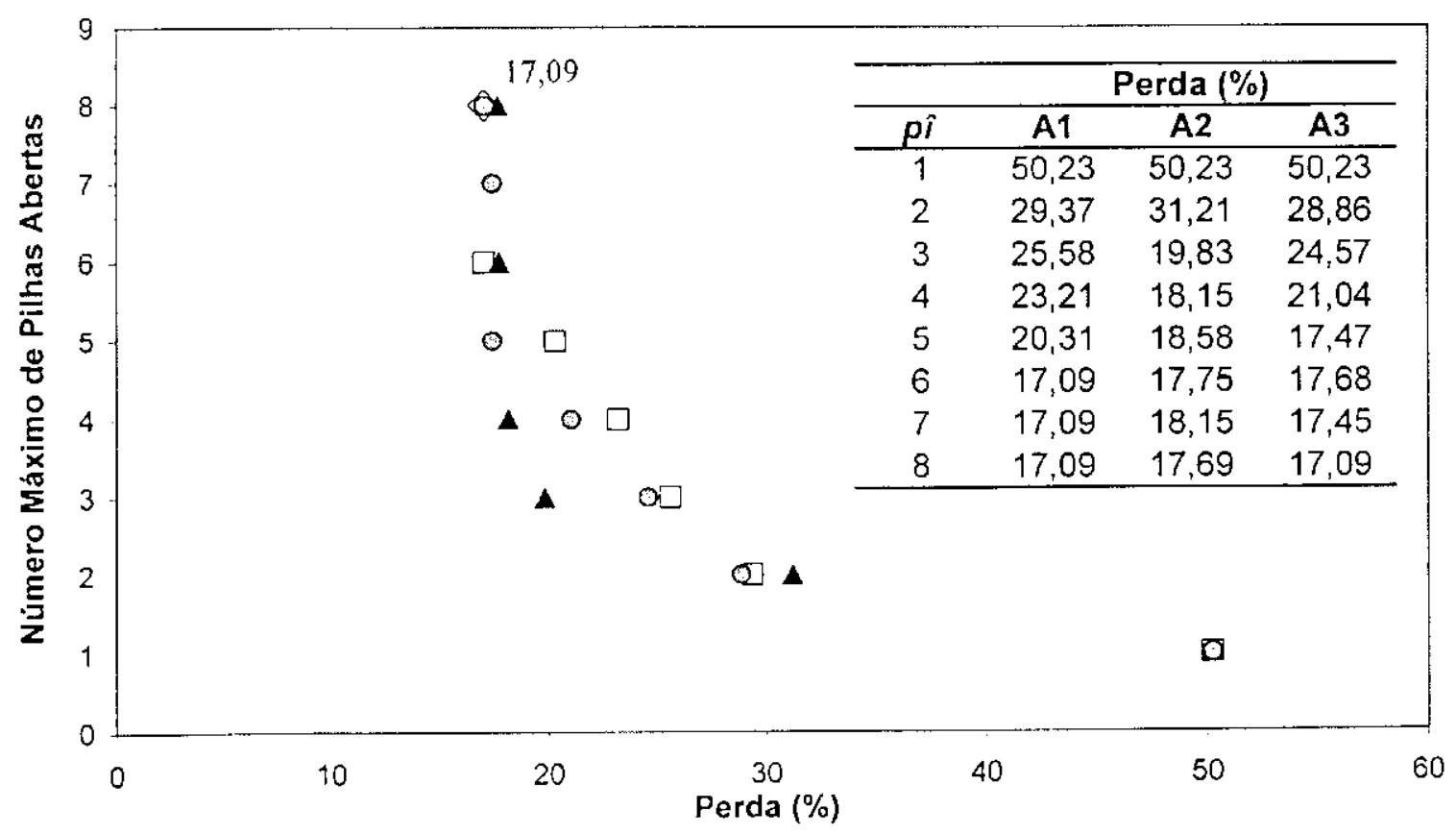

FIGURA 5.8: Curvas de trade-off entre a perda e o número máximo de pilhas abertas para o caso bidimensional - classe 2 - Geou_bi. 
Observe na figura 5.7 que, quando o método $G G_{-} b i$ é utilizado, as Abordagens le 3 são bastante próximas e que a Abordagem 1 domina as Abordagens 2 e 3 . Por outro lado, quando o método Geou_bi (figura 5.8) é utilizado, as Abordagens 1 e 2 não dominam uma a outra, nem a Abordagem 2 domina a Abordagem 3 e vice versa. Neste caso a Abordagem 2 mostrou-se bastante competitiva com as demais.

Note que, quando o método $G G_{--}$bi é utilizado, a Abordagem 2 apresenta o pior desempenho, por outro lado, quando o método Geou_bi é utilizado os melhores desempenhos obtidos alternam-se entre as Abordagens 1,2 e 3 (compare a tabela da figura 5.7 com a tabela da figura e 5.8).

Os resultados obtidos pelas curvas de trade-off mostram que as Abordagens 1 e $2,1 \mathrm{e}$ 3 e 2 e 3, não dominam uma a outra, e as perdas médias obtidas pela Abordagem 2 são, em geral, piores.

\subsection{Análise de um exemplo real}

Para ilustrar o desempenho das abordagens propostas neste trabalho na resolução de um problema real, considere o exemplo da fábrica de móveis Colombini, analisada em Morabito e Arenales (2000), onde chapas com dimensão $(L \times W)=(3.670 \times 1.850) \mathrm{m}^{2}$ são utilizadas, para produzir 15 tipos de itens, cujas dimensões e demandas estão listados na tabela 5.24. Para resolução deste exemplo a espessura de serra de $0.004 \mathrm{~m}$ foi desconsiderada. Inicialmente considerou-se para este exemplo $p \hat{i}=3$.

A máquina de corte da fábrica Colombini permite o corte de padrões com no máximo 2-estágios (Apêndice A). Para resolver o exemplo da tabela 5.24, comparou-se a solução obtida pelo método simplex e pela heuristica 3 de Yuen (1995), que produz um limitante inferior para a perda mínima, com as soluções obtidas pelas Abordagens 1,2 e 3, utilizando para todos os casos o método exato em duas fases de Gilmore e Gomory (1965), GG_bi, para a geração dos padrões . 
TABELA 5.24: Dados da fábrica de móveis Colombini.

\begin{tabular}{cccc}
\hline Item & $\boldsymbol{w}_{\boldsymbol{i}}(\boldsymbol{m})$ & $\boldsymbol{l}_{\boldsymbol{i}}(\boldsymbol{m})$ & $\boldsymbol{b}_{\boldsymbol{i}}$ \\
\hline $\mathbf{1}$ & 0,609 & 0,274 & 320 \\
$\mathbf{2}$ & 0,380 & 0,274 & 1260 \\
$\mathbf{3}$ & 0,425 & 0,330 & 630 \\
$\mathbf{4}$ & 0,650 & 0,361 & 630 \\
$\mathbf{5}$ & 0,348 & 0,270 & 315 \\
$\mathbf{6}$ & 0,705 & 0,270 & 893 \\
$\mathbf{7}$ & 0,718 & 0,328 & 2520 \\
$\mathbf{8}$ & 0,705 & 0,300 & 90 \\
$\mathbf{9}$ & 0,465 & 0,330 & 4410 \\
$\mathbf{1 0}$ & 0,480 & 0,330 & 315 \\
$\mathbf{1 1}$ & 0,465 & 0,330 & 630 \\
$\mathbf{1 2}$ & 1,956 & 0,250 & 112 \\
$\mathbf{1 3}$ & 0,674 & 0,302 & 118 \\
$\mathbf{1 4}$ & 0,674 & 0,270 & 181 \\
$\mathbf{1 5}$ & 0,636 & 0,270 & 493 \\
\hline
\end{tabular}

$\mathrm{Na}$ tabela 5.25 apresenta-se os resultados obtidos pelas Abordagens 1,2 e 3, com o método $G G_{-} b i$ para a geração dos padrões de corte. Nesta tabela a coluna "Método de Solução" corresponde ao método utilizado para resolver o problema, e as colunas "Perda", "Pilha" e "Tempo" correspondem, respectivamente, à perda média (em \%), ao menor número máximo de pilhas abertas e ao tempo (em segundos) encontrados por cada método de solução.

TABELA 5.25: Resultados obtidos para o exemplo da fábrica Colombini - $G G \_b i$.

\begin{tabular}{l|rcc}
\hline \multicolumn{1}{c|}{ Método de Solução } & Perda & Pilha & Tempo \\
\hline Simplex com Heurística 3 & 6,52 & 14 & 0,05 \\
Abordagem 1 & 9,26 & 3,00 & 13,30 \\
Abordagem 2 & 11,68 & 3,00 & 0,53 \\
Abordagem 3 & 8,26 & 3,00 & 5,41 \\
\hline
\end{tabular}

Note na primeira linha da tabela 5.25 que o menor número máximo de pilhas abertas para este exemplo foi 14. Para satisfazer a restrição sobre o número máximo de pilhas abertas definido ( $p \hat{i}=3$ ), é necessário reduzir 11 pilhas. Apesar desta grande redução de 14 para 3 pilhas, observe que a Abordagem 3 apresenta uma solução razoavelmente próxima do limitante inferior (1,74\% de perda a mais), seguida das Abordagens 1 e 2. Os tempos computacionais (ordem de segundos) são bem satisfatórios para as decisões envolvidas nas situações reais.

Apesar de a máquina de corte da fábrica de móveis Colombini só poder cortar padrões em até 2-estágios, a título de ilustração avaliou-se a geração de padrões de corte com mais que 2 estágios através da abordagem em grafo e/ou. Os parâmetros de depth, $\alpha$ e $\beta$ utilizados 
foram 3, 1,01 e 0,9, respectivamente. Na tabela 5.26 abaixo apresenta-se as soluções obtidas, utilizando o método Geou_bi (na coluna "Tempo" os valores estão em minutos).

TABELA 5.26: Resultados obtidos para o exemplo da fábrica Colombini - Geou_bi.

\begin{tabular}{l|ccc}
\hline \multicolumn{1}{c|}{ Método de Solução } & Perda & Pilha & Tempo \\
\hline Simplex com Heuristica 3 & 5,60 & 9 & $<2,0$ \\
Abordagem 1 & 7,12 & 3,00 & 300 \\
Abordagem 2 & 10,48 & 3,00 & 3,0 \\
Abordagem 3 & - & - & - \\
\hline
\end{tabular}

O método simplex com a heurística 3 obteve uma perda de 5,60\% com 9 pilhas abertas, o que corresponde a uma economia de $0,92 \%$ na perda e 5 pilhas a menos em relação ao resultado da tabela 5.25. Note entretanto, que dado que a abordagem $\mathrm{cm}$ grafo e/ou não é exata, esta perda de 5,60\% não necessariamente corresponde a um limitante inferior para o problema, conforme discussão das seções anteriores. Quando a Abordagem 1 com o método Geou_bi é utilizada a perda encontrada é de 7,12\%, que corresponde a uma melhoria de 2,14\%, quando comparada com a perda obtida pela Abordagem 1 com o método $G G$ bi, porém, à custa de um alto tempo computacional (aproximadamente 5 horas). A Abordagem 2 encontra uma solução pior $(10,48 \%)$ do que a Abordagem 1, quando o método Geou_bi é utilizado, mas com um tempo computacional significativamente menor (apenas 3,0 minutos). Note que a Abordagem 2 encontra uma solução um pouco melhor quando o método Geou_bi é utilizado (10,48\%) quando comparada com o método $G G_{-}$bi $(11,68 \%)$. Com relação à Abordagem 3, o programa foi abortado após 10 horas de execução.

Observe que os valores da tabela 5.26 obtidos tanto pelo método simplex como pelas Abordagens 1 e 2 são melhores que os da tabela 5.25, visto que um número maior de estágios agora pode ser utilizado na geração dos padrões. No entanto, os esforços computacionais são substancialmente superiores.

Para avaliar o comportamento das três abordagens para diferentes valores de $p \hat{i}$, as mesmas foram utilizadas para gerar as curvas de trade-off para o exemplo da tabela 5.24 utilizando $G G_{-} b i$ para a geração dos padrões de corte. 


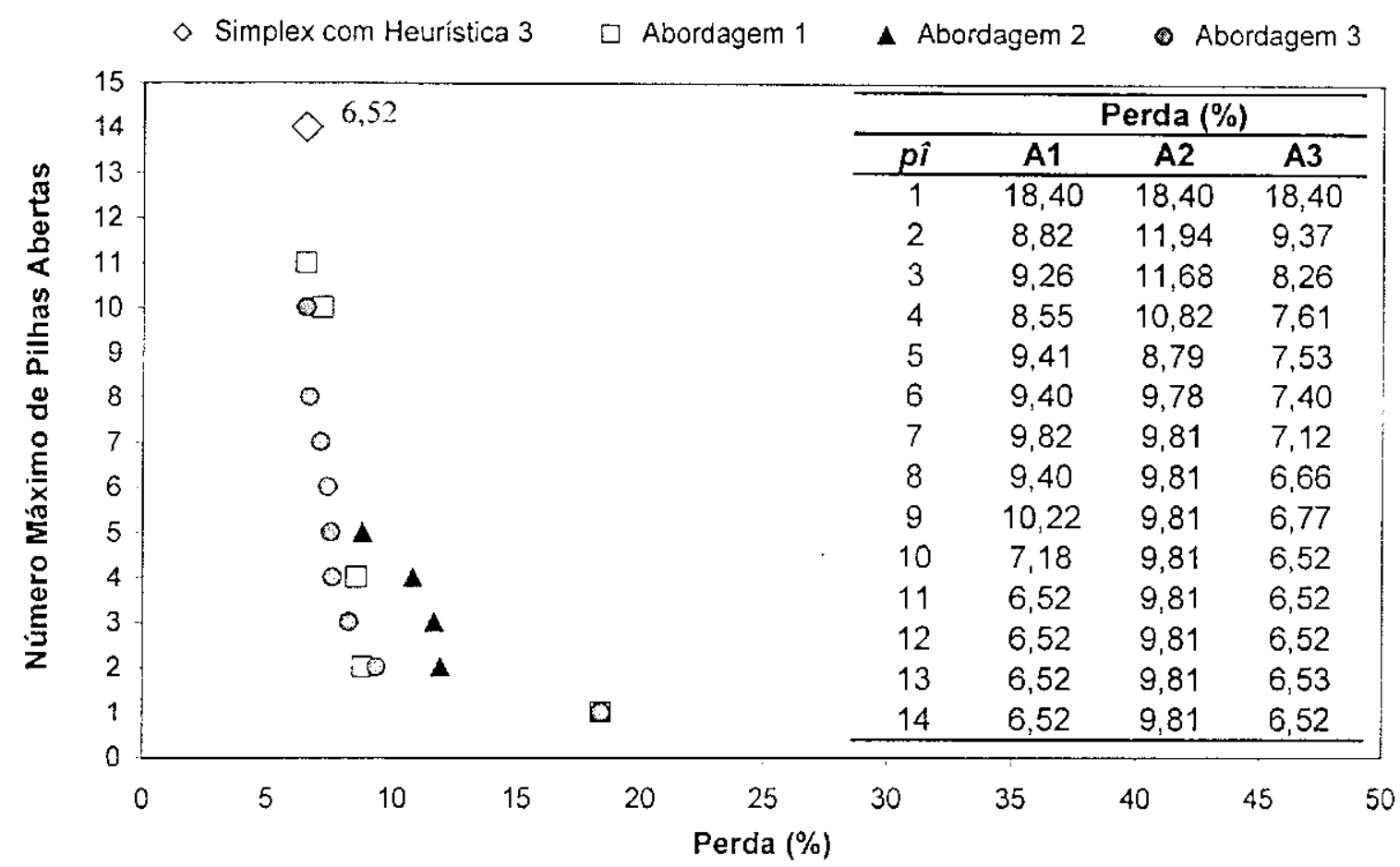

FIGURA 5.9: Curvas de trade-off entre a perda e o número máximo de pilhas abertas para o exemplo da tabela $5.24-G G_{-}$bi.

Conforme pode-se observar pela figura 5.8, as Abordagens 1 e 3 tiveram um comportamento melhor que a Abordagem 2. Em geral, as Abordagens 1 e 3 dominam a Abordagem 2, mas não dominam uma a outra.

Estas curvas podem ser utilizadas na prática para auxiliar, por exemplo, um gerente de produção na tomada de decisão envolvendo perda e número de pilhas abertas. 


\section{CONCLUSÕES E PERSPECTIVAS}

\subsection{Conclusões}

No problema de geração de padrões de corte objetiva-se encontrar um conjunto de padrões que será repetido um certo número de vèes, e que satisfaça algum critério a ser otimizado, por exemplo, minimizar a perda. O problema de seqüenciamento de padrões de corte consiste em determinar uma seqüência na qual os padrões serão cortados, de forma a otimizar algum critério, por exemplo, minimizar o número máximo de pilhas abertas (MOSP).

Em geral, uma boa solução para o problema de corte (isto é, un conjunto de padrões com baixa perda) não resulta numa boa solução para o problema de seqüenciamento (uma seqüència com baixo número máximo de pilhas abertas), e vice-versa. Existe, portanto, um Irate-off entre os objetivos dos dois problemas, o que sugere que os problemas devem ser resolvidos de forma integradia. Lim geral ambos säo resolvidos, tanto na prática como na litcratura, de forma independente e sucessiva. Em um primeiro estágio, resolve-se o problema de corte e, a partir da solução obtida (conjunto de padrôes de mínima perda), resolve-se o problema de seqüenciamento em scgundo estágio, o que pode produzir uma solução com elevado número de pilhas abertas.

Cabe notar que poucos são os trabalhos encontrados na literatura que tratam dos problemas de geração e seqüenciamento de padrões de forma integrada.

Neste trabalho três abordagens foran propostas para resolver estes dois problemas de forma integrada. As três abordagens basciam-se na minimização do objetivo do problema de corte sujeito à limitação do objetivo do problema de seqüenciamento (problema $(P 2)$ ). Estas 
abordagens também podem ser utilizadas para gerar pontos da fronteira eficiente entre perda e número máximo de pilhas abertas, variando-se a limitação do problema de seqüenciamento.

A Abordagem l consiste em resolver os problemas de geração e seqüenciamento de padrões de forma seqüencial e iterativa, isto é, o problema de geração de padrões é resolvido em um primeiro estágio e o de seqüenciamento, em um segundo cstágio. Em função da qualidade da solução obtida para o problema de seqüenciamento, o problema de geração é novamente resolvido, mas agora com informações adicionais, que permitam que um novo conjunto de padrões seja gerado no primeiro estágio. E assim por diante, até que uma solução seja encontrada, ou um certo número de iterações seja rcalizado.

A Abordagem 2 baseia-se num procedimento também iterativo que, em cada iteração, utiliza uma heurística construtiva gulosa para gerar os padrões de corte, um após o outro, levando $\mathrm{cm}$ conta o resultado da seqüência dos mesmos. Ou seja, uma solução para o problema de corte vai sendo construída, passo a passo, considerando o número máximo de pilhas abertas com o seqüenciamento dos padrões como uma restrição. Este procedimento ć repetido por um certo número de vezes, variando-se os valores relativos dos itens.

A Abordagem 3 consiste em resolver o problema de corte, utilizando o método simplex com um procedimento de geração de colunas, de modo que o número máximo de pilhas abertas seja considerado durante o processo de geração de colunas.

Para avaliar o comportamento das três abordagens propostas, as mesmas foram utilizadas para resolver problemas de geração e seqüenciamento de padrões de corte unidimensionais e bidimensionais. O objetivo do problema de geração de padrões considerado foi a minimização da perda, e o objetivo do problema de seqüenciamento foi a minimização do número máximo de pilhas abertas (MOSP). Conforme dito anteriormente (capítulo 5), não se dispõe de limitantes inferiores eficazes para a perda e o número máximo de pilhas abertas do problema combinado de geração e seqüenciamento de padrões de corte. Em função disso, as abordagens foram comparadas entre si, e com o limitante inferior para a perda obtido do problema de corte.

Como seria de se esperar, observa-se que o gap médio entre as abordagens e o limitante inferior é menor no caso unidimensional do que no caso bidimensional. Além disso, no caso bidimensional, a medida cm que o número de tipos de itens aumenta (de $m=10$ para $m=20)$ e o tamanho dos mesmos diminui, este gap aumenta. Cabe observar que nestes casos o número máximo de pilhas abertas é, em média, maior. De modo geral as três abordagens tiveram um bom desempenho para os casos unidimensional e bidimensional, ou seja, o gap entre as soluções obtidas e o limitante inferior é razoavelmente pequeno. 
A Abordagem $/$ obteve os melhores resultados com relação ao número de primeiras colocações, dentre as 4 classes analisadas, ou seja, 3 e 2, respectivamente nos casos unidimensional e bidimensional (tabelas 5.8 e 5.16). A Abordagem 2 foi a que, em geral, obteve as piores colocações (apresentou as piores perdas em 3 das 4 classes analisadas). A Abordagem 3 apresentou um comportamento mais regular com relação ao número de colocações.

Com relação à perda média (tabelas 5.9 e 5.17), a Abordagem 3 obteve as menores perdas para o caso unidimensional, e a Abordagem $l$ as menores para o caso bidimensional. A Abordagem 2 apresentou para os dois casos as piores perdas médias.

Quando a redução necessária entre o número máximo de pilhas abertas obtido pelo seqüenciamento dos padrões gerados pelo método simplex e o limite imposto sobre o número máximo de pilhas abertas, pî́, é pequena, a Abordagem 1 apresenta os melhores desempenhos. A medida em que esta diferença cresce, a Abordagem 3 apresenta desempenhos melhores. Acredita-se que isto ocorre pois, à medida que a diferença entre o número de pilhas abertas obtido pelo seqüenciamento dos padrões gerados pelo método simplex e pîi aumenta, a Abordagem 1 em geral encontra uma solução factivel e com a menor perda a partir da rotina de factibilização da solução (que tem como objetivo obter uma solução com $p i \leq p \hat{i}$ ), pois a proibição de padrões não consegue encontrar soluções com baixa perda e factíveis. Por outro lado, quando essa diferença é pequena, em geral a solução factível e com menor perda é obtida pela rotina de corte.

Com relação aos tempos computacionais, a Abordagem $I$ em geral apresentou tempos computacionais maiores que a Abordagem 3 porém, quando a abordagem em grafo c/ou é utilizada para a geração dos padrões de corte a Abordagem 3 apresenta os maiores tempos. Isto é devido ao conjunto de testes (para verificação da factibilidade do seqüenciamento) aplicado na abordagem em grafo e/ou da Abordagem 3, que é muito mais demorado do que o conjunto de testes aplicado na Abordagem 1 . Cabe notar que isso também ocorre com o algoritmo lexicográfico, ou seja, o conjunto dos testes da Abordagem 3 também é mais demorado que os da Abordagem 1. porém a diferença entre os tempos é pouco significativa neste caso. A Abordagem 2 é a mais rápida de todas (independentemente de qual método é utilizado para a geração dos padrões de corte). Note que os tempos computacionais das três abordagens aumenlam de $m=10$ para $m=20$ e do caso unidimensional para o caso bidimensional. 
As três abordagens propostas também podem ser utilizadas para gerar curvas de trade-off entre a perda e o número máximo de pilhas abertas. Conforme ilustrado pelas curvas das figuras 5.1 a 5.8, as Abordagens 1, 2 e 3 não dominam uma a outra, e as perdas médias obtidas pela Abordagem 2 são, em geral, piores.

As Abordagens I, 2 c 3 também podem ser aplicadas com sucesso na prática, conforme ilustrado pelo exemplo da fábrica de móveis Colombini originalmente com perda média $6,52 \%$ e 14 pilhas abertas. A Abordagem 3 encontra uma solução com perda $8,26 \%$ (isto é, com um aumento de apenas 1,74\%) e apenas 3 pilhas abertas (isto é, com uma redução de 11 pilhas). Conforme ilustrado, as curvas de trade-off podem ser utilizadas na prática para auxiliar na tomada de decisão envolvendo perda e númcro de pilhas abertas.

\subsection{Perspectivas}

Uma perspectiva deste trabalho é desenvolver efetivamente estudos de casos aplicando as abordagens propostas em situações reais e comparar os resultados com os obtidos pelas empresas. Em particular pretende-se realizar estudos de casos $\mathrm{em}$ fábrica de móveis e fábrica de chapas duras.

Conforme mencionado, não foram cncontrados trabalhos na literatura propondo bons limitantes para o problema integrado de geração e seqüenciamento de padrões de corte (além do limitantc da perda para o problema de corte). Uma contribuição importante seria desenvolver limilantes apertados para este problema.

Pesquisas futuras podem ainda ser realizadas para melhorar a Abordagem 1 , em particular as rotinas de eliminação de padrões e factibilização da solução, com o objetivo de encontrar soluções factiveis, do ponto de vista do número de pilhas abertas, com perdas menores.

Conforme visto, a Abordagem 3 pode deixar de encontrar soluções melhores (do ponto de vista de perda), pelo fato de não poder visitar vértices, que correspondam a padrões de cortc. que quando seqüenciados, abram mais pilhas do que o número máximo tolerado $(p \hat{i})$. Uma pesquisa interessante seria desenvolver alternativas que permitam que vértices infactiveis (do ponto de vista do número de pilhas abertas) sejam visitados, com o objetivo de obter uma soluções melhores, isto é, com perdas menores. 
A rotina de seqüenciamento das Abordagens I e 3 utiliza a heurística 3 de Yuen (1995). Uma questão interessante é como variam os comportamentos destas abordagens ao se utilizar outras heurísticas de seqüenciamento mais poderosas. 


\section{REFERÊNCIAS BIBLIOGRÁFICAS}

ARENALES, M. (1993) Teoria para o problema de corte. 48f. Tese (Livre Docência em Ciências da Computação e Matemática Computacional) - Instituto de Ciências Matemáticas e de Computação, Universidade de São Paulo, São Carlos.

ARENALES, M.; MORABITO, R.; YANASSE H. (1999) Cutting and packing problems. Pesquixa Operacional, v.19, n.2, p.107-299.

ARENALES, M.; MORABITO, R., (1995) An and/or-graph approach to the solution of twodimensional non-guilhotine cutting problems. European Journal of Operational Research, v.84, p.599-617.

ARCARO, V. (1988) Recorte de estoque unidimensional. 54f. Dissertação (Mestrado em Ciências da Computação e Matemática Computacional) - Instituto de Ciências Matemáticas de São Carlos, Universidade de São Paulo, São Carlos.

ARROYO, J.E.C. (2002) Heuristicas e metaheurísticas para otimização combinatória multiobjetivo. 256f. Tese (Doutorado em Engenharia Elétrica) - Faculdade de Engenharia Elétrica e de Computação, Universidade Estadual de Campinas.

ASHIKAGA, F.M. (2001) Um método frugal para o problema de minimização de pilhas abertas. 91f. Dissertação (Mestrado em Ciências no Curso de Engenharia Eletrônica e Computação na Área de Informática) - Instituto Tecnológico de Aeronáutica, São José dos Campos.

BAZARRA, M.; JARVIS, J.J.; SHERALI, H.D. (1990) Linear programming and network flows. 2.ed. New York: John Wiley \& Sons.

BEASLEY, J.E. (1985) Algorithms for unscontrained two-dimensional guilhotine cutting. Journal of the Operational Research Society, v.36, n.4, p.297-306.

BECCENERI, J.C. (1999) O problema de seqüenciamento de padrões para a minimização do número máximo de pilhas abertas em ambientes de cortes industriais. 145f. Tese (Doutorado em Ciências no Curso de Engenharia Eletrônica e Computação na Área de Informática) - Instituto Tecnológico de Aeronáutica, São José dos Campos.

BELLUZZO, L. (2002) Otimização nos planos de corte de chapas de fibra de madeira reconstituída: Um estudo de caso na programação da produção da serra Holzma. Dissertação (Mestrado en Engenharia de Produção) - Departamento de Engenharia de Produção, Universidade Federal de São Carlos. 
BERGE, C. (1973) Graphs and Hypergraphs. Amsterdam : North-Holland.

BISCHOFF, E.; WÄSCHER, G. (Eds.) (1995) Cutting and packing. European Journal of Operational Research, v.84, n.3, special issuc.

CARNIERI, C.; MENDOZA, G.A.; GAVINHO, L.C. (1994) Solution procedures for cutting lumber into furniture parts. European Journal of Operational Research, v.73, p.495-501.

CHRISTOFIDES, N.; WHITLOCK, C. (1977) An algorithm for two dimensional cutting problems. Operations Research, v.25, p.30-44.

COHON, J.L. (1978) Multiobjective programming \& planning. New York: Academic Press.

DOWSLAND, K.; DOWSLAND, W. (1992) Packing problems. European Journal of Operational Research, v.56, p.2-14.

DYCKHOFF, H. (1990) A typology of cutting and packing problems. European Journal of Operational Research, v.44, p.145-159.

DYCKHOFF, H.; FINKE, U. (1992) Cutting and packing in production and distribution: Typology and bibliography. Heidelberg : Springler-Verlag.

DYCKHOFF, H.; SCHEITHAUER, G.; TERNO, J. (1997) Cutting and packing. In: AMICO, M.; MAFFIOLI, F.; MARTELLO, S. (Ed.) Annoted bibliographies in combinatorial optimization. New York: John Wiley \& Sons. p.393-414.

DYCKHOFF, H.; WÄSCHER, G. (Eds.) (1990) Cutting and packing. European Journal of Operational Research, v.44, n.2, special issue.

DYSON, R.G.; GREGORY, A.S. (1974) The cutting stock problem in the flat glass industry. Operational Research Quarterly, v.25, p.41-53.

FAGGIOLI, E.; BENTIVOGLIO, C.A. (1998) Heuristic and exact methods for the cutting sequencing problem. European Journal of Operational Research, v.110, n.3, p.564-575.

FARLEY, A. (1983) Practical adaptations of the Gilmore-Gomory approach to cutting stock problems. Operations Research Spektrum, v.10, p.113-123.

FAYARD, D.; ZISSIMOPOULOS, V. (1995) An approximation algorithm for solving unconstrained two-dimensional knapsack problems. European Journal of Operational Research, v.84, p.618-632. 
FINK, A.; VO $\beta$, S. (1999) Applications of modern heuristic search methods to pattern sequencing problems. Computer and Operations Research, v.26, n. l, p.17-34.

FOERSTER, H.E.; WÄSCHER, G. (1998) Simulated annealing for order spread minimization in sequencing cutting patterns. European Journal of Operational Research, v.110, p.272-281.

GARCIA, V. (1996) Geração de padrões de corte de chapas de fibra de madeira reconstituida. 94f. Dissertação (Mestrado em Engenharia de Produção) - Departamento de Engenharia de Produção, Universidade Federal de São Carlos.

GILMORE, P.; GOMORY, R. (1961) A linear programming approach to the cutting stock problem. Operations Research, v.9, p.849-859.

GILMORE, P.; GOMORY, R. (1963) A linear programming approach to the cutting-stock problem II. Operations Research, v.11, p.863-888.

GILMORE, P.; GOMORY, R. (1965) Multistage cutting stock problems of two and more dimensions. Operations Research, v.14. p.94-120.

GILMORE, P.; GOMORY, R. (1966) The theory and computation of knapsack functions. Operations Research, v.14, p.1045-1074.

GONDRAN, M.; MINOUX, M. (1990) Graphs and algorithms. Chichester: John Wiley \& Sons.

GRAMANI, M.C.N. (1997) O problema de corte bidimensional guilhotinado em 2-estágios e restrito. 100f. Dissertação (Mestrado em Ciências da Computação e Matemática Computacional) - Instituto de Ciências Matemáticas e de Computação, Universidade de São Paulo, São Carlos.

GRAMANI, M.C.N. (2001) Otimização do processo de cortagem acoplado ao planejamento da produção. 118f. Tese (Doutorado em Engenharia Elétrica), Faculdade de Engenharia Elétrica e de Computação, Universidade Estadual de Campinas.

HADJICONSTANTINOU, E.; CHRISTOFIDES, N. (1995) An exact algorithm for general, orthogonal, two-dimensional knapsach problems, European Journal of Operational Research, v.83, p. $39-56$.

HAESSLER, R. (1980) A note on computational modifications to the Gilmore-Gomory cutting stock algorithm. Operations Research, v.28, p.1001-1005.

HAESSLER, R.W.; SWEENEY, P.E. (1991) Cutting stock problems and solution procedures. European Journal of Operational Research, v.54, p.141-150. 
HENDRY, L.C.; FOK, K.K.; SHEK, K.W (1996) A cutting stock and scheduling problem in the copper industry. Journal of the Operational Research Society, v.47, p.38-47.

HERZ, J.C. (1972) A recursive computing procedure for two-dimensional stock cutting. IBM Journal of Research and Development, v.16, p.462-469.

HINXMAN, A. (1980) The trim-loss and assortment problems: a survey. European Journal of Operational Research, v.5, p.8-18.

HIFI, M. (1997) The DH/KD algorithm: a hybrid approach for unconstrained two-dimensional cutting problems. European Journal of Operational Research, v.97, n.1, p.41-52.

HIFI, M.; ZISSIMOPOULOS, V. (1996) A recursive exact algorithm for weighted two-dimensional cutting. European Journal of Operational Research, v.91, p.553-564.

HOTO, R.S.V (2001) O problema da mochila compartimentada aplicado no corte de bobinas de aço. Tese - COPPE, Universidade Federal do Rio de Janeiro.

LITTLE, J.D.C.; MURTY, K.G.; SWEENEY, D.W.; KAREL, C. (1963) An algorithm for the travelling salesman problem. Operations Research, v.12, p.972.

MADSEN, O. (1979) Glass cutting in a small firm. Mathematical Programming, v.17. p.85-90.

MADSEN, O. (1988) An application of travelling-salesman routines to solve patternallocation problems in the glass industry. Journal of the Operational Research Society, v.39, p.249-256.

MARQUES, F.P. (2000) O problema da mochila compartimentada. 106f. Dissertação (Mestrado em Computação e Matemática Computacional) - Instituto de Ciências Matemáticas e de Computação, Universidade de São Paulo, São Carlos.

MARTELLO, S.; TOTH, P. (1990) Knapsack problems: algorithms and computer implementations. Chichester : John Wiley \& Sons.

MORABITO, R. (1989) Corte de estoque bidimensional. 57f. Dissertação (Mestrado em Ciências da Computação e Matemática Computacional) - Instituto de Ciências Matemáticas e de Computação, Universidade de São Paulo, São Carlos.

MORABITO, R. (1992) Uma abordagem em grafo e-ou para o problema de empacotamento: aplicação ao carregamento de paletes e contêineres. $212 \mathrm{f}$. Tese (Doutorado em Engenharia de Transportes) - Departamento de Transportes, Universidade de São Paulo, São Carlos. 
MORABITO, R.; ARENALES, M. (1992) Um exame dos problemas de corte e empacotamento. Pesquisa Operacional, v.12, n.1, p.1-20.

MORABITO, R.; ARENALES, M.N. (1994) An and/or-graph approach to the container loading problem. International Transactions on Operations Research, v.1, n.1, p.59-73.

MORABITO, R.; ARENALES, M.N. (1995) Performance of two heuristics for solving large scale two-dimensional guilhotine cutting problems. INFOR, v.33. n.2, p.145-155.

MORABITO, R.; ARENALES, M.N. (1996) Staged and constrained two-dimensional guilhotine cutting problems: an AND/OR-graph approach. European Journal of Operational Research, v.94, p.548-560.

MORABITO, R.; ARENALES, M. (2000) Optimizing the cutting of stock plates in a furniture company. International Journal of Production Research, v.38, p. 2725-2742.

MORABITO, R.; ARENALES, M.N.; ARCARO, V.F. (1992) An and-or-graph approach for two-dimensional cutting problems. European Journal of Operational Research, v.58, p.263-271.

MORABITO, R.; FARAGO, R. (2001) A tight lagrangean relaxation bound for the manufacturer's pallet loading problem. Studia Informatica. (Aceito para publicação).

MORABITO, R.; GARCIA, V. (1998) The cutting stock problem in a hardboard industry: a case study. Computers and Operations Research, v.25, n.6, p.469-485.

MORABITO, R.; MORALES, S. (1998) A simple and effective recursive procedure to the manufacturer's pallet loading problem. Journal of the Operational Research Society, v.49, p.819-828.

MORALES, S.R. (1995) Otimização no carregamento de paletes: uma abordagem heuristica para resolver o problema do produtor. 128f. Dissertação (Mestrado em Engenharia de Produção) - Departamento de Engenharia de Produção, Universidade Federal de São Carlos.

OLIVEIRA, J.; FERREIRA, J. (1990) An improved version of Wang's algorithm for two dimensional cutting problems. European Journal of Operational Research, v.44, p. 256-266.

ORLANDI, M.A. (1992) Abordagens interativas para o problema de cortes de peças irregulares bidimensionais. 79f. Dissertação (Mestrado em Ciências da Computação e Matemática Computacional) - Instituto de Ciências Matemáticas e de Computação, Universidade de São Paulo, São Carlos.

PEARL, J. (1984) Heuristics: intelligent search strategies for computer problem solving. Reading, MA : Addison-Wesley. 
PINTO, M.J. (1999) O problema de corte de estoque inteiro. 98f. Dissertação (Mestrado em Ciências da Computação e Matemática Computacional) - Instituto de Ciências Matemáticas e de Computação, Universidade de São Paulo, São Carlos.

PINTO, M.J. (2001) O problema de corte e sequienciamento de padrões: uma abordagem integrada. 38f. Monografia apresentada para Qualificação no Programa de Doutorado em Computação e Matemática Aplicada - Instituto Nacional de Pesquisas Espaciais, São José dos Campos.

PÓSA, L. (1976) Hamiltonian circuits in random graphs. Discrete Mathematics, v.14, p.359-364.

RIEHME, J.; SCHEITHAUER, G.; TERNO, J. (1996) 'The solution of two-stage guilhotine cutting stock problems having extremely varying order demands. European Journal of Operational Research, v. 91, p.543-552.

SALOMÃO, S.N.A. (1993) Uma abordagem em grafo-e/ou para o problema de corte bidimensional não-guilhotinado. 61f. Dissertação (Mestrado em Ciências da Computação e Matemática Computacional) - Instituto de Ciências Matemáticas e de Computação, Universidade de São Paulo, São Carlos.

SICUP (2002) Special Interest Group on Cutting and Packing. Disponivel em: $<$ http://www.apdio.pt/sicup/> Acesso em 30 Julho 2002

SILVA, R.J. (2001) Otimização da programação de cargas de forno em uma fábrica de fundição em aço-inox. Dissertação (Mestrado em Engenharia de Produção) - Departamento de Engenharia de Produção, Universidade Federal de São Carlos.

SILVEIRA, R.; MORABITO, R. (2002) Um método heurístico baseado em programação dinâmica para o problema de corte bidimensional guilhotinado restrito. Gestão \& Produção, v. 9, n. 1, p. $78-92$.

STEUER, R.E. (1986) Multiple criteria optimization: theory, computation \& application. New York: John Wiley.

SWEENEY, P.; PATERNOSTER, E. (1992) Cutting and packing problems: a categorized, application-oriented research bibliography. Journal of the Operational Research Society, v.43, p.691-706.

TANG, C.S.; DENARDO, E.V. (1988) Models arising from a flexible manufacturing machine, Part I: minimization of the number of the tool switches. Operations Research, v.36, p.767-777. 
VANCE, P.; BARNHART, C.; JOHNSON, E., NEMHAUSER, G. (1994) Solving binary cutting stock problems by column generation and branch-and-bound. Computational optimization and applications v.3, p.111-130.

VIANNA, A. (2000) Problemas de corte e empacotamento: uma abordagem em grafo e/ou. 133. Tese (Doutorado em Computação e Matemática Computacional) - Instituto de Ciências Matemáticas e de Computação, Universidade de São Paulo, São Carlos.

YANASSE, H.H. (1996) Minimization of open orders - polynomial algorithms for some special cases. Pesquisa Operacional, v.16, p.1-26.

YANASSE, H. (1997) On a pattern sequencing problem to minimize the maximum number of open stacks. European Journal of Operational Research, v.100, n.3, p.454-463.

YANASSE, H.H. (1998) A note on generating solutions of a pattern sequencing problem to minimize the maximum number of open orders. Technical Report LAC-002/98, INPE, São José dos Campos. SP, Brasil.

YANASSE, H.H.; ZINOBER, A.S.I.; HARRIS, R.G. (1991) Two-dimensional cutting stock with multiple stock sizes. Journal of the Operational Research Society, v.42, n.8, p.673-683.

YANASSE, H.H.; BECCENERI, J.C.; SOMA, N.Y. (1999) Bounds for a problem of sequencing patterns. Pesquisa Operacional, v.19, n.2, p.1-29.

YUEN, B. (1991) Heuristics for sequencing cutting patterns. European Journal of Operational Research, v.55, p.183-190.

YUEN, B. (1995) Improved heuristics for sequencing cutting patterns. European Journal of Operational Research, v.87, p.57-64.

YUEN, B.; RICHARDSON, K. (1995) Establishing the optimality of sequencing heuristics for cutting stock problems. European Journal of Operational Research, v.84, p.590-598.

WÄSCHER, G.; GAU, T. (1996) Heuristics for the integer one-dimensional cutting stock problem: a computational study. Operations Research Specktrum, v.18, p.131-144.

WANG, P.Y. (1983) Two algorithms for constrained two-dimensional cutting stock problems. Operations Research, v.31, n.3, p.573-586.

WANG, P.Y; WÄSCHER, G. (2002) Cutting and packing. European Journal of Operational Resesearch, v.141, n.2, p.239-469. 


\section{APÊNDICE I}

\section{Descrição da fábrica de móveis Colombini}

A Colombini é uma fábrica de produção de móveis populares (guarda-roupas, armários de cozinha, mesa, etc.) situada na cidade de Araras (SP). A estratégia competitiva da empresa é a minimização dos custos totais de produção, a fim de reduzir os preços de venda dos produtos. Isto é feito através de um controle de custos rígido, domínio da tecnologia de produção em escala e através de um projeto de produto simples.

Para a produção dos móveis populares utiliza-se como matéria-prima chapas de madeira aglomerada e chapas duras (chapas de madeira compensada). Essas chapas são cortadas em função dos itens necessários à confecção dos móveis demandados. O custo das chapas corresponde, em geral, a 40\% do custo final do produto. A produção dos produtos é feita em pequenos lotes de produção, baseada na venda sob encomenda dos produtos que são geralmente entregues quinze dias após a data do pedido. Dentre os diferentes processos pelos quais passa um móvel até que o mesmo seja produzido, dois problemas são de interesse: o de corte e o de seqüenciamento dos padrões de corte gerados. Depois que os padrões de corte são definidos e cortados, ou seja, depois que os problemas de corte e de seqüenciamento são resolvidos, os itens passam por diferentes etapas até serem embalados. O processo de acabamento das chapas duras é diferente do processo de acabamento das chapas de madeira aglomerada. As figuras A.l e A.2 ilustram os processos de acabamento para os dois tipos de chapas.

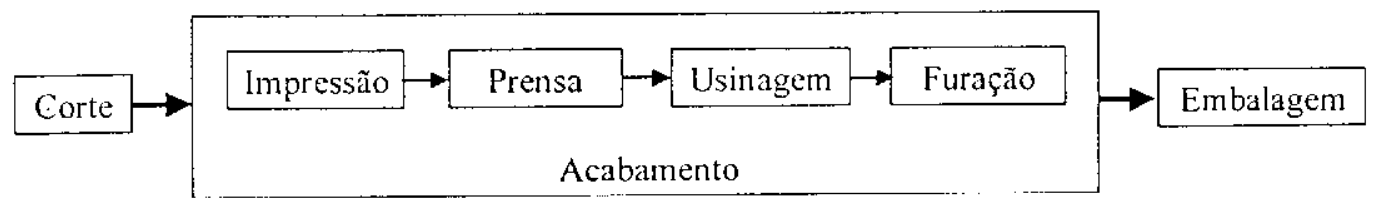

FIGURA A.1: Detalhamento do processo de acabamento para chapas duras.

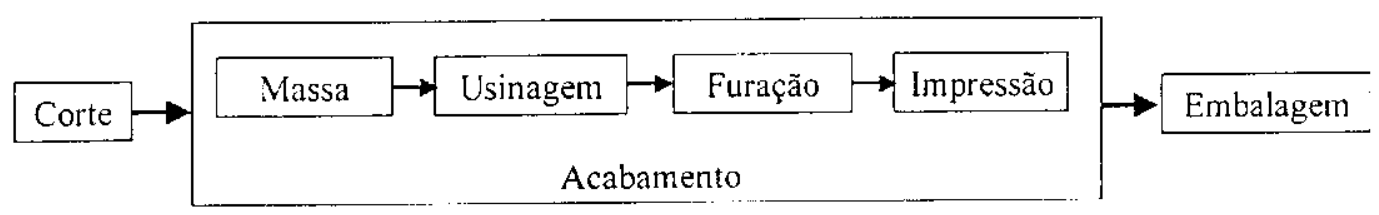

FIGURA A.2: Detalhamento do processo de acabamento para chapa de madeira aglomerada. 
Na impressão são utilizadas impressoras que estampam as chapas em padrões (tipo mogno, tipo cerejeira, etc.). A prensa é fundamental no processamento das chapas duras pois evita que os itens cortados enverguem. Na usinagen os itens são perfilados, fresados e lixados. A furação é a etapa responsável pelos furos nos itens para que os mesmos possam ser montados formando assim um móvel. Nas chapas de aglomerado é aplicada resina protetora. A operação de embalagem consiste em colocar um "kit de montagem" (formado pelos itens que compõem o móvel e os acessórios que permitem que o consumidor monte o móvel) em uma caixa que é destinada ao transporte e à comercialização.

$\mathrm{Na}$ fabricação dos produtos, o processo de corte, além de ser de fundamental importância, é um processo gargalo e causa impacto em dois tipos de estoques: o estoque de matéria-prima e o estoque de produtos em processo. Como a matéria-prima (chapas de madeira) representa $40 \%$ do custo do produto final, um bom desempenho na otimização do corte das chapas, resulta em eficientes aquisições com o objetivo de tentar evitar altos níveis de inventários e, conseqüentemente, um alto volume de capital investido desnecessariamente. Por outro lado, a simples otimização do corte das chapas, não implica em uma redução do estoque de produtos em processo. Para resolver este problema é preciso decidir qual o melhor seqüenciamento para o conjunto de padrões de corte gerado a fim de minimizar o estoque de produtos intermediários.

\section{O problema de geração e seqüenciamento de padrões de corte da fábrica de móveis}

\section{Colombini}

Para atender a carteira de pedidos, ou seja, para que uma demanda de móveis possa ser atendida, chapas de madeira serão cortadas (objetos) em peças menores (itens) que combinados formarão um móvel. A serra utilizada para produção dos itens possui algumas características que viabiliza um corte do tipo bidimensional, guilhotinado, 2-estágios e não exato. O corte é do tipo bidimensional pois duas dimensões são relevantes, no caso, a o comprimento e a largura. Conforme visto anteriormente, um corte é dito guilhotinado quando são feitos a partir de uma borda até a borda oposta, de forma a dividir um retângulo em dois retângulos menores e adjacentes. Como o corte possui 2-estágios, isto implica em dizer que o corte será feito em no máximo 2 estágios. Em um primeiro estágio os cortes são produzidos em uma direção e no segundo estágio os cortes são feitos perpendicularmente à primeira direção. Um corte é dito não exato quando a demanda dos itens não precisar ser satisfeita com igualdade, ou seja, quando puder haver excesso de produção. 
Para resolução do problema de corte considera-se o estoque das chapas de madeira ilimitada. Com estas possuem tamanho e muitas vezes custos unitários diferentes, o objetivo do problema de corte pode variar entre a minimização das perda gerada pelo corte dos padrões ou a minimização dos custos. A decisão de quais itens serão cortados para a produção dos móveis leva em consideração a data de entrega, o tipo de cliente, o tipo de matéria-prima c o processo de produção. Essas quatro características permitem a priorização na composição da matriz de produtos para o processo de corte, a fim de garantir a entrega do produto no prazo previsto. A matriz de produtos para o processo de corte contém: as dimensões dos itens. as quantidades e o tipo de material de cada item.

Conforme descrito, para que os diferentes móveis demandados possam ser produzidos. chapas de madeira scrão cortadas nas dimensões dos itens que compõem os móveis. Ou seja, um conjunto de padrões de corte será produzido e cada um deles será repetido um certo número de vezes. Feito isso é preciso decidir em qual seqüência os padrõcs scrão processados. Quando o corte de um padrão é iniciado, a cada novo tipo de item produzido associa-se uma pilha diferente. A pilha permanecerá aberta até que o último padrão que contenha esse item seja cortado. Para que um móvel possa ser embalado todos os itens que o compõem precisam ter sido cortados. Dependendo da seqüência em que os padrões serão processados um móvel pode demorar mais ou menos tempo para estar completo, o que pode comprometer os prazos de entrega.

O tamanho do lote de produção influencia diretamente na perda e na complexidade do seqüenciamento dos padrões. Quanto maior o número de tipos de móveis que compõem um lote, maior será o número de tipos de itens a serem combinados para formação do padrão, favorecendo assim a minimização da perda mas, por outro lado, aumentando o número de pilhas abertas com o corte dos padrões. Lotes com um número pequeno de tipos de móveis, implicam em um número menor de tipos de itens a serem combinados, o que pode prejudicar possíveis combinações de itens nos padrões, mas resulta na diminuição do número de pilhas abertas, isto é, resulta na complexidade do gerenciamento do corte dos padrões e na redução do capital em estoque intermediário, além da diminuição do fluxo de produtos na linha de produção. Existe, como evidenciado, um trade-off a ser resolvido entre a perda gerada pelo corte dos padrões e a complexidade do gerenciamento no corte dos mesmos. 


\section{APÊNDICE II}

\section{Descrição da fábrica de fibras de madeira reconstituída Duratex}

A Duratex ć uma fábrica de chapas de fibra de madeira reconstituida (também chamadas chapas duras ou hardbourd). Esta empresa localiza-se em Botucatu. A seguir apresenta-se uma breve introdução do processo produtivo da empresa e uma discussão dos problemas de geração e seqüenciamento de padrões encontrados na empresa.

O processo de produção de chapas duras inicia-se na casa de cavacos, onde toras de eucalipto são lavadas e depois picadas em um equipamento chamado chipper (picador). Os cavacos (pedaços picados das toras) são armazenados em grandes áreas ao ar livre $e$ transportados por meio de esteiras rolantes para equipamentos chamados desfibradores que. em um processo termo-mecânico, transformam os cavacos em fibras (cozimento do cavaco).

As fibras são diluídas em água em um sistema de tanques, formando uma polpa, que é então bombeada para um filtro contínuo chamado formadora. Na formadora é produzido um colchão de fibras que, por meio de transportadores de rolo e esteiras, segue até uma prensa. A prensa é um reator onde se processam termomicamente os colchões (retira-se o excesso de água) transformando-os em chapas de fibra de madeira.

As chapas passam por um tratamento térmico que proporciona o término da polimerização da lignina da madeira, garantindo as características mecânicas do produto e por um tratamento de umidificação, que confere às mesmas a umidade e estabilidade dimensional desejada. Após adquirirem as propriedades tecnológicas necessárias, as chapas base passam pela serra de linha, que é responsável pelo corte do refilo, e pelas lixadeiras, que garantem a uniformização de espessura às chapas base. Depois de inspecionadas e classificadas, as chapas (objetos) são então transportadas até o processo de corte, onde são serradas para produzir as chapas menores (itens), ou são transportadas até a linha de pintura (LIPI). As perdas de material, inclusive o material defeituoso, seguem para as caldeiras onde são queimadas como combustível para geração de energia. Os itens produzidos são então acondicionados e expedidos para os clientes.

A Duratex possui três linhas de produção PS1, PS2 e PS3. As linhas de produção operam em 4 turnos por dia (turnos de 6 horas), ou seja, a fábrica funciona 24 horas por dia. A 
linha 1 tem uma produção diária média de 240 toneladas e produz chapas base de dimensões $4.880 \mathrm{~mm} \times 2.130 \mathrm{~mm}$, com espessura de $3 \mathrm{~mm}$ (não produz outra espessura diferente). Esta é a única linha que produz chapas texturadas (WT). Possui uma produtividade média de 59 prensadas por turno e cada prensada produz 30 chapas base.

A linha 2 tem uma produção diária média de 270 toneladas e produz chapas base de dimensões $5.500 \mathrm{~mm} \times 2.130 \mathrm{~mm}$, de diferentes espessuras. A cada mudança de espessura está associado um tempo de setup. Produz 30 chapas base em cada prensada. Não produz chapas texturadas. A produção diária média da linha 3 é de 210 toneladas com chapas de dimensões $7.300 \mathrm{~mm} \times 1100 \mathrm{~mm}$. A capacidade de produção média total (das três linhas) é de 20.000 ton/mês (dependendo do mix de espessura).

As chapas base podem ser de vários tipos, lisa ou texturada, de diferentes espessuras, lixada ou não, com ou sem resina, com intervalos de umidade diferentes ou classificada quanto a qualidade aparente. Após a produção as chapas são classificadas de acordo com o nível de qualidade que apresentam; podem ser classificadas em: chapas "primeira", chapas "segunda" e chapas "terceira".

As chapas "primeira" são aquelas que não apresentam nenhum problema intrínseco (p.e., propriedades mecânicas), nem defeitos superficiais. Chapas "segunda" apresentam problemas de qualidade em áreas específicas (p.e., manchas) que, se recortadas, podem ser aproveitadas normalmente. Chapas "terceira" são aquelas com problemas de qualidade (p.e., resistência mecânica) que inviabilizam o uso de toda a área do material. As chapas de "segunda" e "terceira" são enviadas para uma área de recuperação (AR) composta de serras e equipamentos de menor porte, pouco automatizados e de baixa produtividade, onde cortes são feitos produzindo peças menores e as áreas com defeito são descartadas.

As três linhas de produção possuem serras de linha e lixadeiras. Estas serras são equipamentos que cortam a chapa, deixando-a com as dimensões especificadas, e as lixadeiras corrigem variações de espessura da chapa, dando também acabamento superficial no verso da mesma. As serras de linha são responsáveis por refilarem as bordas das chapas nas dimensões padrão e no caso das linhas PS2 e PS3, padrões de corte simples com peças de dimensões específicas podem scr executados. O descarregamento nestas duas linhas é feito manualmente. A serra de linha de PS1 é utilizada para retirar o refilo das chapas base. As chapas provenientes de PS1 e as de PS2 nas quais não foram executados nenhum plano de corte, ambas com classificação de $1^{a}$ e $2^{a}$, são cortadas em um equipamento programável chamado serra Holzma, ou podem ser vendidas. 
As chapas provenientes das linhas PS1 e PS2 são transportadas para o armazém intermediário de chapa base (AICB). que tem capacidade de armazenagem de 2160 ton, caso sejam de $I^{\text {a }}$ ou de $2^{\text {a }}$, ou são transportadas para o $\mathrm{AR}$, caso sejam de $3^{\mathrm{a}}$. Daí podem seguir para a serra Holzma ou para a LIPI, caso seja do tipo $1^{\mathrm{a}}$. As chapas que seguem direto do AICB para a LIPI são pintadas c, ou embaladas e depois transportadas para o APA, ou transportadas para o AICB para depois serem cortadas (já pintadas) na Holzma. Os itens provenientes do corte na serra Holzma, caso sejam de $\mathrm{I}^{3}$, seguem para o estoque da LIPI (já nas dimensões finais) de onde são transportadas para a LIPI. Itens de $\mathrm{I}^{\text {a }}$ cortados na serra Holzma podem seguir direto para a embalagem e depois para o APA. Se os itens provenientes da serra Holzma forem classificados como de $2^{3}$ e problemáticos são encaminhados para o AR de onde podem seguir para a caldeira ou para a embalagem .

As chapas provenientes de PS2 e PS3, nas quais foram executados planos de corte simples, são classificadas e se forem de $1^{a}$ são transportadas até o estoque da linha de pintura, já nas dimensões finais do item, de onde seguirão para a LIPI. Se forem classificadas como de $3^{a}$ são transportadas para o armazém de recuperação (AR). Caso sejam recuperadas seguem para a embalagem e depois para o armazém de produtos acabados (APA), caso contrário seguem para a caldeira onde serão queimadas.

A Duratex produz chapas base para atender ao mercado externo (sob encomenda) e mercado interno (sob encomenda e para estoque). Em geral, devido à imposição de mercado, praticamente toda produção destinada ao mercado externo (exportação) é lixada, e para o mercado interno não. Os leadtimes de entrega dos produtos são de um mês para o mercado externo e de dez dias para o mercado interno (sob encomenda). $80 \%$ do volume produzido é paletizado. O leadtime do palete é de três dias, pois o mesmo é fabricado na unidade de Agudos.

\section{O problema do planejamento da produção da Duratex}

O problema do corte (na serra Holzma) e o do seqüenciamento dos padrões de corte encontra-se inserido em um problema maior, o qual será denominado aqui Problema do Planejamento da Produção. Este problema inicia-se com a programação das linhas de produção. A partir dos pedidos e do nível de estoque (produtos acabados), o Planejamento e Controle da Produção decide o que será prensado em cada uma das linhas levando em conta a data de entrega dos pedidos (dando prioridade ao mercado interno em relação ao mercado 
externo, dado que o leadtime deste último é maior) e a restrição tecnológica das prensas. Esse planejamento influencia todas as outras decisões subsequentes.

Decidido o que scrá prensado em um dia é preciso decidir se as chapas base, provenientes das linhas de produção e as disponiveis no AICB, deverão ser transportadas para serem cortadas na serra Holzma ou se as mesmas seguirão para o estoque da LIPI. Caso as chapas sejam primeiramente cortadas, os itens produzidos podem seguir para a LIPI ou então serem embalados e encaminhados para o APA. Se por outro lado as chapas base passarem primeiro pela LIPI, as mesmas podem ser transportadas para a serra Holzma ou então podem ser embaladas e colocadas no APA. A figura B.1 abaixo ilustra os possiveis fluxos de materiais.

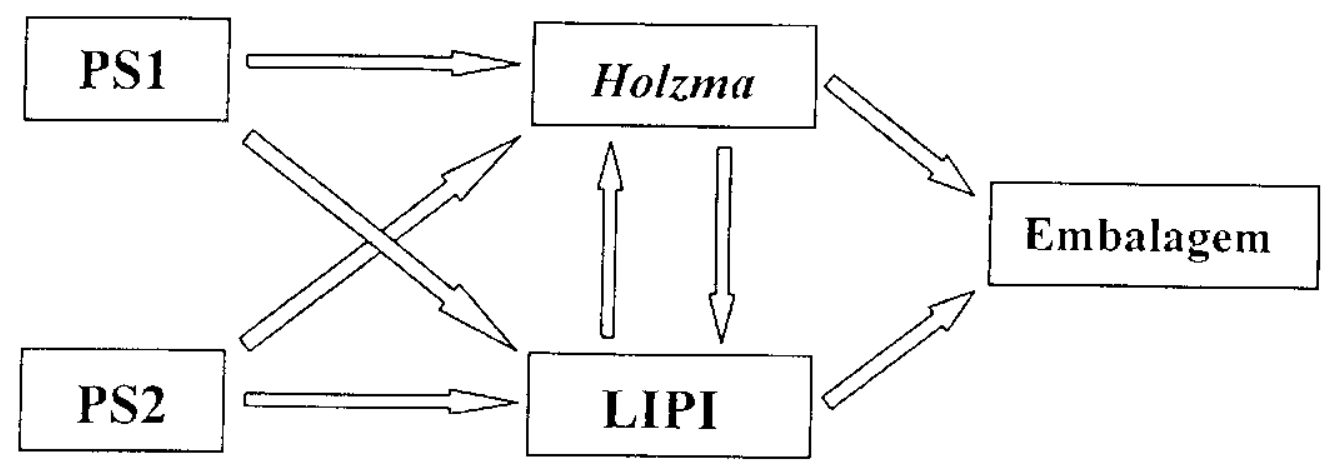

FIGURA B.1: Ilustração dos fluxos de materiais na empresa Duratex.

A programação da serra Holzma (pelo otimizador ou pelo operador), que resulta nos planos de corte a serem cortados, depende da disponibilidade de chapas base (e também da disponibilidade de paletes) e o mesmo acontece com a linha de pintura. Ou seja, a programação das linhas de produção influencia diretamente nas decisões posteriores a serem tomadas. Existe uma importante decisão a ser tomada com relação ao fluxo de material proveniente das linhas PS1 e PS2 (figura B.1), que envolve uma movimentação logística bastante grande, que envolve pilhas de chapas base, empilhadeiras, movimentação de paletes, etc. A otimização deste problema juntamente com um sistema de informações confiável (hoje não disponível) pode resultar em uma melhor organização da fábrica como um todo, possibilitando dados de entrada mais precisos para as operações futuras, como por exemplo, o corte das chapas base na serra Holzma. 


\section{O problema de geração e seqüenciamento de padrões de corte da Duratex}

Dois problemas encontrados na Duratex são de interesse para o trabalho em questão; o problema de corte e o problema de seqüenciamento dos padrões de corte gerados. De forma resumida, para resolver estes dois problemas é preciso determinar a melhor forma de cortar as chapas duras, ou seja, determinar um conjunto de padrões de corte, e em qual ordem os mesmos deverão ser cortados a fim de que uma demanda de itens possa ser atendida.

A serra Holzma é o principal equipamento utilizado para cortar as chapas base em itens finais. É um equipamento de grande flexibilidade, capaz de gerar padrões de corte bastante complexos. É composta por duas serras longitudinais e duas serras transversais: uma serra circular de grande diâmetro, que faz o corte propriamente dito, e uma outra serra circular de pequeno diâmetro, que abre o sulco de corte. Cada uma das pequenas serras caminha na frente das serras de maior diâmetro. Possui sistema de transporte de "Book" de Chapas", totalmente computadorizado, e um sistema de giro que proporciona o corte de padrões mais complicados. A medida que os itens contidos nos padrões vão sendo cortados, eles são encaminhados por esteiras rolantes, para as estações de descarga da serra. Ao todo são 5 estą̧ôes, sendo 4 totalmente automatizadas, e uma manual. As 4 estações automáticas possuem também alimentadores de paletes.

Esta serra possui um otimizador que, a partir de um conjunto de pedidos, gera um conjunto de padrões de corte (plano de corte - PC) necessários para atendê-los e a seqüência na qual os mesmos deverão ser cortados, e alimenta a serra com esses dados para que a mesma serre os padrões de corte produzindo os itens demandados pelos clientes. Padrões de corte também podem ser gerados manualmente por um operador. A decisão de quais pedidos farão parte de um PC é feita pelo operador que para tanto avalia a disponibilidade de material no $\mathrm{AICB}$ e a disponibilidade de palete, respeitando as datas de entrega dos pedidos. Os padrões de corte podem conter até cinco tipos de itens diferentes (ou mais, dependendo do número de funcionários na estação manual). Destes cinco, quatro são descarregados pelas estações automáticas e um (ou mais) na estação automática.

O número máximo de tipos de itens que podem aparecer nos padrões de corte é limitado em cinco (considerar-se-á que apenas um tipo de item diferente é descarregado na estação manual), pois a máquina de corte possui quatro estações de descarregamento automáticas (com alimentadores de paletes) e uma manual. As estações de descarregamento além de imporem una restrição no máximo número de tipos de itens permitidos nos padrões 
de corte, também interfere na seqüência em que os mesmos serão cortados. Dependendo da seqüencia escolhida pode ser inviável processar os padrões, pois o número de tipos de itens produzidos pode ser maior que o número de estações de descarregamento disponíveis, o que inviabiliza a seqüência escolhida.

Devido à restrição do número de tipos de itens possivcis em um mesmo padrão de corte se faz necessário encontrar uma seqüiencia viável de forma que as estações de descarregamento automáticas não fiquem bloqueadas. Por outro lado objetiva-se minimizar a perda dos padrões de corte gerados, visto que o custo da chapa base é bastante alto em relação ao custo do produto final. A escolha de um padrão para ser cortado determina a seqüência dos próximos padrões que serão cortados. O problema de corte, neste caso em particular, não pode ser resolvido independentemente do problema de sequenciamento. Se assim o for, poder-se-ia obter padrões de corte de perda mínima, mas que não fossem seqüenciáveis (devido a restrição das estações de descarregamento automáticas). Existe um trade-off entre padrões de perda mínima e padrões seqüenciáveis.

Quando o processamento de um padrão é iniciado, um ou mais itens são produzidos e são encaminhados para as estações de descarregamento, onde são depositados sobre paletes. A cada item diferente produzido com o corte de um padrão associa-se uma pilha. Diz-se que uma pilha está aberta quando uma estação de descarregamento está ocupada. Uma pilha só é fechada, ou seja, uma estação de descarregamento só é liberada quando o palete estiver completo. Considere um padrão A com quatro tipos diferentes de itens: 1, 5, 7 e 9. Quando o corte deste padrão é iniciado quatro estações de descarregamento são ocupadas, por exemplo, as estações 1, 2, 3 e 4, respectivamente. Suponha que o corte deste padrão não completou nenhum palete. Neste caso tem-se quatro pilhas abertas. Para que as estações possam ser desocupadas, ou para que as pilhas possam ser fechadas, novos padrões que contenham os itens $(\mathbf{1}, \mathbf{5}, 7$ e 9$)$ precisam ser processados a fim de que os paletes associados a esses itens possam ser completados e removidos. O próximo padrão (B) na seqüência necessariamente pode conter apenas um item diferente dos que estão com suas pilhas abertas. Isto é, pode conter itens 1, 5, 7,9 e apenas mais um tipo diferente. Se o padrão $\mathbf{B}$ contiver, por exemplo, os itens $1,5,14$ e 23 o mesmo não poderá ser processado após o padrão $\mathbf{A}$, pois os itens 1 e 5 serão descarregados nas estações 1 e 2, respectivamente; o item 14 será descarregado na estação de número 5 (que é a única estação desocupada) e o item 23 não terá onde ser descarregado.

Conforme ilustrado pelo exemplo acima, os problemas de geração e seqüienciamento de padrões de corte não podem ser resolvidos de forma independente. Os dois problemas 
estão inter-relacionados. Na geração dos padrões de corte é preciso considerar a limitação do número máximo de tipos de itens permitidos e também levar em conta que o conjunto de padrões gerados precisa ser seqüenciável. Se o problema de seqüienciamento não estiver sendo considerado na geração dos padrões, é possivel que se encontre uma solução de mínima perda do ponto de vista do problema de corte, mas que não possa ser seqüenciável. 